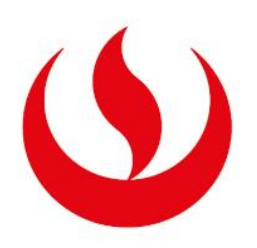

UNIVERSIDAD PERUANA DE CIENCIAS APLICADAS

\author{
FACULTAD DE INGENIERÍA \\ PROGRAMA ACADÉMICO DE INGENIERÍA DE REDES \\ Y COMUNICACIONES
}

\title{
ANÁLISIS DE UNA PLATAFORMA PARA APLICACIONES WEB CON UNA ARQUITECTURA BASADA EN CONTENEDORES PARA IMPLEMENTAR SERVICIOS DIRIGIDOS A STARTUPS
}

\author{
TESIS \\ Para optar el título profesional de Ingeniero de Redes y Comunicaciones \\ AUTOR \\ Quispe Cieza, Francisco (0000-0002-0166-2730) \\ ASESOR \\ Gonzales Figueroa, Renatto Gustavo (0000-0003-3658-3415)
}

Lima, 27 de febrero de 2020 
DEDICATORIA

Quiero dedicar este trabajo a mi familia, quien me brinda el apoyo necesario para lograr todas las metas trazadas en mi vida personal y profesional, ayudándome a afianzar todos los conocimientos necesarios para retos futuros. 


\section{RESUMEN}

Cuando una startup sale al mercado, se enfoca en crecer exponencialmente, utilizando una idea innovadora y un presupuesto relativamente bajo. Este crecimiento exponencial se apoya en la tecnología, la cual debe manejar un rendimiento adecuado en los recursos de hardware para los servicios, acorde con el giro del negocio.

El objetivo principal de este trabajo es realizar un análisis de una plataforma para aplicaciones web con una arquitectura basada en contenedores, que sea capaz de soportar el crecimiento exponencial de usuarios de sus servicios Web.

Las arquitecturas tradicionales basadas en servidores físicos implican tiempos y costos de configuración, despliegue y mantenimiento que son altos. Cuando se hace necesario escalar, se requiere, normalmente, de más recursos de hardware y de tiempo para realizar las configuraciones necesarias. La flexibilidad que provee la virtualización de servidores agiliza los procedimientos de escalamiento y reduce considerablemente el tiempo y los costos, comparados con las soluciones basadas solamente en hardware. Sin embargo, para atender requerimientos más exigentes, la virtualización tiene una huella muy pesada y tiempos de despliegue todavía elevados. La tecnología de contenedores nos ofrece una plataforma liviana y eficiente. Un contenedor es un paquete ejecutable muy liviano que aísla una pieza de software, incluyendo todo lo necesario para ser ejecutado.

Está claro que la velocidad y la eficiencia son las mayores necesidades para las startups, y Docker, uno de los líderes en el mercado de contenedores de software, es capaz de proporcionarlas de manera efectiva. Si bien es cierto no ha reemplazado a las máquinas virtuales, se está notando el potencial de Docker. Eso no quiere decir que las máquinas virtuales quedaran obsoletas, por el contrario, Docker y las máquinas virtuales coexistirán uno al lado del otro, dando a los startups más opciones para ejecutar sus aplicaciones en la nube.

Palabras clave: startups, aplicaciones Web, escalabilidad, Docker, contenedores, máquinas virtuales, Linux, nube. 


\begin{abstract}
When a startup goes to market, it focuses on growing exponentially, using an innovative idea and a relatively low budget. This exponential growth is supported by technology, which must handle adequate performance in the hardware resources for services, in accordance with the line of business.
\end{abstract}

The main objective of this work is to carry out an analysis of a platform for web applications with a container-based architecture, which is capable of supporting the exponential growth of users of its Web services.

Traditional physical server-based architectures involve high configuration, deployment, and maintenance times and costs. When scaling becomes necessary, it usually takes more hardware and time to complete the necessary configurations. The flexibility that server virtualization provides streamlines escalation procedures and greatly reduces time and cost, compared to hardware-only solutions. However, to meet more demanding requirements, virtualization has a very heavy footprint and still high deployment times. Container technology offers us a lightweight and efficient platform. A container is a very lightweight executable package that isolates a piece of software, including everything needed to be run.

It is clear that speed and efficiency are the greatest needs for startups, and Docker, one of the leaders in the software container market, is capable of providing them effectively. While it's true it hasn't replaced virtual machines, Docker's potential is being noticed. That doesn't mean that virtual machines will become obsolete, on the contrary, Docker and virtual machines will coexist side by side, giving startups more options to run their applications in the cloud.

Keywords: startups, Web applications, scalability, Docker, containers, virtual machines, Linux, cloud. 


\section{TABLA DE CONTENIDOS}

1 INTRODUCCIÓN. 1

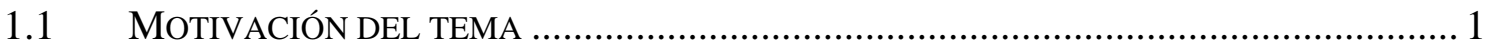

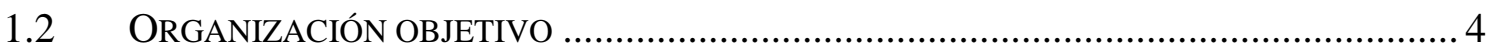

1.3 CAMPO DE ACCIÓN EN LA ORGANIZACIÓN OBJETIVO …........................................ 5

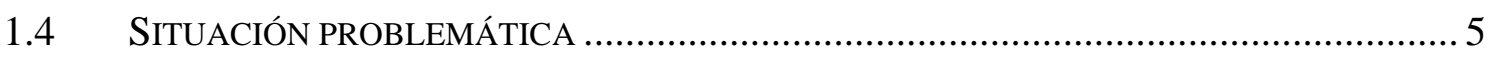

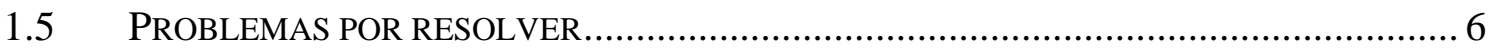

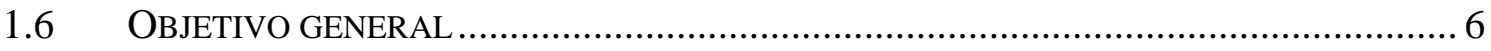

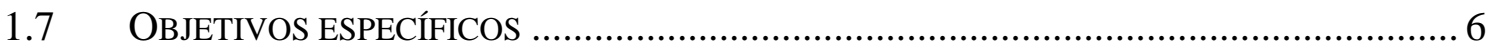

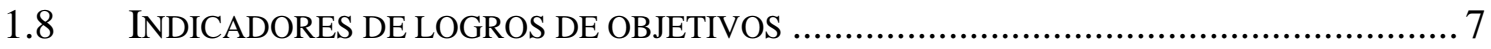

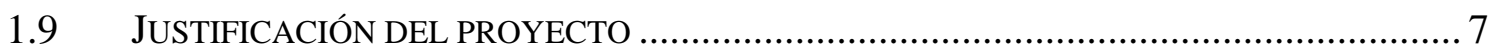

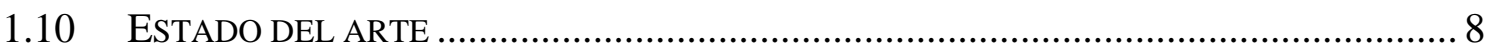

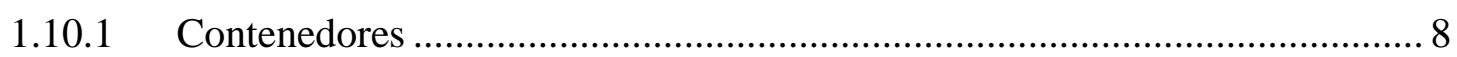

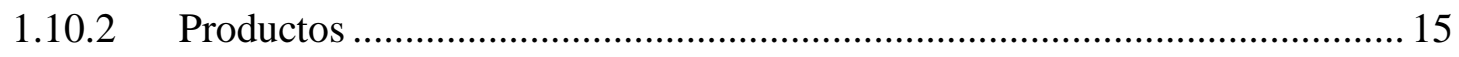

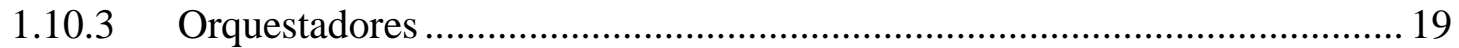

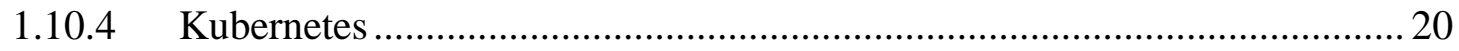

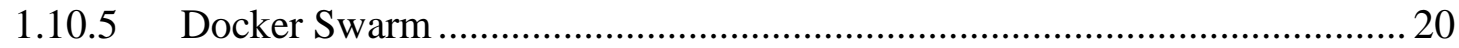

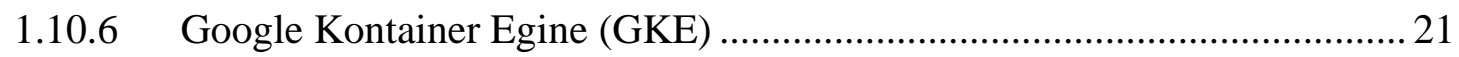

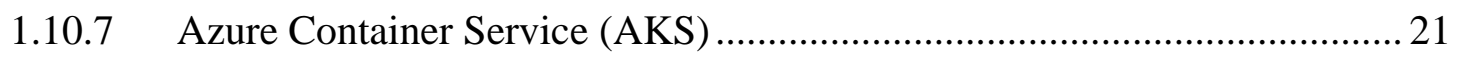

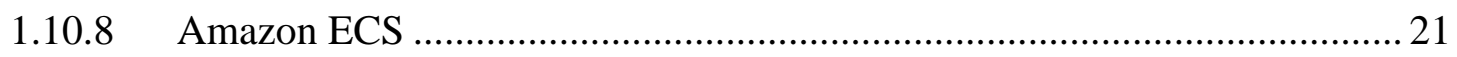

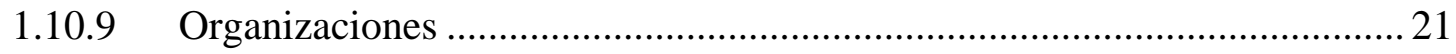

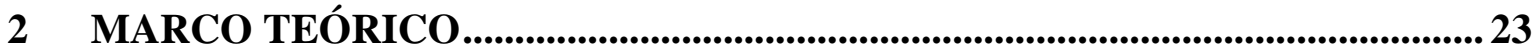

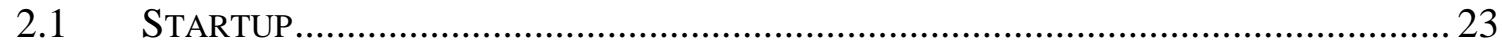

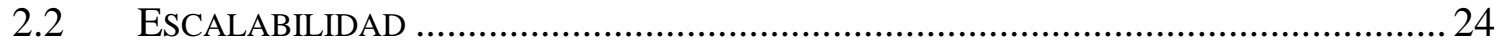

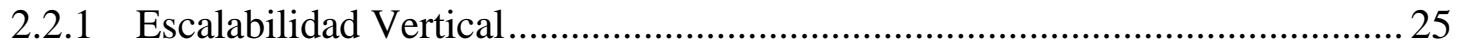

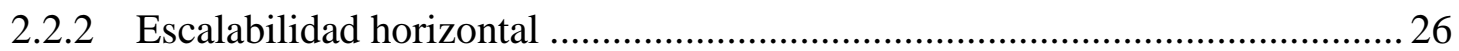

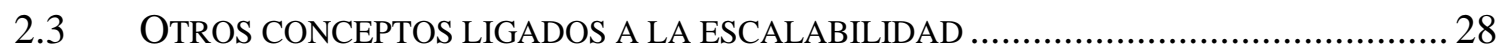

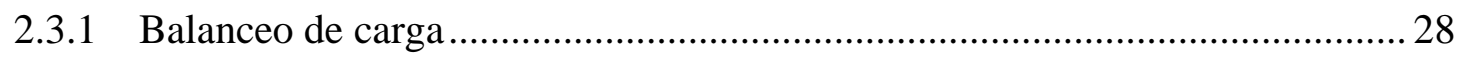

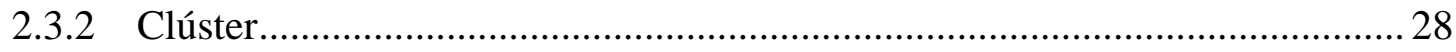

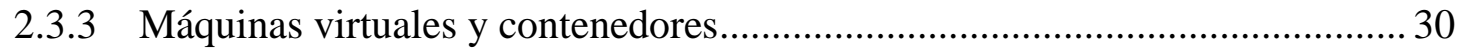

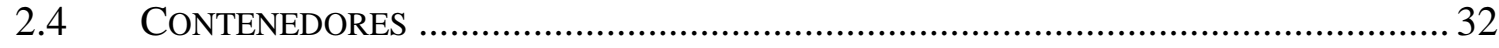

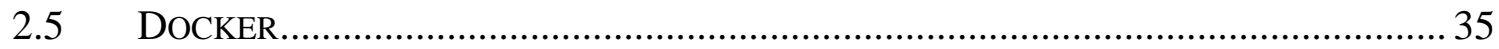




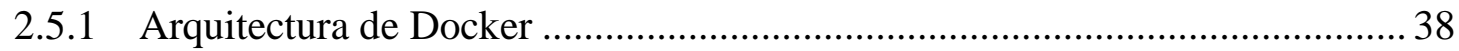

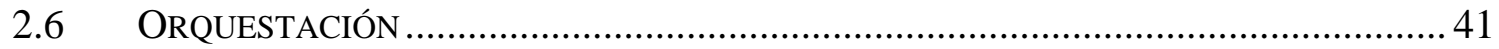

2.6.1 Docker Swarm Mode ..................................................................................... 41

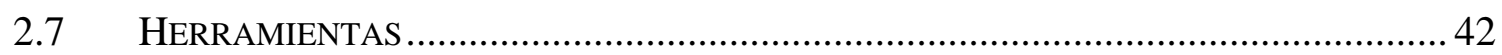

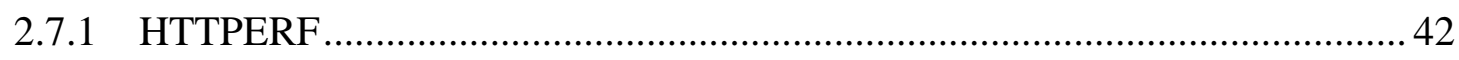

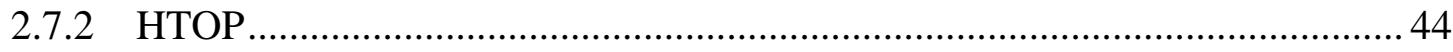

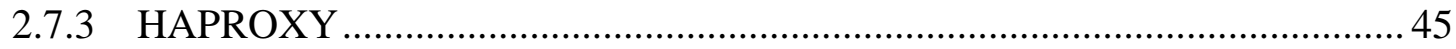

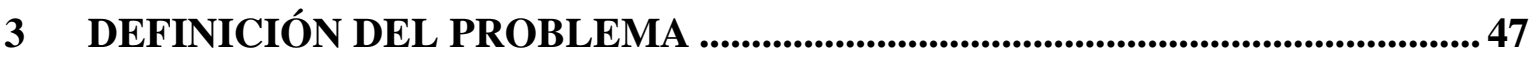

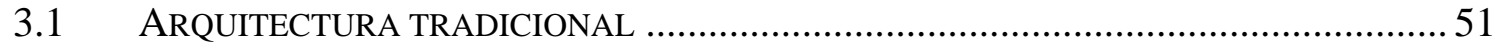

3.1.1 Cantidad de conexiones web concurrentes ...................................................... 54

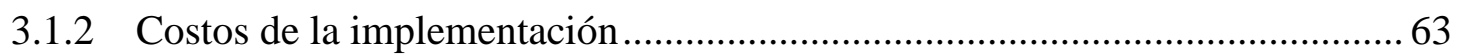

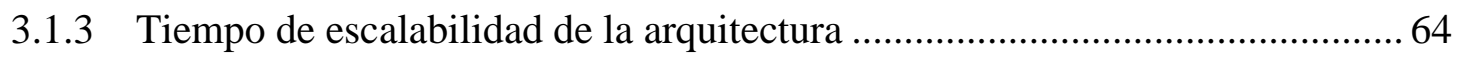

3.2 ARQUITECTURA TRADICIONAL CON ESCALAMIENTO HORIZONTAL .........................6 64

3.2.1 Cantidad de conexiones web concurrentes ...................................................6 67

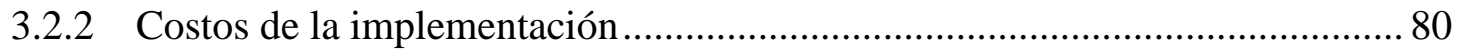

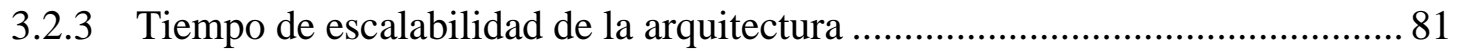

3.3 ARQUITECTURA TRADICIONAL CON ESCALAMIENTO VERTICAL ........................... 82

3.3.1 Cantidad de conexiones web concurrentes .................................................. 83

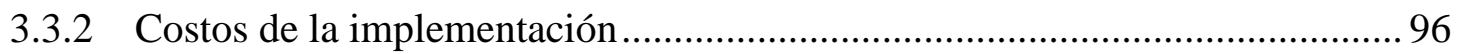

3.3.3 Tiempo de escalabilidad de la arquitectura ................................................... 97

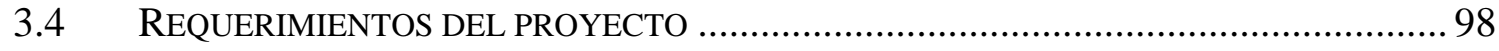

4 DISEÑO DE LA SOLUCIÓN ................................................................................. 100

4.1 CANTIDAD DE CONEXIONES WEB CONCURRENTES .......................................... 105

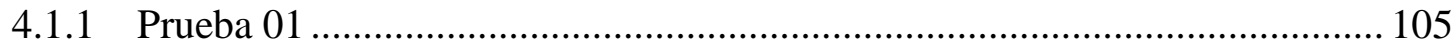

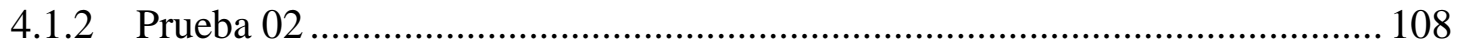

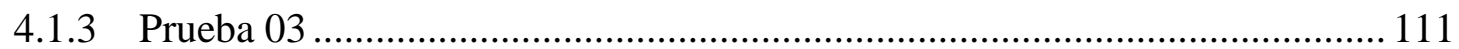

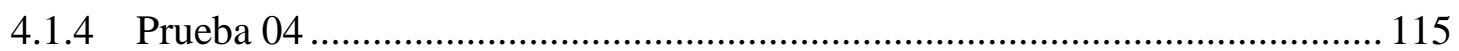

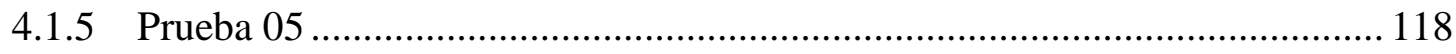

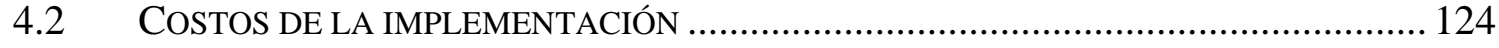

4.3 TIEMPO DE ESCALABILIDAD DE LA ARQUITECTURA …..................................... 126

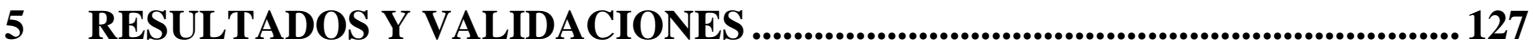


5.1 PRUEBAS Y RESULTADOS DEL INDICADOR 1: CUADROS COMPARATIVOS Y GRAFICAS EN EXCEL DE LOS RESULTADOS OBTENIDOS DE LAS PRUEBAS DE RENDIMIENTO.

5.2 PRUEBAS Y RESULTADOS DEL INDICADOR 2: CUADROS COMPARATIVOS DE COSTOS MEDIANTE OPEX.

5.3 PRUEBAS Y RESULTADOS DEL INDICADOR 3: CUADROS COMPARATIVOS QUE MUESTRE EL TIEMPO QUE TOMA LA ESCALABILIDAD.

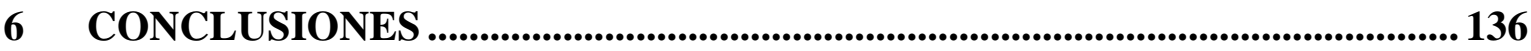

$7 \quad$ RECOMENDACIONES .................................................................................................. 137

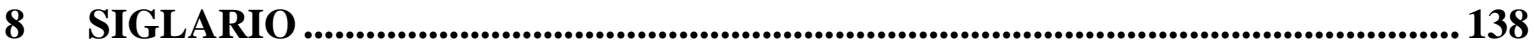

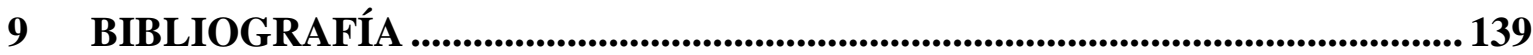




\section{ÍNDICE DE TABLAS}

Tabla 1. Comparativa entre los objetivos específicos, indicadores y métricas .................... 7

Tabla 2. Comparación entre máquinas Virtuales y contenedores .................................... 32

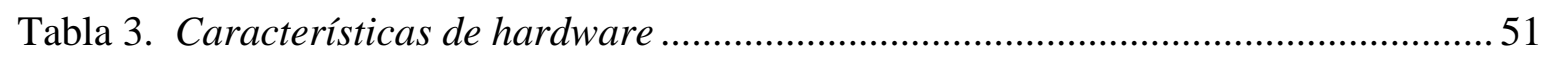

Tabla 4. Características de hardware para el servidor simulador de conexiones Web ..... 52

Tabla 5. Características de hardware para el servidor Web .............................................53

Tabla 6. Resumen de los resultados de las pruebas de conexión ........................................ 61

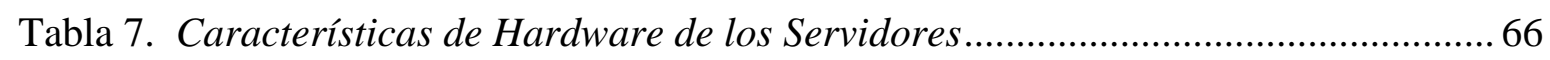

Tabla 8. Resumen de los resultados de las pruebas de conexión ........................................ 78

Tabla 9. Costo mensual de la Arquitectura con siete servidores ....................................... 81

Tabla 10. Tiempo total para la implementación de la Arquitectura con siete servidores . 81

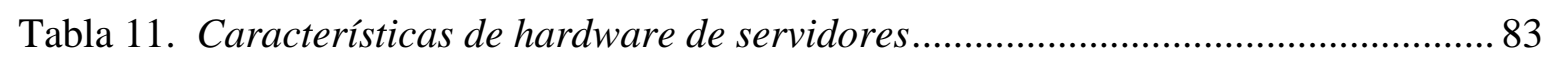

Tabla 12. Resumen de los resultados de las pruebas de conexión ....................................... 94

Tabla 13. Costo mensual de la Arquitectura con siete servidores ..................................... 97

Tabla 14. Tiempo total para el escalamiento vertical en la arquitectura con siete

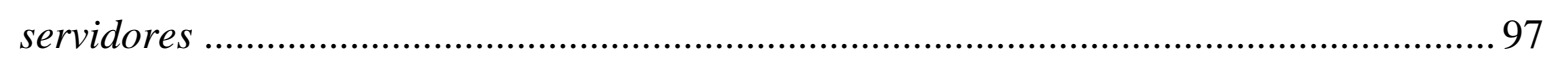

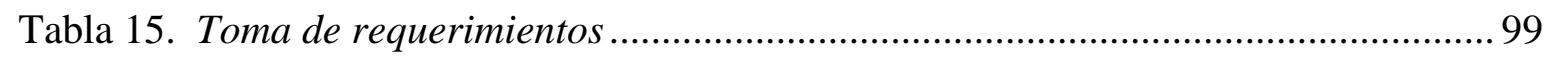

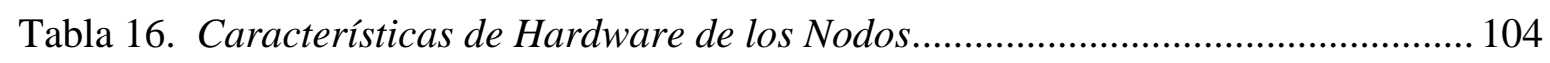

Tabla 17. Resumen de los resultados de las pruebas de conexión .................................... 122

Tabla 18. Costo mensual de la Arquitectura Basada en Contenedores Docker ............... 125

Tabla 19. Tiempo total para el escalamiento horizontal en la Arquitectura Basada en

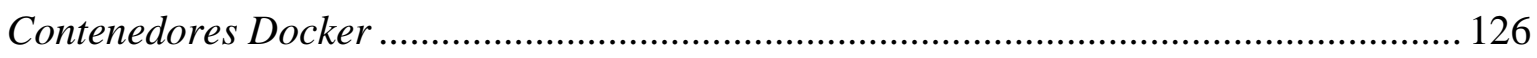

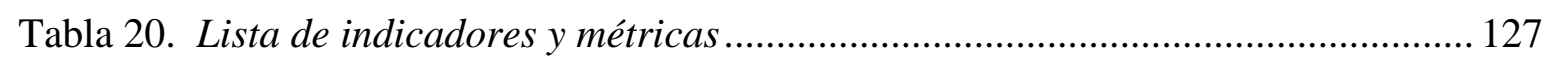

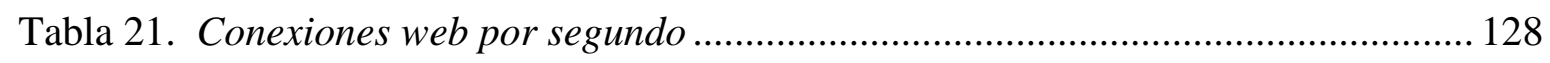

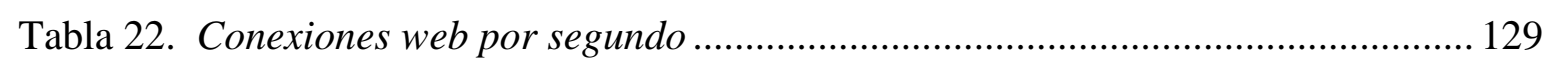

Tabla 23. Costo de los servidores para la arquitectura tradicional ................................ 131

Tabla 24. Costo de los nodos para la Arquitectura Basada en Contenedores Docker.... 132

Tabla 25. Tiempo obtenido para el escalamiento horizontal en la arquitectura tradicional

Tabla 26. Tiempo obtenido para el escalamiento horizontal en la arquitectura basada en contenedores. 


\section{ÍNDICE DE FIGURAS}

Figura 1.Contenerización de aplicaciones con Dockers ................................................... 2

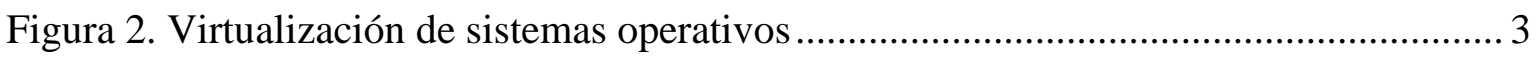

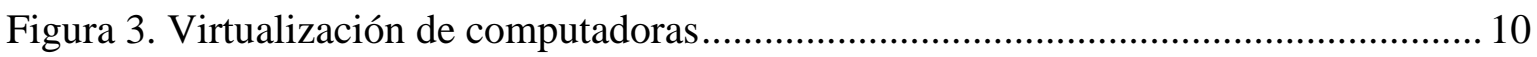

Figura 4. Contenerización de aplicaciones con Dockers .................................................. 11

Figura 5. Comparación entre contenedores basado en Linux............................................. 19

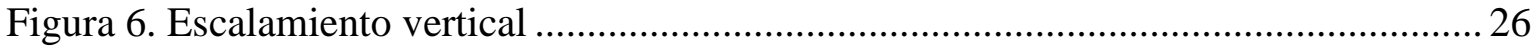

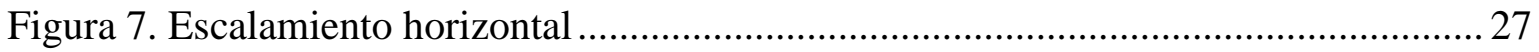

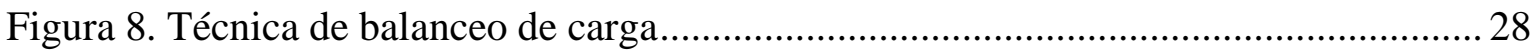

Figura 9. Comparación de contenedores con máquinas virtuales ..................................... 31

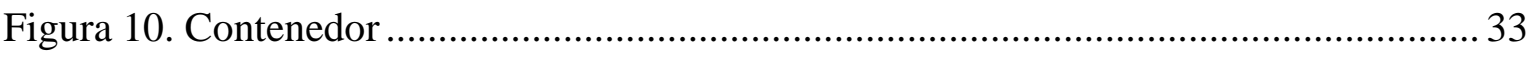

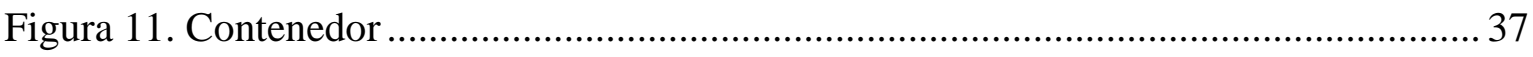

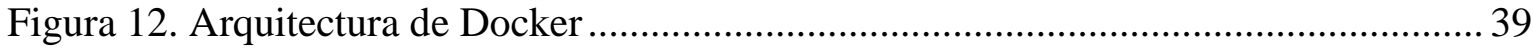

Figura 13. Registro de Imágenes en Docker ...................................................................... 40

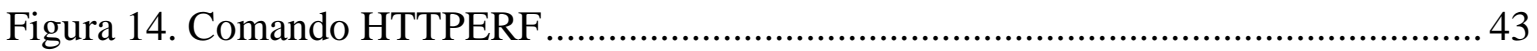

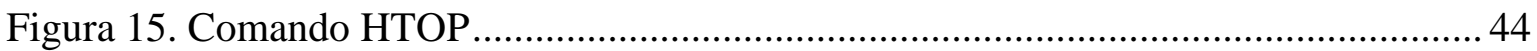

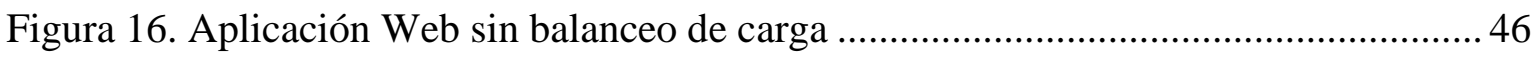

Figura 17. Aplicación Web con balanceo de carga ............................................................ 46

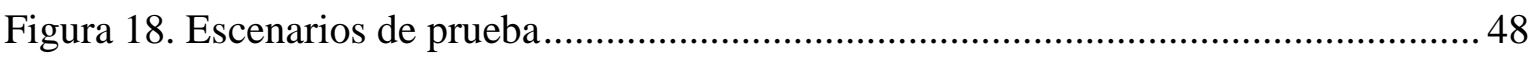

Figura 19. Arquitectura tradicional de una aplicación Web .................................................52

Figura 20. Muestra de consumo de hardware del servidor Web ......................................5 53

Figura 21. Validación de acceso a la aplicación Web ....................................................... 54

Figura 22. Resultados obtenidos en servidor Simulador de Conexiones hacia la aplicación Web. .55

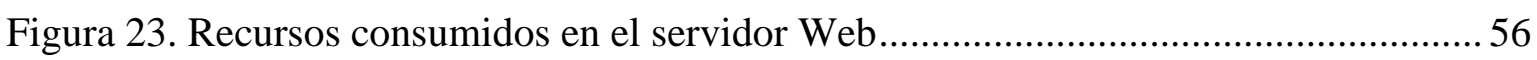

Figura 24. Resultados obtenidos en servidor Simulador de Conexiones hacia la aplicación Web. .57

Figura 25. Recursos consumidos en el servidor Web 58

Figura 26. Resultados obtenidos en servidor Simulador de Conexiones hacia la aplicación Web. .59

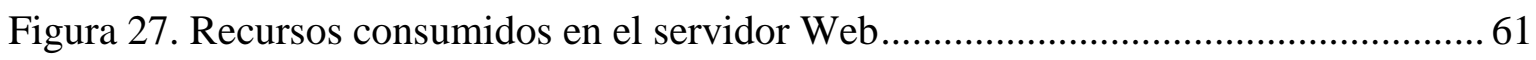

Figura 28. Conexiones enviadas y tiempo de respuesta de las pruebas ...............................62 62

Figura 29. Conexiones por segundo y tiempo de respuesta de la Web ............................... 62 
Figura 30. Costo mensual del servidor Web. 64

Figura 31. Arquitectura escalable basada en servidores

Figura 32. Resultados obtenidos en servidor Simulador de Conexiones hacia la aplicación Web. 68

Figura 33. Recursos consumidos en el servidor 01 - Balanceador Web 69

Figura 34. Recursos consumidos en el servidor 02 - Servidor Web 01 .70

Figura 35. Recursos consumidos en el servidor 03 - Servidor Web 02 70

Figura 36. Resultados obtenidos en servidor Simulador de Conexiones hacia la aplicación Web. .71

Figura 37. Recursos consumidos en el servidor 01 - Balanceador Web. .73

Figura 38. Recursos consumidos en el servidor 02 - Servidor Web 01 .............................. 73

Figura 39. Recursos consumidos en el servidor 03 - Servidor Web 02. 74

Figura 40. Resultados obtenidos en servidor Simulador de Conexiones hacia la aplicación Web. 75

Figura 41. Recursos consumidos en el servidor 01 - Balanceador Web. .76

Figura 42. Recursos consumidos en el servidor 02 - Servidor Web 01 .............................. 77

Figura 43. Recursos consumidos en el servidor 03 - Servidor Web 02 .............................. 77

Figura 44. Conexiones enviadas y tiempo de respuesta de las pruebas ................................ 78

Figura 45. Conexiones por segundo y tiempo de respuesta de la Web ............................... 79

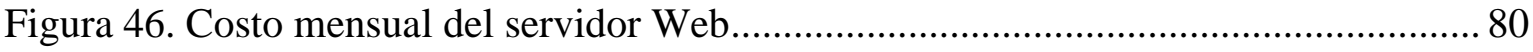

Figura 47. Arquitectura Escalable basada en Servidores - Escalamiento Vertical . 82

Figura 48. Resultados obtenidos en servidor Simulador de Conexiones hacia la aplicación Web. .84

Figura 49. Recursos consumidos en el servidor 01 - Balanceador Web............................. 85

Figura 50. Recursos consumidos en el servidor 02 - Servidor Web 01 .............................. 86

Figura 51. Recursos consumidos en el servidor 03 - Servidor Web 02 .............................. 86

Figura 52. Resultados obtenidos en servidor Simulador de Conexiones hacia la aplicación Web. .87

Figura 53. Recursos consumidos en el servidor 01 - Balanceador Web. .89

Figura 54. Recursos consumidos en el servidor 02 - Servidor Web 01 .89

Figura 55. Recursos consumidos en el servidor 03 - Servidor Web 02 .90

Figura 56. Resultados obtenidos en servidor Simulador de Conexiones hacia la aplicación Web. 91 
Figura 57. Recursos consumidos en el servidor 01 - Balanceador Web........................... 92

Figura 58. Recursos consumidos en el servidor 02 - Servidor Web 01 ............................. 93

Figura 59. Recursos consumidos en el servidor 03 - Servidor Web 02 ............................. 93

Figura 60. Conexiones enviadas y tiempo de respuesta de las pruebas .............................. 94

Figura 61. Conexiones por segundo y tiempo de respuesta de la Web .............................. 95

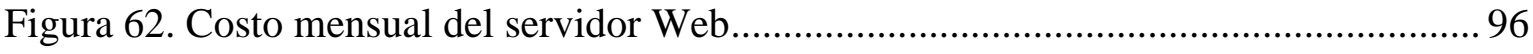

Figura 63. Nodos para la arquitectura escalable basados en contenedores ...................... 100

Figura 64. Docker Swarm - Contenedores y Servicios ..................................................... 101

Figura 65. Docker Swarm - Diseño de la Solución ............................................................ 102

Figura 66. Docker Swarm - Funcionamiento de la Red..................................................... 103

Figura 67. Resultados obtenidos en servidor simulador de conexiones hacia la aplicación

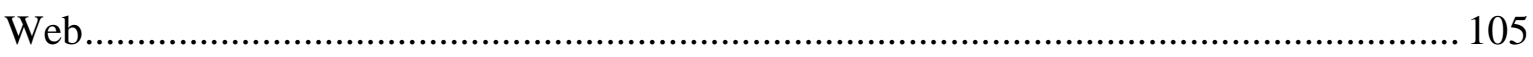

Figura 68. Recursos consumidos en Manager 01 - Docker Swarm ….............................. 106

Figura 69. Recursos consumidos en Worker 01 - Docker Contenedores (Web y MySQL)

Figura 70. Recursos consumidos en Worker 02 - Docker Contenedores (Web y MySQL)

Figura 71. Resultados obtenidos en servidor Simulador de Conexiones hacia la aplicación Web. 108

Figura 72. Recursos consumidos en Manager 01 - Docker Swarm 110

Figura 73. Recursos consumidos en Worker 01 - Docker Contenedores (Web y MySQL)

Figura 74. Recursos consumidos en Worker 02 - Docker Contenedores (Web y MySQL)

Figura 75. Resultados obtenidos en servidor Simulador de Conexiones hacia la aplicación Web.

Figura 76. Recursos consumidos en Manager 01 - Docker Swarm

Figura 77. Recursos consumidos en Worker 01 - Docker Contenedores (Web y MySQL)

Figura 78. Recursos consumidos en Worker 02 - Docker Contenedores (Web y MySQL)

Figura 79. Resultados obtenidos en servidor simulador de conexiones hacia la aplicación Web. 
Figura 80. Recursos consumidos en Manager 01 - Docker Swarm

Figura 81. Recursos consumidos en Worker 01 - Docker Contenedores (Web y MySQL)

Figura 82. Recursos consumidos en Worker 02 - Docker Contenedores (Web y MySQL)

Figura 83. Resultados obtenidos en servidor simulador de conexiones hacia la aplicación

Web. 119

Figura 84. Recursos consumidos en Manager 01 - Docker Swarm 120

Figura 85. Recursos consumidos en Worker 01 - Docker Contenedores (Web y MySQL)

Figura 86. Recursos consumidos en Worker 02 - Docker Contenedores (Web y MySQL)

Figura 87. Conexiones enviadas y tiempo de respuesta de las pruebas 123

Figura 88. Conexiones por segundo y tiempo de respuesta de la Web 123

Figura 89. Costo mensual por del nodo. 125

Figura 90. Conexiones Web por segundo 128

Figura 91. Conexiones web por segundo 129

Figura 92. Conexiones Web por segundo en ambas Arquitecturas 130

Figura 93. Tiempo de respuesta de la Web en ambas Arquitecturas. 130

Figura 94. Costo anual Arquitectura Tradicional y Basada en Contenedores 132

Figura 95. Escalamiento horizontal en arquitectura tradicional y basada en Contenedores 


\section{INTRODUCCIÓN}

\subsection{Motivación del tema}

Un término que venimos escuchando con frecuencia es el de startup. La primera idea que se nos viene a la cabeza es la de una empresa que está iniciando, sin embargo, este concepto trae mucho más consigo.

Según el BBVA, tenemos la siguiente definición: “podría definirse una 'startup' como una empresa emergente, normalmente con un alto componente tecnológico, con grandes posibilidades de crecimiento y que, por lo general, respalda una idea innovadora que sobresale de la línea general del mercado".

El director de Startupbootcamp Fintech México, Eduardo Morelos, nos deja esta definición: "Startup es una gran empresa en su etapa temprana; a diferencia de una Pyme, la Startup se basa en un negocio que será escalable más rápida y fácilmente, haciendo uso de tecnologías digitales".

De las definiciones anteriores, nos queda claro que dos constantes en las startups o empresas emergentes son: las grandes posibilidades de crecimiento y el uso de tecnologías digitales que soporten ese crecimiento. Ejemplos que tenemos a la vista y para los cuales no necesitamos ver muy lejos son: Facebook, Google, Amazon, AirBnb, Uber y podríamos seguir citando muchos otros.

El mercado actual nos presenta una amplia oferta de soluciones, sobre todo en la nube, para atender los requerimientos de estas empresas emergentes. Proveedores como Amazon AWS, Microsoft Azure, Google Cloud, Huawei Cloud, entre otros proponen soluciones escalables y flexibles a tales requerimientos.

Estas soluciones basadas en la nube utilizan la virtualización, creando entornos virtuales aislados para atender los requerimientos de los usuarios, lo que genera un alto overhead de recursos. La aparición de la tecnología de contenedores reduce significativamente este 
overhead, por lo que muchos servicios han migrado a esta tecnología y cuentan con plataformas de gestión y orquestación. Sin embargo, muchas veces se contratan servicios PaaS para desplegar a demanda los servicios y se requiere un manejo adecuado de la contenerización para gestionar los servicios que un startup pueda requerir.

Según docker.com, un contenedor es:

"una unidad estándar de software que empaqueta código y todas sus dependencias de tal forma que la aplicación corra rápido y de manera confiable desde un entorno de cómputo a otro. Una imagen de un contenedor Docker es un paquete de software ligero, aislado y ejecutable que incluye todo lo necesario para ejecutar una aplicación: código, entorno de ejecución, herramientas de sistema, librerías y configuraciones".

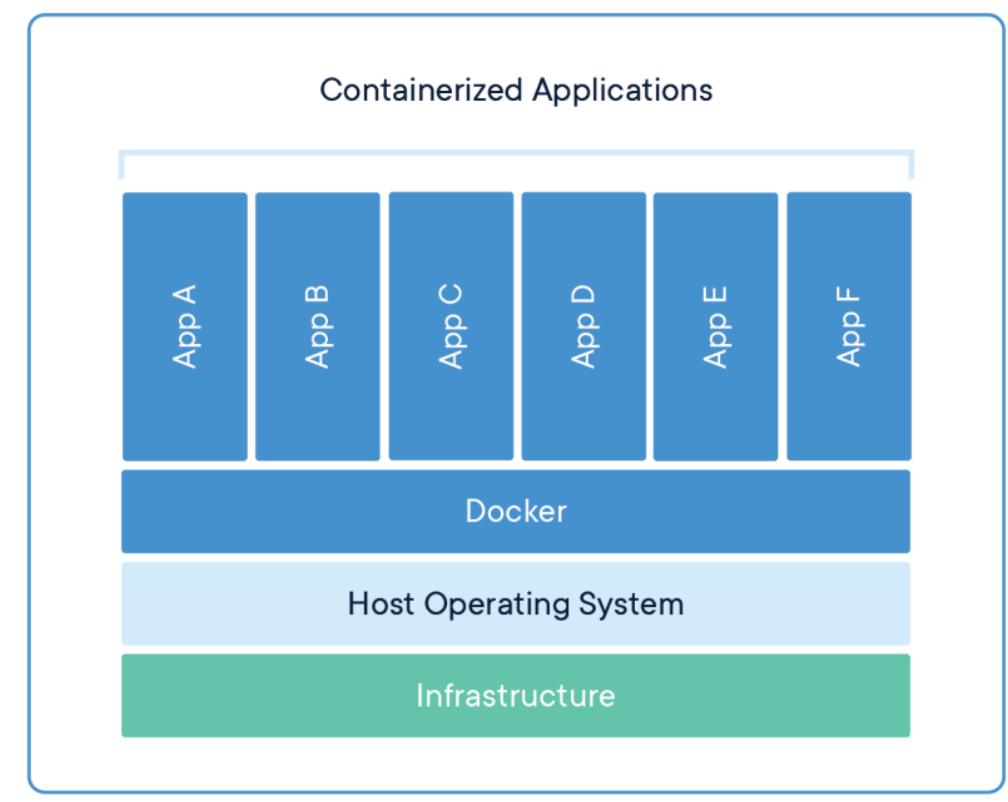

Figura 1.Contenerización de aplicaciones con Dockers

Adaptado de https://www.docker.com/resources/what-container

En vista de esta definición, vemos que un contenedor provee un espacio aislado para ejecutar aplicaciones, a diferencia de la virtualización de sistemas operativos (Ver figura 2), la contenerización permite crear imágenes más pequeñas y aprovechar el mismo sistema operativo, lo que lo hace más ligero. 


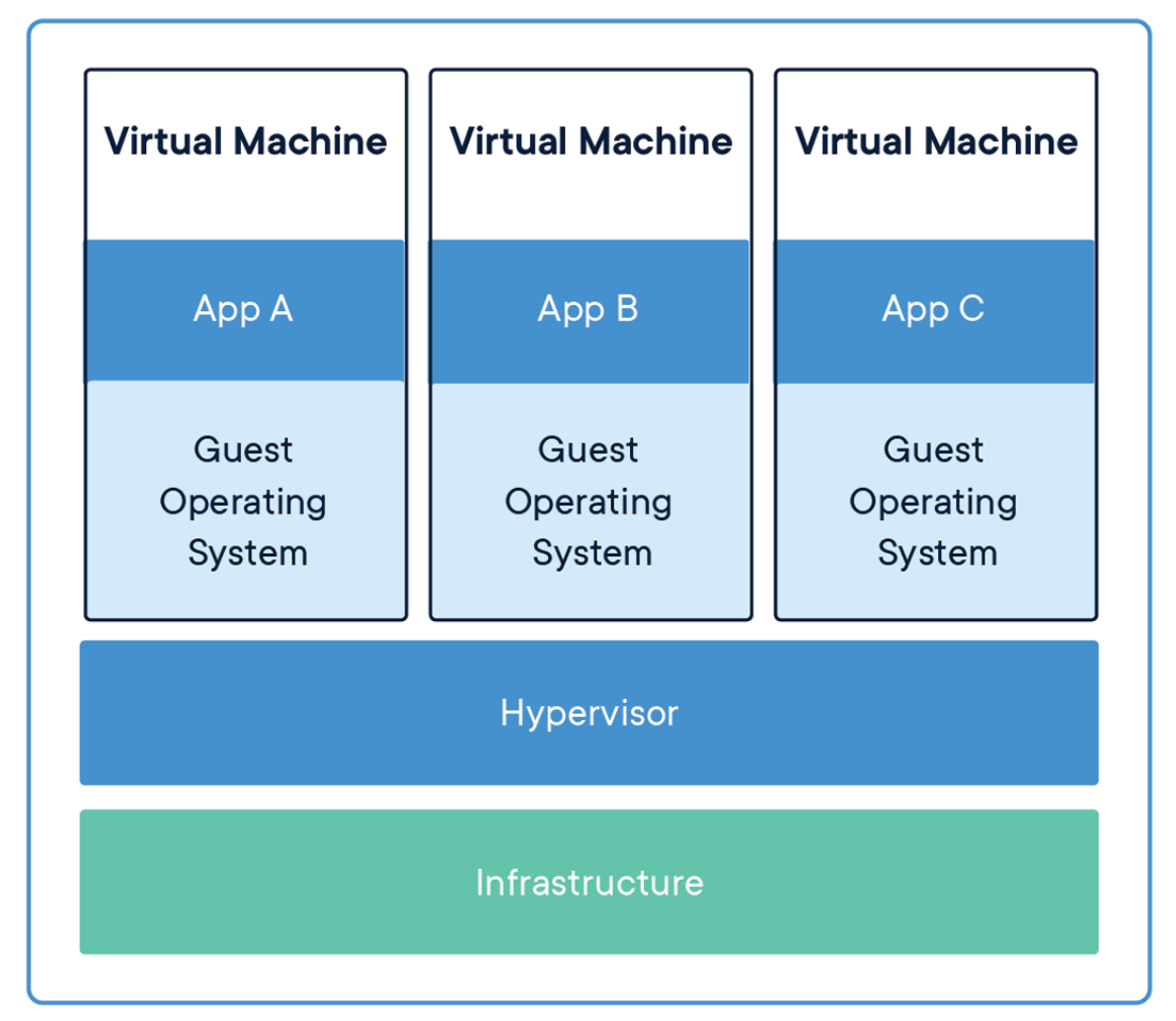

Figura 2. Virtualización de sistemas operativos

Adaptado de https://www.docker.com/resources/what-container

La contenerización ha tenido un gran crecimiento debido a las grandes ventajas que aporta en cuanto a comodidad, flexibilidad, eficiencia y escalabilidad, siendo este el motivo de que la gran cantidad de empresas están migrando sus aplicaciones web a este tipo de arquitectura. Según la revista IT Trends:

"La tecnología de contenedores se expande cada vez más, lo que está impulsando el mercado de herramientas de orquestación, que en los próximos años podría crecer a una tasa interanual compuesta del 17,2 \%. Factores como el crecimiento en el uso de microservicios o el aumento de aplicaciones para IoT contribuirán a que el valor del mercado pase de los 332,7 millones de dólares registrados en 2018 a unos 1.382,1 millones previstos para el año 2026".

Como vemos, las startups van de la mano con la tecnología, y las soluciones basadas en contenerización parecen ser la tecnología que se ajusta más a sus requerimientos. 


\subsection{Organización objetivo}

Como ya mencionamos anteriormente, una startup es una empresa emergente, que se basa en una idea innovadora, utiliza tecnologías digitales y tiene posibilidades muy grandes de crecimiento. Si bien es cierto, hay una gran variedad posible de actividades de negocio que las startups podrían realizar, estas deben estar acompañadas de componentes tecnológicos y, además, tener un potencial de crecimiento exponencial.

Otro factor que muchas startups comparten al inicio también es posiblemente que no cuentan con un presupuesto muy elevado para iniciar. Si bien es cierto, el presupuesto dependerá de la actividad de negocio, según G2 Consultores: "las startups se encuentran en una situación de ventaja, pues los proyectos de base tecnológica no necesitan tanto dinero como los de corte tradicional. Sin embargo, no deja de ser un tema delicado para los emprendedores".

G2 Consultores, con respecto de los problemas económicos que podrían enfrentar las startups, dice:

"Según cifras de la Secretaría de Economía, el financiamiento es la principal causa de mortandad en las empresas nuevas, con un $80 \%$ de negocios que mueren durante sus primeros dos años debido a la falta de presupuesto. La falta de dinero no es un problema en sí mismo, sino que viene de errores en la ejecución, que se reflejan en problemas de ventas y flujo de efectivo".

De aquí podemos ver que muchos emprendimientos podrían desaparecer por errores en la ejecución que, si bien es cierto, pueden deberse a diversos tipos de errores relacionados con el marketing, la gestión, entre otros, también pueden orientarse a problemas con su plataforma tecnológica.

Las startups, por lo tanto, pueden ofrecer diversos tipos de servicios, estos estarán soportados por una plataforma tecnológica, que podría estar onsite o en la nube, y que tiene que ser dimensionada (recursos de cómputo y red) de acuerdo con la cantidad esperada de usuarios y clientes esperados. Este dimensionamiento es clave y va de la mano, además, con las tecnologías emergentes que el mercado pone a disposición, por lo tanto, una buena 
selección y una adecuada configuración pueden garantizar y alargar la vida de un emprendimiento.

\subsection{Campo de acción en la organización objetivo}

El campo de acción es el conjunto de servidores onsite o en la nube, que empleará la startup para implementar sus servicios web, que serán accedidos por usuarios y clientes.

\subsection{Situación problemática}

Como identificamos anteriormente, las startups tienen dos componentes importantes: el gran potencial de crecimiento y el uso de tecnologías de información para soportar su modelo de negocio. Partiendo de estos dos puntos, observamos que una característica fundamental, por lo tanto, es la escalabilidad que tiene que ver justo con el amplio potencial de crecimiento.

Según afirma Morelos:

"Para lograr esta característica [la escalabilidad], se debe integrar tecnología que permita distribuir el producto de manera exponencial. (...). Este tipo de negocios debe tener la capacidad de adquirir usuarios de manera exponencial, con medios de distribución que le permitan llegar a un número mayor de usuarios y de clientes, así como una venta que no sea lineal. Los ingresos crecen mucho más rápido que los gastos de la compañía y esto, normalmente, se logra a través de la tecnología".

Entonces, podemos concluir que la plataforma tecnológica que soporte el modelo de negocio de una startup no solo debe ser escalable sino, además, debe estar preparada para soportar el crecimiento exponencial esperado. Sin embargo, muchas startups inician sus operaciones sin contar con una infraestructura tecnológica que soporte a futuro este crecimiento. Esto debido probablemente al costo de hardware, software, licenciamiento y soporte. Otra alternativa es levantar sus servicios en la nube, donde el desconocimiento muchas veces los lleva a modelos de pago que, a corto plazo, se vuelven inmanejables. 
Generalmente, las peticiones que soportan las aplicaciones web al inicio de sus actividades pueden llegar una cantidad de 50 conexiones concurrentes por segundo, lo que, al superar esa cifra, ocasiona que las aplicaciones presenten lentitud o pérdida de conexiones.

A medida que las aplicaciones web van siendo consumidas con mayor frecuencia, se ha observado que a mayores conexiones por segundo, el consumo de recursos aumenta. Cuando se tiene un mayor consumo de recursos de hardware, llegándolo a saturar, traerá como consecuencia pérdidas de conexiones, debido a que el servidor no soporta las peticiones recibidas.

Todo esto conlleva a que, cuando se requiera que las aplicaciones tengan una mayor demanda, no permita escalar adecuadamente en un tiempo corto que las aplicaciones de las empresas requieren.

\subsection{Problemas por resolver}

Las arquitecturas tradicionales basadas únicamente en virtualización de sistemas operativos no responden adecuadamente al crecimiento de una startup, haciendo complicado el escalamiento de servicios y aplicaciones web que les permitan mantener una mejor continuidad del negocio.

\subsection{Objetivo general}

Analizar una plataforma para aplicaciones web con una arquitectura basada en contenedores, para implementar servicios dirigidos a startups basado en las buenas prácticas de Dockers.

\subsection{Objetivos específicos}

- OE1: Determinar el número de conexiones Web por segundo que soportan las arquitecturas tradicionales contra la arquitectura basada en Contenedores. 
- OE2: Comparar los costos de las arquitecturas tradicionales arquitectura basada en contenedores.

- OE3: Calcular el tiempo de la escalabilidad de las arquitecturas tradicionales contra la arquitectura basada en contenedores.

1.8 Indicadores de logros de objetivos

Tabla 1 .

Comparativa entre los objetivos específicos, indicadores y métricas

\begin{tabular}{|c|c|c|c|}
\hline \multicolumn{2}{|r|}{ OBJETIVO ESPECÍFICO } & INDICADOR DE LOGRO & MÉTRICA \\
\hline OE1: & $\begin{array}{l}\text { Determinar el número de conexiones } \\
\text { web por segundo que soporta las } \\
\text { arquitecturas tradicionales contra la } \\
\text { arquitectura basada en contenedores. }\end{array}$ & $\begin{array}{l}\text { Cuadros comparativos } y \\
\text { gráficas en Excel de los } \\
\text { resultados obtenidos de las } \\
\text { pruebas de rendimiento. }\end{array}$ & $\begin{array}{l}\text { Número de } \\
\text { cantidad de } \\
\text { conexiones }\end{array}$ \\
\hline OE2: & $\begin{array}{l}\text { Comparar los costos de las arquitecturas } \\
\text { tradicionales contra la arquitectura } \\
\text { basada en contenedores. }\end{array}$ & $\begin{array}{l}\text { Cuadros comparativos de } \\
\text { costos mediante OPEX. }\end{array}$ & Costos \\
\hline OE3: & $\begin{array}{l}\text { Calcular el tiempo de la escalabilidad de } \\
\text { las arquitecturas tradicionales contra la } \\
\text { arquitectura basada en contenedores. }\end{array}$ & $\begin{array}{l}\text { Cuadros comparativos que } \\
\text { muestren el tiempo que toma } \\
\text { la escalabilidad. }\end{array}$ & Tiempo \\
\hline
\end{tabular}

Elaboración propia

\subsection{Justificación del proyecto}

Alcanzar una mayor eficiencia, flexibilidad y capacidad de administración de aplicaciones y servicios. Simplificar y dar utilidad real a la infraestructura de las Tecnologías de la Información. Adicionalmente, se presentan varias alternativas para que los administradores de TI puedan analizar los beneficios que ofrecen estas tecnologías, muchas de las opciones son tanto libres como licenciadas.

Con esta tecnología, podemos explotar al máximo los recursos físicos y lógicos de cada servidor anfitrión, descartando así el modelo clásico "una aplicación/servicio en un servidor físico". Nos permitirá eficiente escalabilidad a la hora de redimensionar los 
servicios o aplicaciones, ahorrando el tiempo que se requiere cuando se realiza una nueva instalación y, a la vez, aumentando la agilidad del negocio.

Muchas empresas aún siguen implementando tecnologías tradicionales para el alojamiento de sus aplicaciones web, desconocen formas ágiles de desplegar aplicaciones o servicios y así como también un buen rendimiento para tener una buena escalabilidad de los servicios. Este proyecto permitirá sugerir a las empresas optar por una correcta tecnología para el despliegue de aplicaciones web.

\subsection{Estado del arte}

El uso de contenedores ha cambiado la forma en cómo desarrolladores y administradores de TI conciben el desarrollo, la entrega y el mantenimiento de aplicaciones y servicios. Los contenedores son ligeros y flexibles, y pueden ser desplegados a través de clústeres de máquinas físicas o virtuales.

\subsubsection{Contenedores}

El uso de contenedores se convirtió hace poco en la solución más popular para el despliegue de servicios en la nube, hay diferentes plataformas que utilizan esta tecnología y aprovechan sus ventajas, entre ellas la facilidad de escalamiento. Como lo dicen Xavier y et al (2015):

"La popularidad de la Computación en la nube debido al incremento del número de clientes, ha obligado a los proveedores de servicios en la nube a adoptar soluciones para compartir recursos que soporten la creciente demanda de recursos de infraestructura ... La virtualización basada en contenedores se ha convertido en la solución más popular bajo plataformas PaaS e IaaS..."

La virtualización es la piedra angular de la computación en la nube, al nivel de infraestructura nos permiten crear computadoras virtuales basadas en sistemas operativos donde podemos instalar aplicaciones. Sin embargo, la virtualización es un concepto introducido por IBM muchos años atrás en la década de 1960, se utilizó para impulsar el 
uso de mainframes (bastantes costosos), dividiéndolos en máquinas virtuales individuales, separadas de manera lógica, que podían ejecutar múltiples procesos al mismo tiempo.

Según la página de dockers.com:

"Las máquinas virtuales son una abstracción del hardware convirtiendo un solo servidor en múltiples servidores. El hypervisor permite ejecutar múltiples máquinas virtuales en una sola máquina real. Cada máquina virtual incluye una copia completa del sistema operativo, las aplicaciones, las librerías y los archivos binarios necesarios, utilizando decenas de GBs. Las máquinas virtuales pueden ser lentas al arrancar".

En la virtualización tradicional, como observamos en la figura 3, un hypervisor controla los recursos de hardware de la computadora anfitrión. En este contexto, la virtualización basada en hypervisor puede darle a cada máquina virtual aparentemente más recursos de los que el hardware posee. Esto lo logra, por ejemplo, al compartir recursos de memoria que no todas las máquinas virtuales que estén ejecutándose utilizarán al mismo tiempo.

Para aumentar aún más la eficiencia del uso del hardware, apareció el concepto de contenedores. Según Pahl (2015), "Los contenedores son una solución similar, pero más ligera que la virtualización, ya que los contenedores usan mucho menos recursos y tiempo comparados con la virtualización tradicional”. 


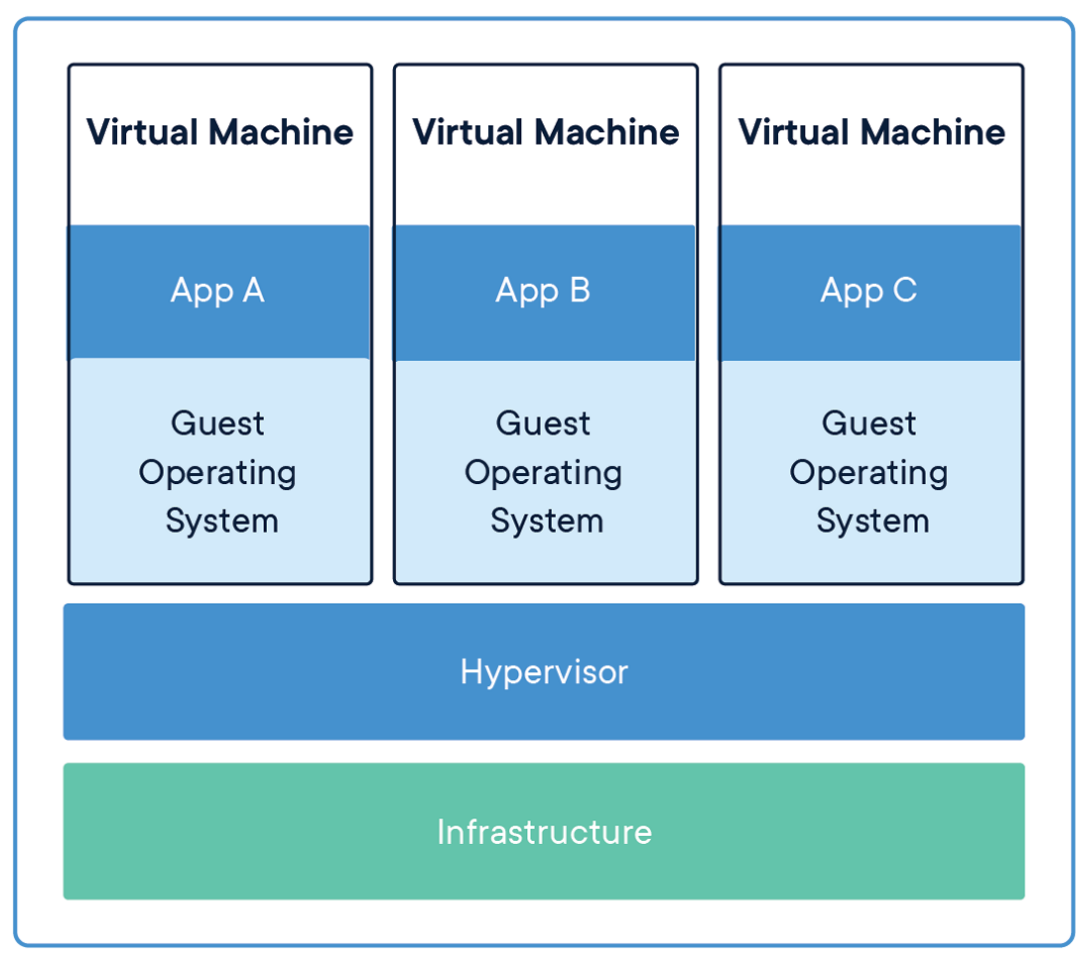

Figura 3. Virtualización de computadoras

Adaptado de https://www.docker.com/resources/what-container

En la página de docker.com, se define un contenedor como:

"una unidad estándar de software que empaqueta código y todas sus dependencias de tal forma que la aplicación corra rápido y de manera confiable desde un entorno de cómputo a otro. Una imagen de un contenedor Docker es un paquete de software ligero, aislado y ejecutable que incluye todo lo necesario para ejecutar una aplicación: código, entorno de ejecución, herramientas de sistema, librerías y configuraciones" (Ver figura 4).

En la guía de .NET Microservices de Microsoft (2019), se define la contenerización como: "un enfoque para el desarrollo de software en el cual una aplicación o servicio, sus dependencias y su configuración... son empaquetados juntos como una imagen. La aplicación contenerizada ... puede ser desplegada como una instancia de imagen al sistema operativo anfitrión... Los contenedores además aíslan las aplicaciones unas de otras dentro de un [mismo] sistema operativo compartido... Por lo tanto, los contenedores tienen una huella significativamente más pequeña que las imágenes de máquinas virtuales". 


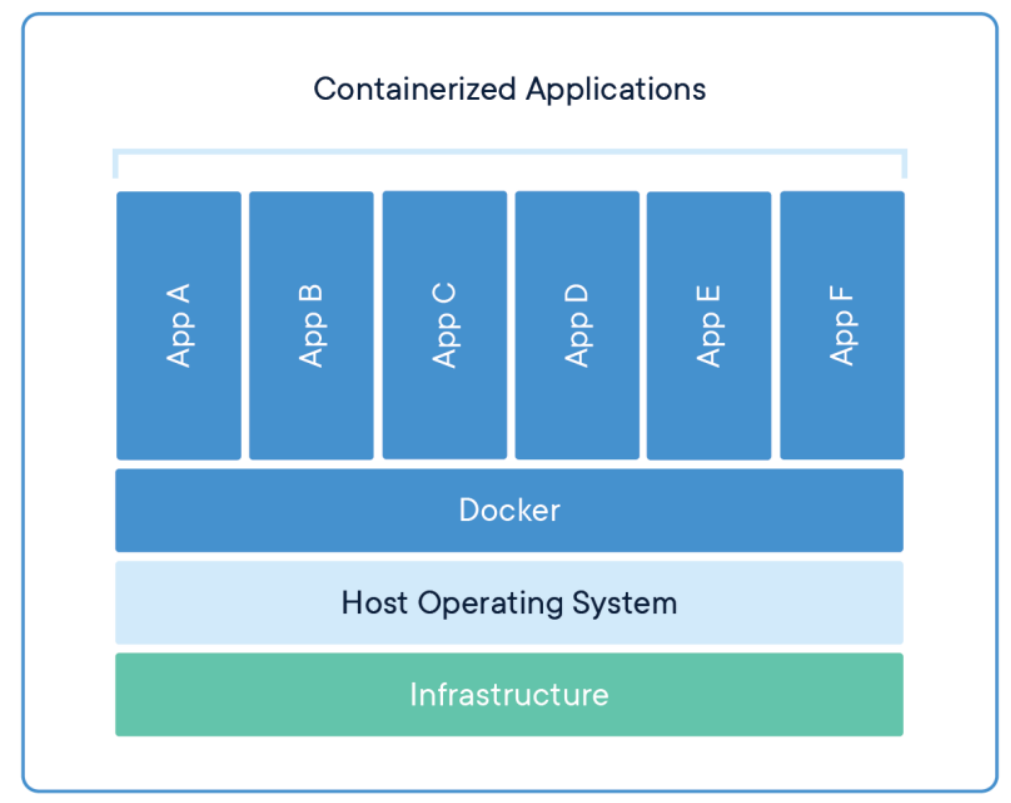

Figura 4. Contenerización de aplicaciones con Dockers

Adaptado de https://www.docker.com/resources/what-container

Como vemos en ambas definiciones, la constante sobre la tecnología de contenedores es el aislamiento de los recursos para la ejecución de la aplicación de tal manera que se puede crear una imagen portable y sobre todo ligera. Estas características han hecho que la contenerización se convierta en la tendencia actual para proveer servicios en la nube.

Según la revista IT Trends:

"La tecnología de contenedores se expande cada vez más, lo que está impulsando el mercado de herramientas de orquestación, que en los próximos años podría crecer a una tasa interanual compuesta del 17,2 \%. Factores como el crecimiento en el uso de microservicios o el aumento de aplicaciones para IoT contribuirán a que el valor del mercado pase de los 332,7 millones de dólares registrados en 2018 a unos 1.382,1 millones previstos para el año 2026”.

Esto nos lleva a concluir que el uso de contenedores está en auge y sigue creciendo debido a las grandes ventajas que aporta en cuanto a comodidad, flexibilidad, eficiencia y escalabilidad, siendo este el motivo de que la gran cantidad de empresas están migrando sus aplicaciones web a este tipo de arquitectura. 


\subsubsection{Antecedentes}

A pesar de que recién hace unos años hemos oído hablar del uso de contenedores, su creación se remonta a varios años atrás. En el blog de Aqua Security, Rani Osnat, VP Strategy de la marca, nos cuenta una breve historia sobre los contenedores. "Para este viaje, suba dentro de mi máquina del tiempo DeLorean, y viajemos a 1979, cuando surgió por primera vez el concepto de contenedores (Osnat, 2020).

En el artículo de Rani: A Brief History of Containers: From the 1970s Till Now (en español: Una breve historia de contenedores: Desde 1970 hasta ahora) podremos ver cómo ha evolucionado esta tecnología:

1979: Unix V7. Durante el desarrollo de Unix V7, en 1979, se introdujo el sistema chroot, cambiando el directorio raíz de un proceso y sus hijos a una nueva ubicación en el sistema de archivos. Este avance fue el inicio del proceso de aislamiento: segregando el acceso a los archivos para cada proceso. Chroot fue añadido a BSD en 1982.

2000: FreeBSD Jails. Casi dos décadas después, en el año 2000, un pequeño proveedor de hosting de entorno compartido presentó FreeBSD Jails para lograr una clara separación entre sus servicios y los de sus clientes por seguridad y facilidad de administración. FreeBSD Jails permite a los administradores separar un sistema operativo FreeBSD en varios sistemas independientes más pequeños, denominados "Jails", con la capacidad de asignar una dirección IP para cada sistema y configuración.

2001: Linux VServer. Al igual que FreeBSD Jails, Linux VServer es un mecanismo "Jail" que puede separar los recursos (sistemas de archivos, direcciones de red, memoria) en un sistema operativo. Introducido en 2001, este sistema operativo de virtualización se implementa mediante un parche al kernel de Linux. Los parches experimentales todavía están disponibles, pero el último parche estable fue lanzado en 2006.

2004: Oracle Solaris Containers. Oracle lanzó la versión beta de un Contenedor Solaris que combinaba controles de recursos del sistema y una separación de límites proporcionados 
por zonas, que fueron capaces de aprovechar características como instantáneas y clonación de ZFS.

2005: Open VZ (Open Virtuzzo). Se trata de una tecnología de virtualización a nivel de sistema operativo que utiliza un kernel Linux parchado para virtualización, aislamiento, administración de recursos. El código no fue lanzado como parte oficial del kernel de Linux.

2006: Process Containers. Process Containers (lanzado por Google en 2006) fue diseñado para limitar, contabilizar y aislar el uso de recursos (CPU, memoria, I/O de disco, red) de una colección de procesos. Fue renombrado "Grupos de control (cgroups)" un año después y, finalmente, se fusionó con el kernel 2.6.24 de Linux.

2008: LXC. LXC (LinuX Containers) fue la primera y más completa implementación del gestor de contenedores Linux. Se implementó en el año 2008 utilizando cgroups y namespaces de Linux, y funcionaba en un solo kernel de Linux sin necesidad de parches.

2011: Warden. En 2011, CloudFoundry comenzó Warden, utilizando LXC en las etapas iniciales y, posteriormente, lo reemplazó con su propia implementación. Warden puede aislar entornos en cualquier sistema operativo, ejecutándose como un daemon y proporcionando una API para la gestión de contenedores. Desarrolló un modelo clienteservidor para administrar una colección de contenedores a través de múltiples hosts, Warden incluye un servicio para administrar cgroups, namespaces y el ciclo de vida del proceso.

2013: LMCTFY. Let Me Contain That For You (LMCTFY) se lanzó en 2013 como una versión de código abierto de los contenedores de Google, proporcionando contenedores de aplicaciones Linux. Las aplicaciones pueden hacerse "conscientes del contenedor", crear y administrar sus propios subcontenedores. El despliegue activo en LMCTFY se detuvo en 2015, después de que Google comenzó a aportar conceptos básicos de LMCTFY a libcontainer, que ahora forma parte de la Open Container Foundation. 
2013: Docker. Cuando Docker apareció en 2013, los contenedores aumentaron su popularidad. No es coincidencia, por lo tanto, que el crecimiento de Docker y el uso de contenedores vayan de la mano. Al igual que Warden, Docker también usó LXC en sus etapas iniciales y, más tarde, lo reemplazaron por su propia librería, libcontainer. Sin embargo, Docker se caracterizó por ofrecer un ecosistema completo para el manejo de contenedores.

2014: CRIU. Es un proyecto para implementar la funcionalidad de punto de comprobación/restauración para Linux. Checkpoint / Restore In Userpace o CRIU, es una herramienta de software para el sistema operativo Linux. Mediante esta herramienta, puede congelarse una aplicación en ejecución (o parte de ella) y marcarla como una colección de archivos en disco. A continuación, puede utilizar los archivos para restaurar la aplicación y ejecutarlo exactamente como lo fue durante el tiempo de congelación. Con esta característica, la migración en vivo de aplicaciones, instantáneas, depuración remota y muchas otras cosas son posibles. CRIU comenzó como un proyecto de Virtuozzo y creció con la tremenda ayuda de la comunidad. Actualmente, se utiliza (integrado en) OpenVZ, LXC / LXD, Docker y otro software, y los paquetes CRIU se incluyen en muchas distribuciones de Linux.

2015: OpenVZ re-born. OpenVZ renace con un nuevo modelo de desarrollo, nuevo kernel y herramientas.

2016: La importancia de la seguridad en contenedores. Con la adopción de aplicaciones basadas en contenedores, los sistemas se vuelven más complejos y riesgosos, dejando terreno de trabajo a la seguridad de contenedores. El objetivo es construir contenedores seguros desde el inicio sin reducir el tiempo necesario para salir al mercado.

2017: Maduran las herramientas para contenedores. Cientos de herramientas se han construido para hacer de la gestión de contenedores algo fácil. A pesar de que estas herramientas han estado disponibles desde hace años, 2017 es el año donde estas herramientas empezaron a tener relevancia. Por ejemplo, Kubernetes, desde que fue adoptada en la Cloud Native Computing Foundation (CNCF) en 2016, empresas como 
VMWare, Azure, AWS, e incluso Docker han anunciado su soporte dentro de sus infraestructuras.

2018: El Estandard de Oro. En el 2018, vimos como la contenerización se convirtió en la fundación para las infraestructuras de software modernas y Kubernets empezó a ser utilizado por la mayoría de los proyectos de contenedores empresariales. La adopción masiva de Kubernets empujó a los vendedores de servicios en la nube, como AWS, Azure, Google y Oracle, a ofrecer servicios gestionados con Kubernetes.

2019: Un panorama cambiante. El año 2019, marcó el comienzo de cambios significativos en el panorama de los contenedores. Los nuevos motores en tiempo de ejecución ahora comenzaron a reemplazar el motor de Docker, especialmente Containerd, un motor de tiempo de ejecución de contenedor de código abierto y CRI-O, un motor de tiempo de ejecución ligero para Kubernetes. Docker Enterprise ha sido comprado y como resultado Docker Swarm ha sido puesto en un horizonte final de dos años.

\subsubsection{Productos}

\subsubsection{Docker}

Docker es una empresa líder en el mercado de contenedores, combina una plataforma de contenerización de carácter empresarial con servicios de clase mundial, proporcionándoles, a los desarrolladores y gestores de TI, la libertad de construir, administrar y asegurar aplicaciones sin el temor de enganchase a una tecnología o infraestructura particular.

Desde su página Docker.com:

"Docker entrega una plataforma para manejar la transformación digital a través de la línea completa dentro del portafolio de aplicaciones de una empresa, hecha para que funcione de la manera que quieres que funcione, soportando arquitecturas on-premise, en la nube o híbridas".

Ventajas de utilizar contenedores Docker: 
- Estándar: Docker es el estándar en la industria de contenedores, por lo que pueden ser portados donde sea.

- Peso Ligero: Los contenedores comparten el kernel del sistema operativo y, por lo tanto, no requieren un sistema operativo por aplicación, mejorando la eficiencia y reduciendo los costos de recursos del servidor y licencias.

- Seguro: Las aplicaciones son seguras en contenedores y Dockers provee la capacidad de aislamiento más fuerte del mercado.

Como resultado, en su página Docker asegura que las organizaciones reportan un $300 \%$ de mejoras en sus tiempos de salir al mercado con un $50 \%$ del costo.

Docker es utilizado ampliamente en diferentes entornos. Un ejemplo de caso de uso del Docker:

"En Lindsay, nuestro negocio está realmente enfocado en enfrentar los desafíos que surgen de una población global que crece rápidamente hacia 10 mil millones de personas. Eso crea muchos desafíos muy difíciles, pero también algunas oportunidades muy interesantes, ya sea que nuestro negocio de tecnología de riego se centre en ayudar a alimentar al mundo de manera más eficiente y sostenible" (Brian Magnuson VP of Technology and Innovation, Lindsay Corporation).

Docker se distribuye como edición Community libre (CE) y como versión de pago Enterprise (EE), y es compatible con diversas distribuciones Linux. La versión libre también se puede utilizar como aplicación nativa para Windows y macOS desde la versión 1.12. Desde septiembre de 2016, la versión Enterprise también está disponible de forma nativa para Windows Server 2016.

\subsubsection{RKT (Rocket)}

Fue presentado, en el 2014, por el distribuidor de Linux CoreOS y se ha convertido en el mayor competidor de Docker en el mercado. RKT es un motor para contener aplicaciones, desarrollado para atender el mercado moderno de entornos de producción en la nube. 
En su página coreos.com, se explica cómo es su arquitectura: "La unidad de ejecución de RKT es el pod, una colección de una o más aplicaciones ejecutándose en un contexto compartido". RKT permite a los usuarios aplicar diferentes configuraciones tanto al nivel de un pod, como al nivel más granular de una aplicación. La arquitectura RKT permite la ejecución de un pod, siguiendo el modelo clásico de procesos UNIX dentro de un entorno aislado y autocontenido. RKT puede ejecutar imágenes appc que son el formato estándar que soporta, sin embargo, también puede ejecutar otras imágenes como por ejemplo la de Docker.

Un caso de aplicación de RKT: "We find CoreOS's RKTa compelling container engine in Kubernetes because of how RKTcomposes with underlying systemd. The RKT runtime assumes only the responsibility it needs to, then delegates to other system services where appropriate. This separation of concerns is important to us" (Encontramos el motor de contenedor RKTa convincente de CoreOS en Kubernetes debido a cómo RKT se compone con el systemd subyacente. El tiempo de ejecución de RKT solo asume la responsabilidad que necesita y luego delega a otros servicios del sistema, según corresponda. Esta separación de preocupaciones es importante para nosotros. Mark Petrovic, Senior MTS and architect, XOOM a PayPal Service).

\subsubsection{Linux Containers - Infraestructure for Container Projects}

Linux containers.org es el proyecto paraguas detrás de LXC, LXD y PXFS, tiene como objetivo ofrecer un entorno neutral para distribuciones y vendedores, orientado al desarrollo de tecnologías de contenedores para Linux.

Los proyectos activos que mantiene Linux Conteiners son 3 LXC, LXD y LXFS, para este caso, hablaremos de los dos primeros que permiten la gestión de contenedores en entornos Linux.

\subsubsection{Linux Containers LXC}

Es una interface para el espacio de usuarios para las características de contenerización del kernel de Linux. Utiliza un API y herramientas simples para permitirles a los usuarios 
crear y gestionar contenedores. LXC se distribuye como software libre en su mayoría bajo la licencia GNU LGPLv2.1+.

Sus principales características son:

- Espacios de nombres del kernel (ipc, uts, mount, pid, network y user)

- Perfiles para Apparmor y SELinux

- Políticas Seccomp

- Chroot (usando pivot_root)

- CGroops (grupos de control)

Con estas características, LXC busca crear el entorno más cercano posible al de una instalación estándar de Linux, pero sin la necesidad de un kernel independiente.

\subsubsection{Linux Containers LXD}

LXD es la siguiente generación de un sistema gestor de contenedores. Ofrece una experiencia similar a las máquinas virtuales, pero utilizando contenedores bajo Linux. LXD se distribuye como software libre en su mayoría bajo la licencia GNU LGPLv2.1+. En noviembre de 2014, canonical, lanzo LSD como alternativa a Docker; ampliando la tecnología de LXC a través del demonio LXD, lo que hace que lo podamos considerar como un hipervisor de contenedores.

El núcleo de LXD es un demonio con privilegios que trabaja con una REST API sobre un socket local Unix así como sobre la red, si es que es activado. Lo que hace posible que a través del REST API cualquier cliente pueda hacer lo mismo que haría desde la línea de comandos. Básicamente, está compuesto de tres elementos: el demonio LXD, la herramienta cliente terminal LXC y un plug-in de nova (Open Stack Nova), la comunicación entre el cliente y el demonio es a través de un REST API.

Estos son cuatro de los principales competidores en el mercado de contenedores, en la página Digital Guide de IONOS, podemos encontrar una tabla comparativa entre ellos, como observamos en la figura 5. Del gráfico, podemos ver que RKT soporta más formatos 
y que Doker, por ejemplo, es el que corre en la mayoría de los sistemas operativos y entornos de nube.

\begin{tabular}{|c|c|c|c|c|}
\hline & Docker & rkt & LXC & LXD \\
\hline $\begin{array}{l}\text { Tecnología de } \\
\text { virtualización }\end{array}$ & En el nivel del sistema operativo & $\begin{array}{l}\text { En el nivel del } \\
\text { sistema operativo, } \\
\text { hipervisor }\end{array}$ & $\begin{array}{l}\text { En el nivel del } \\
\text { sistema } \\
\text { operativo }\end{array}$ & $\begin{array}{l}\text { En el nivel del } \\
\text { sistema } \\
\text { operativo }\end{array}$ \\
\hline $\begin{array}{l}\text { Full system } \\
\text { container }\end{array}$ & No & No & Sí & Sí \\
\hline $\begin{array}{l}\text { Contenedor de } \\
\text { aplicaciones }\end{array}$ & Sí & Sí & No & No \\
\hline Licencia & Apache 2.0 & Apache 2.0 & GNU LGPLv2.1+ & Apache 2.0 \\
\hline $\begin{array}{l}\text { Formato del } \\
\text { contenedor }\end{array}$ & Docker Container & $\begin{array}{l}\text { appc, } \\
\text { DockerContainer }\end{array}$ & $\begin{array}{l}\text { Linux Container } \\
\text { (LXC) }\end{array}$ & $\begin{array}{l}\text { Linux Container } \\
(\mathrm{LXC})\end{array}$ \\
\hline $\begin{array}{l}\text { Plataformas } \\
\text { compatibles }\end{array}$ & $\begin{array}{l}\text { Linux, Windows, macos, Microsoft } \\
\text { Azure, Amazon Web Services } \\
\text { (AWS) }\end{array}$ & $\begin{array}{l}\text { Linux, Windows, } \\
\text { macos }\end{array}$ & Linux & Linux \\
\hline $\begin{array}{l}\text { Último } \\
\text { lanzamiento }\end{array}$ & Abril de 2017 & Febrero de 2017 & Enero de 2017 & Marzo de 2017 \\
\hline $\begin{array}{l}\text { El núcleo de Linux } \\
\text { requiere un } \\
\text { parche }\end{array}$ & No & No & No & No \\
\hline $\begin{array}{l}\text { Lenguaje de } \\
\text { programación }\end{array}$ & Go & Go & $\begin{array}{l}\text { C, Python 3, } \\
\text { Shell, Lua }\end{array}$ & Go \\
\hline
\end{tabular}

Figura 5. Comparación entre contenedores basado en Linux

Adaptado de https://www.ionos.es/digitalguide/servidores/know-how/alternativas-a-los-contenedores-en$\underline{\text { docker/ }}$

\subsubsection{Orquestadores}

Como ya mencionamos, los contenedores y sus ventajas están en auge, y las aplicaciones se han vuelto cada vez más complejas. Lo que obliga a que, generalmente, no se utilice un único contenedor si no es necesario desplegar varios contenedores en producción, esto permite dividir a la aplicación en diferentes servicios, para escalar de manera más natural. Para cubrir esta necesidad, se requiere de una herramienta que automatice el despliegue, la gestión, el escalado y la interconexión de las aplicaciones contenerizadas.

Un orquestador de contenedores debe cumplir tareas como:

- Configuración automática

- Despliegue automático de servicios

- Intercambio de datos y conectividad en la red 
- Balanceado de carga

- Mantenimiento de parámetros y configuraciones

- Autoescalado y autoreinicio de contenedores

Algunos de los orquestadores más conocidos son:

\subsubsection{Kubernetes}

Es actualmente el contenedor más popular, utilizado en un amplio número de organizaciones y soluciones en el mercado. Comenzó como un proyecto de Google y, actualmente, miles de equipos de desarrolladores lo usan para desplegar contenedores en producción.

Según la página de Google Cloud:

"Se desarrolló allí [Google Cloud] originalmente y se lanzó como código abierto en 2014. Kubernetes creció hasta convertirse en la solución más popular para administrar cargas de trabajo en contenedores en cualquier lugar. Kubernetes mejora la confiabilidad y reduce el tiempo y los recursos destinados a DevOps mediante la organización automatizada de los contenedores y la administración eficiente de las máquinas".

Kubernetes agrupa los contenedores que conforman una aplicación en unidades lógicas para que sea más fácil su administración y su descubrimiento.

\subsubsection{Docker Swarm}

Es la propuesta de Docker para orquestar aplicaciones y está incluida junto al motor de Docker desde su versión 1.12.0. Aplica la misma filosofia de simplicidad, es más fácil de usar que Kubernetes, sin embargo, no tiene la potencia de Kubernetes y no es utilizado por tantas empresas, proveedores de cloud o por la comunidad. 
GKE se monta sobre Kubernetes y su objetivo es optimizar el desarrollo de aplicaciones y mejorar la gestión de carga de trabajo de los contenedores. Utiliza una interfase transparente y fácil de utilizar para ocultar tareas de gestión complejas.

\subsubsection{Azure Container Service (AKS)}

Es utilizado para crear, configurar y gestionar la infraestructura de contenedores Docker abiertos. Está optimizado para trabajar con las máquinas virtuales de Azure (Azure Virtual Machines). Tiene soporte para Kubernetes, Mesosphere DC/OS o Swarm.

\subsubsection{Amazon ECS}

Es el servicio de orquestación de Amazon ECS para contenedores, es altamente escalable pero solo permite ejecutar contenedores en instancias EC2. Tiene muchos componentes para el despliegue de clústeres, tareas y servicios sobre Docker. Su ventaja se basa en el uso de servicios propios de AWS: CloudTrail, CloudWatch, Elastic Load Balancing, etc.

Existen otras herramientas para orquestar contenedores, sin embargo, estas son las más relevantes, entre ellas Swarm destaca por su simplicidad y por el uso que se le puede dar en proyectos de investigación y laboratorios.

\subsubsection{Organizaciones}

\subsubsection{Open Container Initiative (OCI $)^{1}$}

Es una estructura abierta de gobernanza de peso ligero. Fue lanzada en junio de 2015, auspiciada por la Fundación Linux y conformada por Docker, CoreOS, Cisco, Google,

\footnotetext{
${ }^{1}$ Extraído de opencontainer.org
} 
Huawei, entre otros líderes en la industria, llegando a hasta 20 organizaciones. OCI contiene dos especificaciones: La especificación en tiempo de ejecución (runtime-spec) y la especificación de imágenes (image-spec).

Según su página, OCI asegura que: el flujo de trabajo completo debe soportar la experiencia de usuario (UX), que los usuarios, valga la redundancia, esperan de los motores de contenedores como Docker o Rocket. Para admitir esta experiencia de usuario, el formato de la imagen OCI debe contener información suficiente para iniciar la aplicación en la plataforma destino (por ejemplo: comandos, argumentos, variables de entorno entre otros). En esta especificación, se define cómo crear una imagen OCI, esta se realiza por un sistema de compilación y se genera un manifiesto de imagen, una serialización del sistema de archivos y una configuración de imagen. La combinación del manifiesto de la imagen, la configuración de la imagen y una o más serializaciones del sistema de archivos se denomina Imagen OCI.

Esta estandarización beneficiará a los usuarios que no tendrán que preocuparse de los problemas de compatibilidad, a largo plazo, de los componentes básicos del sistema, pudiendo elegir con más libertad el proveedor que más innovaciones o fiabilidad le dé en un determinado momento. 


\section{MARCO TEÓRICO}

Este proyecto se centra en el análisis de una plataforma para aplicaciones Web donde nos basaremos en el uso de tecnologías de contenedores para garantizar la escalabilidad en el diseño del despliegue de los servicios que requiere un startup al momento de iniciar sus operaciones. Por lo tanto, en este capítulo se mencionarán las definiciones en los temas relevantes al proyecto para una adecuada compresión.

\subsection{Startup}

Ya se dieron algunas definiciones de un startup en el capítulo anterior, sin embargo, aquí formalizaremos estas definiciones y ampliaremos un poco los conceptos sobre startups para entender mejor el enfoque de este proyecto.

"Startup es una gran empresa en su etapa temprana; a diferencia de una Pyme, la startup se basa en un negocio que será escalable más rápida y fácilmente, haciendo uso de tecnologías digitales” (Morelos, 2018).

Este término se utiliza cuando la empresa está iniciando, está arrancando (startup), una vez que haya crecido dejará de llamarse así. En un artículo escrito por Ricardo Dorantes para la revista digital Entrepreneur, el autor refiere que las tres características que definen un startup son: Temporalidad, Escalabilidad y Crecimiento Exponencial. La escalabilidad, que tiene que ver con el crecimiento potencial de la empresa, es el segundo aspecto fundamental de una startup; afirma Dorantes.

Del artículo de Dorantes, también podemos extraer estas conclusiones expuestas por Morelos:

"Este tipo de negocios debe tener la capacidad de adquirir usuarios de manera exponencial, con medios de distribución que le permitan llegar a un número mayor de usuarios y de clientes, así como una venta que no sea lineal. Los ingresos crecen mucho más rápido que los gastos de la compañía y esto, normalmente, se logra a través de la tecnología... Para lograr esta característica, se de integrar tecnología que permita distribuir el producto de manera exponencial”. 
Por lo tanto, después de haber encontrado una bastante clara y acertada definición de startup, también hemos podido entender la característica principal que nos lleva a este proyecto: El crecimiento exponencial que debe ser asumido por la plataforma tecnológica necesaria para escalar de la mano con el startup.

Entendemos, por lo tanto, que la escalabilidad en un startup tiene que ver con:

"la facultad de adaptación de un proceso, red o sistema manteniendo la calidad y la fluidez del trabajo; sin aumentar los costes. Dicho de una forma más sencilla: la capacidad de aumentar la actividad sin perder calidad en los servicios ofrecidos y mantener o incluso reducir los costes por unidad vendida/producida" (Hector Fernandez, cofundador de Economía TIC).

Esta escalabilidad debe ser conseguida a través del uso intensivo de las tecnologías de la información y la comunicación. De aquí que el diseño de la plataforma tecnológica al inicio un startup es importante, para que pueda mantener el crecimiento de manera eficiente y sin interrupciones durante esta primera etapa de la empresa.

\subsection{Escalabilidad}

Una vez definida la escalabilidad en términos y necesidades de un startup, ahora definiremos a la escalabilidad en términos tecnológicos, ya que en con ellos diseñaremos la plataforma que deberá soportar la escalabilidad necesaria para conseguir el crecimiento exponencial de un startup.

La escalabilidad de una aplicación es la capacidad de adaptarse y responder a las necesidades de rendimiento del mismo a medida que aumenta significativamente el número de usuarios y el número de transacciones sin sufrir degradamiento en su desempeño. La escalabilidad de un sistema está muy ligada a su diseño e influye significativamente en su rendimiento.

Como la escalabilidad se relaciona con el aumento de la carga de trabajo, esto implica que el sistema también debe crecer en recursos, entonces nos planteamos la pregunta: ¿Cómo 
puedo diseñar un sistema que aumente recursos indefinidamente? Oscar Blancarte, en su blog oscarblancarte.org, responde:

"La realidad es que las aplicaciones no pueden crecer infinitamente, por lo que siempre es clave determinar desde el diseño el grado de escalamiento que una aplicación podrá soportar, ya que por más estrategias que utilicemos el sistema ya no dará más".

Podemos asegurar, por lo tanto, que la escalabilidad de una aplicación debe definirse desde su diseño para que afronte las necesidades del negocio al que esta va a aportar. Siendo, por lo tanto, la escalabilidad un factor crítico en una aplicación, se deben evaluar dos posibilidades:

a) La aplicación debe crecer a través de aumentarle al hardware del servidor (nodo) mayor potencia y recursos.

b) La aplicación debe crecer a través de aumentar el número de servidores (nodos) con la misma potencia de hardware y recursos.

Entonces, para escalar un sistema o una aplicación, podemos optar por cualquiera de las dos opciones, es decir, podemos distinguir dos tipos de escalabilidad:

\subsubsection{Escalabilidad Vertical}

La escalabilidad vertical, como observamos en la figura 6, se refiere a escalar hacia arriba, es decir, a migrar de un nodo a otro nuevo con hardware de mayores características y con más recursos. En resumen, es hacer crecer el hardware del nodo. Para esto hay que garantizar que la arquitectura del nuevo hardware sea compatible con el sistema o aplicación y solamente hay que realizar un respaldo y una reinstalación. El impacto en el código de la aplicación suele ser mínimo. Sin embargo, se debe contar con qué llegará un momento en que al ampliar las características del hardware no se podrá continuar por limitaciones físicas. Por otro lado, el costo de adquirir hardware cada vez más potente también se incremente de una manera no lineal. 


\section{Ventajas:}

- No implica un gran problema para las aplicaciones, pues todo el cambio es sobre el hardware.

- Es mucho más fácil de implementar que el escalamiento horizontal.

- Puede ser una solución rápida y económica (compara con modificar el software).

Desventajas:

- El crecimiento está limitado por el hardware.

- Una falla en el servidor implica que la aplicación se detenga.

- No soporta la alta disponibilidad.

- Hacer un upgrade del hardware al máximo puede llegar a ser muy caro, ya que las partes más nuevas suelen ser caras con respecto del rendimiento de un modelo anterior.

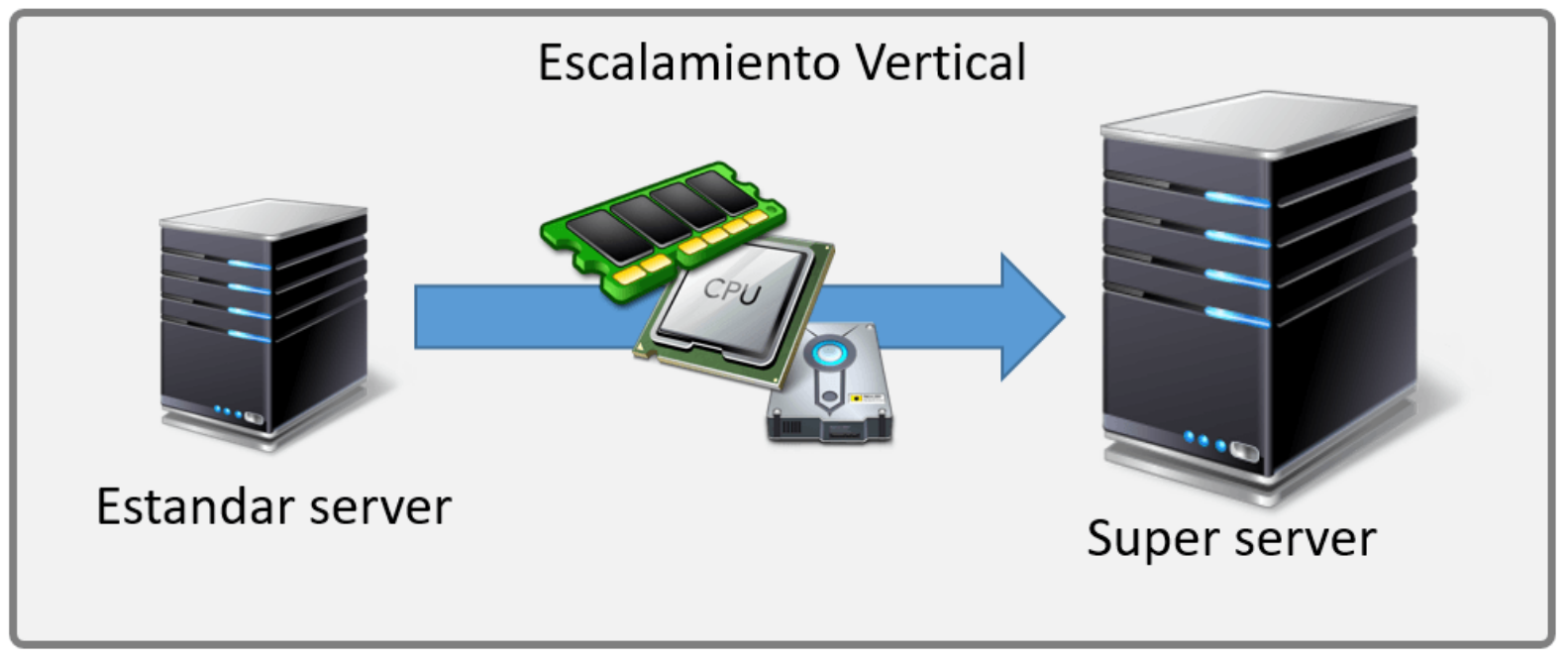

Figura 6. Escalamiento vertical

Adaptado de https://www.oscarblancarteblog.com/2017/03/07/escalabilidad-horizontal-y-vertical/

\subsubsection{Escalabilidad horizontal}

La escalabilidad horizontal se refiere a escalar hacia un costado, es decir, a aumentar el número de nodos que está ejecutando la aplicación, a través de nodos con características de hardware iguales o similares al resto. Este escalamiento es mucho más potente, pero es más complicado, ya que debemos hacer que todos estos nodos funcionen como uno solo. 
Como observamos en la figura 7, la escalabilidad horizontal se alcanza utilizando clústers de computadoras. De esta manera, los nodos se reparten las tareas para conseguir funcionar como un solo nodo de gran potencia. Bajo esta perspectiva, el crecimiento horizontal no tiene límites, sin embargo, son limitaciones de software que no permiten un crecimiento ilimitado ideal.

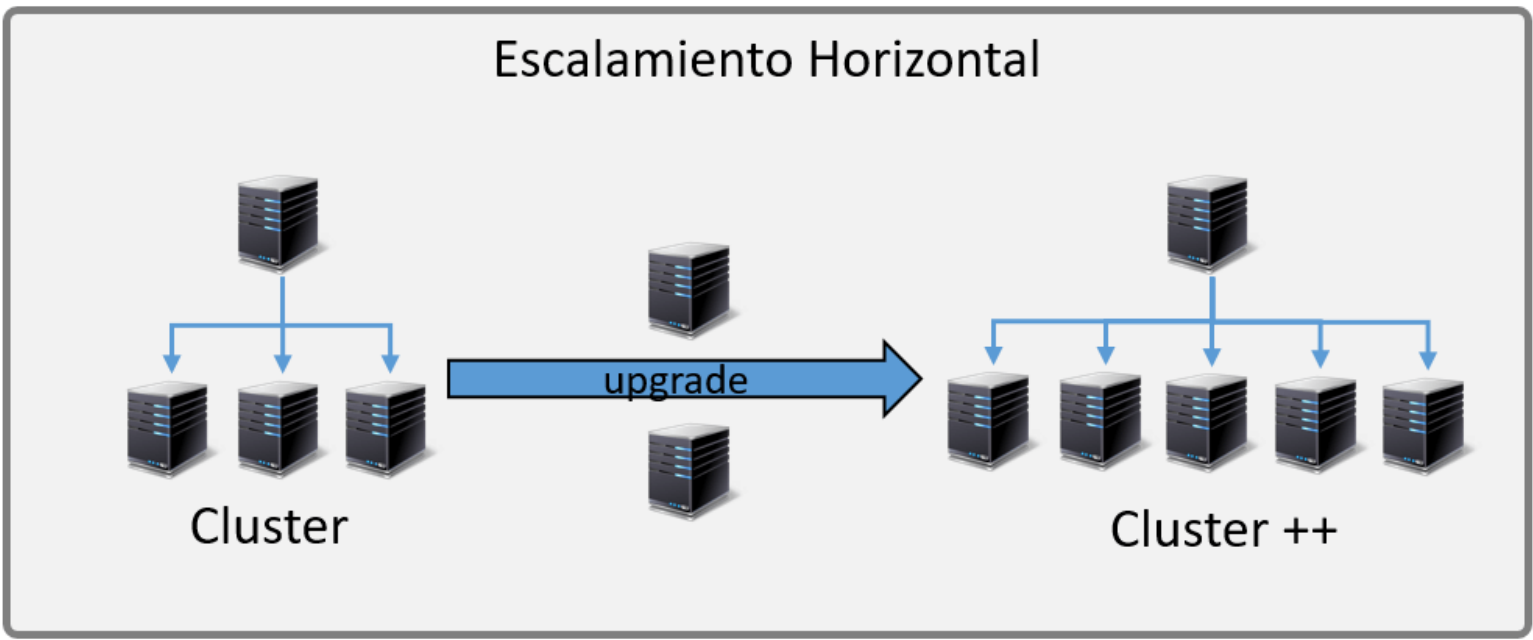

Figura 7. Escalamiento horizontal

Adaptado de https://www.oscarblancarteblog.com/2017/03/07/escalabilidad-horizontal-y-vertical/

Ventajas:

- El crecimiento es prácticamente infinito, podríamos agregar cuantos servidores sean necesarios.

- Es posible combinarse con el escalamiento vertical.

- Soporta la alta disponibilidad

- Si un nodo falla, los demás sigue trabajando.

- Soporta el balanceo de cargas.

Desventajas:

- Requiere de mucho mantenimiento.

- Es difícil de configurar.

- Requiere de grandes cambios en las aplicaciones (si no fueron diseñadas para trabajar en clúster). 
- Requiere de una infraestructura más grande.

2.3 Otros conceptos ligados a la escalabilidad

\subsubsection{Balanceo de carga}

Dentro del contexto de este proyecto, el balanceo de carga es una técnica que permite dividir el trabajo para que sea compartido por varios nodos. El balance de carga suele hacerse de forma equitativa entre los nodos participantes.

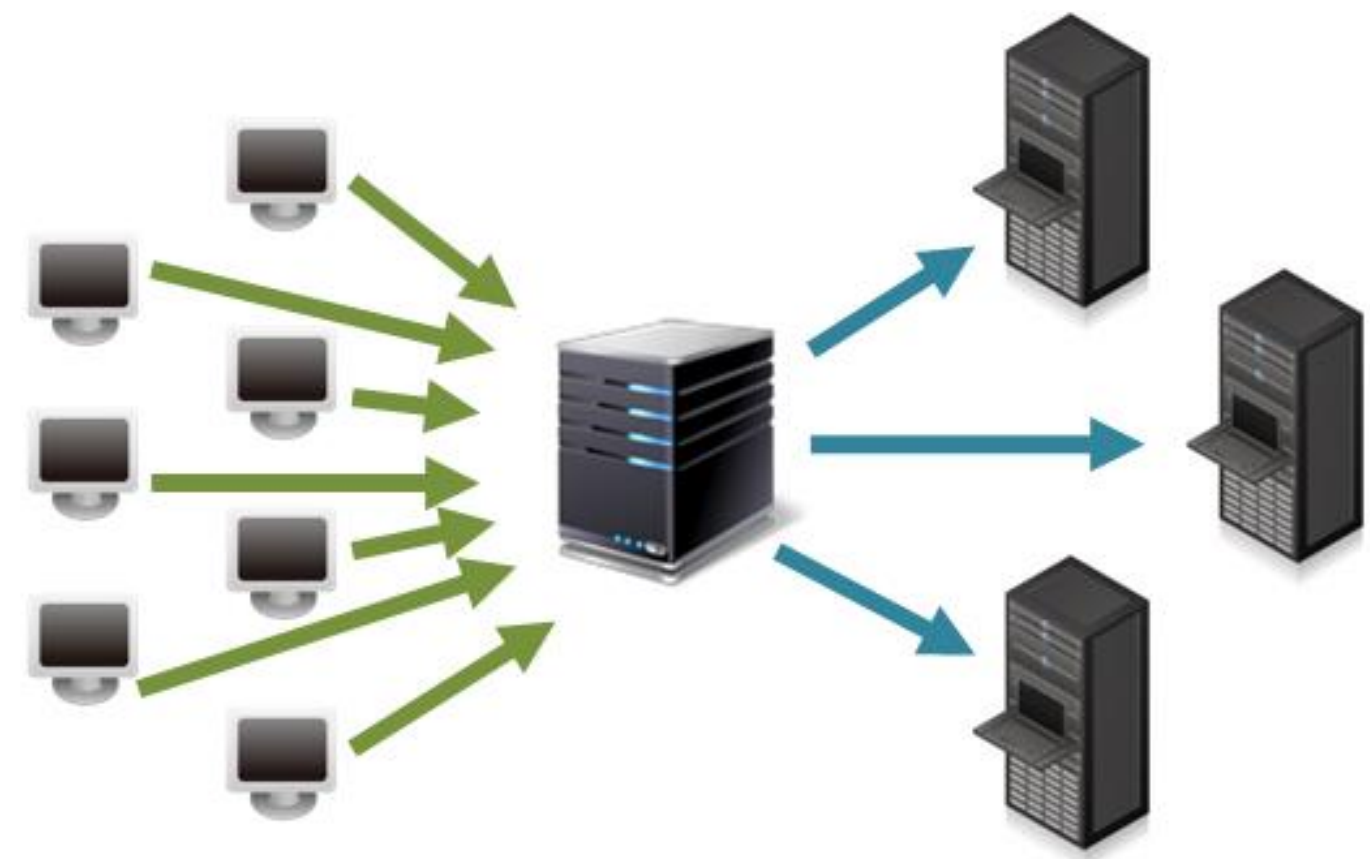

Figura 8. Técnica de balanceo de carga

Adaptado de https://laredinfinita.wordpress.com/2014/05/11/balanceo-de-carga/

Como observamos en la figura 8 , mediante el balanceo, todas las solicitudes al sistema se reparten entre diversos servidores $\mathrm{y}$, con ello, se aumenta la cantidad de usuarios concurrentes que pueden ser atendidos.

\subsubsection{Clúster}


Un clúster hace referencia a un conjunto de servidores con características similares que trabajan en paralelo para conseguir una tarea común. Es decir, trabajan en conjunto como si fueran un único servidor.

Los tipos de clúster pueden ser:

\subsubsection{Clúster de Alto Rendimiento}

Su finalidad es realizar tareas que requieren de una gran capacidad de procesamiento y de memoria. En este caso, todos los nodos de la red ejecutan una parte de la tarea total. Para este tipo de clúster, los nodos pueden tener características de hardware no muy potente e incluso dispar.

\subsubsection{Clúster de Alta Disponibilidad}

Su finalidad es garantizar que un servicio se pueda dar de manera ininterrumpida. Los sistemas de clúster de alta disponibilidad están conformados por dos o más nodos, los cuales funcionan como un servicio y, ante la caída de un nodo del clúster, el software se encarga de restablecer los servicios en los demás nodos del clúster, a fin de que el servicio vuelva a funcionar. Para conseguir tal fin. se suele duplicar toda la infraestructura.

Los clústers suelen tener los siguientes componentes:

- Nodos: Es el nombre genérico que se dará a cualquier máquina que forme parte del clúster. Dependiendo del tipo de clúster, los nodos pueden ser PCs de escritorio o servidores.

- Sistema operativo: Se puede utilizar cualquier sistema operativo que tenga dos características básicas: multiproceso y multiusuario.

- Conexión de Red: Los diferentes nodos deben estar conectados entre sí, para esto se pueden conectar utilizando una red Ethernet u otro tipo de conexión más especializada. 
- Middleware: Es el nombre que recibe el software que se encuentra entre el sistema operativo y las aplicaciones. El middleware permite al usuario gestionar el clúster como si se tratara de un solo nodo.

- Sistema de almacenamiento: Para lograr mayor eficiencia en los clústers, se pueden utilizar como almacenamiento desde configuraciones especiales en los discos duros hasta el uso dispositivos NAS (Network Attaches Storage) o redes SAN (Storage Area Network).

\subsubsection{Máquinas virtuales y contenedores}

En un artículo publicado por Sébastien Vaucher, de la universidad de Neuchâtel, Switzerland, afirma: "Cuando un único servidor necesita ser dividido entre varios clientes la solución más práctica es utilizar máquinas virtuales". Sin embargo, las necesidades actuales no solo requieren compartir servidores, sino servicios. En el mismo artículo, Sebastien Voucher nos menciona: "Mientras las máquinas virtuales utilizan virtualización completa creando una computadora virtual, los contenedores utilizan y comparten las características estándar del kernel. Por lo que los contenedores proveen un mejor desempeño al costo de cierta rigidez en cuanto a compatibilidad".

Adrian Mouat (2015), en su libro Using Docker, afirma:

"Lo más importante, el objetivo fundamental de las máquinas virtuales (VM) y de los contenedores es diferente - el propósito de una VM es emular de manera completa un entorno ajeno, mientras que el propósito de un contenedor es hacer aplicaciones portables y autónomas". 


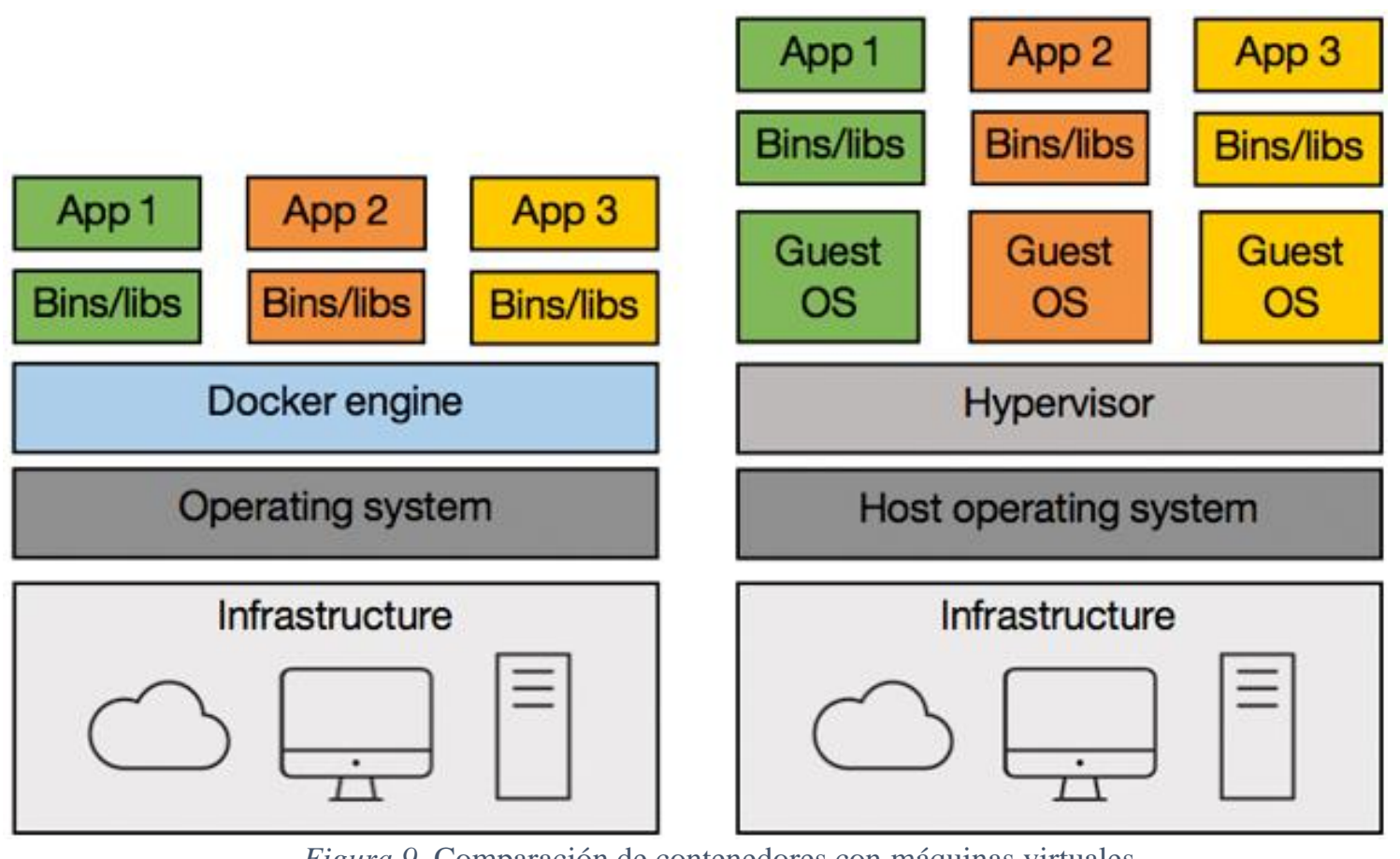

Figura 9. Comparación de contenedores con máquinas virtuales

Adaptado de https://www.ibm.com/developerworks/ssa/cloud/library/cl-cloud-orchestration-technologiestrs/index.html

En la figura 9, podemos observar lo que nos quiere decir Adrian Mouat. Con los contenedores, las aplicaciones comparten los recursos del kernel, pero aislando sus dependencias, haciendo que la imagen del contenedor sea ligera y altamente portable. Mientras que, la máquina virtual, comparte los recursos de hardware, aislando al sistema operativo completo. En el caso de las máquinas virtuales, es necesario un software, el Hypervisor, que se encarga de gestionar y repartir los recursos de hardware por cada VM creada. En el caso de los contenedores el software, por ejemplo: Docker engine, es la que gestiona y reparte los recursos del SO entre los contenedores. 
Tabla 2.

Comparación entre máquinas Virtuales y contenedores

\begin{tabular}{|c|c|}
\hline Virtual Machines (VMs) & Containers \\
\hline $\begin{array}{c}\text { Representa virtualización a nivel de } \\
\text { hardware }\end{array}$ & $\begin{array}{r}\text { Representa virtualización a nivel de } \\
\text { sistema operativo. }\end{array}$ \\
\hline Pesada & Ligera \\
\hline Aprovisionamiento Lento & Aprovisionamiento y escalabilidad \\
& en tiempo real \\
\hline Desempeño limitado & Desempeño nativo \\
\hline Aislamiento completo, por lo tanto, es & $\begin{array}{c}\text { Aislamiento a nivel de procesos, por } \\
\text { lo tanto, es menos segura }\end{array}$ \\
\hline
\end{tabular}

Adaptado de Pethuru Raj y et al. (2015). Learning Docker: Optimize the power of Docker to run your applications quickly and easily

La tabla 2, resume las diferencias entre máquinas virtuales y contenedores, los contenedores ganan por ser ligeros, de mayor desempeño y fáciles de escalar. Sin embargo, es necesario tomar medidas de seguridad específicas durante su implementación.

\subsection{Contenedores}

Para responder a la pregunta: ¿Qué son los contenedores?, veremos que nos dicen los expertos:

De la página de docker.com, una de las empresas líderes en contenedores, tenemos lo siguiente:

"Un contenedor es una unidad estándar de software que empaqueta código y todas sus dependencias de tal forma que la aplicación corra rápido y de manera confiable desde un entorno de cómputo a otro. Una imagen de un contenedor Docker es un paquete de software ligero, aislado y ejecutable que incluye todo lo necesario para ejecutar una aplicación: código, entorno de ejecución, herramientas de sistema, librerías y configuraciones”. 
Red Hat líder mundial en soluciones de código abierto para empresas responde a esta pregunta de la siguiente manera: "Los contenedores de Linux son tecnologías que le permiten empaquetar y aislar las aplicaciones junto con todo el entorno que necesitan durante su tiempo de ejecución, es decir, con todos los archivos que requieren para ejecutarse. Esto permite mover la aplicación que se encuentra dentro del contenedor entre los entornos (desarrollo, prueba, producción, etc.), sin perder ninguna de sus funciones".

AWS líder mundial en ofrecer servicios en la nube nos da su definición:

"Los contenedores le ofrecen un modo estándar de empaquetar el código, las configuraciones y las dependencias de su aplicación en un único objeto. Los contenedores comparten un sistema operativo instalado en el servidor, y se ejecutan como procesos aislados de los recursos, lo que garantiza implementaciones rápidas, fiables y consistentes sea cual sea el entorno en el que se realizan".

Otro concepto:

"Contenedores son el encapsulamiento de una aplicación con todas sus dependencias. A primera vista, se ven solo como una forma ligera de máquina virtual, ya que, como una máquina virtual, aíslan una instancia del sistema operativo, que se puede utilizar para correr aplicaciones". (Mouat, 2015)

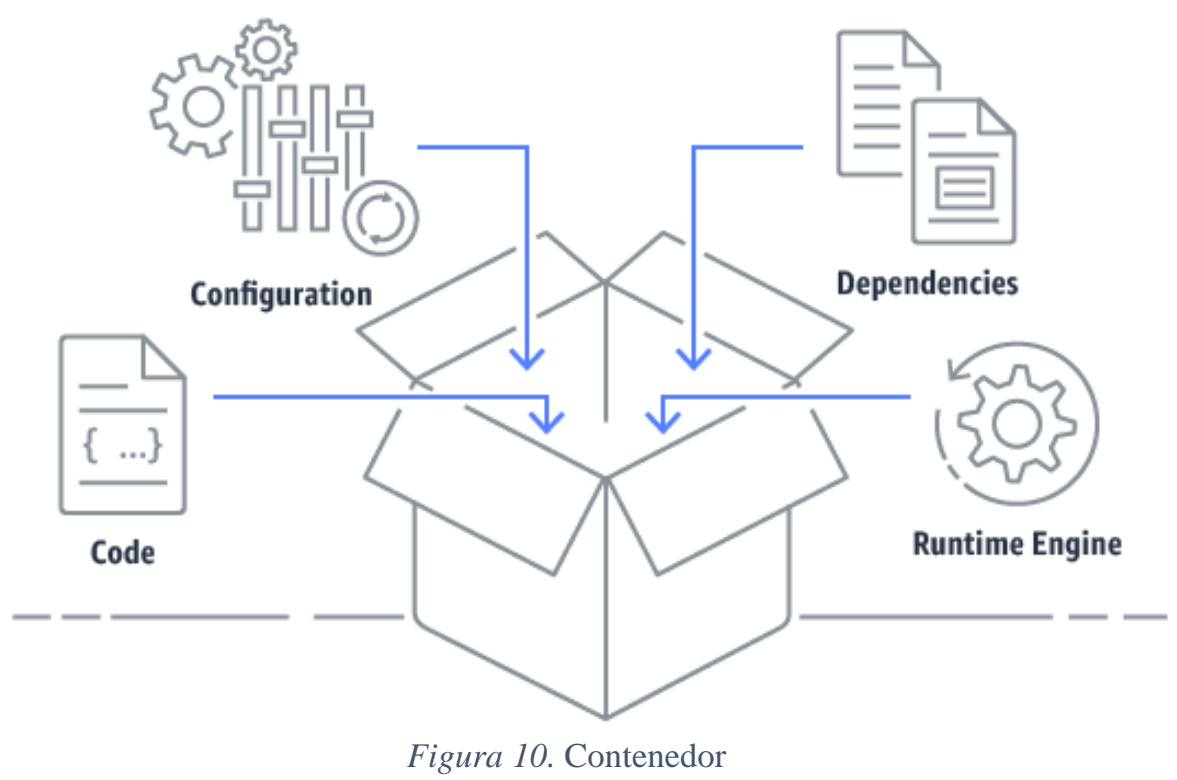

Adaptado de https://aws.amazon.com/es/containers/ 
Como podemos observar en la figura 10, la principal fortaleza de los contenedores radica en el aislamiento de recursos necesarios para que una aplicación se ejecute completamente. Los contenedores se distribuyen en imágenes que son bastante ligeras y fáciles de portar. Todo esto lo hace una herramienta clave para que una aplicación pueda escalar de manera horizontal con facilidad.

Los contenedores tienen principalmente las siguientes piezas:

- Los espacios de nombres (Namespaces) del kernel son el principal componente de los contenedores Linux, que aíslan las aplicaciones dentro de diferentes "espacios de usuarios"', como la red, los procesos, los propios usuarios y el sistema de archivos.

- Grupos de control (Control Group) también conocidos como cgroups, que limitan varios recursos de hardware del host. Esto incluye actualmente el conteo y el uso de la CPU, el rendimiento del disco, la memoria y otros límites del proceso.

- Las capacidades de root (Root Capabilities) ayudan a reforzar los espacios de nombres en los llamados contenedores "privilegiados" reduciendo el poder de la raíz (root), en algunos casos sin energía.

- Pivot_root es un syscall es una llamada al sistema para crear un sistema de archivos raíz en el nuevo entorno de contenedor. Aunque el uso e implementación de pivot_root y los pasos de inicialización relacionados del init del contenedor no se discutirán explícitamente, hacer este cambio correctamente puede ser crucial para la seguridad.

- Controles de Acceso Obligatorios (Manditory Access Controls MAC) tales como AppArmor y SELinux para crear contenedores, pero a menudo es un elemento clave para su seguridad. MAC ayuda a reforzar los controles de seguridad implementados por otras características de contenedor, agregando la defensa en profundidad (Defense in Depth) y la seguridad general de la plataforma para cualquier nivel de permiso dentro del contenedor, usuario privilegiado o de otra manera. 


\subsection{Docker}

Docker es una empresa líder en el mercado de contenedores, combina una plataforma de contenerización de carácter empresarial con servicios de clase mundial, proporcionándoles, a los desarrolladores y gestores de TI, la libertad de construir, administrar y asegurar aplicaciones sin el temor de enganchase a una tecnología o infraestructura particular.

En Docker.com se señala:

"Docker entrega una plataforma para manejar la transformación digital a través de la línea completa dentro del portafolio de aplicaciones de una empresa, hecha para que funcione de la manera que quieres que funcione, soportando arquitecturas on-premise, en la nube o híbridas".

En un artículo del 2016, publicado en la página de IBM, Suchitra Venugopal, se plantean con mucha claridad los beneficios de utilizar Docker:

- Entregar aplicaciones más rápidamente. Docker es perfecto para ayudar con el ciclo de la vida del desarrollo. Permite desarrollar contenedores locales que contienen las aplicaciones y servicios

- Desplegar y escalar más fácilmente. La plataforma basada en contenedores de Docker permite cargas de trabajo altamente portátiles. Se pueden ejecutar en el host local de un desarrollador, en máquinas físicas o virtuales de un centro de datos o en la nube. Es posible utilizar Docker para ampliar o reducir rápidamente aplicaciones y servicios.

- Lograr mayor densidad y ejecutar más cargas de trabajo. Docker es ligero y rápido. Brinda una alternativa viable y rentable a las máquinas virtuales basadas en hypervisor. Esto es especialmente útil en entornos de alta densidad, como construir su propia nube o plataforma como servicio. Sin embargo, también es útil para despliegues de tamaños pequeño y mediano en los que quiere obtener más de los recursos que tiene.

- Eliminar inconsistencias del entorno. Al empaquetar la aplicación junto con sus configuraciones y dependencias y al enviar el paquete como un contenedor, la aplicación siempre funcionará en otra máquina como si hubiese sido diseñada localmente. 
- Potencia la creatividad del desarrollador. Las capacidades de aislamiento de los contenedores de Docker liberan a los desarrolladores de tener que utilizar pilas y herramientas de lenguajes aprobados. Los desarrolladores pueden utilizar el mejor lenguaje y las mejores herramientas para el servicio de su aplicación, sin tener que preocuparse de causar conflictos.

- Acelerar la entrada de desarrolladores. Con Docker, es posible hacer fácilmente copias del entorno en directo y ejecutarlas en cualquier extremo nuevo que ejecuta Docker. Lo que hace que se pierdan horas intentando configurar entornos de desarrollo, crear nuevas instancias y hacer copias del código de producción para ejecutarlo localmente.

Docker inicio como un contenedor Linux tradicional, se desarrolló inicialmente con la tecnología LXC. Con LXC tenemos una experiencia de virtualización ligera, pero sin favorecer mucho la experiencia del desarrollador y el usuario. Docker facilita el proceso de creación y diseño de contenedores, de envío de imágenes y de creación de versiones de imágenes (entre otras cosas).

Como vemos en la figura 11, cuando comparamos Docker con LXC, en los contenedores tradicionales Linux el proceso init.d gestiona varios procesos haciendo que cada aplicación se ejecute con todos sus procesos como uno solo. Sin embargo, Docker le agrega granularidad, al hacer que la aplicación se ejecute en sus procesos individualmente, ya que proporciona las herramientas para gestionarlos. 


\section{Traditional Linux containers vs. Docker}
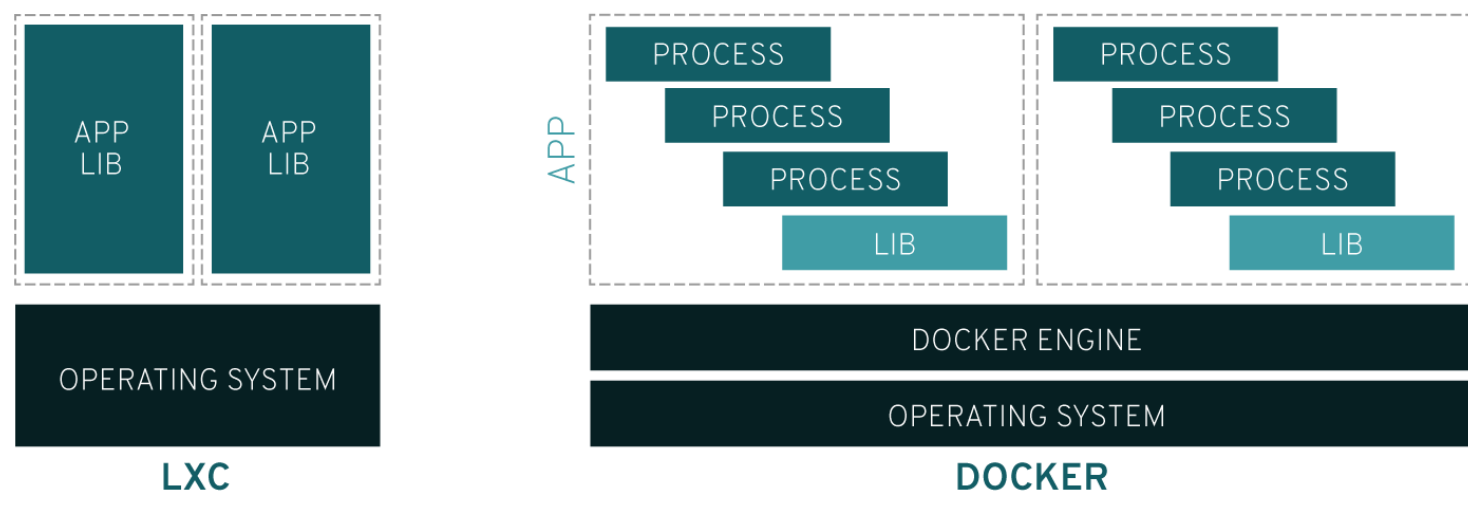

Figura 11. Contenedor

Adaptado de https://www.redhat.com/es/topics/containers/what-is-docker

Esto plantea las siguientes ventajas:

Modularidad: Se centra en la capacidad de tomar solo una parte de una aplicación, para actualizarla o repararla, sin necesidad de tomar la aplicación completa. Además de este enfoque basado en los microservicios, puede compartir procesos entre varias aplicaciones de la misma forma que funciona la arquitectura orientada al servicio (SOA).

Control de versiones de imágenes y capas: Cada archivo de imagen de Docker se compone de una serie de capas. Estas capas se combinan en una sola imagen. Una capa se crea cuando la imagen cambia. Cada vez que un usuario especifica un comando, como ejecutar o copiar, se crea una nueva capa. El control de versiones es inherente a la creación de capas. Cada vez que se produce un cambio nuevo, básicamente, se tiene ya un registro de cambios incorporado: control completo de sus imágenes de contenedor.

Restauración: La gran ventaja de la creación de capas es la capacidad de restauración. Toda imagen tiene capas. Si la interacción actual de una imagen no es satisfactoria, es posible restaurarla a la versión anterior. Esto es compatible con un enfoque de desarrollo ágil y permite hacer realidad la integración e implementación continuas (CI/CD) desde una perspectiva de las herramientas. 
Implementación rápida: Solía demorar días desarrollar un nuevo hardware, ejecutarlo, proveerlo y facilitarlo. Y el nivel de esfuerzo y sobrecarga era extenuante. Los contenedores basados en Docker pueden reducir el tiempo de implementación a segundos. Al crear un contenedor para cada proceso, puede compartir rápidamente los procesos similares con nuevas aplicaciones. Y, debido a que un SO no necesita iniciarse para agregar o mover un contenedor, los tiempos de implementación son sustancialmente inferiores.

\subsubsection{Arquitectura de Docker}

Para que podamos entender mejor como Docker consigue su versatilidad, veamos sus principales componentes, según la figura 12:

- El demonio docker (docker daemon) responsoble de crear, ejecutar y monitorear a los contenedores. Permite crear imágenes y almacenarlas.

- El cliente docker (docker cliente) puede hablar con el demonio docker a través de HTTP, suele hacerse a través de un socket UNIX, sin embargo, también puede hacerse a través de sockets TCP para habilitar clientes remotos. Dado que toda la comunicación es a través de HTTP, es simple conectarse remotamente a demonios remotamente. Al utilizar un API bastante bien documentado, da la facilidad a los desarrolladores a crear interfaces directas con el demonio docker, sin la necesidad de usar el cliente. 


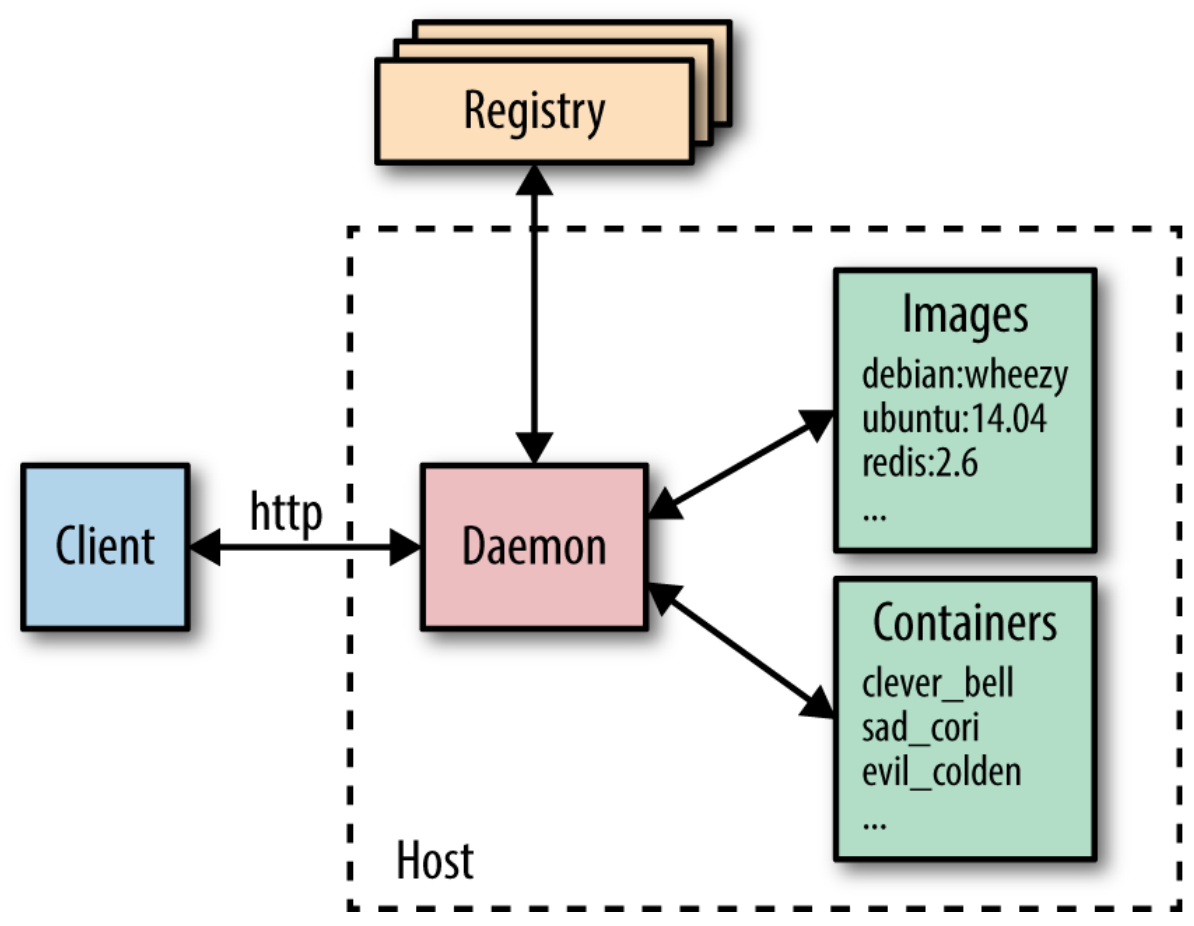

Figura 12. Arquitectura de Docker

Adaptado de Mouat, A. (2016) Using Docker.

- El registro docker (docker Registry) que se encarga de almacenar y distribuir imágenes. El registro por defecto se conoce como docker hub que aloja cientos de imágenes públicas. Muchas organizaciones mantienen sus propios registros que los utilizan de forma comercial o para almacenar sus propias imágenes de manera local.

Adicionalmente, el demonio Docker utiliza, para crear contenedores, un controlador de ejecución: runc. Este controlador tiene soporte para tecnologías LXC y utiliza las siguientes características del kernel.

- Cgroups, se encarga de gestionar los recursos utilizados por un contenedor. Además, son también responsables por congelar y descongelar contenedores, a medida que se utiliza la función pausa de Docker.

- namespaces, se encarga de aislar contenedores, asegurándose de que el sistema de archivos, nombre de host, usuarios, redes y procesos de un contenedor se mantengan separados del resto del sistema. 
Dentro de la arquitectura de Docker, también está el concepto de imagen, que es una de las piedras angulares de esta tecnología. En un artículo de docs.microsof.com (2018): Contenedores, imágenes y registros de Docker, encontramos la relación entre contenedores e imágenes. Una imagen es una aplicación almacenada con sus dependencias y librerías correspondientes de manera estática, es decir, no se está ejecutando. Un contenedor es la aplicación ejecutándose con sus dependencias y librerías, a partir de una imagen, es decir, un contenedor es una instancia de una imagen ejecutándose.

Por lo tanto, como observamos en la figura 13, un registro es una colección de imágenes almacenadas. A partir del registro, tomamos una imagen y ejecutamos una instancia de ella, esta instancia en ejecución es un contenedor.

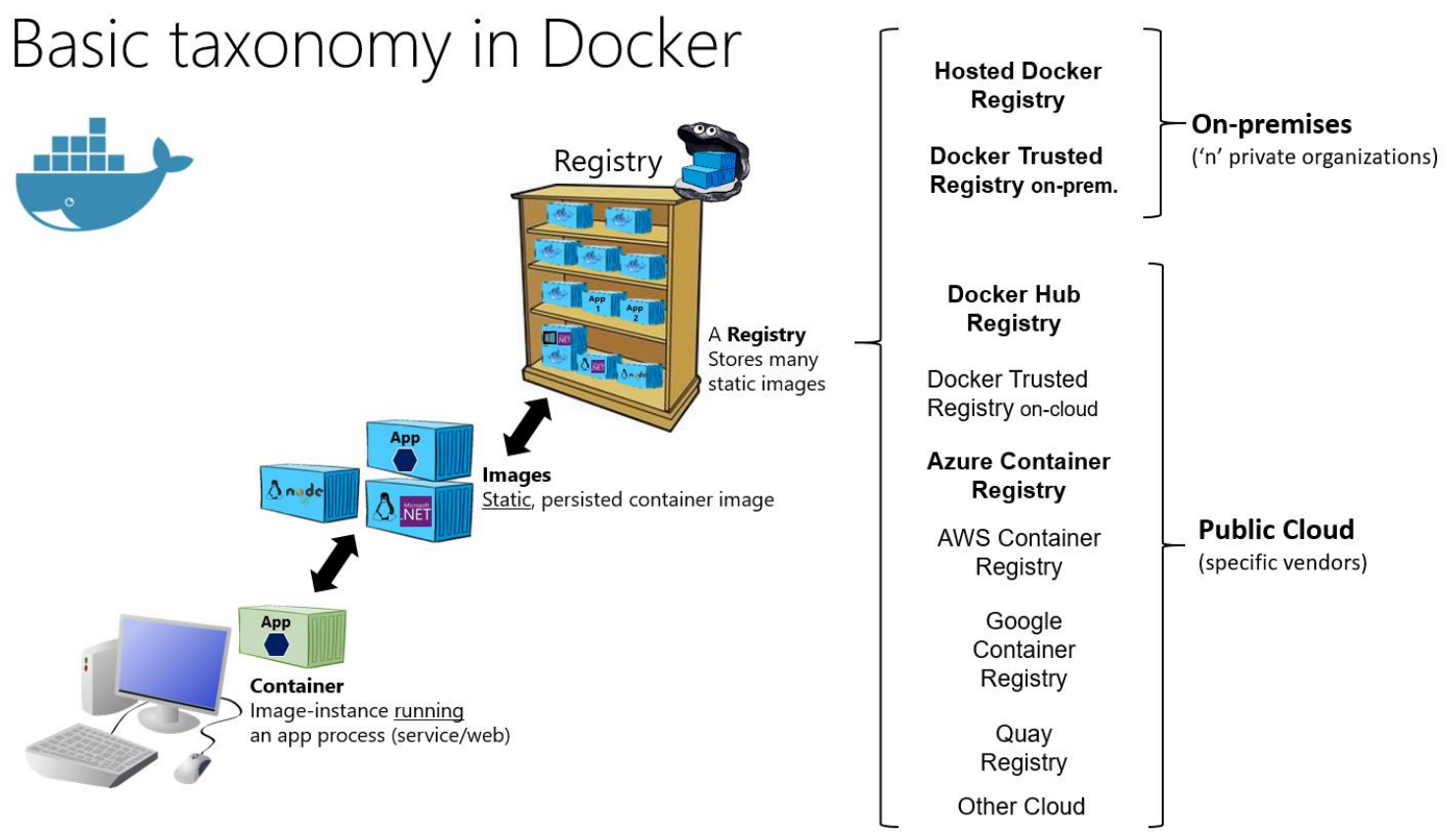

Figura 13. Registro de Imágenes en Docker

Adaptado de https://docs.microsoft.com/es-es/dotnet/architecture/microservices/container-dockerintroduction/docker-containers-images-registries 


\subsection{Orquestación}

Como hemos visto, el uso de contenedores nos permite crear, gestionar y desplegar aplicaciones con facilidad. Esto favorece la escalabilidad de las aplicaciones al momento de necesitar más recursos, ya que con los contenedores la escalabilidad horizontal se vuelve más fácil de implementar. Sin embargo, esto también introduce la necesidad de trabajar con todas estas imágenes y contenedores, la necesidad orquestar todas estas aplicaciones para que trabajen en conjunto.

En el estado del arte, hemos visto varias herramientas de orquestación de las cuales Kubernetes, creada por Google, lidera el mercado de orquestación en la nube. Sin embargo, también Docker tiene su propia herramienta de orquestación que no es tan completa como Kubernetes, pero que es lo suficientemente potente para el desarrollo de este proyecto.

\subsubsection{Docker Swarm Mode}

Con la introducción del modo Swarm, Docker es capaz de realizar tareas de orquestación, clustering y planificación de manera incorporada en su motor. Por lo que ahora es posible manejar múltiples máquinas y hacer balanceo de carga, por ejemplo.

En la página de documentación ${ }^{2}$ de Dockers se pueden ver algunas de sus características principales:

- Gestión integrada de clúster con el motor Docker: Utilizando el CLI del motor Docker es posible crear un Swarm de motores Docker y desplegar aplicaciones, sin necesidad de instalar ningún software adicional de orquestación.

- Escalamiento: Por cada servicio, es posible declarar el número de tareas que se quiere correr. Al momento de escalar hacia arriba o abajo, el gestor Swarm automáticamente se adapta agregando o quitando tareas para mantener el estado deseado.

\footnotetext{
${ }^{2}$ docs.docker.com/engine/Swarm/
} 
- Redes Multi-host: Es posible especificar una red superpuesta para los servicios. El gestor Swarm automáticamente asigna direcciones a los contenedores en la red superpuesta al momento de inicializar o actualizar la aplicación.

- Descubrimiento de servicios: El gestor de Swarm asigna un nombre DNS único a cada servicio y balancea la carga de los contenedores que se están ejecutando. Es posible consultar a cada contenedor, ejecutándose a través del servidor DNS embebido con el gestor Swarm.

- Balanceo de carga: Es posible exponer los puertos para los servicios a un balanceador de carga externo. Internamente el gestor Swarm permite especificar cómo distribuir los servicios entre los nodos.

- Seguridad por defecto: Cada nodo utiliza autenticación TLS y encriptación para asegurar las comunicaciones entre ellos y otros nodos. Provee la opción de utilizar certificados autofirmados o certificados de una CA.

\subsection{Herramientas}

\subsubsection{HTTPERF}

Es una herramienta en línea de comandos utilizada para medir el rendimiento de los servidores web. Fue creada por David Mosberger de Hewlett-packard y desarrollada en C, para garantizar su mejor desempeño. Con httperf es posible generar diferentes tipos de carga de trabajo (workloads) de tipo HTTP, para medir el desempeño de los servidores web. Httperf se distingue por ser robusto, soportar HTTP=/1.1 y la posibilidad de ser extensible a otros generadores de tráfico.

El uso básico del comando httperf que utilizaremos es:

\$ httperf -server 165.227.199.154 --port 80 --num-conns 3000 --rate 50

Donde:

--server: es la dirección del servidor web al que vamos a enviar le tráfico.

--port: es el puerto en el servidor web al que enviaremos el tráfico.

--num-cons: es el número de conexiones que serán solicitadas en total al servidor. 
--rate: es la tasa de conexiones por segundo con la que se solicitaran las conexiones al servidor

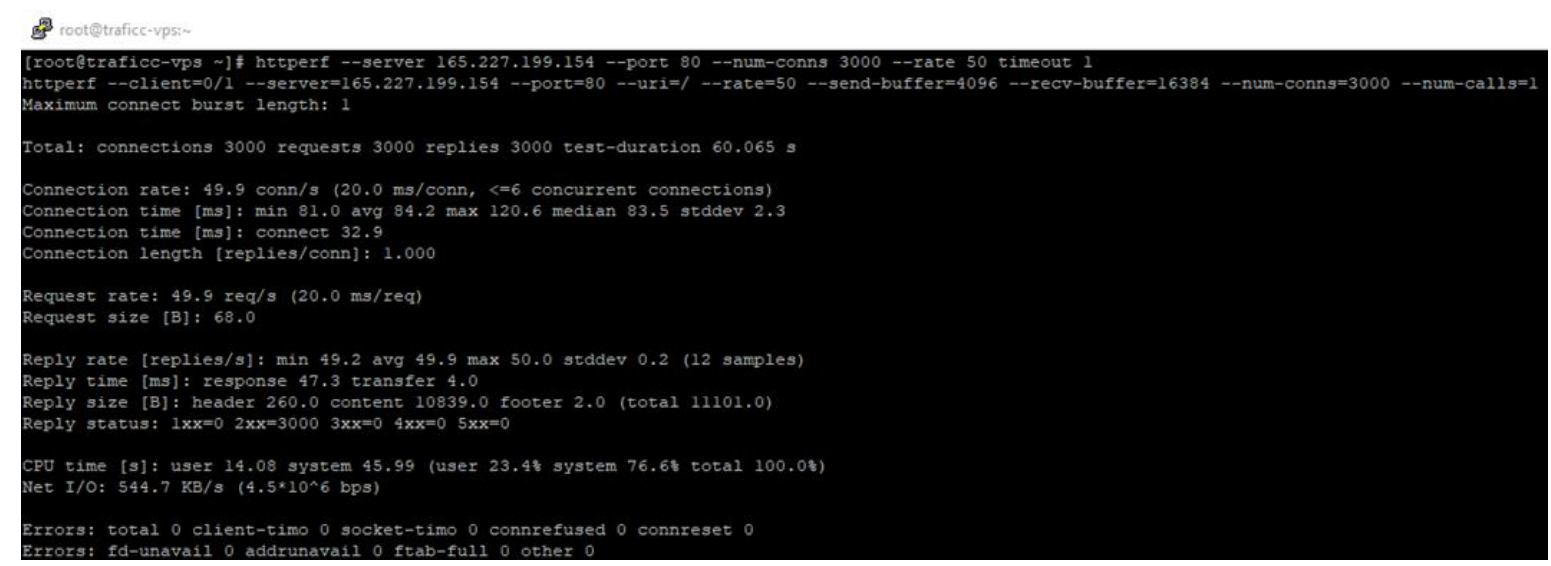

Figura 14. Comando HTTPERF

Elaboración propia

Como vemos en la figura 14, el resultado de httpperf nos muestra:

- Total: Indica el total de conexiones que fueron iniciadas. Ejm: 3000.

- Connection Rate: Indica la tasa en conexiones por segundo. Adicionalmente, entre paréntesis (el intervalo entre conexiones y el número de conexiones concurrentes que se iniciaron).

- Connection Time: Indica el tiempo de vida de una conexión TCP, es decir, desde que se inicia hasta que se cierra.

- Connection Time: Esta segunda opción de connection time, indica el tiempo de conexión promedio. Si se iniciaron múltiples conexiones.

- Connection Length: Indica el número promedio de respuestas que cada conexión ha tenido.

- Request Rate: Indica la tasa de solicitudes por segundo a la que httperf fue configurada.

- Request Size: Indica el tamaño de las solicitudes en bytes.

- Reply Rate: Indica la tasa a la que el servidor respondió a las solicitudes. 


\subsubsection{HTOP}

Es un visor de procesos interactivo para sistemas de tipo UNIX. Esta aplicación que funciona en modo texto nos permite monitorear y gestionar los procesos.

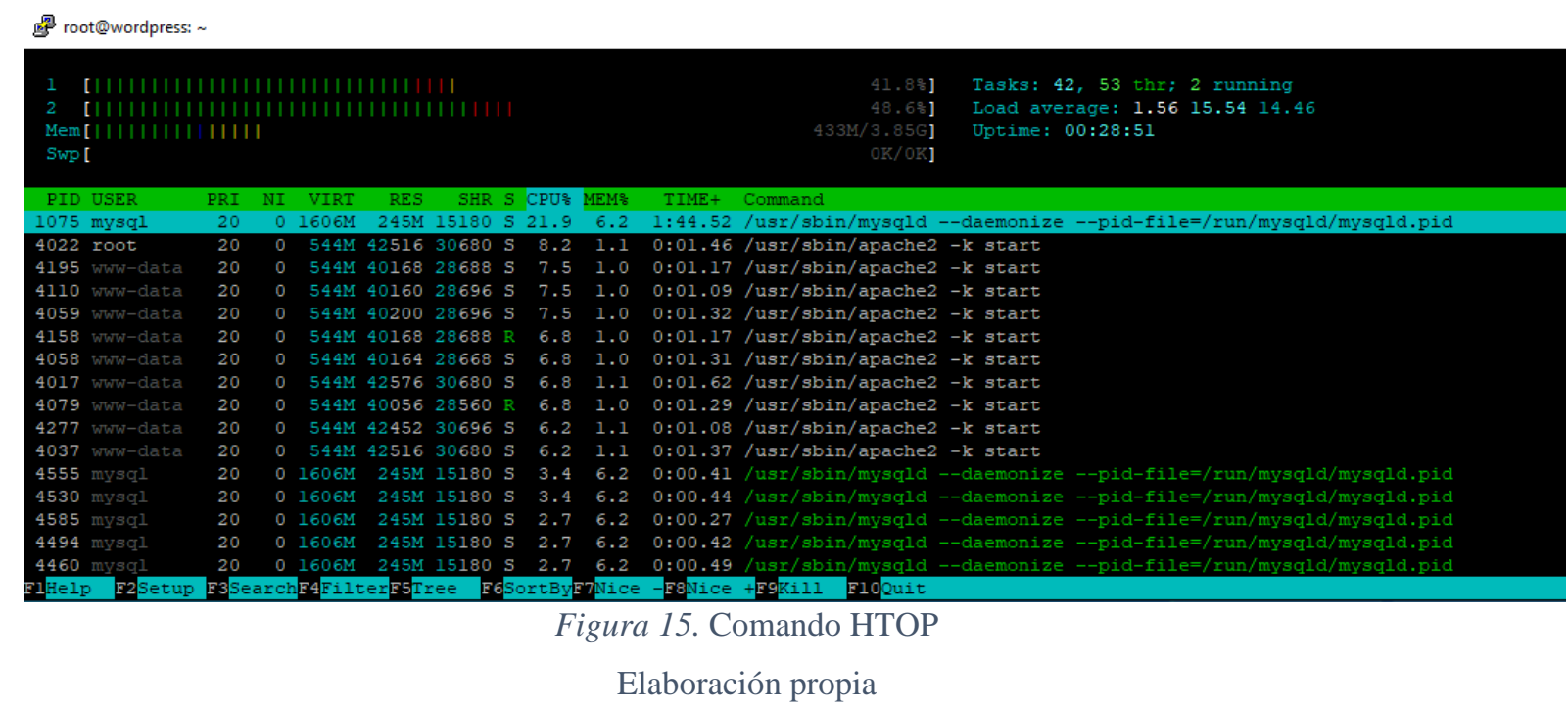

En la figura 15, podemos observar la salida del comando Htop, para interpretarla adecuadamente se explica el detalle de la salida mostrada.

Las dos primeras filas representan carga de cada uno de los dos procesadores que tiene el servidor, seguido de la carga de memoria RAM y, luego, el archivo de paginación o memoria virtual (SWAP). A la derecha, observamos el total de procesos corriendo, el total de hilos y el tiempo que lleva el sistema ejecutándose.

Luego observamos una tabla que nos muestra los procesos, aquí está la descripción de cada uno de los valores que podemos ver por proceso.

- PID: Número que identifica al proceso.

- USER: Usuario que ejecutó el proceso.

- PRI: Prioridad.

- NI: Nivel de prioridad (nice)

- VIRT: Cantidad de memoria virtual utilizada (swap)

- RES: Memoria RAM en megabytes.

- SHR: Memoria compartida utilizada. 
- S: Stado del proceso (Sleeping, Zombie, Running)

- CPU\%: Porcentaje de CPU utilizada (procesador)

- MEM\%: Porcentaje de memoria RAM utilizada

- TIME+: Tiempo de vida del proceso.

- Command: Comando utilizado para lanzar el proceso

\subsubsection{HAPROXY}

High Abailability Proxy es una aplicación de código abierto utilizada para balancear carga TCP/HTTP, mejorando la disponibilidad y la confiabilidad distribuyendo el tráfico a través de múltiples servidores.

Según su propia página $\mathrm{web}^{3}$ :

"HAProxy es una solución gratuita, rápida y confiable que ofrece alta disponibilidad, balanceo de carga y proxy para aplicaciones basadas en TCP y HTTP. Está hecha particularmente para sitios web con alto tráfico y potencia un gran número de los sitios web más visitados. Es el balanceador de carga por defecto y viene incluido en la mayoría de las distribuciones Linux, usualmente desplegado por defecto en las plataformas en la nube".

En la figura 16, podemos observar una aplicación web sin balanceo de carga. Como podemos observar, los clientes consultan directamente al servidor web, en caso aumenten las solicitudes de conexión simultáneas este será el único servidor que las podrá atenderlas. Lo que significa que se irá volviendo lento hasta que se sobre carga y la aplicación web deja de funcionar.

\footnotetext{
${ }^{3}$ haproxy.org
} 


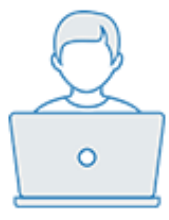

User

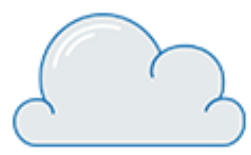

Internet

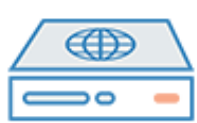

Web Server

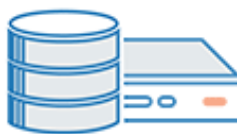

Database Server

http://yourdomain.com/

Figura 16. Aplicación Web sin balanceo de carga

Adaptado de https://www.digitalocean.com/community/tutorials/an-introduction-to-haproxy-and-load-

balancing-concepts

En la figura 17, podemos observar una aplicación web en la que se aplica el balanceo de carga con HAProxy. En esta arquitectura, el cliente hace sus solicitudes de conexión al balanceador de carga y este envía las solicitudes a uno de los servidores que se encuentra en el web-backend. En esta configuración, las solicitudes se van enviando a diferentes servidores web, si uno de ellos llega a dejar de funcionar, el otro sigue atendiendo solicitudes y los clientes seguirán accediendo al servicio.

\section{Layer 4 Load Balancing}

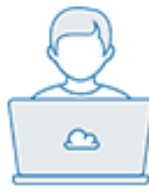

User

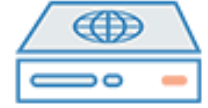

Load Balancer

http://yourdomain.com/

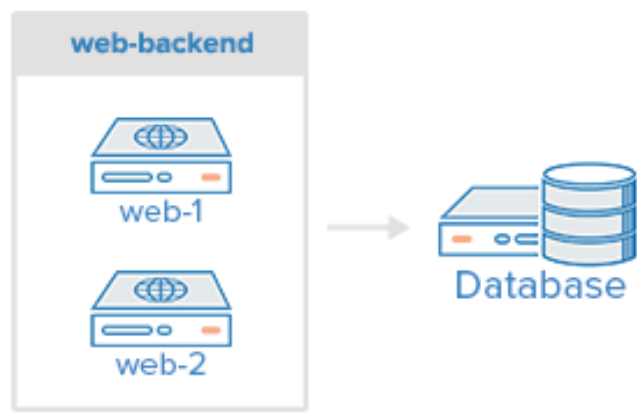

Figura 17. Aplicación Web con balanceo de carga

Adaptado de https://www.digitalocean.com/community/tutorials/an-introduction-to-haproxy-and-loadbalancing-concepts 


\section{DEFINICIÓN DEL PROBLEMA}

En este capítulo, analizaremos el problema identificado en el capítulo 1 y elaboraremos los requerimientos necesarios que permitirán implementar una arquitectura de contenedores escalable.

Problema: "Las arquitecturas tradicionales basadas únicamente en virtualización de sistemas operativos no responden adecuadamente al crecimiento de una startup, haciendo complicado el escalamiento de servicios y aplicaciones web que les permitan mantener una mejor continuidad del negocio".

Como ya hemos mencionado, en capítulos anteriores las startups se caracterizan por sus necesidades de crecimiento exponencial, estas necesidades deben ser cubiertas por la tecnología que acompaña a sus innovadores modelos de negocio. Para responder adecuadamente a estas necesidades, es necesario que la plataforma tecnológica que soporte los servicios de una startup pueda escalar con rapidez y facilidad, a la par del crecimiento del negocio.

En un principio, las empresas suelen utilizar arquitecturas basadas en servidores físicos o en la virtualización de estos servidores. Con el auge de la virtualización y los servicios en la nube, es común adquirir entornos virtuales y desplegar servicios en servidores virtuales instalando las aplicaciones en un servidor virtual y adquiriendo un pool de servidores virtuales para responder al escalamiento y la alta disponibilidad. Sin embargo, a medida que transcurre el tiempo y aumente la cantidad de solicitudes de servicio es posible que los recursos virtuales desplegados no lo soporten, generando la saturación de los servidores.

Un ejemplo claro, puede ser observado cuando los clientes que usan aplicaciones móviles o navegadores web realizan una gran cantidad de conexiones http o https por segundo de manera simultánea hacia el servidor. Estas conexiones solicitan servicios al puerto 80 vía el protocolo TCP, lo cual generará lentitud e inclusive caídas del servidor, como consecuencia las peticiones subsiguientes de los clientes no podrán ser atendidas.

Para realizar el análisis, nos plantearemos tres escenarios de prueba bien diferenciados, como podemos observar en la figura 18: 


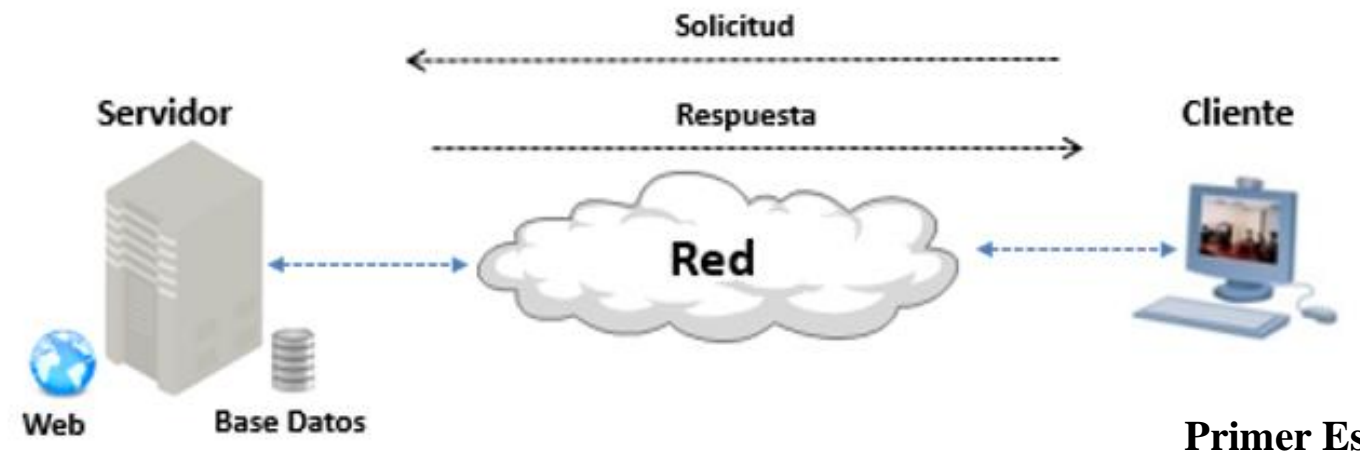

\section{Primer Escenario}

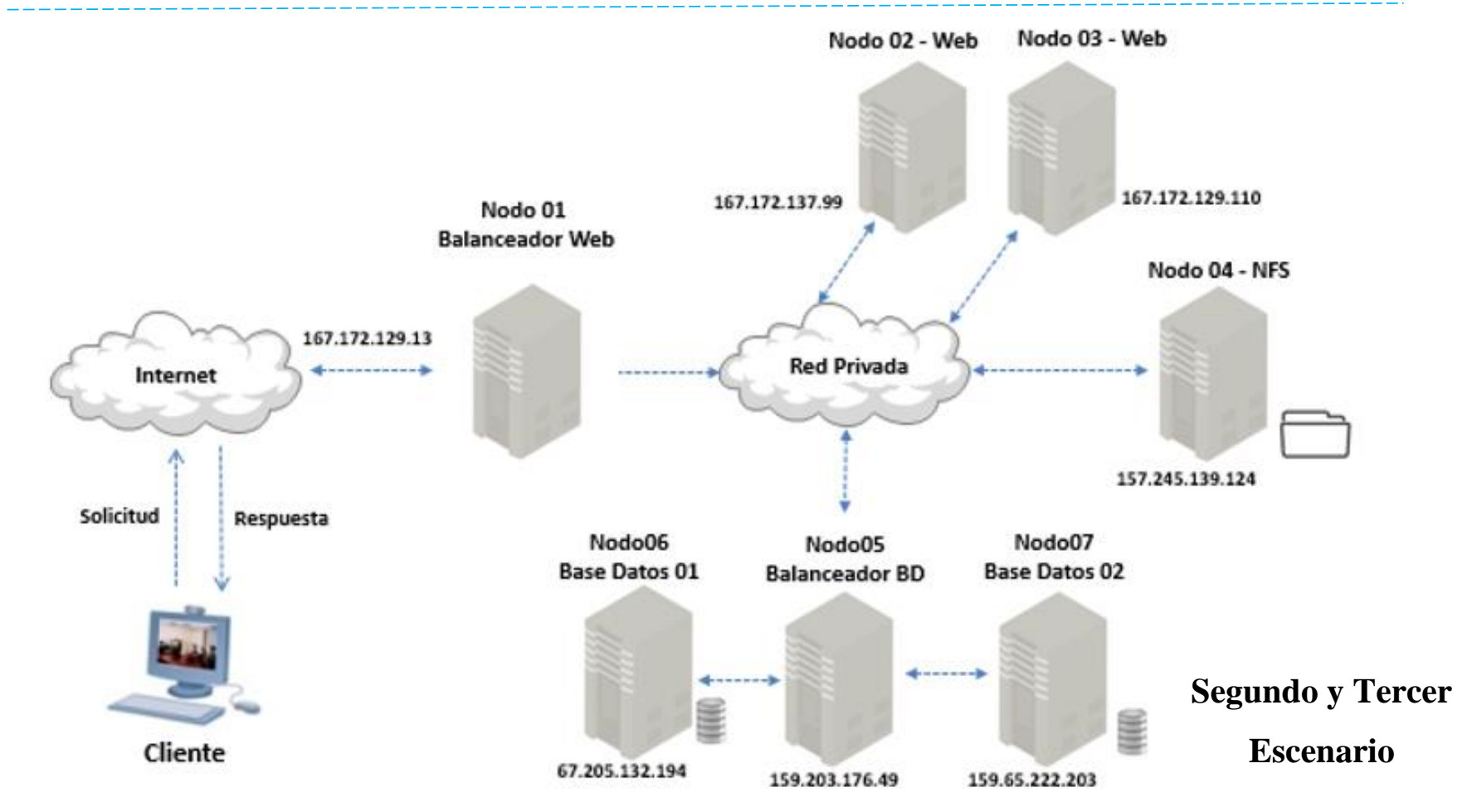

Figura 18. Escenarios de prueba

Elaboración propia

- El primer escenario representa una arquitectura básica cliente/servidor con un solo servidor en hardware alojando todos los servicios: servidor web y servidor de base de datos.

- El segundo escenario representa una solución al problema de escalabilidad del escenario anterior, utilizando escalabilidad horizontal con virtualización de servidores. Se presentan siete servidores: un balanceador de carga de conexiones web, dos servidores web Apache, un balanceador de carga de conexiones MySQL, 
dos servidores de base de datos MySQL y un servidor que aloja el sistema de archivos con el contenido web.

- El tercer escenario representa la misma configuración de servidores que el segundo escenario, sin embargo, aquí aplicamos la escalabilidad vertical, aumentando los recursos de hardware de cada servidor para solucionar los problemas de escalabilidad.

Como podemos observar, para los tres escenarios se ha elegido una aplicación web, el motivo de esta elección es que la mayoría de las empresas y emprendimientos utilizan aplicaciones web para hacer llegar su modelo de negocio a los clientes.

Cada escenario, además, contará con un simulador de conexiones, este simulador no será más que un servidor ejecutando HTTPERF para simular las conexiones de los clientes.

Para implementar estos escenarios de pruebas, se contará principalmente con herramientas de código abierto basadas en Linux, las cuales se ejecutarán en servidores virtuales adquiridos a la empresa DigitalOcean, la que nos provee con los requisitos necesarios para realizar estas pruebas.

Aquí el detalle del software que se va a utilizar:

- Linux Server Ubuntu 18.04 LTS: Sistema operativo para servidores de libre y de código abierto. Se utilizará tanto para los servidores que conforman los escenarios como para generar el tráfico que simulará a los clientes del servicio.

- Servidor Web APACHE 2.4.38-3.

- Servidor de Base de Datos MySQL 5.1: Es un sistema de gestión de base de datos relacional.

- WordPress: Es un sistema de gestión de contenidos, enfocado a la creación de cualquier tipo de página web. Esta aplicación web será la que usaremos para medir las conexiones web.

- HTOP: Es una aplicación de monitorización, administración y visor de procesos que nos permite gestionarlos. También nos enseña el estado de la memoria, la swap (memoria virtual) y el consumo de CPU. 
- HTTPERF 0.9.0-1: Es una herramienta de prueba para medir el rendimiento de los servidores web.

Utilizamos como proveedor de servicio de máquinas virtuales a DigitalOcean debido a la simplicidad para crear y administrar servidores. Podemos crear un "droplet" (servidor) en pocos minutos y tener el acceso de manera más rápida. Un droplet es un servidor únicamente para tu sitio web con una dirección IP propia. En el esquema de precios, DigitalOcean es más accesible y prácticamente solo se paga por el consumo de los recursos seleccionados, siendo esto un punto muy importante para todo inicio de una Startup.

Los servidores seleccionados en DigitalOcean contarán con el sistema operativo Linux Server Ubuntu 18.04 LTS y los requisitos mínimos que Ubuntu Server necesita para la instalación de su sistema operativo son los siguientes:

- 20 GB de espacio libre en disco recomendado.

- 2 GB de memoria RAM recomendado

- Procesador a $1 \mathrm{GHz}$ o superior.

Tomando en cuenta las características de hardware recomendadas por Ubuntu y en vista de que el servidor ejecutará un servicio Web se va a considerar las siguientes características:

- Procesador: Se debe tener en consideración como mínimo un procesador que soporte dos núcleos con una velocidad de $2.6 \mathrm{GHz}$ debido a la carga de procesos del servidor web.

- Memoria RAM: Es recomendable utilizar ECC (Error-correcting code), estas memorias son capaces de recuperarse de ciertos errores en algunos casos detectando y corrigiendo los errores de los datos. La ejecución de las instancias dependiendo del S.O. y de las aplicaciones o servicios que brindara, el consumo de la RAM pude ser mucha o poca. Para este caso, se aconseja un mínimo de 4 GB de RAM.

- Discos Duros: Entre las tecnologías de Disco Duros tenemos:

- SATA (7 200 o $10000 \mathrm{rpm}$ ): Hasta 3TB de almacenamiento y bus de 3Gbps.

○ SAS (10 000 o $15000 \mathrm{rpm}$ ): hasta $900 \mathrm{~GB}$ de almacenamiento y bus de 6Gbps. 
- SSD: Hasta 256 GB de almacenamiento, aunque algunas unidades de estado sólido llegan hasta 4TB y bus de 3 o 6 Gbps. En cuanto a la capacidad, al no necesitar mucho almacenamiento para alojar la Web utilizaremos un SSD de 25 GB para aprovecharnos de su alta velocidad.

Según lo explicado, para cada servidor que se utilizará en las pruebas en los diferentes escenarios se van a considerar las siguientes características de hardware:

Tabla 3.

Características de hardware

\begin{tabular}{|l|c|}
\hline \multicolumn{2}{|c|}{ Servidor } \\
\hline Procesador & Intel Xeon CPU E5-2697A v4 2.60 GHz (2 core) \\
\hline Memoria RAM & 4 GB DDR3 \\
\hline Disco Duro & $1 \times 25$ G SSD \\
\hline Interfaz de Red & $2 \times 1 \mathrm{GbE}$ \\
\hline
\end{tabular}

Elaboración propia

En los escenarios de prueba, se estará utilizando la cantidad de 3 mil conexiones web en total, debido a que nos toma menos tiempo en las respuestas que nos brindarán las pruebas realizadas. La medición se basará únicamente en las conexiones web por segundo que se estarán enviando desde un servidor externo hacia nuestra aplicación web, tomaremos como valor inicial un mínimo de 50 conexiones, las cuales, al ir midiendo paulatinamente, veremos los resultados y estaremos aumentando las conexiones en los escenarios propuestos.

A continuación, iniciamos las pruebas en los tres escenarios y daremos los detalles de configuración y recursos empleados en cada uno, así como los resultados de las pruebas de conexión.

\subsection{Arquitectura tradicional}

Para este escenario, nos basaremos en una arquitectura tradicional, utilizando un solo servidor. A continuación, se muestra el diagrama del escenario actual: 


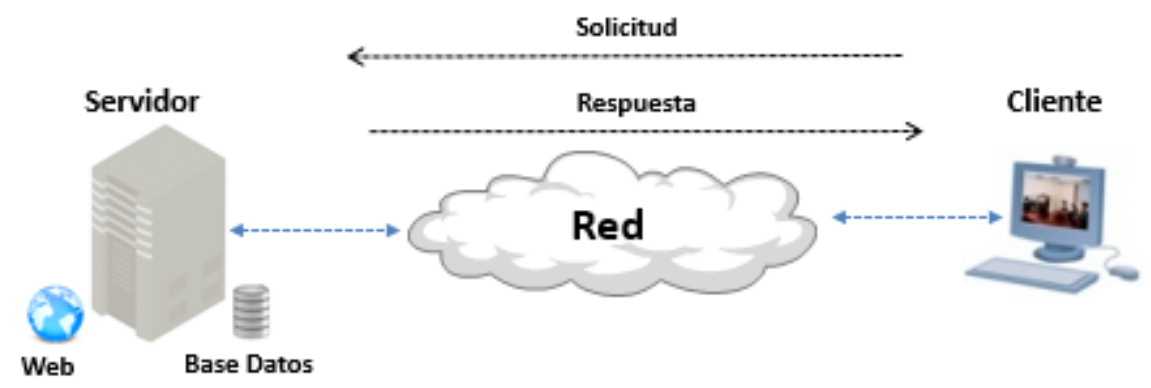

Figura 19. Arquitectura tradicional de una aplicación Web

Elaboración propia

Como vemos en la figura 19, en este escenario los clientes enviarán sus solicitudes de conexión web directamente al servidor, que está escuchando en el puerto 80. Una vez validados los datos, este responderá con la página solicitada enviando de regreso la información en formato web.

Para simular las conexiones que enviaría un cliente hacia la aplicación Web, vamos a utilizar un servidor de prueba con la aplicación HTTPERF el cual tiene las siguientes características:

Tabla 4.

Características de hardware para el servidor simulador de conexiones Web

\begin{tabular}{|c|c|c|c|}
\hline Servidor & Nombre Servidor & IP WAN & Recursos de Harware (CPU / RAM / HDD) \\
\hline Simulador de Conexiones & traficc-vps & 104.128 .75 .24 & Intel Xeon CPU E5-2697A v4 2.60GHz (2 core) / 4GB / 25GB Disk \\
\hline
\end{tabular}

Elaboración propia

En la siguiente tabla, se muestran las características del hardware que estaremos utilizando para este escenario: 


\section{Tabla 5}

Características de hardware para el servidor Web

\begin{tabular}{|c|c|c|c|}
\hline Servidor & Nombre Servidor & IP WAN & Recursos de Harware (CPU / RAM / HDD) \\
\hline WordPress & wordpress & 165.227 .199 .154 & Intel Xeon CPU E5-2697A v4 2.60GHz (2 core) / 4GB / 25GB Disk \\
\hline
\end{tabular}

Elaboración propia

En el siguiente gráfico, veremos el consumo de recursos de hardware del servidor:

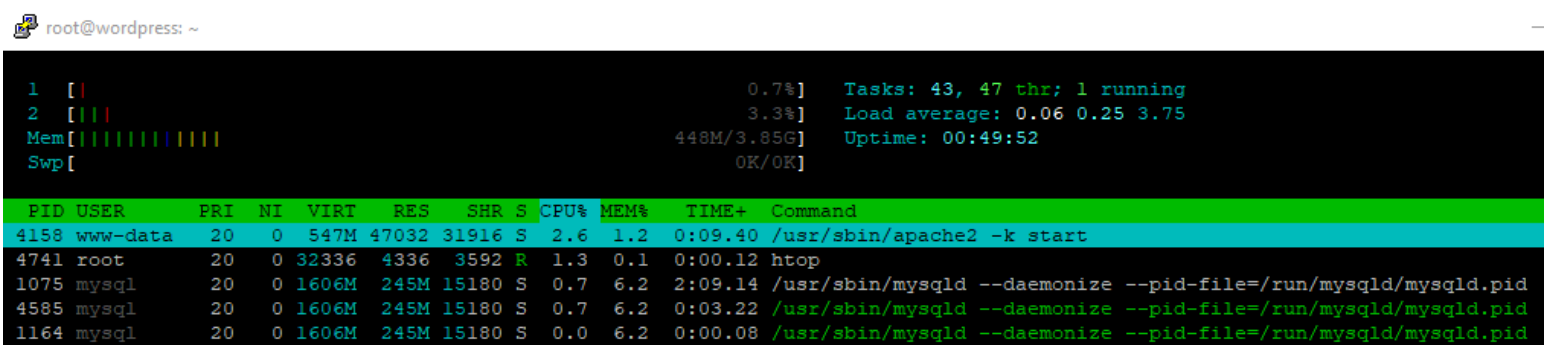

Figura 20. Muestra de consumo de hardware del servidor Web

Elaboración propia

Mediante la aplicación HTOP, podemos observar que los recursos de hardware del servidor web no se están consumiendo debido a que no se están realizando conexiones web. Se está usando aproximadamente el $4 \%$ de los dos núcleos que tenemos en el procesador y 448MB de memoria RAM.

Validar el acceso a la aplicación web: 


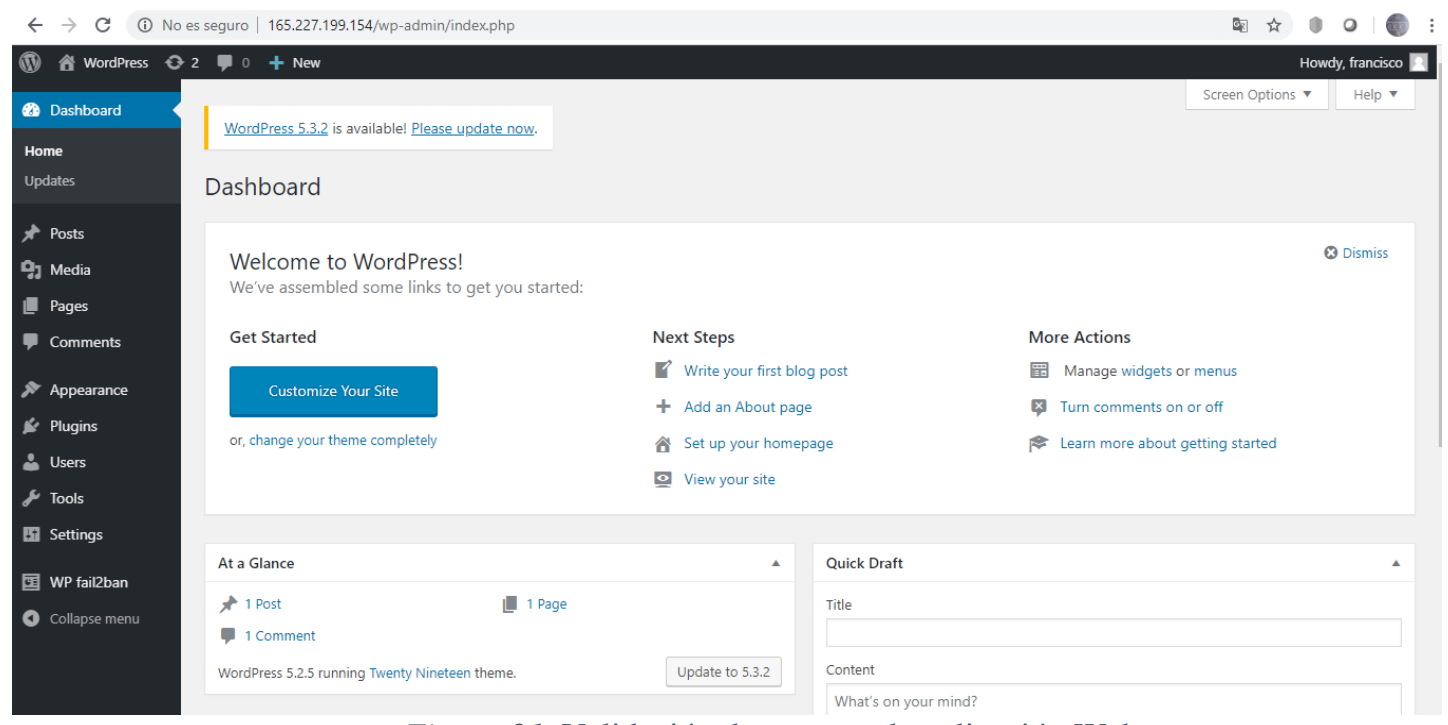

Figura 21. Validación de acceso a la aplicación Web

Elaboración propia

En la figura 21,se está validando el acceso a la aplicación web utilizando un navegador de Internet que podría Firefox, Google Chrome, Internet Explorer, etc.

\subsubsection{Cantidad de conexiones web concurrentes}

Para medir el rendimiento de la aplicación Web, se utilizará la herramienta httperf ejecutándola desde un servidor externo el cual simulará en tiempo real las conexiones por segundo que soportará el servidor web.

\subsubsection{Prueba 01}

Envío de un total de 3000 de conexiones con una velocidad de 50 conexiones por segundo.

Desde el servidor Simulador de Conexiones Web se ejecutará el siguiente comando: httperf --server 165.227.199.154 --port 80 --num-conns 3000 --rate 50 timeout 1

Se enviará hacia el servidor web con dirección IP 165.227.199.154 con número de puerto 80 (HTTP) una cantidad total de 3000 peticiones con una velocidad de 50 conexiones por segundo. 


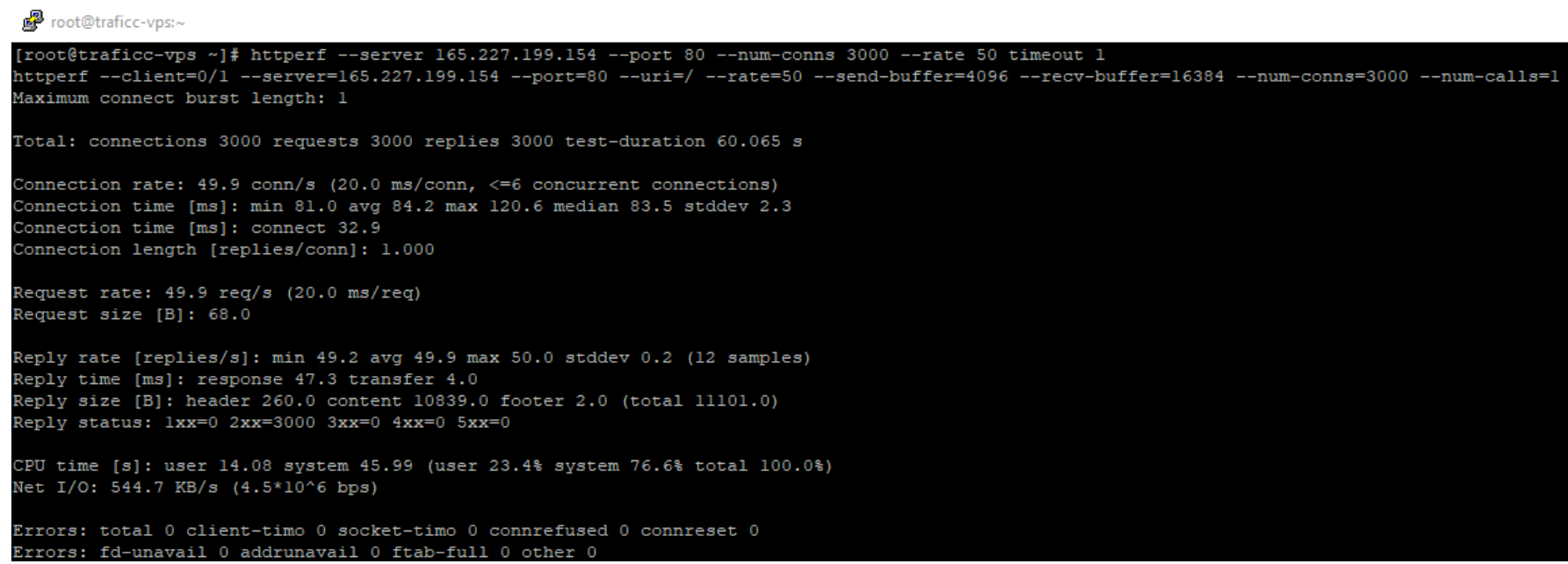

Figura 22. Resultados obtenidos en servidor Simulador de Conexiones hacia la aplicación Web

Elaboración propia

En la figura 22, podemos observar todos los resultados obtenidos de la prueba realizada. A continuación, se explicarán los resultados de los puntos más importantes que hemos obtenido.

Total: connections 3000 requests 3000 replies 3000 test-duration $60.065 \mathrm{~s}$

Muestra que se iniciaron 3000 conexiones, se realizaron 3000 solicitudes y se recibieron 3000 respuestas.

También muestra que la duración total de la prueba fue de 60.065 segundos, lo que significa que la tasa de solicitud promedio fue casi exactamente 50 solicitudes por segundo.

\section{Connection rate: $49.9 \mathrm{conn} / \mathrm{s}(20.0 \mathrm{~ms} / \mathrm{conn},<=6$ concurrent connections $)$}

Muestra que las nuevas conexiones se iniciaron a una velocidad de 50 conexiones por segundo. Esta tasa corresponde a un período de 20.0 milisegundos por conexión. Finalmente, el último número muestra que, como máximo, seis conexiones estaban abiertas al servidor en un momento dado.

\section{Connection time [ms]: $\min 81.0$ avg 84.2 max 120.6 median 83.5 stddev 2.3}

Muestra que la vida útil de la conexión mínima (min) fue de 81.0 milisegundos, la vida útil promedio (avg) fue de 84.2 milisegundos, la vida útil máxima (max) fue de 120.6 milisegundos, la vida mediana (median) fue de 83.5 milisegundos, y que la desviación estándar de los tiempos de vida fue de 2.3 milisegundos. 


\section{Reply rate [replies/s]: min 49.2 avg 49.9 max 50.0 stddev 0.2 (12 samples)}

Muestra la tasa de respuesta mínima (min), promedio (avg) y máxima (max) fue aproximadamente de 50 respuestas por segundo. Dados estos números, la desviación estándar es 0.2 milisegundos.

\section{Errors: total 0 client-timo 0 socket-timo 0 connrefused 0 connreset 0 \\ Errors: fd-unavail 0 addrunavail 0 ftab-full 0 other 0}

Los errores totales sumaron cero debido a que todas las conexiones resultaron exitosas.

En la prueba realizada, se pudo observar que el consumo de los recursos de hardware aumentó en la web debido a la cantidad de conexiones enviadas, los resultados se muestran en la siguiente imagen:

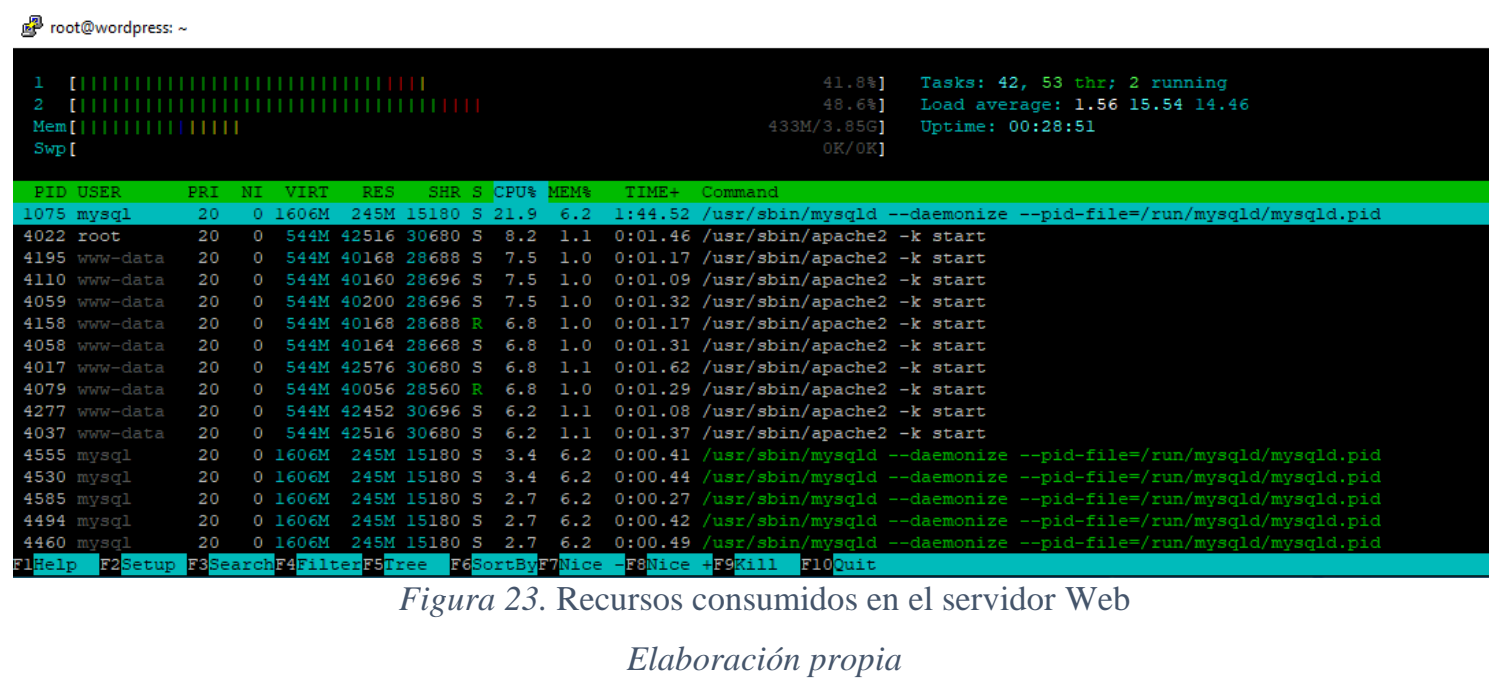

Mediante la aplicación HTOP, podemos observar que los recursos del servidor Web se incrementaron debido a la cantidad de conexiones Web que fueron recibidas. Se puede apreciar que estas conexiones que llegaron hacia el servidor pertenecen a la aplicación Apache que corresponde al servicio Web. Se está usando aproximadamente $50 \%$ de los dos núcleos que tenemos en el procesador y 433MB de memoria RAM. 


\subsubsection{Prueba 02}

Envío de un total de 3000 de conexiones con una velocidad de 80 conexiones por segundo.

Desde el servidor Simulador de Conexiones Web se ejecutará el siguiente comando: httperf --server 165.227.199.154 --port 80 --num-conns 3000 --rate 80 timeout 1

Se enviará hacia el servidor web con dirección IP 165.227.199.154 con número de puerto 80 (HTTP) una cantidad total de 3000 peticiones con una velocidad de 80 conexiones por segundo.

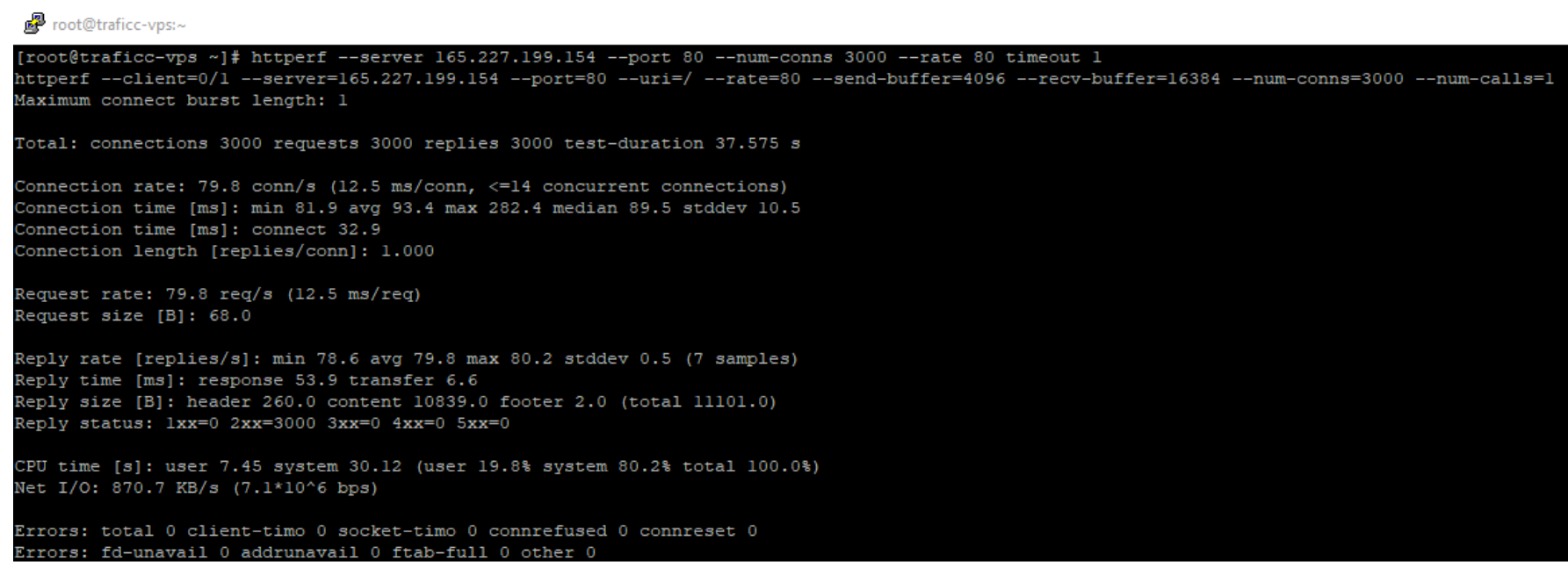

Figura 24. Resultados obtenidos en servidor Simulador de Conexiones hacia la aplicación Web Elaboración propia

En la figura 24, podemos observar todos los resultados obtenidos en la prueba realizada. A continuación, se explicarán los resultados de los puntos más importantes que hemos obtenido.

Total: connections 3000 requests 3000 replies 3000 test-duration $37.575 \mathrm{~s}$

Muestra que se iniciaron 3000 conexiones, se realizaron 3000 solicitudes y se recibieron 3000 respuestas.

También muestra que la duración total de la prueba fue de 37.575 segundos, lo que significa que la tasa de solicitud promedio fue casi exactamente 79 solicitudes por segundo.

Connection rate: $79.8 \mathrm{conn} / \mathrm{s}(\mathbf{1 2 . 9} \mathrm{ms} / \mathrm{conn},<=14$ concurrent connections) 
Muestra que las nuevas conexiones se iniciaron a una velocidad de 80 conexiones por segundo. Esta tasa corresponde a un período de 12.9 milisegundos por conexión. Finalmente, el último número muestra que, como máximo, catorce conexiones estaban abiertas al servidor en un momento dado.

\section{Connection time [ms]: min 81.9 avg 93.4 max 282.4 median 89.5 stddev 10.5}

Muestra que la vida útil de la conexión mínima (min) fue de 81.9 milisegundos, la vida útil promedio (avg) fue de 93.4 milisegundos, la vida útil máxima (max) fue de 282.4 milisegundos, la vida mediana (median) fue de 89.5 milisegundos, y que la desviación estándar de los tiempos de vida fue de 10.5 milisegundos.

\section{Reply rate [replies/s]: min 78.6 avg 79.8 max 80.2 stddev 7.0 (7 samples)}

Muestra la tasa de respuesta mínima (min), promedio (avg) y máxima (max) fue aproximadamente de 80 respuestas por segundo. Dados estos números, la desviación estándar es 7.0 milisegundos.

\section{Errors: total 0 client-timo 0 socket-timo 0 connrefused 0 connreset 0 \\ Errors: fd-unavail 0 addrunavail 0 ftab-full 0 other 0}

Los errores totales sumaron cero debido a que todas las conexiones resultaron exitosas.

En la prueba realizada, se pudo observar que el consumo de los recursos de hardware aumento en el servidor web debido a la cantidad de conexiones enviadas, los resultados se muestran en la siguiente imagen:

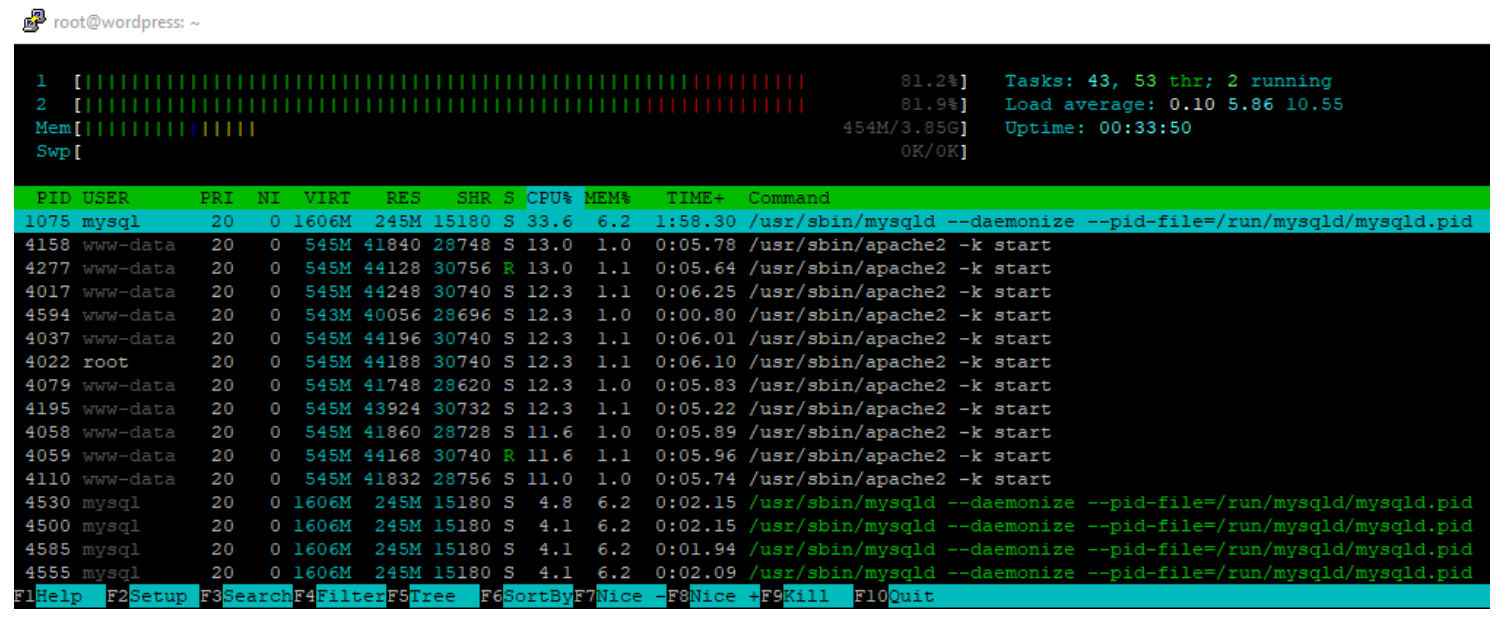

Figura 25. Recursos consumidos en el servidor Web 
Mediante la aplicación HTOP, podemos observar que los recursos del servidor se elevaron debido a las conexiones Web que se recibieron. Se puede apreciar que el servicio más usado es Apache que corresponde a la Web. Se está usando aproximadamente $82 \%$ de los dos núcleos que tenemos en el procesador y 454MB de memoria RAM.

\subsubsection{Prueba 03}

Envío de un total de 3000 de conexiones con una velocidad de 100 conexiones por segundo.

Desde el servidor Simulador de Conexiones Webse ejecutará el siguiente comando:

$$
\text { httperf --server 165.227.199.154 --port } 80 \text {--num-conns } 3000 \text {--rate } 100 \text { timeout } 1
$$

Se enviará hacia el servidor web con dirección IP 165.227.199.154 con número de puerto 80 (HTTP) una cantidad total de 3000 peticiones con una velocidad de 100 conexiones por segundo.

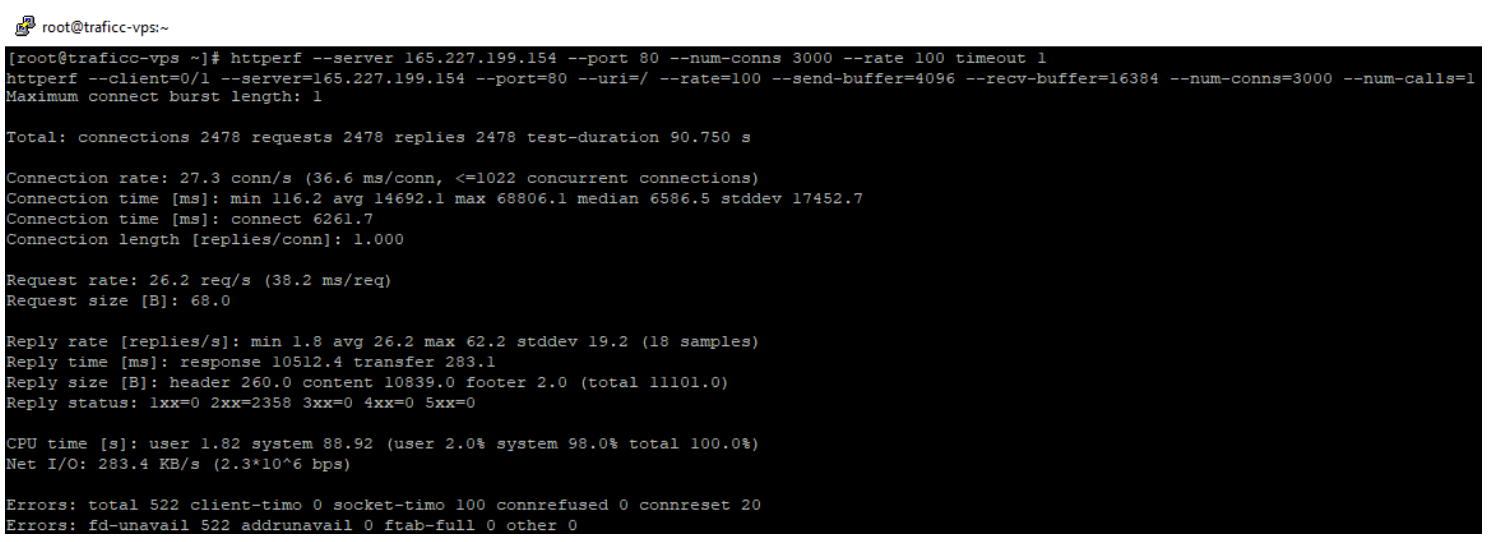

Figura 26. Resultados obtenidos en servidor Simulador de Conexiones hacia la aplicación Web

Elaboración propia

En la figura 26, podemos observar todos los resultados obtenidos en la prueba realizada. A continuación, se explicarán los resultados de los puntos más importantes que hemos obtenido.

\section{Total: connections 2478 requests 2478 replies 2458 test-duration 90.750 s}

Muestra que se iniciaron 2478 conexiones, se realizaron 2478 solicitudes y se recibieron 2478 respuestas de las 3000 que fueron enviadas. 
También muestra que la duración total de la prueba fue de 90.750 segundos, lo que significa que la tasa de solicitud promedio fue casi exactamente 27 solicitudes por segundo.

Connection rate: $27.3 \mathrm{conn} / \mathrm{s}$ ( $36.6 \mathrm{~ms} / \mathrm{conn},<=1022$ concurrent connections)

Muestra que las nuevas conexiones se iniciaron a una velocidad de 27 conexiones por segundo. Esta tasa corresponde a un período de 36.6 milisegundos por conexión. Finalmente, el último número muestra que, como máximo, mil veintidós conexiones estaban abiertas al servidor en un momento dado.

Connection time [ms]: $\min 116.2$ avg $14692.1 \max 68806.1$ median 6558.5 stddev 17452.7

Muestra que la vida útil de la conexión mínima (min) fue de 116.2 milisegundos, la vida útil promedio (avg) fue de 14692.1 milisegundos, la vida útil máxima (max) fue de 68806.1 milisegundos, la vida mediana (median) fue de 6558.5 milisegundos, y que la desviación estándar de los tiempos de vida fue de 17452.7 milisegundos.

\section{Reply rate [replies/s]: min 1.8 avg 26.2 max $62.2 \mathrm{stddev} 19.2$ (18 samples)}

Muestra la tasa de respuesta mínima (min), promedio (avg) y máxima (max) fue aproximadamente de 62 respuestas por segundo. Dados estos números, la desviación estándar es 19.2 milisegundos.

\section{Errors: total 522 client-timo 0 socket-timo 0 connrefused 0 connreset 0 Errors: fd-unavail 522 addrunavail 0 ftab-full 0 other 0}

La suma total de los errores fue de 522 conexiones. El error presentado se da en el fd-unavail el cual indica que el número de veces que el cliente web httperf se quedó sin respuesta debido a que sus recursos de hardware se encuentran sobrecargado.

En la prueba realizada, se pudo observar que el consumo de los recursos de hardware aumentó en su totalidad en el servidor web debido a la cantidad de conexiones enviadas. En esta prueba, no se llegaron a establecer todas las conexiones, los resultados se muestran en la siguiente imagen. 


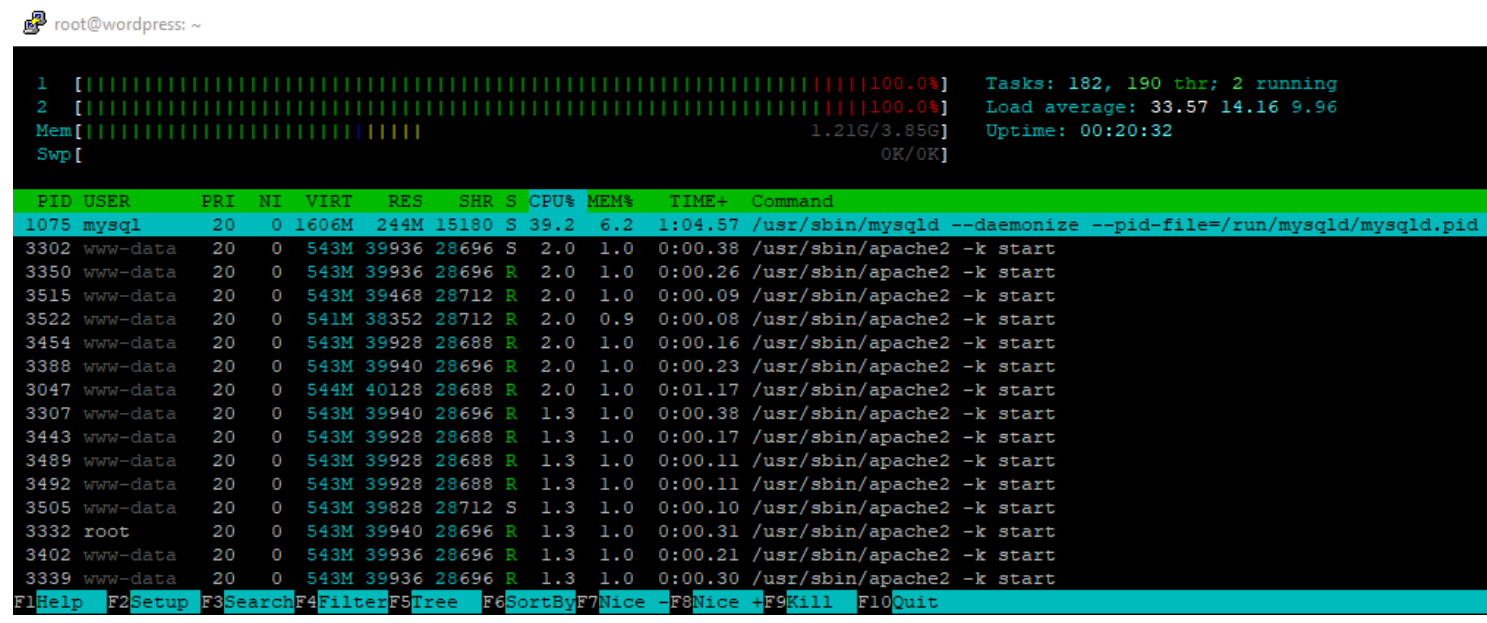

Figura 27. Recursos consumidos en el servidor Web

Elaboración propia

Mediante la aplicación HTOP, podemos observar que los recursos del servidor se elevaron debido a las conexiones Web que se recibieron. Se puede apreciar que el servicio más usado es Apache que corresponde a la Web. Se está usando el $100 \%$ de los dos núcleos que tenemos en el procesador y $1.21 \mathrm{~GB}$ de memoria RAM.

En las tres pruebas realizadas, hemos obtenido diferentes resultados los cuales se muestran en la siguiente tabla:

Tabla 6.

Resumen de los resultados de las pruebas de conexión

\begin{tabular}{|l|r|r|r|r|r|r|r|r|}
\hline $\begin{array}{c}\text { Número } \\
\text { de Prueba }\end{array}$ & $\begin{array}{c}\text { Conexiones } \\
\text { Enviadas }\end{array}$ & $\begin{array}{c}\text { Conexiones } \\
\text { Respondidas }\end{array}$ & $\begin{array}{c}\text { Conexiones No } \\
\text { Respondidas }\end{array}$ & $\begin{array}{c}\text { Tiempo de } \\
\text { respuesta de } \\
\text { la prueba }\end{array}$ & $\begin{array}{c}\text { Conexiones } \\
\text { por segundo } \\
\text { Enviadas }\end{array}$ & $\begin{array}{c}\text { Conexiones } \\
\text { por segundo } \\
\text { Respondidas }\end{array}$ & $\begin{array}{c}\text { Tiempo de } \\
\text { respuesta de } \\
\text { la Web }\end{array}$ & $\begin{array}{c}\text { Máximo de } \\
\text { respuestas } \\
\text { recibidas }\end{array}$ \\
\hline Primera & 3000 & 3000 & 0 & 60 & 50 & 50 & 0.12 & 50 \\
\hline Segunda & 3000 & 3000 & 0 & 38 & 80 & 80 & 0.2824 & 68 \\
\hline Tercera & 3000 & 2478 & 522 & 91 & 100 & 27 & 80 \\
\hline
\end{tabular}

Elaboración propia

En la tabla 6, podemos observar todos los resultados que se han obtenido en el desarrollo de esta prueba. 
Para tener un mejor panorama de los resultados, estaremos mostrando las gráficas de las conexiones que se enviaron en total y también la cantidad de conexiones por segundo, en cada una de ellas se estará mostrando el tiempo que se tomó en la ejecución de la prueba.
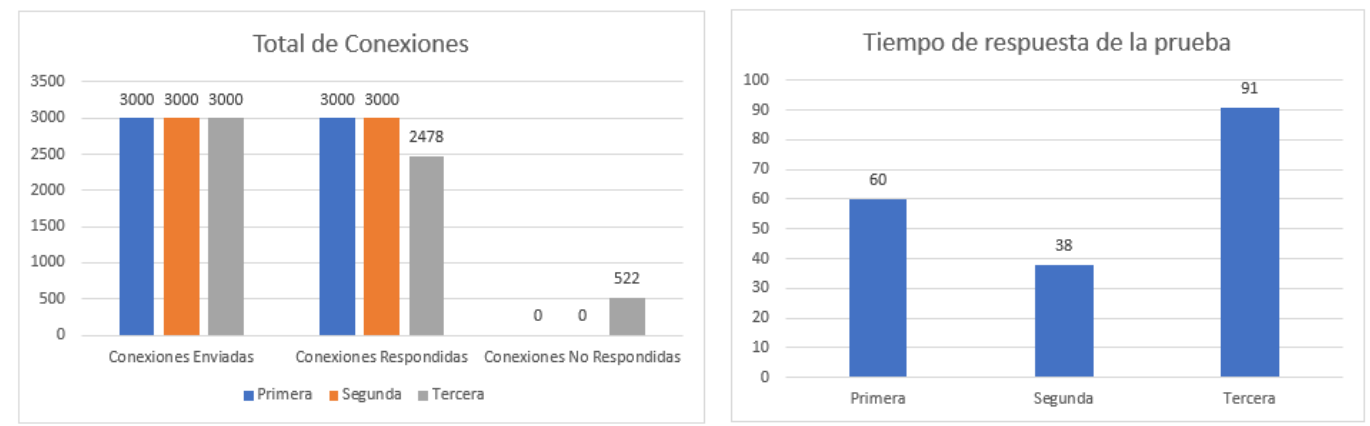

Figura 28. Conexiones enviadas y tiempo de respuesta de las pruebas

Elaboración propia

En la figura 28, podemos observar lo siguiente:

- En la primera prueba, se enviaron 3000 conexiones, respondieron todas y el tiempo de ejecución fue de 60 segundos. Todas las conexiones se llegaron a realizar.

- En la segunda prueba, se enviaron 3000 conexiones, respondieron todas y el tiempo de ejecución fue de 38 segundos. Todas las conexiones se llegaron a realizar.

- En la tercera prueba, se enviaron 3000 conexiones, respondieron solamente 2478 y el tiempo de ejecución fue de 91 segundos. Se llegaron a perder 522 conexiones debido a la saturación de los equipos.
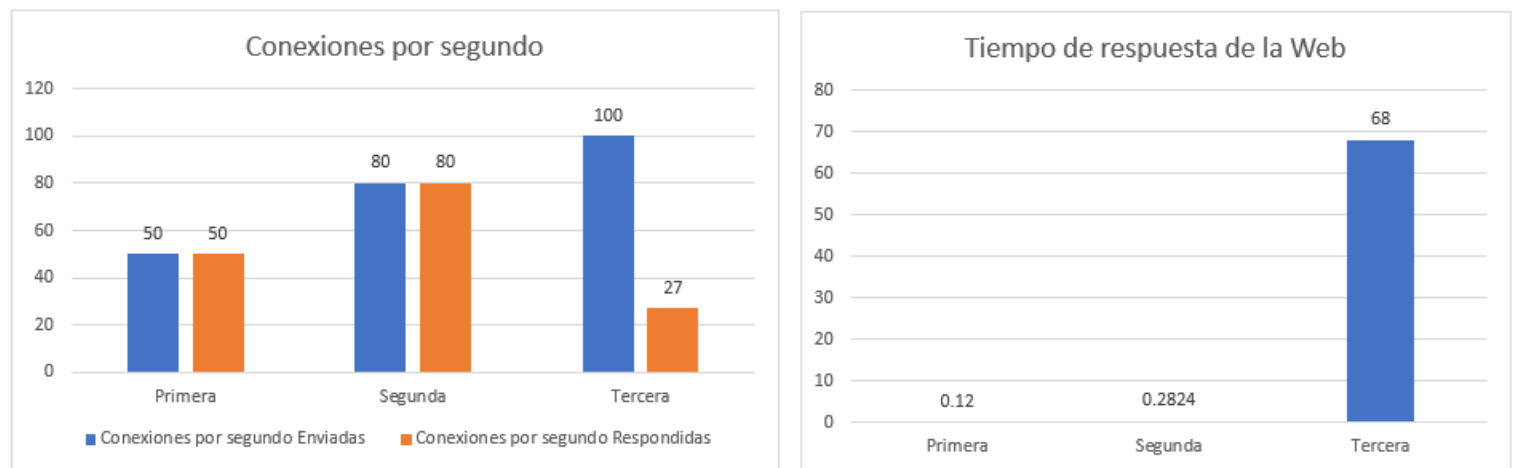

Figura 29. Conexiones por segundo y tiempo de respuesta de la Web

Elaboración propia 
En la figura 29, podemos observar lo siguiente:

- En la primera prueba, se enviaron 50 conexiones por segundo, respondieron todas y el tiempo de respuesta de la Web fue de 0.12 segundos.

- En la segunda prueba, se enviaron 80 conexiones por segundo, respondieron todas y el tiempo de respuesta de la Web fue de 0.28 segundos.

- En la tercera prueba, se enviaron 100 conexiones por segundo, respondieron solamente 27 y el tiempo de respuesta de la Web fue de 68 segundos.

En resumen, podemos determinar lo siguiente:

- En las tres pruebas realizadas, desde el servidor Simulador de Conexiones hacia el servidor de la aplicación Web se pudo observar que sí llegaron a ejecutar.

- Se observó que, durante las dos primeras pruebas, los recursos de hardware se elevaron, pero no llegaron a consumir su totalidad.

- En la primera y segunda prueba, se llegaron a ejecutar todas las conexiones web sin ningún error.

- Se observó que, durante la tercera prueba, los recursos de hardware se elevaron llegándose a consumir en su totalidad.

- En la tercera prueba, no se llegaron a ejecutar todas las conexiones debido a la sobrecarga del servidor.

\subsubsection{Costos de la implementación}

Para las pruebas realizadas en este primer escenario, las características de hardware para el servidor que tendrá la aplicación Web son los siguientes:

- Procesador Intel Xeon CPU E5-2697A v4 2.60GHz (2 core)

- Memoria RAM: 4GB

- Disco Duro: 25GB SSD DDR3

El costo de este servidor es de $\$ 40$ dólares mensuales. 


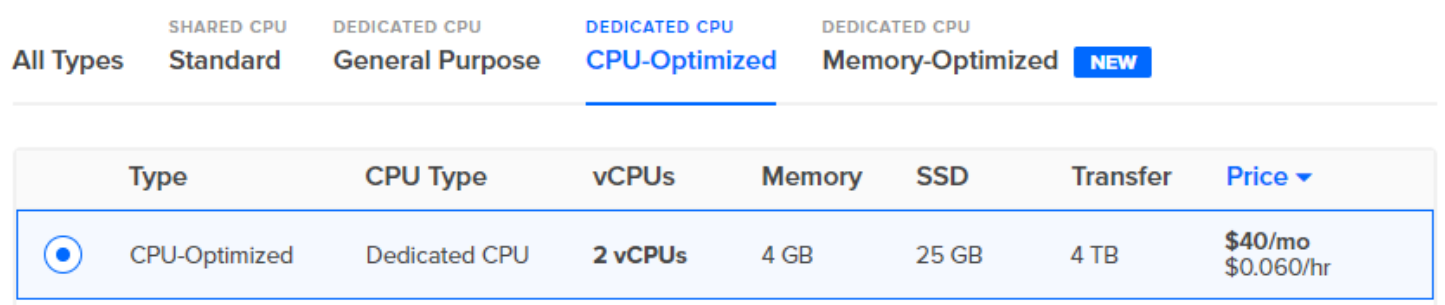

Figura 30. Costo mensual del servidor Web

Adaptado de https://cloud.digitalocean.com/

En la figura 30, que fue obtenida desde el proveedor DigitalOcean, podemos ver el costo que tendrá el servidor seleccionado para la aplicación Web.

\subsubsection{Tiempo de escalabilidad de la arquitectura}

En este escenario podrían haberse aumentado los recursos de hardware realizando un escalamiento vertical el cual permitiría una mayor cantidad de conexiones por segundo. En este caso, no vamos a realizar este tipo de escalamiento debido a que seguiría siendo un solo servidor y al tener una caída no se tendría acceso a la aplicación.

\subsection{Arquitectura tradicional con escalamiento horizontal}

Para este escenario, nos basaremos de una arquitectura tradicional realizando un escalamiento horizontal. En este tipo de escalamiento se va a instalar nuevos servidores, basándonos en máquinas virtuales, las cuales contarán con los servicios que se van a utilizar en la aplicación web. Este escenario tendrá siete servidores en su estructura.

A continuación, mostramos la estructura, elementos que la componen y cómo van a estar conectados entre sí: 


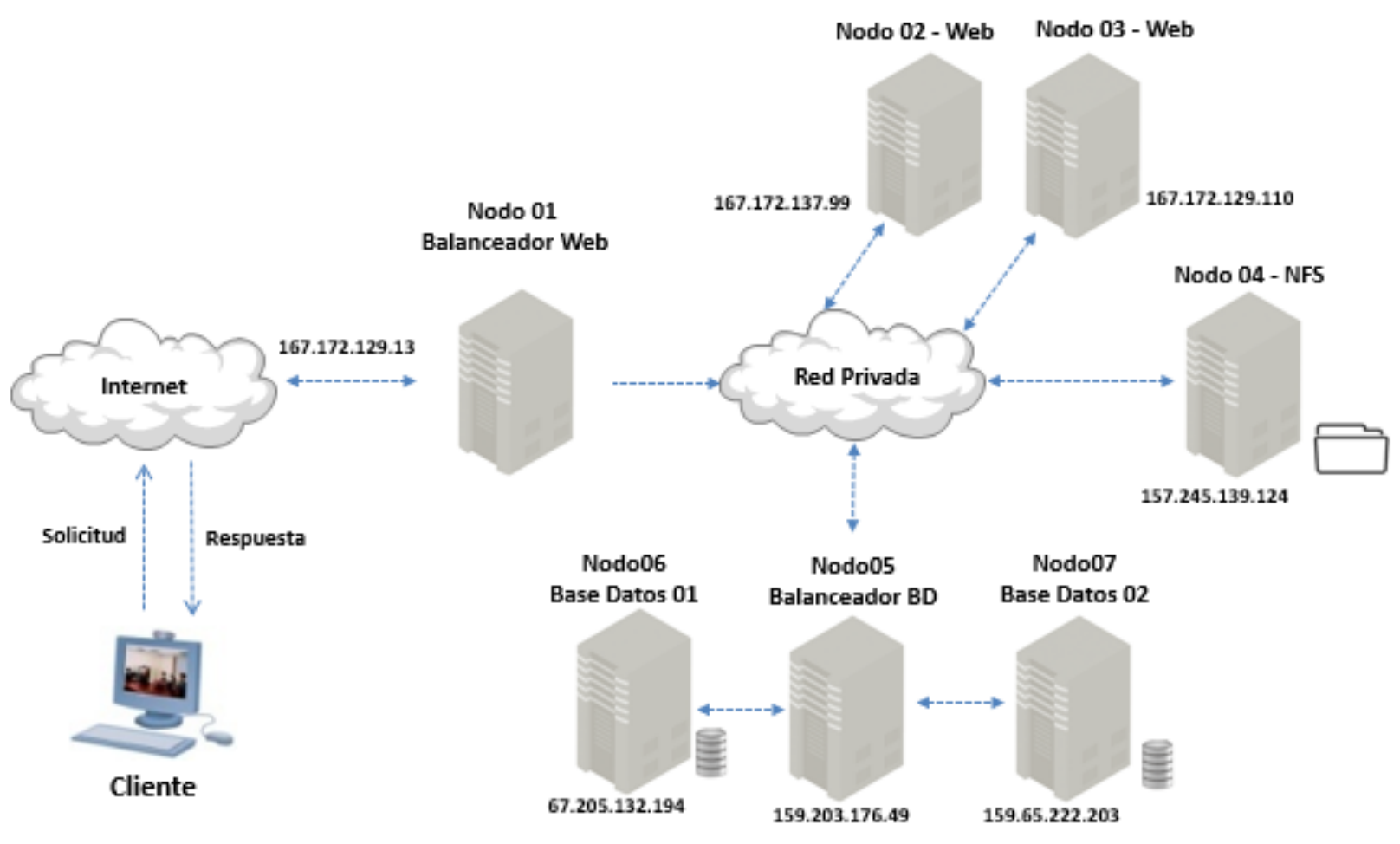

Figura 31. Arquitectura escalable basada en servidores

Elaboración propia

En la figura 31, podemos ver el escenario en donde el cliente envía una petición (conexión) hacia el servidor 01 el cual es un balanceador Web y se encargara de distribuir las conexiones hacia los servidores 02 y 03 quienes tiene el servicio Web. Al recibir la petición con la información, correcta estará enviando una respuesta y en consecuencia mostrando la información de la Web. Las conexiones que se van a simular serán enviadas desde el Simulador de Conexiones Web que se utilizó en el primer escenario. Las características del hardware las podemos ver en el siguiente cuadro: 
Tabla 7.

Características de Hardware de los Servidores

\begin{tabular}{|c|c|c|c|}
\hline Servidor & Nombre Servidor & IP WAN & Recursos de Harware (CPU / RAM / HDD) \\
\hline Balanceador Web & srv01 & 167.172 .129 .13 & Intel Xeon CPU E5-2697A v4 2.60GHz (2 core) / 4GB / 25GB Disk \\
\hline Web 01 & srv02 & 167.172 .137 .99 & Intel Xeon CPU E5-2697A v4 2.60GHz (2 core) / 4GB / 25GB Disk \\
\hline Web 02 & srv03 & 167.172 .129 .110 & Intel Xeon CPU E5-2697A v4 2.60GHz (2 core / 4GB / 25GB Disk \\
\hline NFS & srv04 & 157.245 .139 .124 & Intel Xeon CPU E5-2697A v4 2.60GHz (2 core) / 4GB / 25GB Disk \\
\hline Balanceador BD & srv05 & 159.203 .176 .49 & Intel Xeon CPU E5-2697A v4 2.60GHz (2 core) / 4GB / 25GB Disk \\
\hline MySQL 01 & srv06 & 67.205 .132 .194 & Intel Xeon CPU E5-2697A v4 2.60GHz (2 core $/ 4 \mathrm{~GB} / 25 \mathrm{~GB}$ Disk \\
\hline MySQL 02 & svr07 & 159.65 .222 .203 & Intel Xeon CPU E5-2697A v4 2.60GHz (2 core) / 4GB / 25GB Disk \\
\hline
\end{tabular}

Elaboración propia

Como podemos observar en la tabla 7, cada uno de los servidores cumplen funciones diferentes y muy específicas. Vamos a detallar la función de cada uno de los equipos que componen esta arquitectura:

Srv01 - Balanceador Web

Este servidor que cuenta con el software HAProxy se encargará de recibir las peticiones de los clientes y distribuirá la carga entre los servidores Web que se tiene en nuestra arquitectura. Se encarga de mejorar el rendimiento de un entorno servidor mediante la distribución de la carga de trabajo a través de múltiples servidores.

Srv02 y Srv03 - Apache

Estos dos servidores cuentan con el software Apache, son equipos que se encargan de servir las páginas web que les pide el servidor balanceador.

\section{Srv04 - NFS}

Este servidor es el que conforma el servicio de almacenamiento de los archivos que se tendrá de nuestra aplicación. Este será el encargado de servir a través de la red las páginas web a los servidores Apache. Cuando un usuario haga una solicitud de una página web, el servidor Balanceador pedirá a uno de los servidores Apache que le sirva dicha página y este servidor deberá comunicarse con el servicio de almacenamiento para recoger esa página web y servirla. 
Srv05 - Balanceador MySQL

Este servidor que cuenta con el software HAProxy se encargará de recibir las solicitudes de los clientes y distribuirá la carga entre los servidores de base de datos que se tiene en la arquitectura. Se encarga de mejorar el rendimiento de un entorno servidor mediante la distribución de la carga de trabajo a través de múltiples servidores.

Srv06 y Srv07 - MySQL

Estos dos servidores cuentan con el software MySQL, son servidores de base de datos que se encargaran encargan de guardar la información que envía el servidor balanceador MySQL.

Los servidores 05, 06 y 07 se encuentran distribuidos mediante un clúster de base de datos.

\subsubsection{Cantidad de conexiones web concurrentes}

Para medir el rendimiento de la aplicación Web, se utilizará la herramienta httperf ejecutándola desde un servidor externo el cual simulará en tiempo real las conexiones por segundo que soportará el servidor web.

\subsubsection{Prueba 01}

Envío de un total de 3 mil de conexiones con una velocidad de 100 conexiones por segundo.

Desde el servidor Simulador de Conexiones Web se ejecutará el siguiente comando: httperf --server 167.172.129.13 --port 80 --num-conns 3000 --rate 100 timeout 1

Se enviará hacia el servidor balanceador web con dirección IP 167.172.129.13 con numero de puerto 80 (HTTP) una cantidad total de 3 mil peticiones con una velocidad de 100 conexiones por segundo 


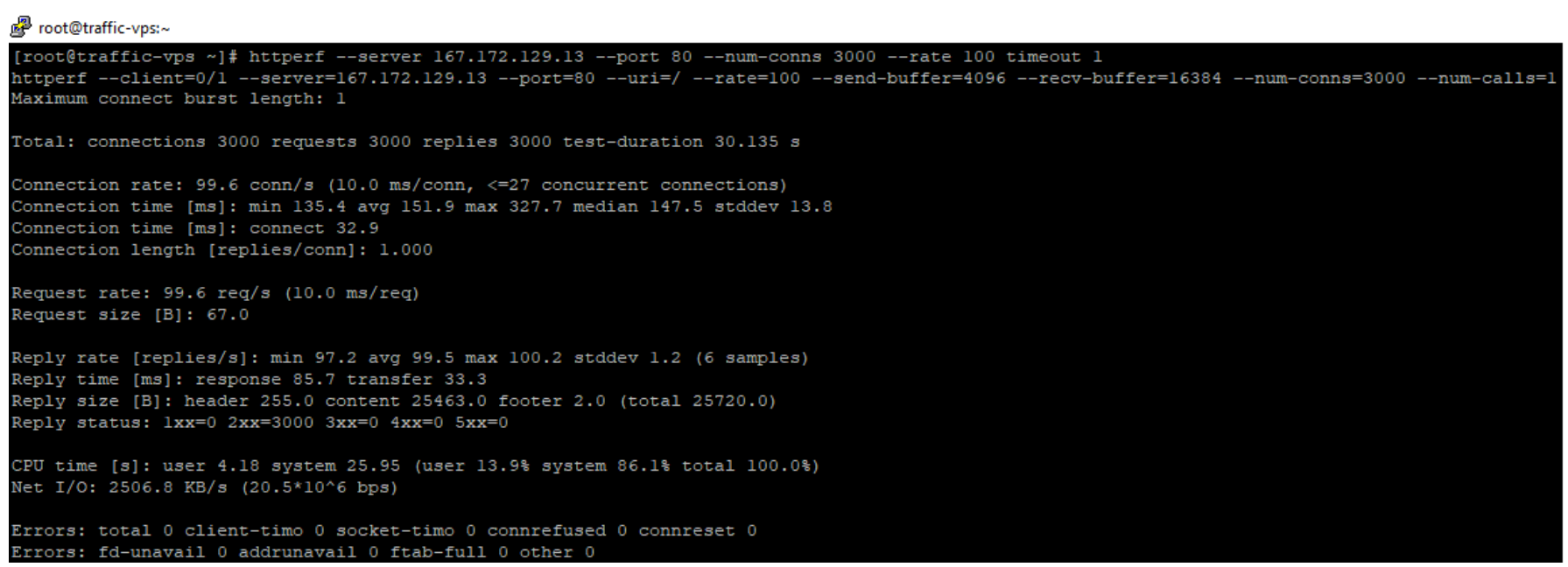

Figura 32. Resultados obtenidos en servidor Simulador de Conexiones hacia la aplicación Web Elaboración propia

En la figura 32, podemos observar todos los resultados obtenidos de la prueba realizada. A continuación, se explicarán los resultados de los puntos más importantes que hemos obtenido.

\section{Total: connections 3000 requests 3000 replies 3000 test-duration $30.135 \mathrm{~s}$}

Muestra que se iniciaron 3000 conexiones, se realizaron 3000 solicitudes y se recibieron 3000 respuestas.

También muestra que la duración total de la prueba fue de 30.135 segundos, lo que significa que la tasa de solicitud promedio fue casi exactamente 100 solicitudes por segundo.

\section{Connection rate: $99.6 \mathrm{conn} / \mathrm{s}(\mathbf{1 0 . 0} \mathrm{ms} / \mathrm{conn},<=27$ concurrent connections)}

Muestra que las nuevas conexiones se iniciaron a una velocidad de 100 conexiones por segundo. Esta tasa corresponde a un período de 10.0 milisegundos por conexión. Finalmente, el último número muestra que, como máximo, veinte siete conexiones estaban abiertas al servidor en un momento dado.

Connection time [ms]: $\min 135.4$ avg 151.9 max 327.7 median 147.5 stddev 13.8

Muestra que la vida útil de la conexión mínima (min) fue de 135.4 milisegundos, la vida útil promedio (avg) fue de 151.9 milisegundos, la vida útil máxima (max) fue 
de 327.7 milisegundos, la vida mediana (median) fue de 147.5 milisegundos, y que la desviación estándar de los tiempos de vida fue de 13.8 milisegundos.

\section{Reply rate [replies/s]: min 97.2 avg 99.5 max 100.2 stddev 1.2 (6 samples)}

Muestra la tasa de respuesta mínima (min), promedio (avg) y máxima (max) fue aproximadamente de 100 respuestas por segundo. Dados estos números, la desviación estándar es 1.2 milisegundos.

\section{Errors: total 0 client-timo 0 socket-timo 0 connrefused 0 connreset 0 Errors: fd-unavail 0 addrunavail 0 ftab-full 0 other 0}

Los errores totales sumaron cero debido a que todas las conexiones resultaron exitosas.

En esta prueba, se va a considerar únicamente el servidor 01 que es el equipo balanceador Web y los servidores 02 y 03 que son los que están recibiendo las conexiones web. Los otros servidores no se están tomando en cuenta porque durante las pruebas realizadas no llegaron a consumir mayores recursos.

El consumo de los recursos de hardware y los resultados de los tres primeros servidores se muestran en las siguientes imágenes:

Svr01 - Balanceador Web

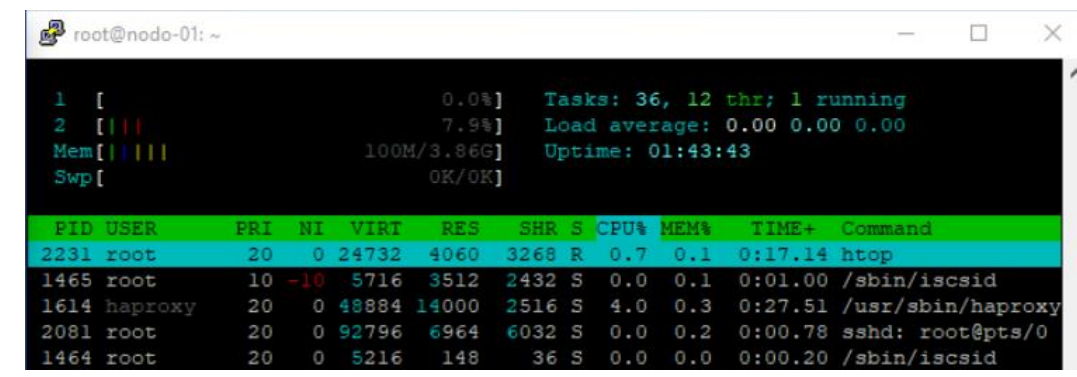

Figura 33. Recursos consumidos en el servidor 01 - Balanceador Web

Elaboración propia

Mediante la aplicación HTOP, podemos observar que los recursos de hardware del servidor balanceador web se mantuvieron bajo debido a que solamente realiza conexiones TCP. Se puede apreciar que el servicio usado es el HAProxy. Se está usando 
aproximadamente $8 \%$ de los dos núcleos que tenemos en el procesador y 100MB de memoria RAM.

Svr02- Servidor Web 01

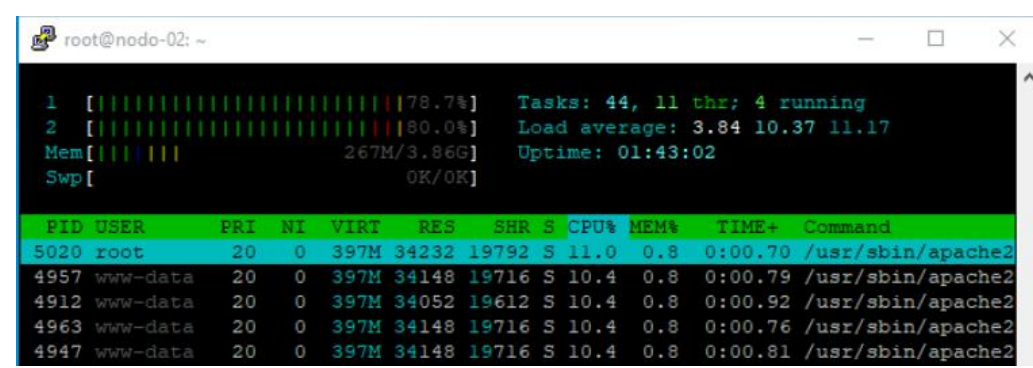

Figura 34. Recursos consumidos en el servidor 02 - Servidor Web 01

Elaboración propia

Mediante la aplicación HTOP, podemos observar que los recursos del servidor se elevaron debido a las conexiones Web que se recibieron. Se puede apreciar que el servicio más usado es Apache que corresponde a la Web. Se está usando aproximadamente $79 \%$ de los dos núcleos que tenemos en el procesador y 267MB de memoria RAM.

\section{Svr03- Servidor Web 02}

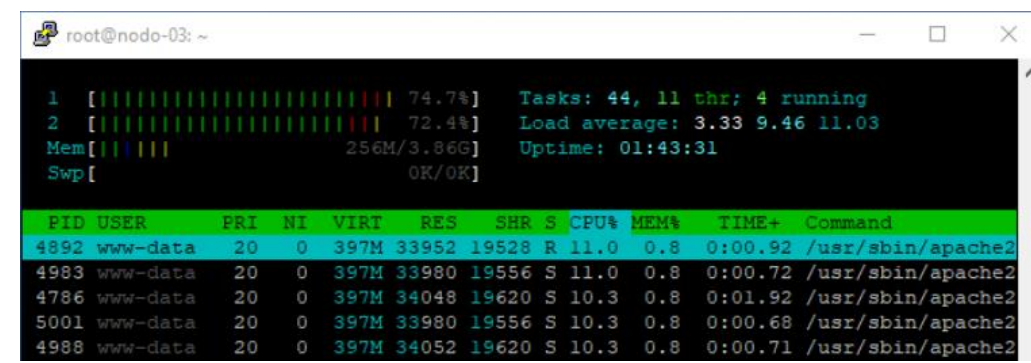

Figura 35. Recursos consumidos en el servidor 03 - Servidor Web 02

Elaboración propia

Mediante la aplicación HTOP, podemos observar que los recursos del servidor se elevaron debido a las conexiones Web que se recibieron. Se puede apreciar que el servicio más usado es Apache que corresponde a la Web. Se está usando aproximadamente $74 \%$ de los dos núcleos que tenemos en el procesador y 256MB de memoria RAM. 
En los tres servidores, se observó que el consumo de hardware estaba dentro de lo normal y se llegaron a establecer todas las conexiones.

\subsubsection{Prueba 02}

Envío de un total de 3000 de conexiones con una velocidad de 150 conexiones por segundo.

Desde el servidor Simulador de Conexiones Web se ejecutará el siguiente comando:

httperf --server 167.172.129.13 --port 80 --num-conns 3000 --rate 150 timeout 1

Se enviará hacia el servidor balanceador web con dirección IP 167.172.129.13 con número de puerto 80 (HTTP) una cantidad total de 3 mil peticiones con una velocidad de 150 conexiones por segundo.

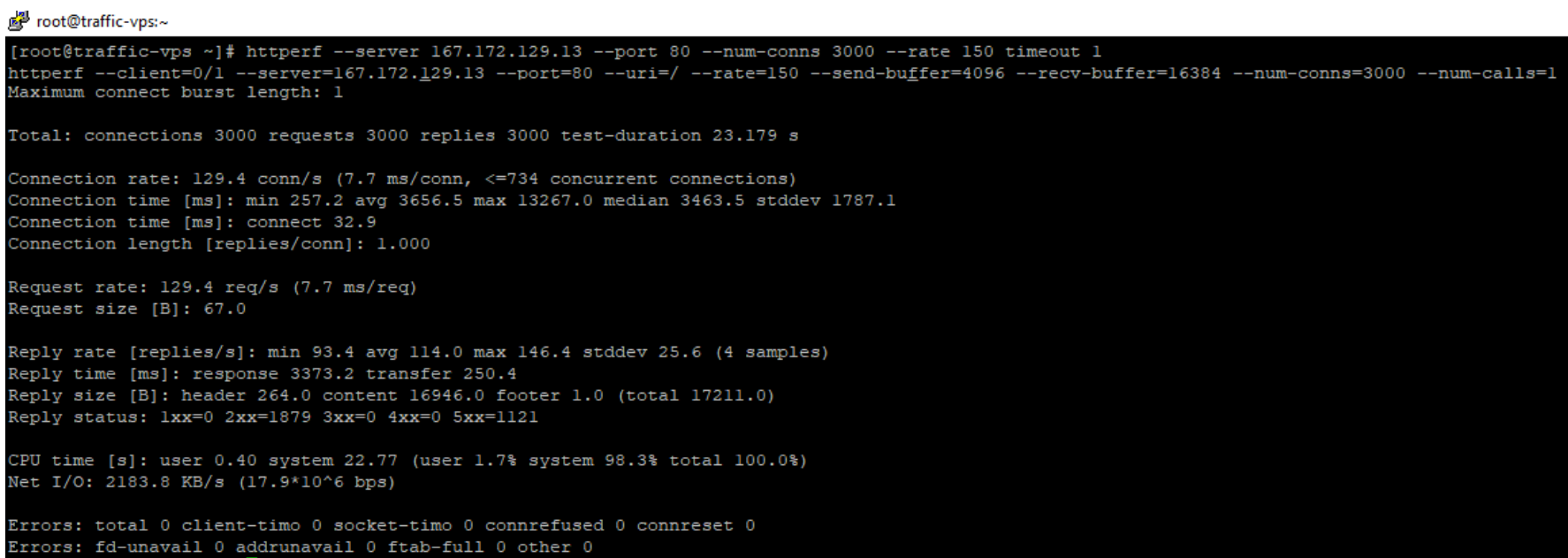

Figura 36. Resultados obtenidos en servidor Simulador de Conexiones hacia la aplicación Web

Elaboración propia

En la figura 36, podemos observar todos los resultados obtenidos en la prueba realizada. A continuación, se explicarán los resultados de los puntos más importantes que hemos obtenido. 
Total: connections 3000 requests 3000 replies 3000 test-duration $23.179 \mathrm{~s}$

Muestra que se iniciaron 3000 conexiones, se realizaron 3000 solicitudes y se recibieron 3000 respuestas.

También muestra que la duración total de la prueba fue de 23.179 segundos, lo que significa que la tasa de solicitud promedio fue casi exactamente 130 solicitudes por segundo.

Connection rate: $129.4 \mathrm{conn} / \mathrm{s}$ ( $7.7 \mathrm{~ms} / \mathrm{conn},<=734$ concurrent connections)

Muestra que las nuevas conexiones se iniciaron a una velocidad de 129 conexiones por segundo. Esta tasa corresponde a un período de 7.7 milisegundos por conexión. Finalmente, el último número muestra que, como máximo, setecientos treinta y cuatro conexiones estaban abiertas al servidor en un momento dado.

Connection time [ms]: $\min 257.2$ avg $3656.5 \max 13267.0$ median 3463.5 stddev 1787.1

Muestra que la vida útil de la conexión mínima (min) fue de 257.2 milisegundos, la vida útil promedio (avg) fue de 3656.5 milisegundos, la vida útil máxima (max) fue de 13267.0 milisegundos, la vida mediana (median) fue de 3463.5 milisegundos, y que la desviación estándar de los tiempos de vida fue de 1787.1 milisegundos.

\section{Reply rate [replies/s]: min 93.4 avg 114.0 max 146.4 stddev 25.6 (4 samples)}

Muestra la tasa de respuesta mínima (min), promedio (avg) y máxima (max) fue aproximadamente de 146 respuestas por segundo. Dados estos números, la desviación estándar es 25.6 milisegundos.

\section{Errors: total 0 client-timo 0 socket-timo 0 connrefused 0 connreset 0 Errors: fd-unavail 0 addrunavail 0 ftab-full 0 other 0}

Los errores totales sumaron cero debido a que todas las conexiones resultaron exitosas.

En esta prueba, se va a considerar únicamente el servidor 01 que es el equipo balanceador web y los servidores 02 y 03 que son los que están recibiendo las conexiones web. Los otros servidores no se están tomando en cuenta porque durante las pruebas realizadas no llegaron a consumir mayores recursos.

El consumo de los recursos de hardware y los resultados de los tres primeros servidores se muestran en las siguientes imágenes: 
Svr01 - Balanceador Web

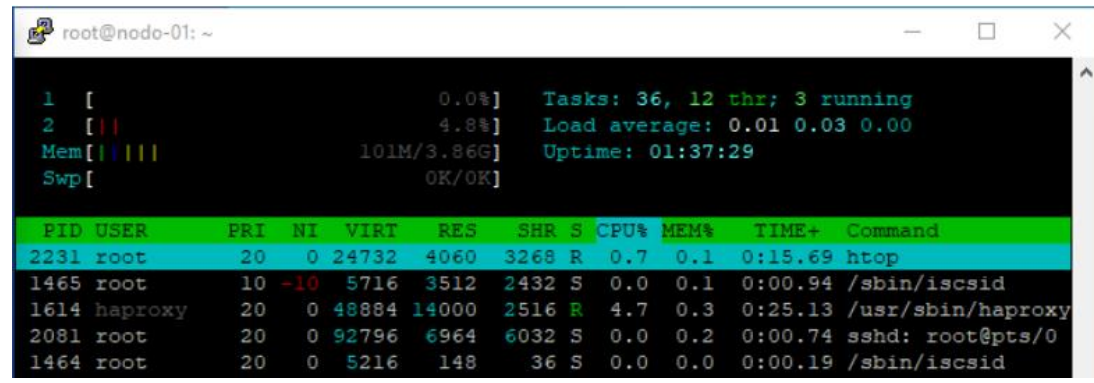

Figura 37. Recursos consumidos en el servidor 01 - Balanceador Web

Elaboración propia

Mediante la aplicación HTOP, podemos observar que los recursos de hardware del servidor balanceador web se mantuvieron bajo debido a que solamente realiza conexiones TCP. Se puede apreciar que el servicio usado es el HAProxy. Se está usando aproximadamente $5 \%$ de los dos núcleos que tenemos en el procesador y $101 \mathrm{MB}$ de memoria RAM.

Svr02- Servidor Web 01

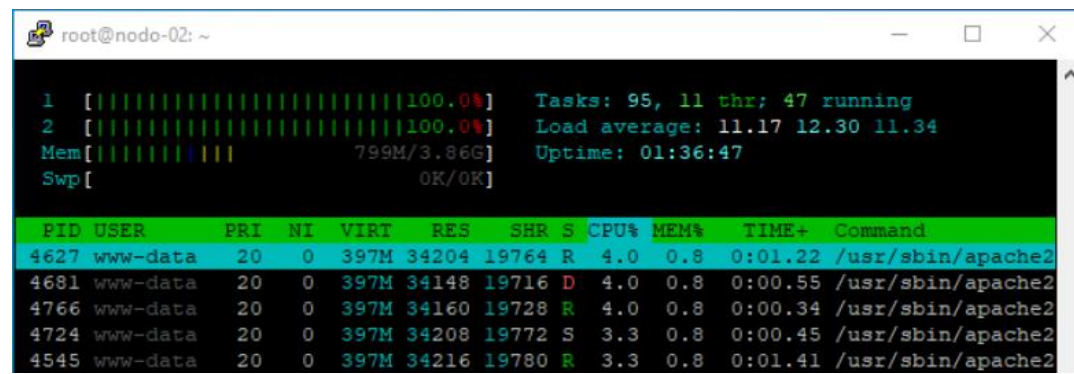

Figura 38. Recursos consumidos en el servidor 02 - Servidor Web 01

Elaboración propia

Mediante la aplicación HTOP, podemos observar que los recursos del servidor se elevaron debido a las conexiones Web que se recibieron. Se puede apreciar que el servicio más usado es Apache que corresponde a la Web. Se está usando el $100 \%$ de los dos núcleos que tenemos en el procesador y 799MB de memoria RAM. 
Svr03- Servidor Web 02

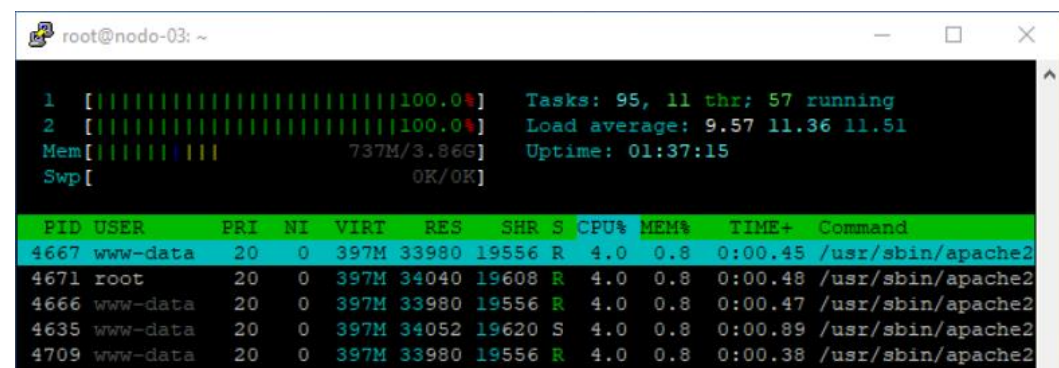

Figura 39. Recursos consumidos en el servidor 03 - Servidor Web 02

Elaboración propia

Mediante la aplicación HTOP, podemos observar que los recursos del servidor se elevaron debido a las conexiones Web que se recibieron. Se puede apreciar que el servicio más usado es Apache que corresponde a la Web. Se está usando el $100 \%$ de los dos núcleos que tenemos en el procesador y 737MB de memoria RAM.

En el servidor 01, el consumo de hardware se mantuvo dentro de lo normal, pero en los servidores 02 y 03 que pertenecen al servicio Web se observó que el consumo de hardware aumento a su máximo. En esta prueba se llegaron a establecer todas las conexiones.

\subsubsection{Prueba 03}

Envío de un total de 3 mil de conexiones con una velocidad de 170 conexiones por segundo.

Desde el servidor Simulador de Conexiones Web se ejecutará el siguiente comando:

httperf --server 167.172.129.13 --port 80 --num-conns 3000 --rate 170 timeout 1

Se enviará hacia el servidor balanceador web con dirección IP 167.172.129.13 con número de puerto 80 (HTTP) una cantidad total de 3000 peticiones con una velocidad de 150 conexiones por segundo. 


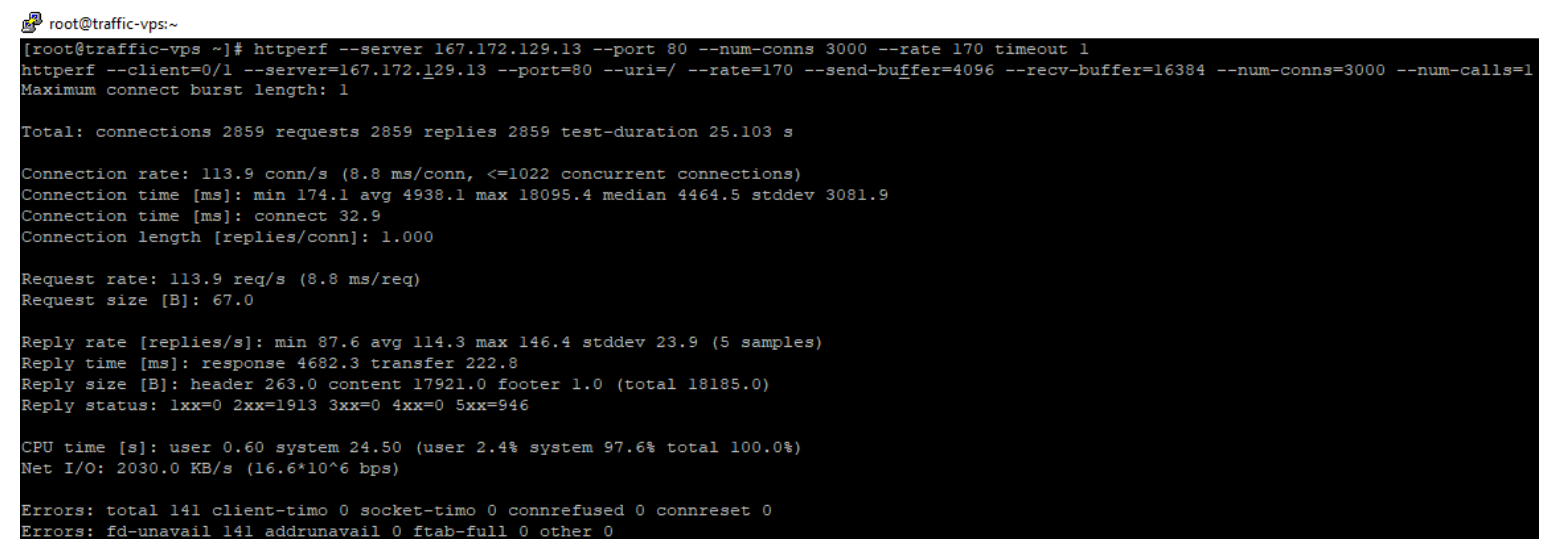

Figura 40. Resultados obtenidos en servidor Simulador de Conexiones hacia la aplicación Web Elaboración propia

En la figura 40, podemos observar todos los resultados obtenidos en la prueba realizada. A continuación, se explicarán los resultados de los puntos más importantes que hemos obtenido.

En el resumen, tomando los parámetros más importantes, podemos observar lo siguiente:

Total: connections 2859 requests 2859 replies 2859 test-duration 25.103 s

Muestra que se iniciaron 2859 conexiones, se realizaron 2859 solicitudes y se recibieron 2859 respuestas de las 3000 que fueron enviadas.

También muestra que la duración total de la prueba fue de 25.103 segundos, lo que significa que la tasa de solicitud promedio fue casi exactamente 114 solicitudes por segundo.

\section{Connection rate: $113.9 \mathrm{conn} / \mathrm{s}(8.8 \mathrm{~ms} / \mathrm{conn},<=1022$ concurrent connections)}

Muestra que las nuevas conexiones se iniciaron a una velocidad de 114 conexiones por segundo. Esta tasa corresponde a un período de 8.8 milisegundos por conexión. Finalmente, el último número muestra que, como máximo, mil veintidós conexiones estaban abiertas al servidor en un momento dado.

Connection time [ms]: min 174.1 avg 4938.1 max 18095.4 median 4464.5 stddev 3081.9

Muestra que la vida útil de la conexión mínima (min) fue de 174.1 milisegundos, la vida útil promedio (avg) fue de 4938.1 milisegundos, la vida útil máxima (max) fue 
de 18095.4 milisegundos, la vida mediana (median) fue de 4464.5 milisegundos, y que la desviación estándar de los tiempos de vida fue de 3081.9 milisegundos.

\section{Reply rate [replies/s]: min 87.6 avg 114.3 max 146.4 stddev 23.9 (5 samples)}

Muestra la tasa de respuesta mínima (min), promedio (avg) y máxima (max) fue aproximadamente de 146 respuestas por segundo. Dados estos números, la desviación estándar es 23.9 milisegundos.

\section{Errors: total 141 client-timo 0 socket-timo 0 connrefused 0 connreset 0 Errors: fd-unavail 141 addrunavail 0 ftab-full 0 other 0}

La suma total de los errores fue de 141 conexiones. El error presentado se da en el fd-unavail el cual indica que el número de veces que el cliente web httperf se quedó sin respuesta debido a que sus recursos de hardware se encuentran sobrecargados.

En esta prueba, se va a considerar únicamente el servidor 01, que es el equipo balanceador web y los servidores 02 y 03 que son los que están recibiendo las conexiones web. Los otros servidores no se están tomando en cuenta porque durante las pruebas realizadas no llegaron a consumir mayores recursos.

El consumo de los recursos de hardware y los resultados de los tres primeros servidores se muestran en las siguientes imágenes:

Svr01- Balanceador Web

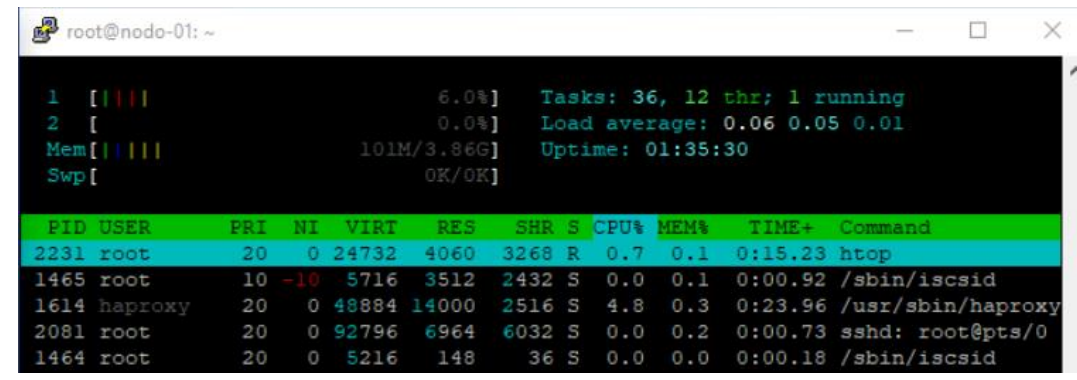

Figura 41. Recursos consumidos en el servidor 01 - Balanceador Web

Elaboración propia

Mediante la aplicación HTOP, podemos observar que los recursos de hardware del servidor balanceador web se mantuvieron bajo debido a que solamente realiza conexiones TCP. Se puede apreciar que el servicio usado es el HAProxy. Se está usando 
aproximadamente $6 \%$ de los dos núcleos que tenemos en el procesador y $101 \mathrm{MB}$ de memoria RAM.

\section{Svr02 - Servidor Web 01}

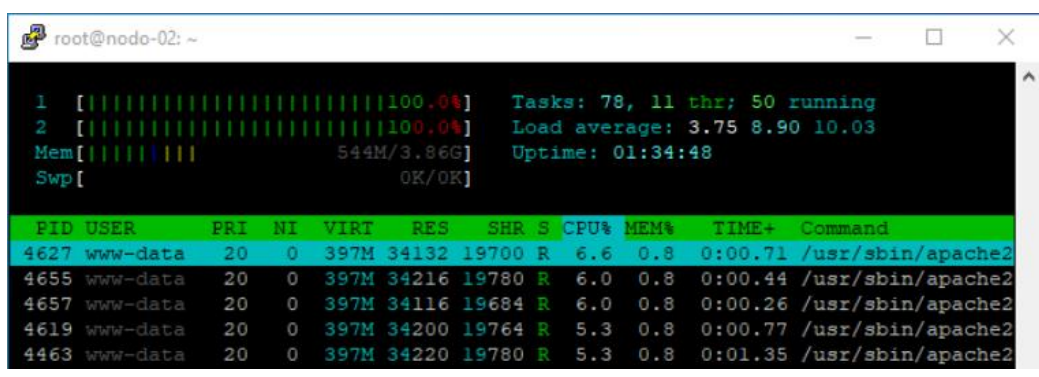

Figura 42. Recursos consumidos en el servidor 02 - Servidor Web 01

Elaboración propia

Mediante la aplicación HTOP, podemos observar que los recursos del servidor se elevaron debido a las conexiones Web que se recibieron. Se puede apreciar que el servicio más usado es Apache que corresponde a la Web. Se está usando el $100 \%$ de los dos núcleos que tenemos en el procesador y 544MB de memoria RAM.

Svr03- Servidor Web 02

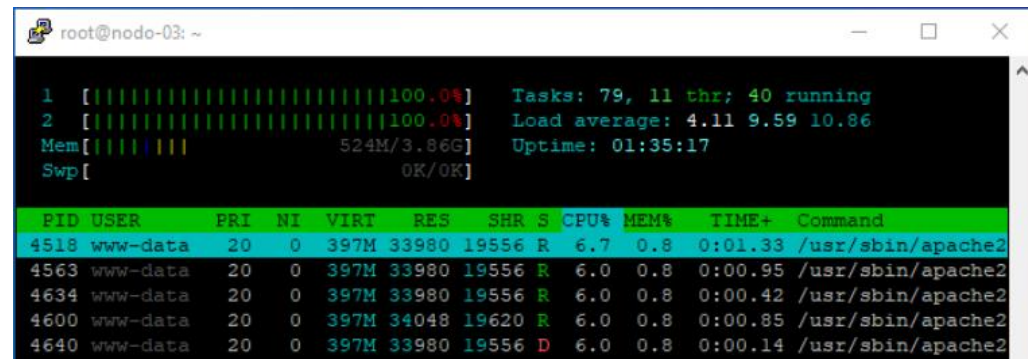

Figura 43. Recursos consumidos en el servidor 03 - Servidor Web 02

Elaboración propia

Mediante la aplicación HTOP, podemos observar que los recursos del servidor se elevaron debido a las conexiones Web que se recibieron. Se puede apreciar que el servicio más usado es Apache que corresponde a la Web. Se está usando el $100 \%$ de los dos núcleos que tenemos en el procesador y 524MB de memoria RAM. 
En el servidor 01, el consumo de hardware se mantuvo dentro de lo normal, pero en los servidores 02 y 03 que pertenecen al servicio Web se observó que el consumo de hardware aumento a su máximo. En esta prueba no se llegaron a establecer todas las conexiones.

En las tres pruebas realizadas hemos obtenido diferentes resultados los cuales se muestran en la siguiente tabla y gráfica:

Tabla 8.

Resumen de los resultados de las pruebas de conexión

\begin{tabular}{|l|r|r|r|r|r|r|r|r|}
\hline $\begin{array}{c}\text { Número } \\
\text { de Prueba }\end{array}$ & $\begin{array}{c}\text { Conexiones } \\
\text { Enviadas }\end{array}$ & $\begin{array}{c}\text { Conexiones } \\
\text { Respondidas }\end{array}$ & $\begin{array}{c}\text { Conexiones No } \\
\text { Respondidas }\end{array}$ & $\begin{array}{c}\text { Tiempo de } \\
\text { respuesta de } \\
\text { la prueba }\end{array}$ & $\begin{array}{c}\text { Conexiones } \\
\text { por segundo } \\
\text { Enviadas }\end{array}$ & $\begin{array}{c}\text { Conexiones } \\
\text { por segundo } \\
\text { Respondidas }\end{array}$ & $\begin{array}{c}\text { Tiempo de } \\
\text { respuesta de } \\
\text { la Web }\end{array}$ & $\begin{array}{c}\text { Máximo de } \\
\text { respuestas } \\
\text { recibidas }\end{array}$ \\
\hline Primera & 3000 & 3000 & 0 & 30 & 100 & 100 & 0.3277 & 100 \\
\hline Segunda & 3000 & 3000 & 0 & 23 & 150 & 130 & 13 & 146 \\
\hline Tercera & 3000 & 2859 & 141 & 25 & 170 & 114 & 18 & 146 \\
\hline
\end{tabular}

Elaboración propia

En la tabla 8, podemos observar todos los resultados que se han obtenido en el desarrollo de esta prueba.

Para tener un mejor panorama de los resultados estaremos mostrando las gráficas de las conexiones que se enviaron en total y también la cantidad de conexiones por segundo, en cada una de ellas se estará mostrando el tiempo que se tomó en la ejecución de la prueba.
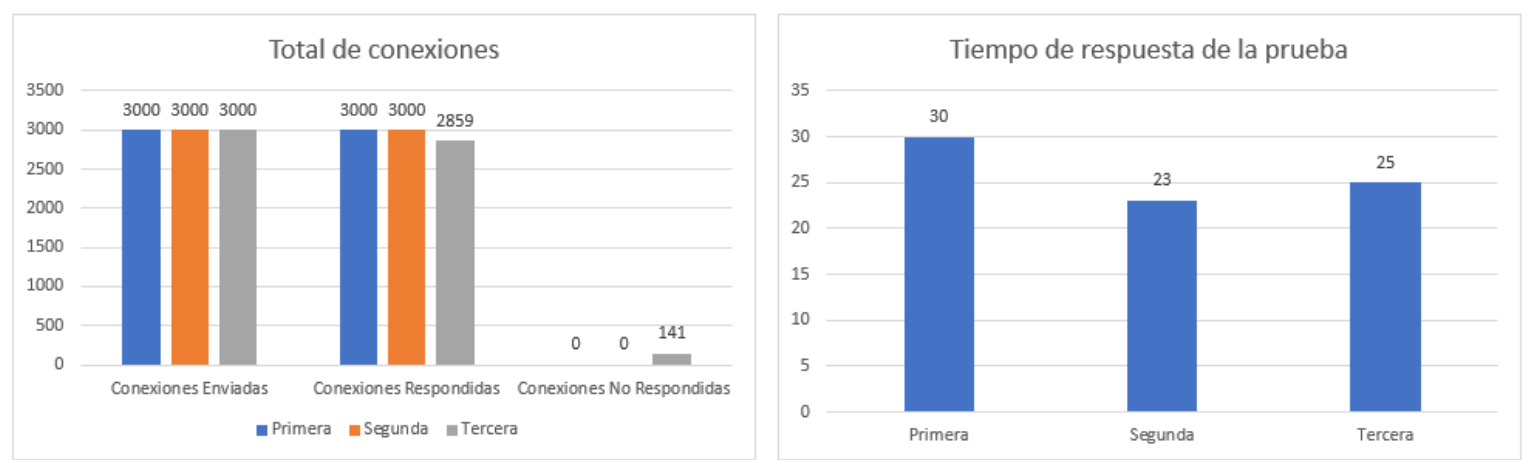

Figura 44. Conexiones enviadas y tiempo de respuesta de las pruebas

Elaboración propia 
En la figura 44, podemos observar lo siguiente:

- En la primera prueba, se enviaron 3 mil conexiones, respondieron todas y el tiempo de ejecución fue de 30 segundos. Todas las conexiones se llegaron a realizar.

- En la segunda prueba, se enviaron 3 mil conexiones, respondieron todas y el tiempo de ejecución fue de 23 segundos. Todas las conexiones se llegaron a realizar.

- En la tercera prueba, se enviaron 3 mil conexiones, respondieron solamente 2859 y el tiempo de ejecución fue de 25 segundos. Se llegaron a perder 141 conexiones debido a la saturación de los equipos.
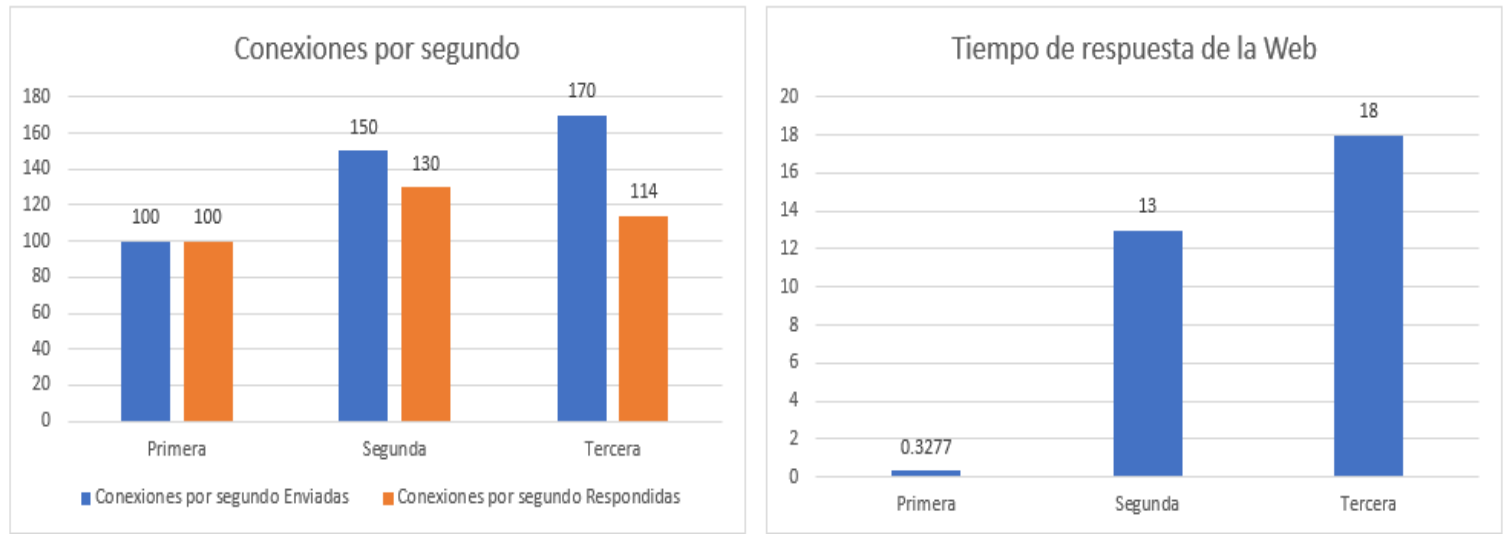

Figura 45. Conexiones por segundo y tiempo de respuesta de la Web

Elaboración propia

En la figura 45, podemos observar lo siguiente:

- En la primera prueba se enviaron 50 conexiones por segundo, respondieron todas y el tiempo de respuesta de la Web fue de 0.12 segundos.

- En la segunda prueba, se enviaron 80 conexiones por segundo, respondieron todas y el tiempo de respuesta de la Web fue de 0.28 segundos.

- En la tercera prueba, se enviaron 100 conexiones por segundo, respondieron solamente 27 y el tiempo de respuesta de la Web fue de 68 segundos.

En resumen, podemos determinar lo siguiente:

- En las tres pruebas realizadas desde el servidor Simulador de Conexiones hacia el servidor Balanceador Web se pudo observar que si llegaron a ejecutar.

- Se observó que, en la primera prueba, los recursos de hardware se elevaron, pero no llegó a consumir su totalidad. 
- Se observó que, en la segunda prueba, los recursos de hardware se elevaron, llegándose a consumir su totalidad.

- En la primera y segunda prueba, se llegaron a ejecutar todas las conexiones sin ningún error.

- Se observó que, en la tercera prueba, los recursos de hardware se elevaron llegándose a consumir en su totalidad.

- En la tercera prueba, no se llegaron a ejecutar todas las conexiones debido a la sobrecarga del servidor.

\subsubsection{Costos de la implementación}

Para las pruebas realizadas en este segundo escenario, las características de hardware que tendrá cada uno de los siete servidores son las siguientes:

- Procesador Intel ${ }^{\circledR}$ Xeon ${ }^{\circledR}$ CPU E5-2697A v4 2.60GHz (2 core)

- Memoria RAM: 4GB DDR3

- Disco Duro: 25GB SSD

El costo de este servidor es de \$40dólares mensuales.

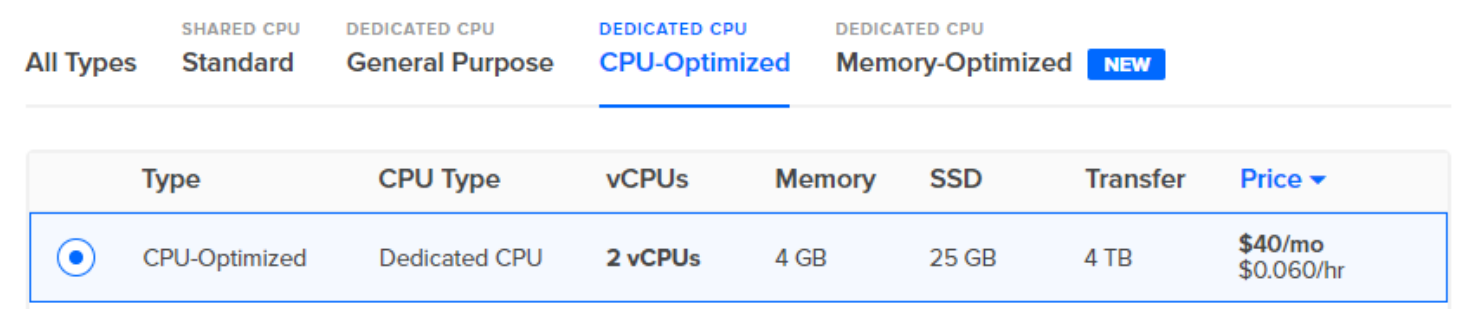

Figura 46. Costo mensual del servidor Web Adaptado de https://cloud.digitalocean.com

En la figura 46, que fue obtenida desde el proveedor DigitalOcean, podemos ver el costo que tendrá cada uno de los servidores que estamos utilizando para la aplicación web. El costo mensual por los siete equipos que usaremos para esta arquitectura se muestra en la siguiente tabla: 
Tabla 9 .

Costo mensual de la Arquitectura con siete servidores

\begin{tabular}{|l|c|}
\hline Descripción de servidores & Costo en dólares \\
\hline Balanceador Web & $\$ 40.00$ \\
\hline Web 01 & $\$ 40.00$ \\
\hline Web 02 & $\$ 40.00$ \\
\hline NFS & $\$ 40.00$ \\
\hline Balanceador BD & $\$ 40.00$ \\
\hline MySQL 01 & $\$ 40.00$ \\
\hline MySQL 02 & $\$ 40.00$ \\
\hline Costo Total: & $\$ 280.00$ \\
\hline
\end{tabular}

Elaboración propia

En la tabla 9, podemos observar que el costo para el escenario basado en una arquitectura tradicional realizando un escalamiento horizontal será de \$280 dólares mensuales.

\subsubsection{Tiempo de escalabilidad de la arquitectura}

En esta arquitectura, en la que se ha realizado un escalamiento horizontal, desde un solo servidor hasta siete servidores se ha tomado un tiempo determinado para la implementación el cual se muestra a continuación:

Tabla 10 .

Tiempo total para la implementación de la Arquitectura con siete servidores

\begin{tabular}{|l|c|c|c|c|c|c|c|}
\hline \multirow{2}{*}{ Proceso realizado } & \multicolumn{5}{c|}{ Tiempo en minutos en cada Servidor } \\
\cline { 2 - 8 } & $\begin{array}{c}\text { Servidor } \\
\mathbf{0 1}\end{array}$ & $\begin{array}{c}\text { Servidor } \\
\mathbf{0 2}\end{array}$ & $\begin{array}{c}\text { Servidor } \\
\mathbf{0 3}\end{array}$ & $\begin{array}{c}\text { Servidor } \\
\mathbf{0 4}\end{array}$ & $\begin{array}{c}\text { Servidor } \\
\mathbf{0 5}\end{array}$ & $\begin{array}{c}\text { Servidor } \\
\mathbf{0 6}\end{array}$ & $\begin{array}{c}\text { Servidor } \\
\mathbf{0 7}\end{array}$ \\
\hline Seleccionar el servidor con sistema operativo Linux Ubuntu 18.04 & $\mathbf{5}$ & $\mathbf{5}$ & $\mathbf{5}$ & $\mathbf{5}$ & $\mathbf{5}$ & $\mathbf{5}$ & 5 \\
\hline Actualización y configuración de seguridad en el sistema operativo & 15 & 15 & 15 & 15 & 15 & 15 & 15 \\
\hline Instalación y configuración Balanceador Web HAProxy & 10 & 0 & 0 & 0 & 0 & 0 & 0 \\
\hline Instalación y configuración de servicios Web (Apache) & 0 & 10 & 10 & 0 & 0 & 0 & 0 \\
\hline Instalación y configuración de servicio NFS & 0 & 0 & 0 & 10 & 0 & 0 & 0 \\
\hline Instalación y configuración Balanceador Base Datos & 0 & 0 & 0 & 0 & 10 & 0 & 0 \\
\hline Instalación y configuración de servicios de Base de Datos (MySQL) & 0 & 0 & 0 & 0 & 0 & 10 & 10 \\
\hline Pruebas de acceso & 5 & 5 & $\mathbf{5}$ & $\mathbf{5}$ & $\mathbf{5}$ & $\mathbf{5}$ & 5 \\
\hline Tiempo total por servidor & 35 & 35 & 35 & 35 & 35 & 35 & 35 \\
\hline Tiempo total: 245 minutos & & & & & \\
\hline
\end{tabular}

Elaboración propia

En la tabla 10, se puede observar que para cada servidor se ha tomado un tiempo de 35 minutos en instalación, configuración y pruebas de acceso. El tiempo total que se ha 
tomado para esta implementación realizando el escalamiento horizontal fue de 245 minutos que equivalen a cuatro horas con cinco minutos (4.05 horas).

\subsection{Arquitectura tradicional con escalamiento vertical}

Para este escenario, nos basaremos de la arquitectura tradicional seleccionada en el escenario realizando en el punto 3.2 (Arquitectura Tradicional con Escalamiento Horizontal) y se estará realizando un escalamiento vertical. En este tipo de escalamiento, se estará aumentando los recursos de hardware del procesador y memoria RAM en los siete servidores que se están usando.

A continuación, mostramos la estructura y elementos que lo componen y cómo van a estar conectados entre sí:

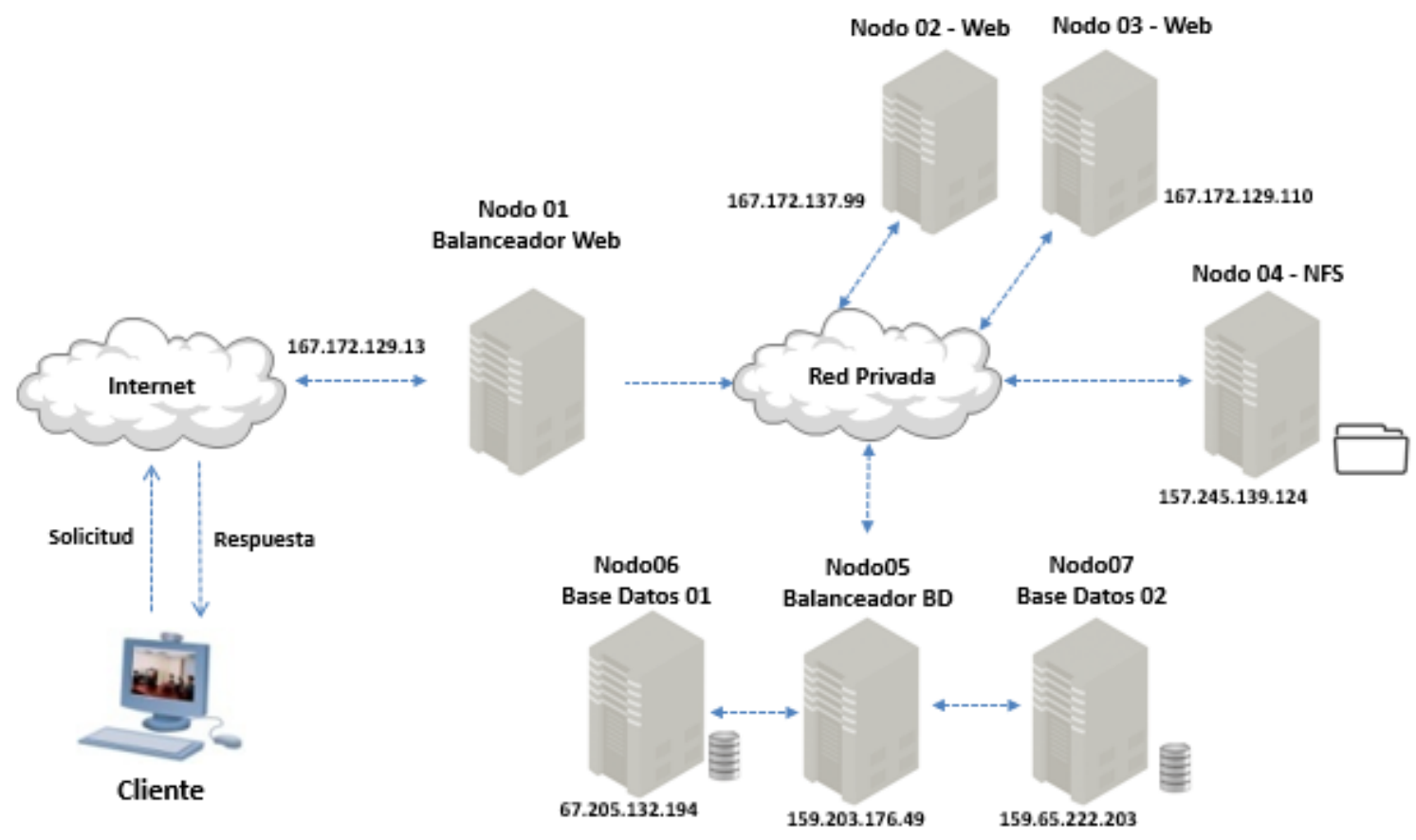

Figura 47. Arquitectura Escalable basada en Servidores - Escalamiento Vertical

Elaboración propia

En este escenario, el cliente envía una petición (conexión) hacia el servidor 01, el cual es un balanceador web y se encargará de distribuir las conexiones hacia los servidores 02 y 03 quienes tienen el servicio Web. Al recibir la petición con la información correcta, estará 
enviando una respuesta y, en consecuencia, mostrando la información de la Web. Las características del hardware las podemos ver en el siguiente cuadro:

Tabla 11.

Características de hardware de servidores

\begin{tabular}{|c|c|c|c|}
\hline Servidor & Nombre Servidor & IP WAN & Recursos de Harware (CPU / RAM / HDD) \\
\hline Balanceador Web & srv01 & 167.172 .129 .13 & Intel Xeon CPU E5-2697A v4 2.60GHz (4core) / 8GB / 25GB Disk \\
\hline Web01 & srv02 & 167.172 .137 .99 & Intel Xeon CPU E5-2697A v4 2.60GHz (4core) / 8GB / 25GB Disk \\
\hline Web02 & srv03 & 167.172 .129 .110 & Intel Xeon CPU E5-2697A v4 2.60GHz (4core) / 8GB / 25GB Disk \\
\hline NFS & srv04 & 157.245 .139 .124 & Intel Xeon CPU E5-2697A v4 2.60GHz (4core) / 8GB / 25GB Disk \\
\hline Balanceador BD & srv05 & 159.203 .176 .49 & Intel Xeon CPU E5-2697A v4 2.60GHz (4core) / 8GB / 25GB Disk \\
\hline MySQL 01 & srv06 & 67.205 .132 .194 & Intel Xeon CPU E5-2697A v4 2.60GHz (4core) / 8GB / 25GB Disk \\
\hline MySQL 02 & svr07 & 159.65 .222 .203 & Intel Xeon CPU E5-2697A v4 2.60GHz (4core) / 8GB / 25GB Disk \\
\hline
\end{tabular}

Elaboración propia

Como podemos observar en la tabla 11, cada uno de los servidores cumplen funciones diferentes y muy específicas. Las funciones de cada uno de los elementos son los mismos que fueron descritos en el punto 3.2.

\subsubsection{Cantidad de conexiones web concurrentes}

Para medir el rendimiento de la aplicación Web, utilizaremos la herramienta httperf ejecutándola desde un servidor externo el cual simulará en tiempo real las conexiones por segundo que soportará el servidor web.

\subsubsection{Prueba 01}

Envío de un total de 3000 de conexiones con una velocidad de 170 conexiones por segundo.

Desde el servidor Simulador de Conexiones Web se ejecutará el siguiente comando: httperf --server 167.172.129.13 --port 80 --num-conns 3000 --rate 170 timeout 1 
Se enviará hacia el servidor web con dirección IP 167.172.129.13 con número de puerto 80 (HTTP) una cantidad total de 3000 peticiones con una velocidad de 170 conexiones por segundo.

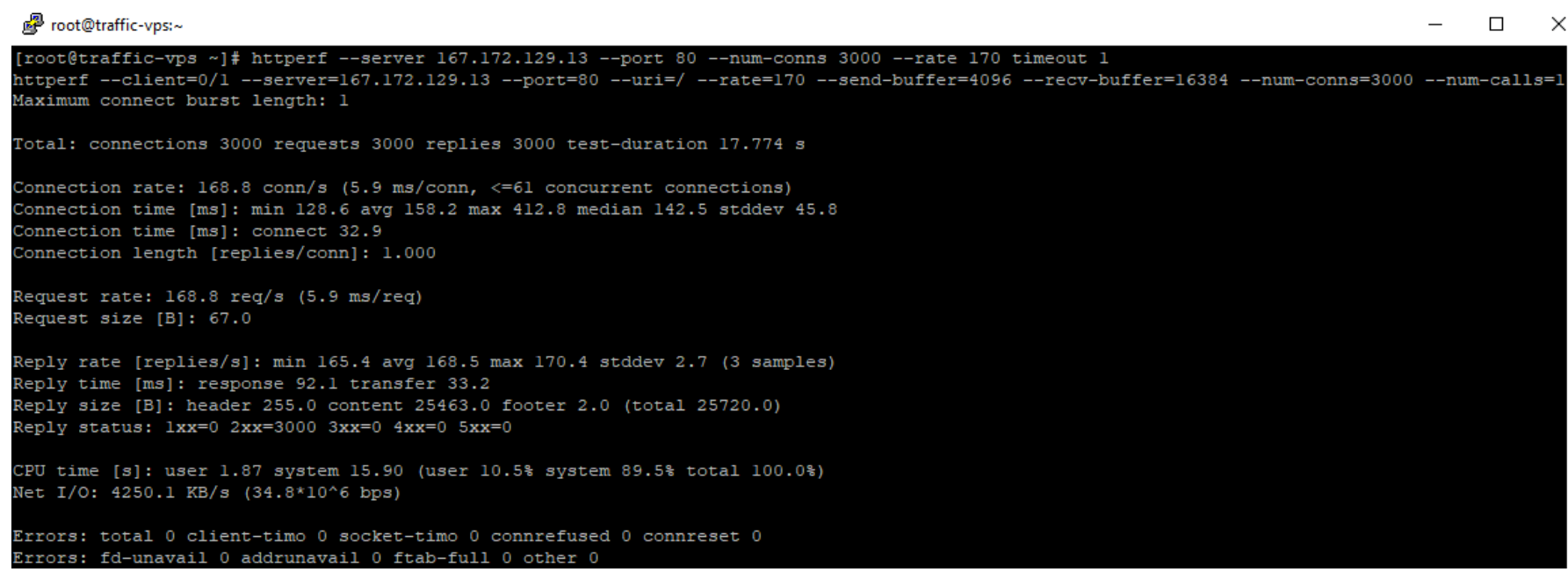

Figura 48. Resultados obtenidos en servidor Simulador de Conexiones hacia la aplicación Web

Elaboración propia

En la figura 48, podemos observar todos los resultados obtenidos en la prueba realizada. A continuación, se explicarán los resultados de los puntos más importantes que hemos obtenido.

Total: connections 3000 requests 3000 replies 3000 test-duration $17.774 \mathrm{~s}$

Muestra que se iniciaron 3000 conexiones, se realizaron 3000 solicitudes y se recibieron 3000 respuestas.

También muestra que la duración total de la prueba fue de 17.774 segundos, lo que significa que la tasa de solicitud promedio fue casi exactamente 169 solicitudes por segundo.

\section{Connection rate: $168.8 \mathrm{conn} / \mathrm{s}(5.9 \mathrm{~ms} / \mathrm{conn},<=61$ concurrent connections)}

Se enviaron 169 conexiones por segundo.

\section{Connection rate: 99.6 conn/s (10.0 ms/conn, $<=27$ concurrent connections)}

Muestra que las nuevas conexiones se iniciaron a una velocidad de 169 conexiones por segundo. Esta tasa corresponde a un período de 5.9 milisegundos por conexión. Finalmente, el último número muestra que, como máximo, sesenta y uno conexiones estaban abiertas al servidor en un momento dado.

Connection time [ms]: $\min 128.6$ avg 158.2 max 412.8 median 142.5 stddev 45.8 
Muestra que la vida útil de la conexión mínima (min) fue de 128.6 milisegundos, la vida útil promedio (avg) fue de 158.2 milisegundos, la vida útil máxima (max) fue de 412.8 milisegundos, la vida mediana (median) fue de 142.5 milisegundos, y que la desviación estándar de los tiempos de vida fue de 45.8 milisegundos.

\section{Reply rate [replies/s]: min 165.4 avg 168.5 max 170.4 stddev 2.7 (3 samples)}

Muestra la tasa de respuesta mínima (min), promedio (avg) y máxima (max) fue aproximadamente de 170 respuestas por segundo. Dados estos números, la desviación estándar es 2.7 milisegundos.

\section{Errors: total 0 client-timo 0 socket-timo 0 connrefused 0 connreset 0 Errors: fd-unavail 0 addrunavail 0 ftab-full 0 other 0}

Los errores totales sumaron cero debido a que todas las conexiones resultaron exitosas.

En esta prueba se va a considerar únicamente el servidor 01, que es el equipo balanceador web y los servidores 02 y 03 que son los que están recibiendo las conexiones web. Los otros servidores no se están tomando en cuenta porque durante las pruebas realizadas no llegaron a consumir mayores recursos.

El consumo de los recursos de hardware y los resultados de los tres primeros servidores se muestran en las siguientes imágenes:

Svr01 - Balanceador Web

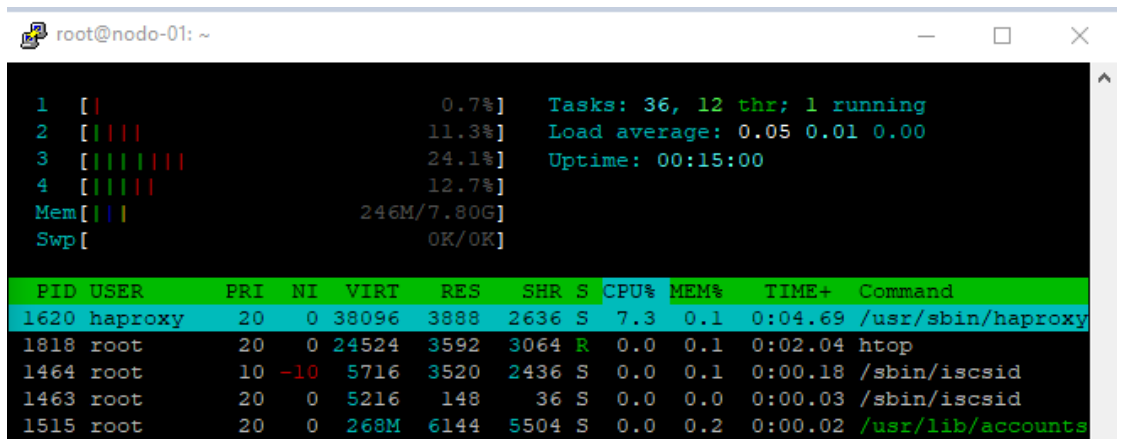

Figura 49. Recursos consumidos en el servidor 01 - Balanceador Web

Elaboración propia 
Mediante la aplicación HTOP podemos observar que los recursos de hardware del servidor balanceador web se mantuvieron bajo debido a que solamente realiza conexiones TCP. Se puede apreciar que el servicio usado es el HAProxy. Se está usando aproximadamente 47 $\%$ de los cuatro núcleos que tenemos en el procesador y 246MB de memoria RAM.

Svr02 - Servidor Web 01

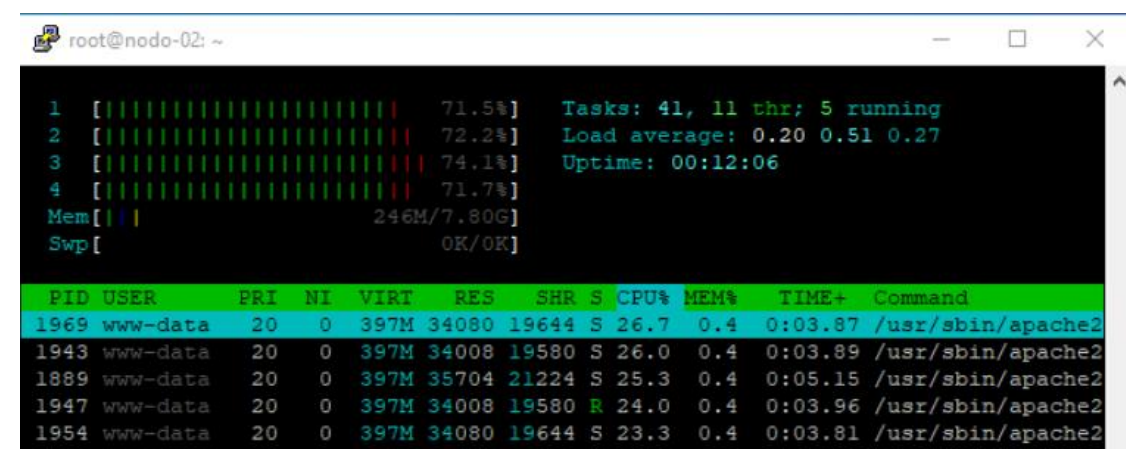

Figura 50. Recursos consumidos en el servidor 02 - Servidor Web 01

Elaboración propia

Mediante la aplicación HTOP, podemos observar que los recursos del servidor se elevaron debido a las conexiones Web que se recibieron. Se puede apreciar que el servicio más usado es Apache que corresponde a la Web. Se está usando aproximadamente $72 \%$ de los cuatro núcleos que tenemos en el procesador y $246 \mathrm{MB}$ de memoria RAM.

Svr03 - Servidor Web 02

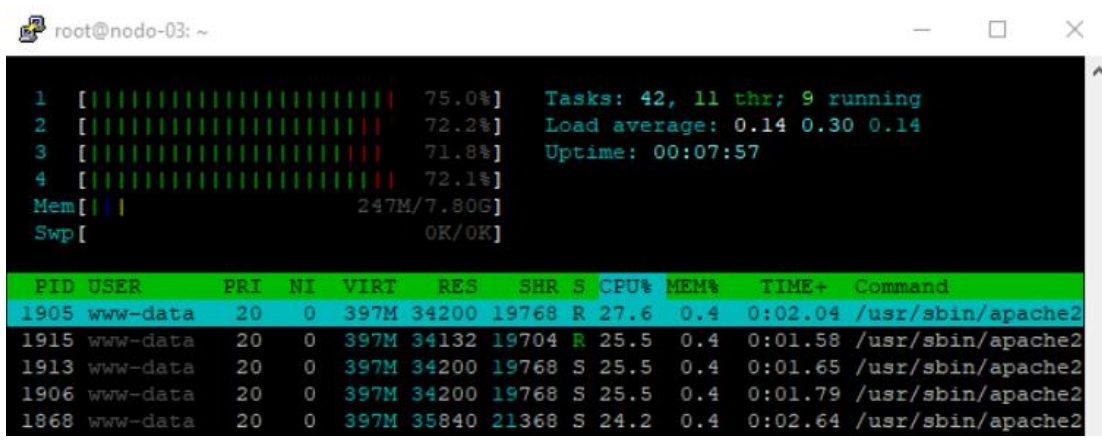

Figura 51. Recursos consumidos en el servidor 03 - Servidor Web 02

Elaboración propia 
Mediante la aplicación HTOP, podemos observar que los recursos del servidor se elevaron debido a las conexiones Web que se recibieron. Se puede apreciar que el servicio más usado es Apache que corresponde a la Web. Se está usando aproximadamente $73 \%$ de los cuatro núcleos que tenemos en el procesador y $247 \mathrm{MB}$ de memoria RAM.

En los tres servidores, se observó que el consumo de hardware estaba dentro de lo normal y se llegaron a establecer todas las conexiones.

\subsubsection{Prueba 02}

Envío de un total de 300 de conexiones con una velocidad de 300 conexiones por segundo.

Desde el servidor Simulador de Conexiones Web se ejecutará el siguiente comando:

$$
\text { httperf --server 167.172.129.13 --port } 80 \text {--num-conns } 3000 \text {--rate } 300 \text { timeout } 1
$$

Se enviará hacia el servidor web con dirección IP 167.172.129.13 con número de puerto 80 (HTTP) una cantidad total de 3000 peticiones con una velocidad de 300 conexiones por segundo.

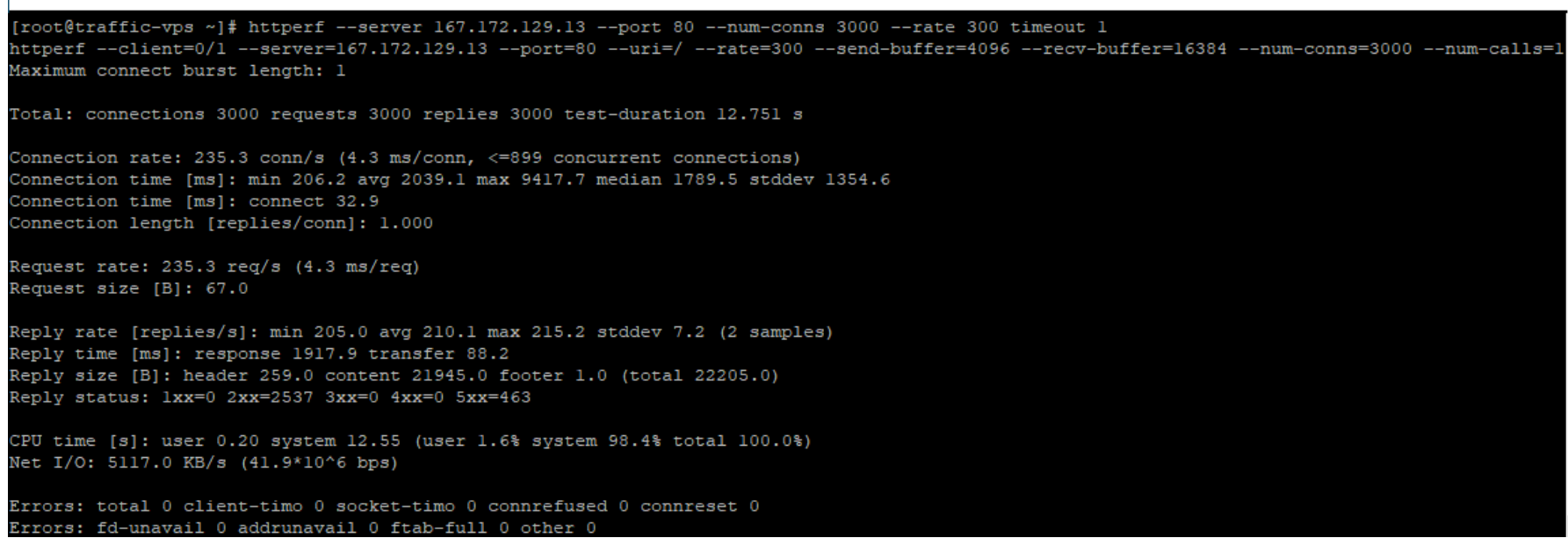

Figura 52. Resultados obtenidos en servidor Simulador de Conexiones hacia la aplicación Web Elaboración propia 
En la figura 52, podemos observar todos los resultados obtenidos en la prueba realizada. A continuación, se explicarán los resultados de los puntos más importantes que hemos obtenido.

Total: connections 3000 requests 3000 replies 3000 test-duration $12.751 \mathrm{~s}$

Muestra que se iniciaron 3000 conexiones, se realizaron 3000 solicitudes y se recibieron 3000 respuestas.

También muestra que la duración total de la prueba fue de 12.751 segundos, lo que significa que la tasa de solicitud promedio fue casi exactamente 235 solicitudes por segundo

Connection rate: $235.3 \mathrm{conn} / \mathrm{s}(4.3 \mathrm{~ms} / \mathrm{conn},<=899$ concurrent connections)

Muestra que las nuevas conexiones se iniciaron a una velocidad de 235 conexiones por segundo. Esta tasa corresponde a un período de 4.3 milisegundos por conexión. Finalmente, el último número muestra que, como máximo, ochocientos noventa y nueve conexiones estaban abiertas al servidor en un momento dado.

Connection time [ms]: $\min 206.2$ avg 2039.1 max 9417.7 median 1789.5 stddev 1354.6

Muestra que la vida útil de la conexión mínima (min) fue de 206.2 milisegundos, la vida útil promedio (avg) fue de 2039.1 milisegundos, la vida útil máxima (max) fue de 9417.7 milisegundos, la vida mediana (median) fue de 1789.5 milisegundos, y que la desviación estándar de los tiempos de vida fue de 1354.6 milisegundos.

\section{Reply rate [replies/s]: min 205.0 avg 210.1 max 215.2 stddev 7.2 (2 samples)}

Muestra la tasa de respuesta mínima (min), promedio (avg) y máxima (max) fue aproximadamente de 215 respuestas por segundo. Dados estos números, la desviación estándar es 7.2 milisegundos.

\section{Errors: total 0 client-timo 0 socket-timo 0 connrefused 0 connreset 0}

\section{Errors: fd-unavail 0 addrunavail 0 ftab-full 0 other 0}

Los errores totales sumaron cero debido a que todas las conexiones resultaron exitosas.

En esta prueba, se va a considerar únicamente el servidor 01 que es el equipo balanceador Web y los servidores 02 y 03 que son los que están recibiendo las conexiones web. Los 
otros servidores no se están tomando en cuenta porque durante las pruebas realizadas no llegaron a consumir mayores recursos.

El consumo de los recursos de hardware y los resultados de los tres primeros servidores se muestran en las siguientes imágenes:

Svr01 - Balanceador Web

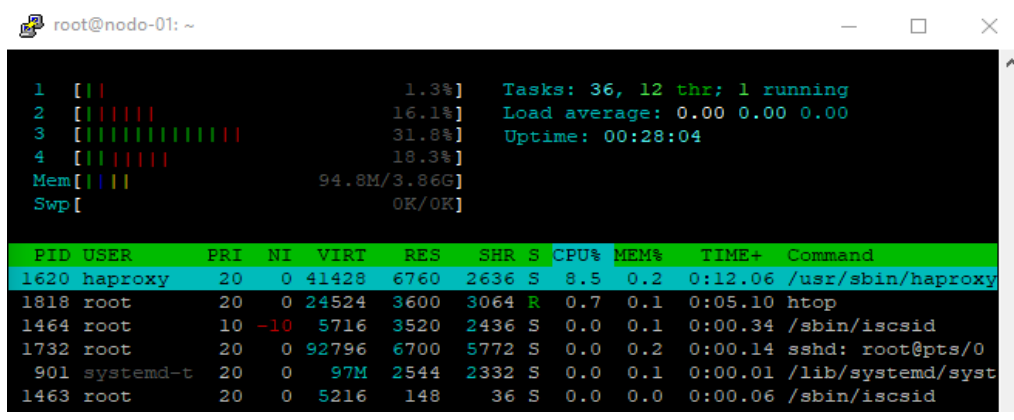

Figura 53. Recursos consumidos en el servidor 01 - Balanceador Web

Elaboración propia

Mediante la aplicación HTOP, podemos observar que los recursos de hardware del servidor balanceador web se mantuvieron bajo debido a que solamente realiza conexiones TCP. Se puede apreciar que el servicio usado es el HAProxy. Se está usando aproximadamente $17 \%$ de los cuatro núcleos que tenemos en el procesador y 94.8MB de memoria RAM.

Svr02- Servidor Web 01

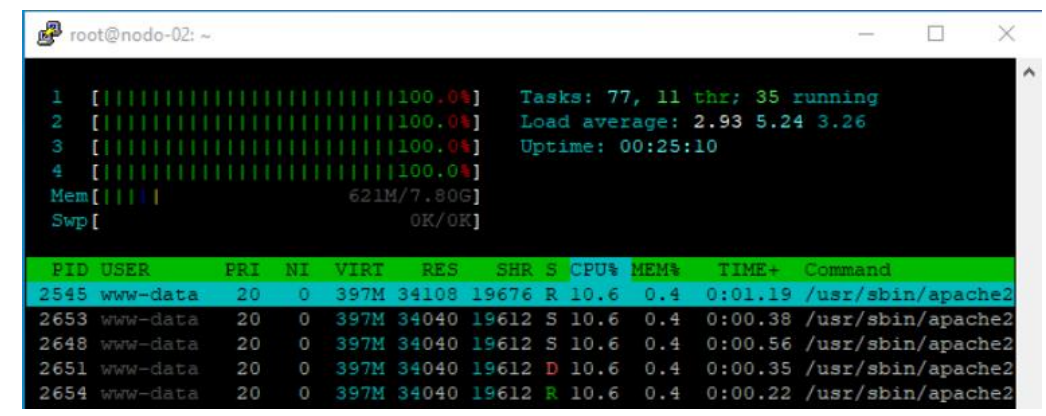

Figura 54. Recursos consumidos en el servidor 02 - Servidor Web 01

Elaboración propia 
Mediante la aplicación HTOP, podemos observar que los recursos del servidor se elevaron debido a las conexiones Web que se recibieron. Se puede apreciar que el servicio más usado es Apache que corresponde a la Web. Se está usando el $100 \%$ de los cuatro núcleos que tenemos en el procesador y $621 \mathrm{MB}$ de memoria RAM.

Svr03- Servidor Web 02

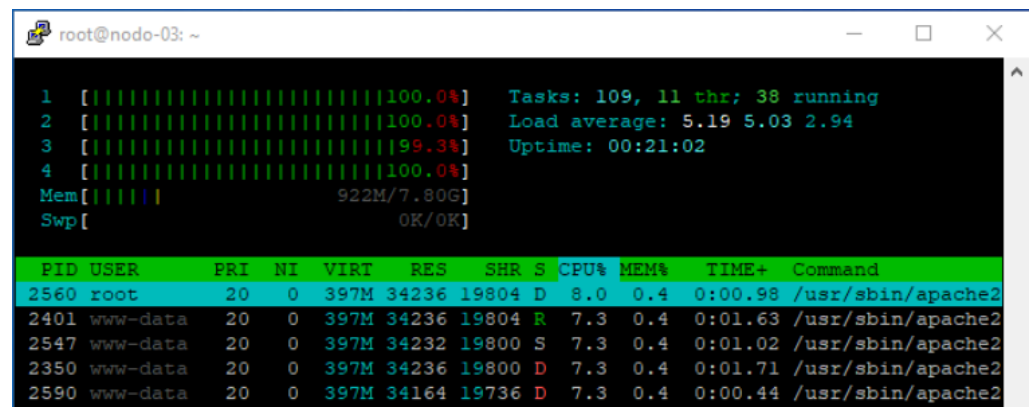

Figura 55. Recursos consumidos en el servidor 03 - Servidor Web 02

Elaboración propia

Mediante la aplicación HTOP, podemos observar que los recursos del servidor se elevaron debido a las conexiones Web que se recibieron. Se puede apreciar que el servicio más usado es Apache que corresponde a la Web. Se está usando el $100 \%$ de los cuatro núcleos que tenemos en el procesador y 922MB de memoria RAM.

En el servidor 01 el consumo de hardware se mantuvo dentro de lo normal, pero en los servdiores 02 y 03 que pertenecen al servicio Web se observó que el consumo de hardware aumento a su máximo. En esta prueba, se llegaron a establecer todas las conexiones.

\subsubsection{Prueba 03}

Envío de un total de 300 de conexiones con una velocidad de 320 conexiones por segundo. Desde el servidor Simulador de Conexiones Web se ejecutará el siguiente comando:

httperf --server 167.172.129.13 --port 80 --num-conns 3000 --rate 320 timeout 1 
Se enviará hacia el servidor web con dirección IP 167.172.129.13 con número de puerto 80 (HTTP) una cantidad total de 3 mil peticiones con una velocidad de 320 conexiones por segundo.

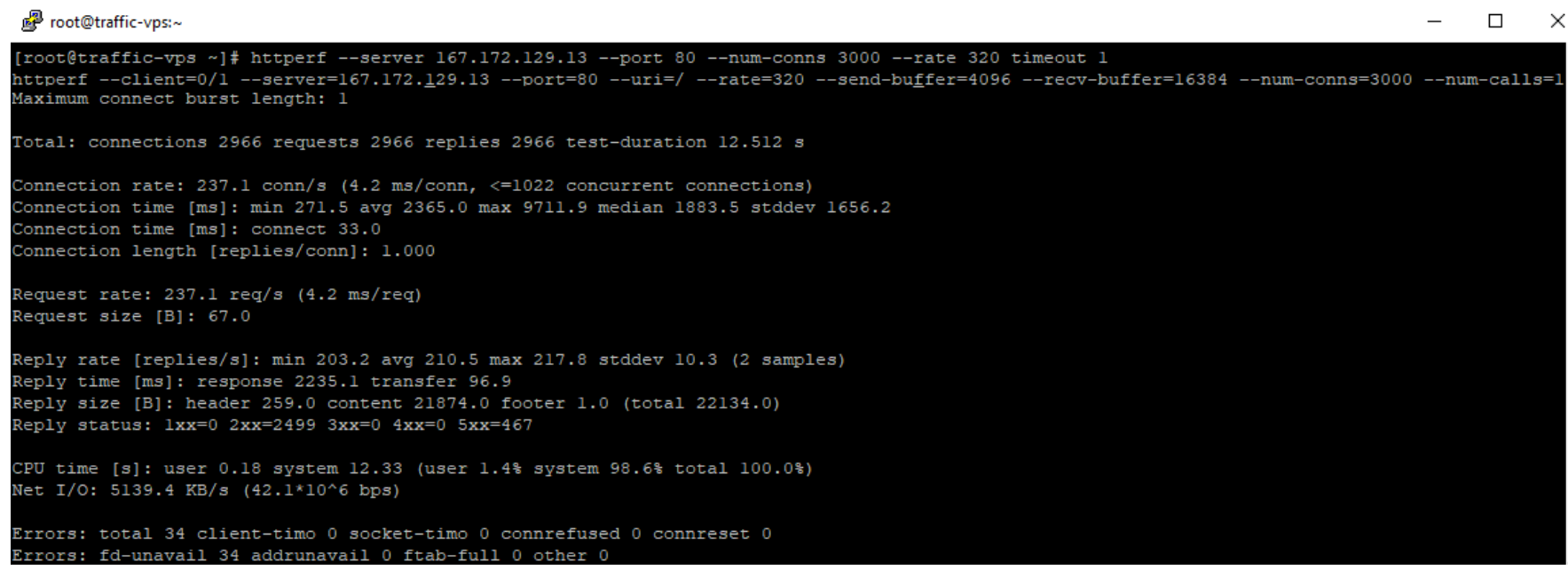

Figura 56. Resultados obtenidos en servidor Simulador de Conexiones hacia la aplicación Web

Elaboración propia

En la figura 56, podemos observar todos los resultados obtenidos en la prueba realizada. A continuación, se explicarán los resultados de los puntos más importantes que hemos obtenido.

En el resumen, tomando los parámetros más importantes podemos observar lo siguiente:

Total: connections 2966 requests 2966 replies 2966 test-duration 12.512 s

Muestra que se iniciaron 2966 conexiones, se realizaron 2966 solicitudes y se recibieron 2966 respuestas.

También muestra que la duración total de la prueba fue de 12.512 segundos, lo que significa que la tasa de solicitud promedio fue casi exactamente 235 solicitudes por segundo

Connection rate: 237.1 conn/s (4.2 ms/conn, $<=1022$ concurrent connections)

Muestra que las nuevas conexiones se iniciaron a una velocidad de 237 conexiones por segundo. Esta tasa corresponde a un período de 4.2 milisegundos por conexión. Finalmente, el último número muestra que, como máximo, ochocientos noventa y nueve conexiones estaban abiertas al servidor en un momento dado.

Connection time [ms]: $\min 271.5$ avg 2365.0 max 9711.9 median 1883.5 stddev 1656.2 
Muestra que la vida útil de la conexión mínima (min) fue de 271.5 milisegundos, la vida útil promedio (avg) fue de 2365.0 milisegundos, la vida útil máxima (max) fue de 9711.9 milisegundos, la vida mediana (median) fue de 1883.5 milisegundos, y que la desviación estándar de los tiempos de vida fue de 1656.2 milisegundos.

\section{Reply rate [replies/s]: min 203.2 avg 210.5 max 217.8 stddev 10.3 (2 samples)}

Muestra la tasa de respuesta mínima (min), promedio (avg) y máxima (max) fue aproximadamente de 218 respuestas por segundo. Dados estos números, la desviación estándar es 10.3 milisegundos.

\section{Errors: total 34 client-timo 0 socket-timo 0 connrefused 0 connreset 129 Errors: fd-unavail 34 addrunavail 0 ftab-full 0 other 0}

La suma total de los errores fue de 34 conexiones. El error presentado se da en el fd-unavail el cual indica que el número de veces que el cliente web httperf se quedó sin respuesta debido a que sus recursos de hardware se encuentran sobrecargado.

En esta prueba se va a considerar únicamente el servidor 01 que es el equipo balanceador web y los servidores 02 y 03 que son los que están recibiendo las conexiones web. Los otros servidores no se están tomando en cuenta porque durante las pruebas realizadas no llegaron a consumir mayores recursos.

El consumo de los recursos de hardware y los resultados de los tres primeros servidores se muestran en las siguientes imágenes:

Svr01 - Balanceador Web

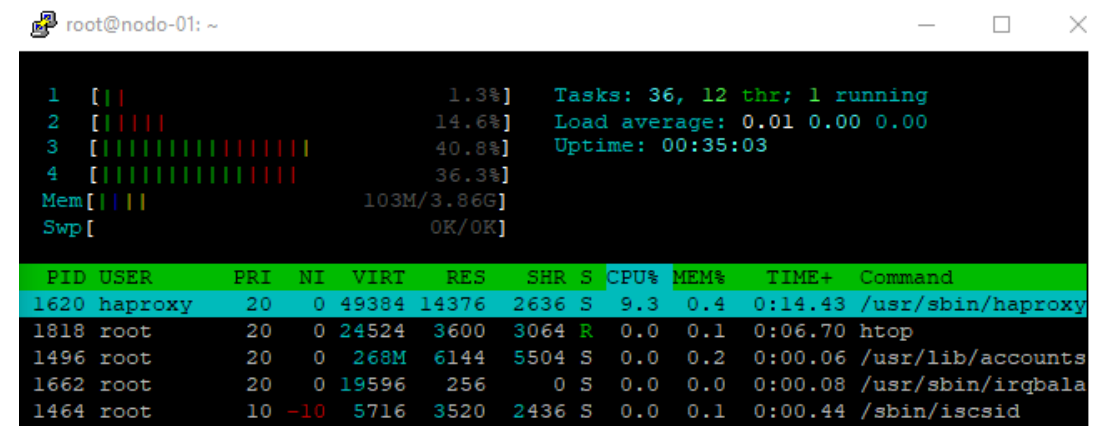

Figura 57. Recursos consumidos en el servidor 01 - Balanceador Web

Elaboración propia

Mediante la aplicación HTOP, podemos observar que los recursos de hardware del servidor balanceador web se mantuvieron bajo debido a que solamente realiza conexiones 
TCP. Se puede apreciar que el servicio usado es el HAProxy. Se está usando aproximadamente $23 \%$ de los cuatro núcleos que tenemos en el procesador y $103 \mathrm{MB}$ de memoria RAM.

Svr02- Servidor Web 01

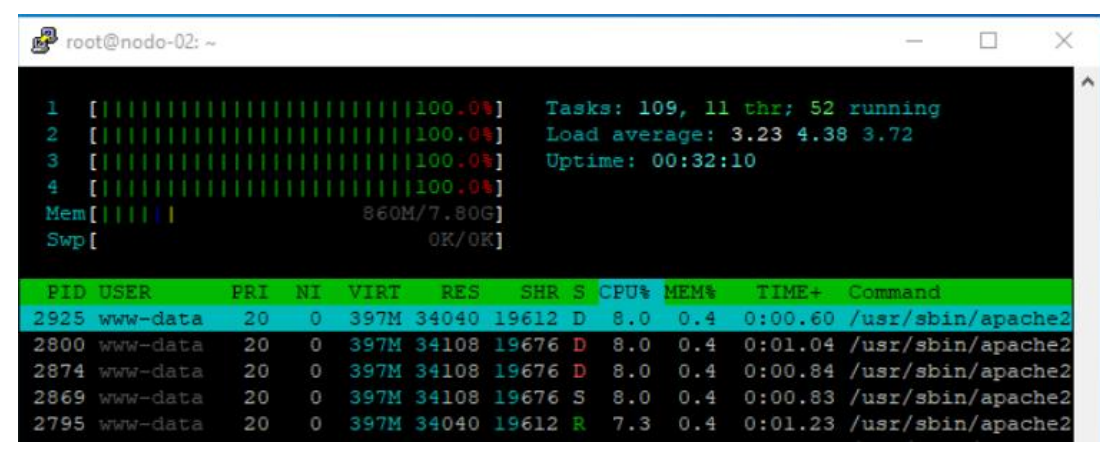

Figura 58. Recursos consumidos en el servidor 02 - Servidor Web 01

Elaboración propia

Mediante la aplicación HTOP podemos observar que los recursos del servidor se elevaron debido a las conexiones Web que se recibieron. Se puede apreciar que el servicio más usado es Apache que corresponde a la Web. Se está usando el $100 \%$ de los cuatro núcleos que tenemos en el procesador y $860 \mathrm{MB}$ de memoria RAM.

Svr03- Servidor Web 02

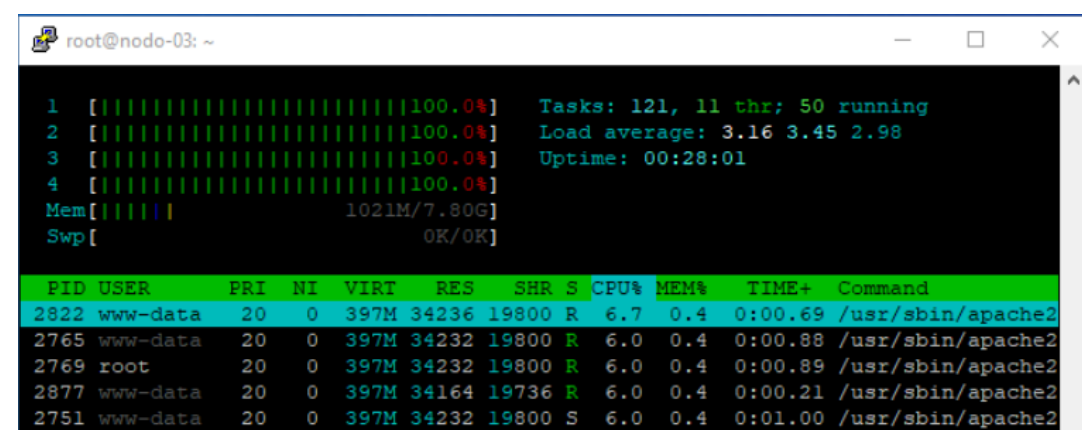

Figura 59. Recursos consumidos en el servidor 03 - Servidor Web 02

Elaboración propia

Mediante la aplicación HTOP, podemos observar que los recursos del servidor se elevaron debido a las conexiones Web que se recibieron. Se puede apreciar que el servicio más 
usado es Apache que corresponde a la Web. Se está usando el $100 \%$ de los cuatro núcleos que tenemos en el procesador y 1021MB de memoria RAM.

En el servidor 01, el consumo de hardware se mantuvo dentro de lo normal, pero en los servidores 02 y 03 que pertenecen al servicio Web se observó que el consumo de hardware aumento a su máximo. En esta prueba no se llegaron a establecer todas las conexiones.

En las tres pruebas realizadas hemos obtenido diferentes resultados los cuales se muestran en la siguiente tabla y gráfica:

Tabla 12.

Resumen de los resultados de las pruebas de conexión

\begin{tabular}{|l|r|r|r|r|r|r|r|r|}
\hline $\begin{array}{c}\text { Número de } \\
\text { Prueba }\end{array}$ & $\begin{array}{c}\text { Conexiones } \\
\text { Enviadas }\end{array}$ & $\begin{array}{c}\text { Conexiones } \\
\text { Respondidas }\end{array}$ & $\begin{array}{c}\text { Conexiones No } \\
\text { Respondidas }\end{array}$ & $\begin{array}{c}\text { Tiempo de } \\
\text { respuesta de } \\
\text { la prueba }\end{array}$ & $\begin{array}{c}\text { Conexiones } \\
\text { por segundo } \\
\text { Enviadas }\end{array}$ & $\begin{array}{c}\text { Conexiones } \\
\text { por segundo } \\
\text { Respondidas }\end{array}$ & $\begin{array}{c}\text { Tiempo de } \\
\text { respuesta de } \\
\text { la Web }\end{array}$ & $\begin{array}{c}\text { Máximo de } \\
\text { respuestas } \\
\text { recibidas }\end{array}$ \\
\hline Primera & 3000 & 3000 & 0 & 18 & 170 & 169 & 0.4128 & 170 \\
\hline Segunda & 3000 & 3000 & 0 & 13 & 300 & 235 & 9.41 & 215 \\
\hline Tercera & 3000 & 2859 & 34 & 12 & 320 & 237 & 9.71 & 218 \\
\hline
\end{tabular}

Elaboración propia

En la tabla 12, podemos observar todos los resultados que se han obtenido en el desarrollo de esta prueba. Para tener un mejor panorama de los resultados, estaremos mostrando las gráficas de las conexiones que se enviaron en total y también la cantidad de conexiones por segundo, en cada una de ellas se estará mostrando el tiempo que se tomó en la ejecución de la prueba.

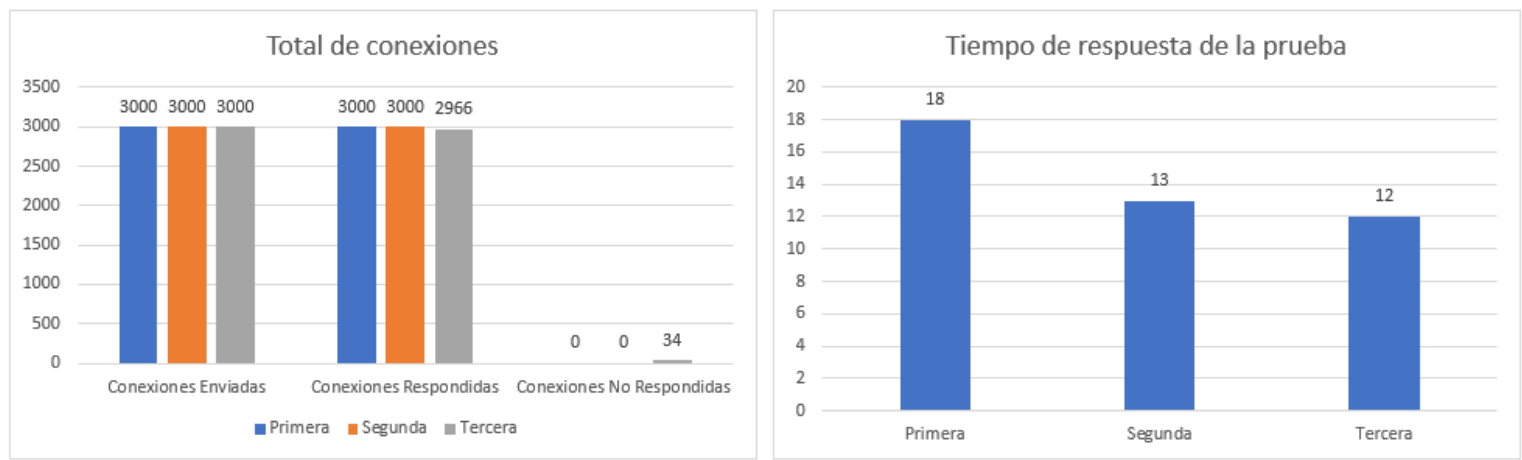

Figura 60. Conexiones enviadas y tiempo de respuesta de las pruebas

Elaboración propia

En la figura 60, podemos observar lo siguiente: 
- En la primera prueba se enviaron 3000 conexiones, respondieron todas y el tiempo de ejecución fue de 18 segundos. Todas las conexiones se llegaron a realizar.

- En la segunda prueba se enviaron 3000 conexiones, respondieron todas y el tiempo de ejecución fue de 13 segundos. Todas las conexiones se llegaron a realizar.

- En la tercera prueba se enviaron 3000 conexiones, respondieron solamente 2966 y el tiempo de ejecución fue de 12 segundos. Se llegaron a perder 34 conexiones debido a la saturación de los equipos.

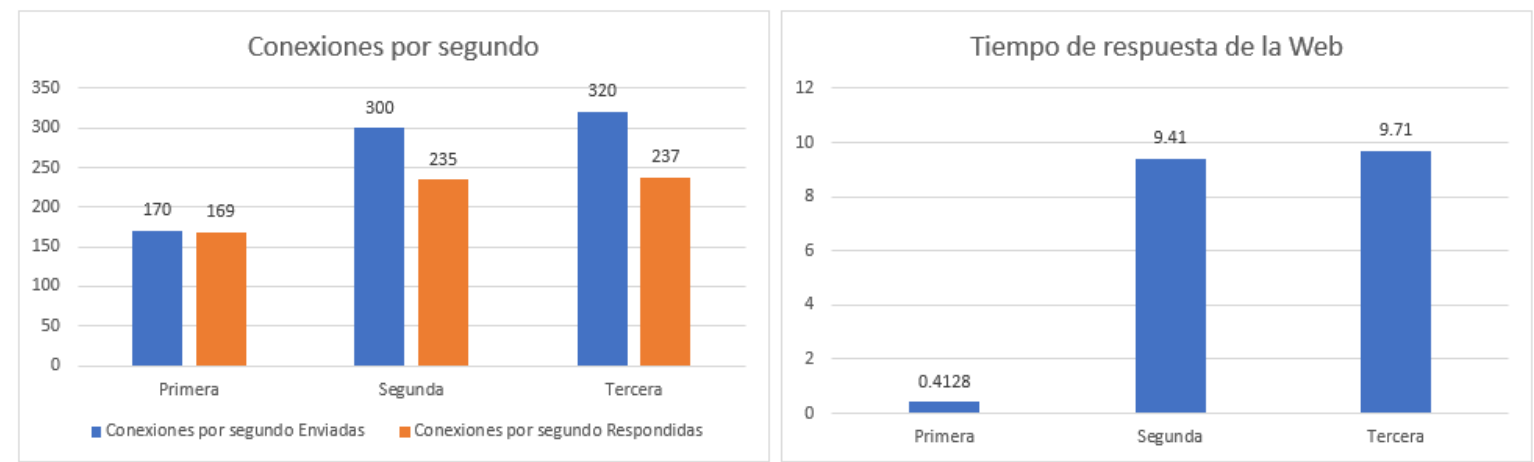

Figura 61. Conexiones por segundo y tiempo de respuesta de la Web

Elaboración propia

En la figura 61, podemos observar lo siguiente:

- En la primera prueba, se enviaron 170 conexiones por segundo, respondieron $169 \mathrm{y}$ el tiempo de respuesta de la Web fue de 0.41 segundos.

- En la segunda prueba, se enviaron 300 conexiones por segundo, respondieron 235 y el tiempo de respuesta de la Web fue de 9.41 segundos.

- En la tercera prueba, se enviaron 320 conexiones por segundo, respondieron $237 \mathrm{y}$ el tiempo de respuesta de la Web fue de 9.71 segundos.

En resumen, podemos determinar lo siguiente:

- En las tres pruebas ejecutadas desde el servidor Simulador de Conexiones hacia el servidor Balanceador Web, se pudo observar que si llegaron a ejecutar.

- Se observó que, en la primera prueba, los recursos de hardware se elevaron, pero no llego a consumir su totalidad.

- Se observó que, en la segunda prueba, los recursos de hardware se elevaron, llegándose a consumir su totalidad. 
- En la primera y segunda prueba, se llegaron a ejecutar todas las conexiones sin ningún error.

- Se observó que, en la tercera prueba, los recursos de hardware se elevaron llegándose a consumir en su totalidad.

- En la tercera prueba, no se llegaron a ejecutar todas las conexiones debido a la sobrecarga del servidor.

\subsubsection{Costos de la implementación}

Para las pruebas realizadas en este tercer escenario, las características de hardware que tendrá cada uno de los siete servidores son las siguientes:

- Procesador IntelXeon CPU E5-2697A v4 2.60GHz (4 core)

- Memoria RAM: 8GB DDR3

- Disco Duro: 25GB SSD

El costo de este servidor es de $\$ 80$ dólares mensuales.

\begin{tabular}{|c|c|c|c|c|c|c|c|}
\hline All Types & $\begin{array}{l}\text { SHARED CPU } \\
\text { Standard }\end{array}$ & $\begin{array}{l}\text { DEDICATED CPU } \\
\text { General Purpose }\end{array}$ & $\begin{array}{l}\text { DEDICATED CPU } \\
\text { CPU-Optimized }\end{array}$ & $\begin{array}{l}\text { DEDIC } \\
\text { Men }\end{array}$ & $\begin{array}{l}\text { rED CPU } \\
\text { ryptimized }\end{array}$ & NEW & \\
\hline & Type & CPU Type & vCPUs & Memory & SSD & Transfer & Price - \\
\hline & CPU-Optimized & Dedicated CPU & 2 vCPUs & $4 \mathrm{~GB}$ & $25 \mathrm{~GB}$ & 4 TB & $\begin{array}{l}\$ 40 / \mathrm{mo} \\
\$ 0.060 / \mathrm{hr}\end{array}$ \\
\hline (-) & CPU-Optimized & Dedicated CPU & 4 vCPUs & $8 \mathrm{~GB}$ & $25 \mathrm{~GB}$ & 5 TB & $\begin{array}{l}\$ 80 / \mathrm{mo} \\
\$ 0.119 / \mathrm{hr}\end{array}$ \\
\hline
\end{tabular}

Figura 62. Costo mensual del servidor Web

Adaptado de https://cloud.digitalocean.com/

En la figura 62, que fue obtenida desde el proveedor DigitalOcean podemos ver el costo que tendrá cada uno de nuestros servidores que estamos utilizando para la aplicación web. El costo mensual por los siete equipos que usaremos para esta arquitectura se muestra en la siguiente tabla: 
Tabla 13.

Costo mensual de la Arquitectura con siete servidores

\begin{tabular}{|l|c|}
\hline Descripción de servidores & Costo en dólares \\
\hline Balanceador Web & $\$ 80.00$ \\
\hline Web 01 & $\$ 80.00$ \\
\hline Web 02 & $\$ 80.00$ \\
\hline NFS & $\$ 80.00$ \\
\hline Balanceador BD & $\$ 80.00$ \\
\hline MySQL 01 & $\$ 80.00$ \\
\hline MySQL 02 & $\$ 80.00$ \\
\hline Costo Total: & $\$ 560.00$ \\
\hline
\end{tabular}

Elaboración propia

En la tabla 13, podemos observar que el costo para este escenario el cual, en un inicio, se basó en la arquitectura trabajada en el punto 3.2, luego de ello, se ha realizado un escalamiento vertical el cual tendrá el costo de \$560 dólares mensuales.

\subsubsection{Tiempo de escalabilidad de la arquitectura}

En esta arquitectura en la que se ha realizado un escalamiento vertical en los siete servidores, se ha tomado un tiempo determinado para la implementación, el cual se muestra a continuación:

Tabla 14.

Tiempo total para el escalamiento vertical en la arquitectura con siete servidores

\begin{tabular}{|l|c|c|c|c|c|c|c|}
\hline \multirow{2}{*}{ Proceso realizado } & \multicolumn{7}{|c|}{ Tiempo en minutos en cada Nodo } \\
\cline { 2 - 9 } & $\begin{array}{c}\text { Servidor } \\
\mathbf{0 1}\end{array}$ & $\begin{array}{c}\text { Servidor } \\
\mathbf{0 2}\end{array}$ & $\begin{array}{c}\text { Servidor } \\
\mathbf{0 3}\end{array}$ & $\begin{array}{c}\text { Servidor } \\
\mathbf{0 4}\end{array}$ & $\begin{array}{c}\text { Servidor } \\
\mathbf{0 5}\end{array}$ & $\begin{array}{c}\text { Servidor } \\
\mathbf{0 6}\end{array}$ & $\begin{array}{c}\text { Servidor } \\
\mathbf{0 7}\end{array}$ \\
\hline Corte de servicio & 5 & 5 & 5 & 5 & 5 & 5 & 5 \\
\hline Actualización de Hardware & 5 & 5 & 5 & 5 & 5 & 5 & 5 \\
\hline Pruebas de acceso & 5 & 5 & 5 & 5 & 5 & 5 & 5 \\
\hline Tiempo total por servidor & 15 & 15 & 15 & 15 & 15 & 15 & 15 \\
\hline Tiempo total: 105 minutos \\
\hline
\end{tabular}

Elaboración propia

En la tabla 14, se puede observar que, para cada servidor, se ha tomado un tiempo de 15 minutos para realizar el escalamiento vertical. El tiempo total que se ha tomado para 
realizar este escalamiento en los siete servidores fue de 105 minutos que equivalen a una hora con cuarenta y cinco minutos (1.45 horas).

En resumen, habiendo realizado todas estas pruebas, se puede determinar lo siguiente:

- En el primer escenario, el servidor llegó a soportar como máximo 80 conexiones por segundo sin presentar problemas. En este escenario, al ser el único servidor alojando todos los servicios al saturar sus recursos se perderá por completo acceso a la aplicación.

- En el segundo escenario, para solucionar el problema del primer escenario, se realizó escalamiento horizontal. Migrar al segundo escenario tomó, en promedio, unos 245 minutos, implementado 7 servidores con máquinas. Es este escenario, se pudo alcanzar hasta 150 conexiones por segundo sin presentar problemas de conexión.

- En el tercer escenario, se realizó escalamiento vertical en las máquinas virtuales, aumentando los recursos de procesamiento y memoria RAM. Realizar esta tarea nos tomó un tiempo de 35 minutos durante los cuales no se tuvo acceso a la aplicación. Es este escenario se pudo alcanzar hasta 300 conexiones por segundo sin que presente ningún problema.

Podemos concluir que, ante problemas de escalamiento, las máquinas virtuales nos presentan una arquitectura flexible capaz de crecer horizontal y verticalmente, sin embargo, toman un tiempo considerable al momento de realizar estos procesos de escalamiento. Por lo tanto, surge la necesidad de diseñar un modelo que permita la escalabilidad de recursos requeridos por las aplicaciones de manera independiente, que proporcione una mayor flexibilidad para las aplicaciones web y en menor tiempo.

\subsection{Requerimientos del proyecto}

De acuerdo con los resultados obtenidos, estableceremos los requerimientos que debemos considerar para diseñar el escalamiento con contenedores. 
Tabla 15.

Toma de requerimientos

\begin{tabular}{|c|c|c|}
\hline $\mathbf{N} .^{\circ}$ & Requerimiento & Descripción \\
\hline 1 & $\begin{array}{l}\text { La arquitectura que alojara la aplicación } \\
\text { web debe estar preparada para recibir el } \\
\text { número de } 350 \text { conexiones por segundo. }\end{array}$ & $\begin{array}{l}\text { La aplicación web en un inicio de gestión podría recibir } \\
\text { entre } 10 \text { a } 50 \text { conexiones por segundo, pero a mayor } \\
\text { demanda se va a necesitar que responda a una mayor } \\
\text { cantidad de conexiones. }\end{array}$ \\
\hline 2 & $\begin{array}{l}\text { La arquitectura solución para el } \\
\text { alojamiento de la aplicación web debe ser } \\
\text { diseñada para soportar los servicios } \\
\text { actuales y posible crecimiento de los } \\
\text { nuevos servicios a implementar. }\end{array}$ & $\begin{array}{l}\text { En la arquitectura solución se maneja la aplicación } \\
\text { Web que cuenta con dos servicios (Web y Base de } \\
\text { Datos) lo cuales están distribuidos en } 03 \text { servidores. } \\
\text { Docker recomienda que todo diseño basado en } \\
\text { contenedores debe tener como mínimo } 03 \text { servidores. }\end{array}$ \\
\hline 3 & $\begin{array}{l}\text { La arquitectura solución debe permitir una } \\
\text { mejor administración de los servidores. }\end{array}$ & $\begin{array}{l}\text { Se debe tener una administración centralizada y de } \\
\text { fácil manejo. }\end{array}$ \\
\hline 4 & $\begin{array}{l}\text { La arquitectura solución debe manejar } \\
\text { menos cantidad de servidores una mejor } \\
\text { administración. }\end{array}$ & $\begin{array}{l}\text { En la arquitectura tradicional se necesitó de } 07 \\
\text { servidores para el funcionamiento de la aplicación web } \\
\text { mientras que en la arquitectura solución se necesitó } \\
\text { solo } 03 \text { servidores. }\end{array}$ \\
\hline 5 & $\begin{array}{l}\text { La Escalabilidad debe ser flexible y no } \\
\text { debe tomar mucho tiempo para el } \\
\text { crecimiento ante la demanda del servicio. }\end{array}$ & $\begin{array}{l}\text { Los tiempos de Escalabilidad deben ser mínimos } \\
\text { cuando se tenga una demanda de servicio debido a que } \\
\text { no se debe perder la continuidad del servicio. }\end{array}$ \\
\hline
\end{tabular}

Elaboración propia 


\section{DISEÑO DE LA SOLUCIÓN}

Para responder al problema de escalamiento analizado en el capítulo anterior, utilizaremos una arquitectura basada en contenedores. La virtualización de servicios basados en contenedores es una solución que simplifica al máximo las operaciones de TI para desplegar aplicaciones de una forma más rápida, ágil, segura y rentable sin poner en riesgo su integridad y la seguridad de la infraestructura.

En este proyecto, hemos decidido utilizar como herramienta a Docker que, tal como se vio en el marco teórico, es uno de los líderes en soluciones de contenedores en el mercado. Así como las mismas herramientas de código abierto que utilizamos en el capítulo 3: Ubuntu Server, APACHE y MySQL.

La arquitectura planteada está formada por tres nodos, en los cuales distribuiremos los servicios que nos permitirán desplegar la aplicación web, analizada en el problema. Se continuará utilizando a DigitalOcean como proveedor de alojamiento para los nodos virtuales. En la figura 63, podemos observar los nodos que componen el diseño propuesto.

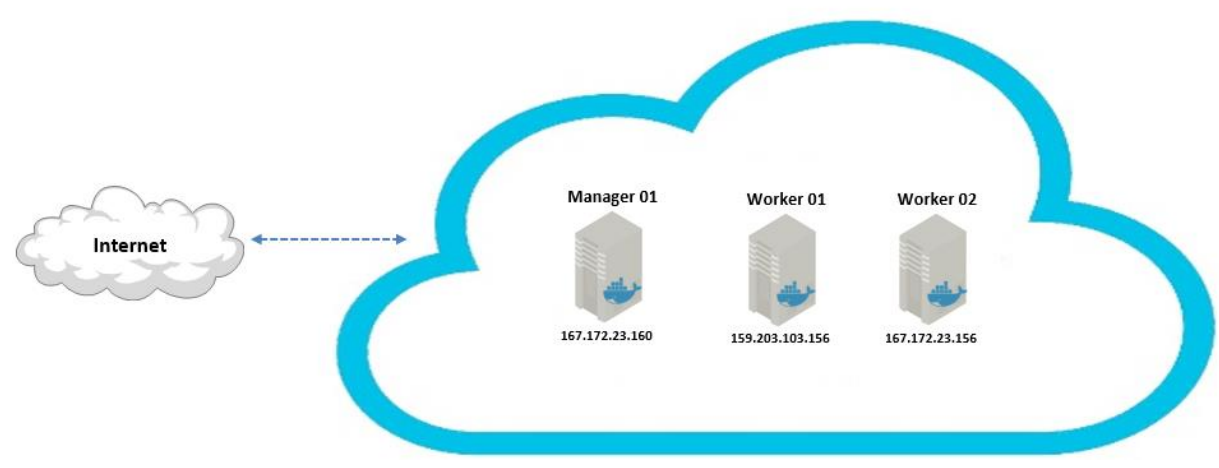

Figura 63. Nodos para la arquitectura escalable basados en contenedores

Elaboración propia

Docker recomienda que se deben configurar como mínimo tres nodos, con el fin de aprovechar sus características, además, también nos recomienda el uso de números impares de nodos, como podemos leer en docker.com: "Implementar un número impar de nodos de acuerdo con los requisitos de Escalabilidad. Cuando tiene varios administradores, puede 
recuperarse de la falla de un nodo de administrador sin tiempo de inactividad". Como la solución está orientada a una startup en su fase inicial, se utilizará el mínimo valor de nodos recomendados, tres.

Cada uno de estos nodos contará con las aplicaciones necesarias para ejecutar el servicio web. El conjunto de nodos que cuentan con la tecnología de Docker y el Orquestador Swarm es conocido como Docker Swarm, por lo tanto, en este caso se estará creando un Docker Swarm para desplegar un servicio web.

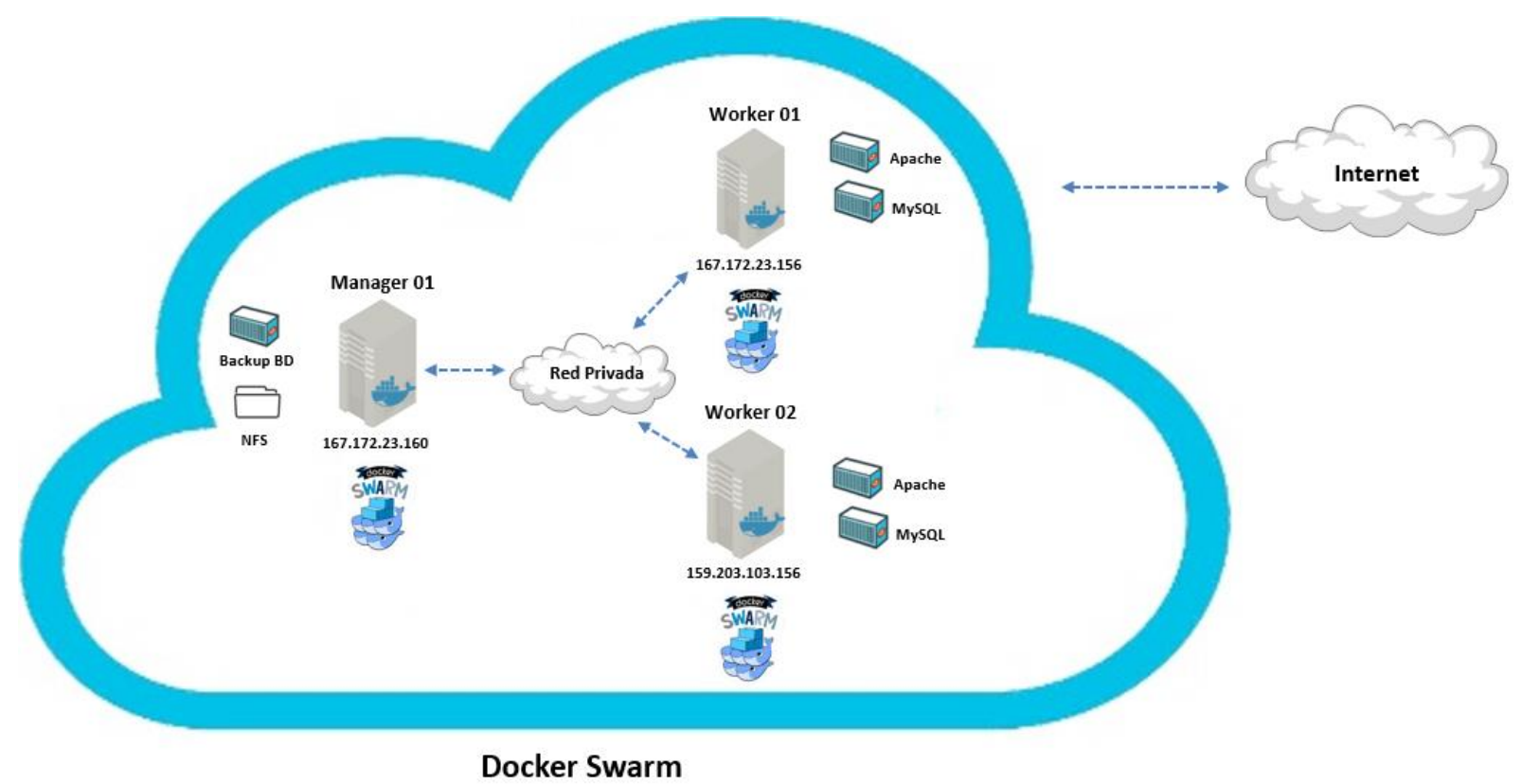

Figura 64. Docker Swarm - Contenedores y Servicios

Elaboración propia

En la figura 64, se observa cada nodo con los contenedores: un Manager 01 que aloja al orquestador nativo de Docker, Swarm y dos nodos Worker 01 y Worker02 que alojan los contenedores con las aplicaciones: APACHE y MySQL. A continuación, se describe a cada uno de estos nodos:

\section{Manager 01}

En este nodo tendrá instalada la herramienta de orquestación Docker Swarm, que es la aplicación nativa de Docker para la gestión de clústers de nodos, como se vio en el marco teórico. El rol de este nodo será de Swarm Manager y almacenará las imágenes de los servicios que se van a utilizar; adicionalmente se va a contar con una partición NFS que 
almacenara los archivos de la página web. También incluye un contenedor que actúa como respaldo a la base de datos.

La tarea de Docker Swarm será recibir las solicitudes de los clientes y distribuir la carga entre los nodos Worker 01 y 02 que forman parte de la arquitectura.

\section{Worker 01 y Worker 02}

Estos nodos asumen el rol de Swarm Worker, en cada uno de estos dos nodos se ejecutan los contenedores del servidor web APACHE y el gestor de base de datos MySQL. Estos nodos atenderán las solicitudes derivadas por el nodo maestro Manger01, mediante Docker Swarm.

A continuación, se explica cómo se realizan las solicitudes de acceso hacia el Docker Swarm que es el encargado de proveer el servicio web.

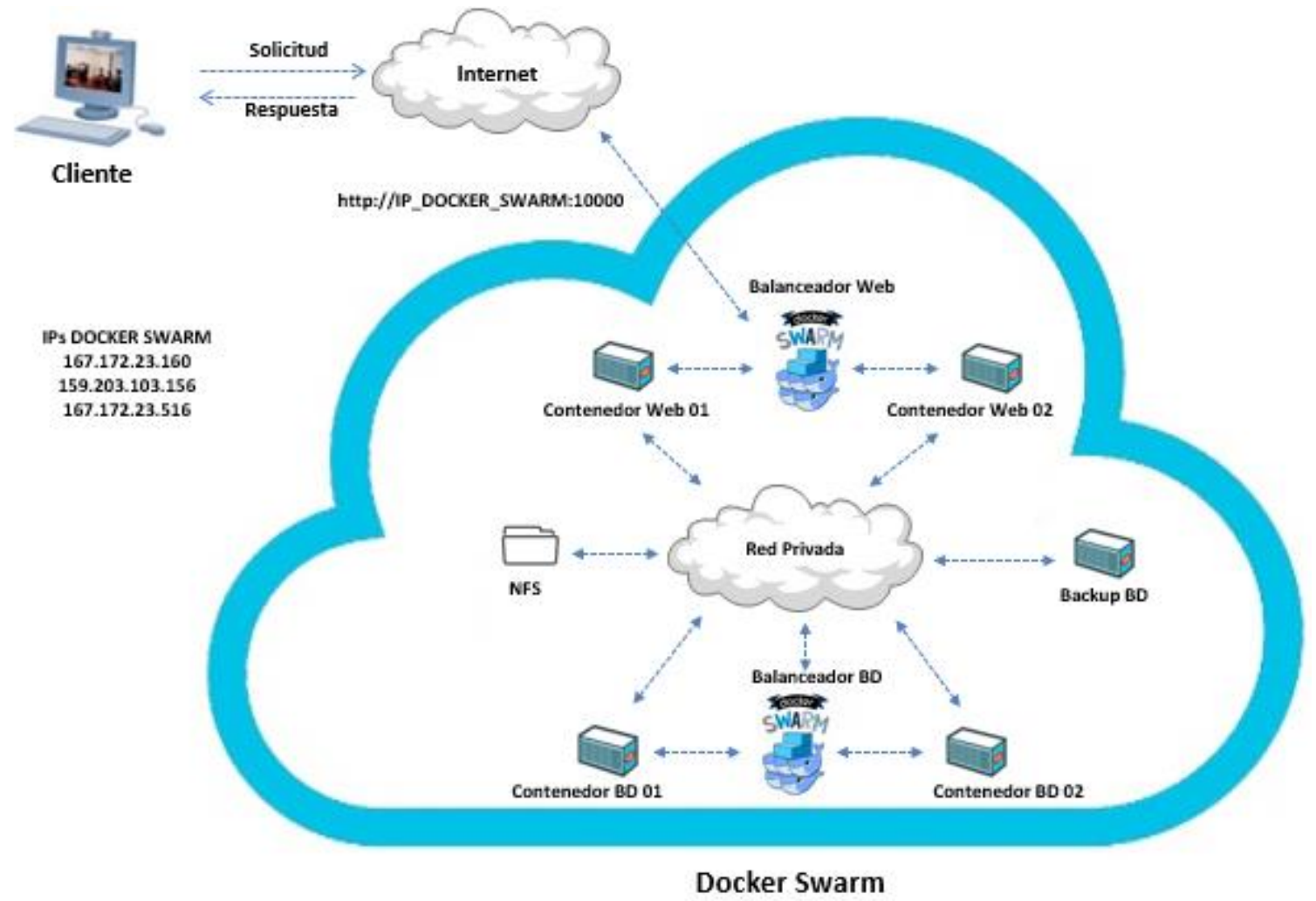

Figura 65. Docker Swarm - Diseño de la Solución

Elaboración propia 
En la figura 65, se puede observar cómo se ha diseñado el Docker Swarm, y cómo interactúan sus componentes. Cuando un cliente envía una solicitud (conexión) hacia la nube de Docker Swarm, puede hacerlo a cualquiera de las 3 direcciones IP públicas disponibles. El nodo Manager 01 recibe la solicitud y se encarga de distribuirla a cualquiera de los nodos Worker01 y Worker02, donde es atendida por el contenedor web APACHE. Si es necesario consultar a la base de datos, el orquestador se encargará de enviar la solicitud correspondiente al contenedor ejecutando el gestor de base de datos. Una vez procesada la solicitud del cliente, el contenedor que atendió la solicitud responderá directamente al cliente con la información correspondiente.

En la siguiente imagen se muestra el funcionamiento de la red interna del Docker Swarm:

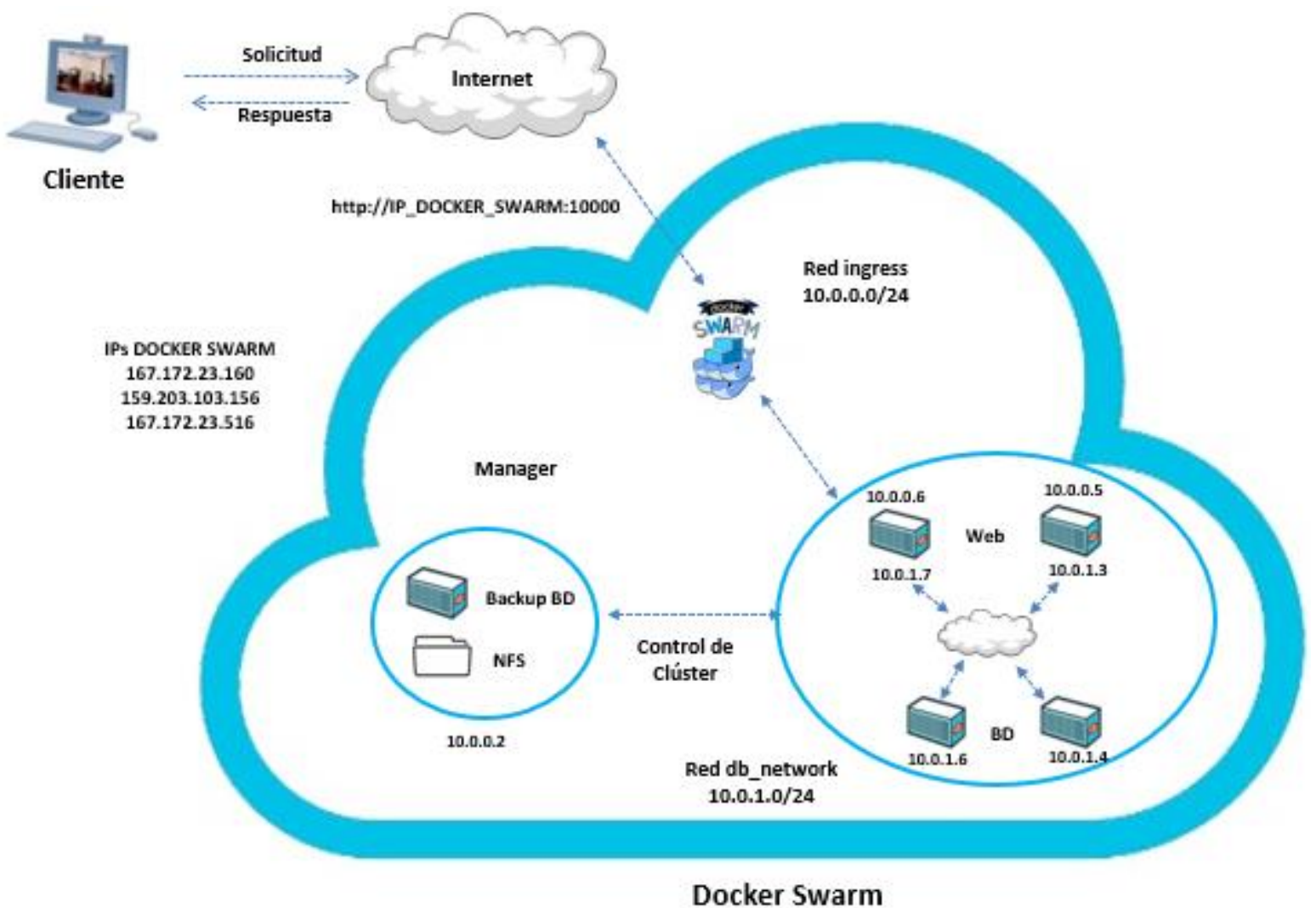

Figura 66. Docker Swarm - Funcionamiento de la Red

Elaboración propia

En la figura 66, se puede observar que dentro del Docker Swarm se tiene dos redes creadas. 
- La primera red que es la 10.0.0.0/24 con nombre "ingress" es la red que ha sido asignada por Swarm mientras que la segunda red que es la 10.0.1.0/24 con nombre "db_network" es la red que se ha creado para el clúster de base de datos que se maneja dentro del escenario.

- Los servicios Web se encuentran en la red 10.0.0.0/24 que es la que fue creada por Swarm mientras que los de Base de Datos se encuentran en la red 10.0.1.0/24.

- Swarm se encargará de crear las redes entre contenedores, asignar la dirección IP a cada contenedor y realizar el balanceo de los servicios que se tiene dentro de Docker Swarm.

Docker hará un round-robin entre todos los contenedores y distribuirá las conexiones entrantes que van hacia Swarm. Este tipo de funcionamiento de la red brindara un mayor beneficio a las Startups debido a que no tienen por qué preocuparse por esos detalles. En una red tradicional se tendría que contar con un personal que administre los servidores y configuraciones de red que se tendrían que implementar para las aplicaciones web.

Las características del hardware se pueden ver en el siguiente cuadro:

Tabla 16.

Características de Hardware de los Nodos

\begin{tabular}{|c|c|c|c|}
\hline Nodos & Nombre de Nodos & IP & Recursos de Harware (CPU / RAM / HDD) \\
\hline Docker Manager & Manager 01 & 167.172 .23 .160 & Intel Xeon CPU E5-2697A v4 2.60GHz (2 core) / 4GB / 25GB Disk \\
\hline Docker Worker & Worker 01 & 159.203 .103 .156 & Intel Xeon CPU E5-2697A v4 2.60GHz (2 core) / 4GB / 25GB Disk \\
\hline Docker Worker & Worker 02 & 167.172 .23 .156 & Intel Xeon CPU E5-2697A v4 2.60GHz (2 core) / 4GB / 25GB Disk \\
\hline
\end{tabular}

Elaboración propia

Como se puede observar en la tabla 16, los recursos de hardware para cada nodo del Docker Swarm será el mismo que se utilizó en el escenario 3.1 Arquitectura Tradicional del capítulo 03.

Con este escenario planteado, realizaremos las mismas pruebas de rendimiento, costo de inversión y tiempo de escalamiento, para la arquitectura basada en contenedores. 


\subsection{Cantidad de conexiones web concurrentes}

Para medir el rendimiento de la aplicación Web, utilizaremos la herramienta httperf ejecutándola desde un servidor externo, el cual simulará en tiempo real las conexiones por segundo que soportará el servidor web.

\subsubsection{Prueba 01}

Envío de un total de 3 mil de conexiones con una velocidad de 150 conexiones por segundo.

Desde el servidor Simulador de Conexiones Web se ejecutará el siguiente comando:

$$
\text { httperf --server 167.172.23.160 --port } 10000 \text {--num-conns } 30000 \text {--rate } 150 \text { timeout } 1
$$

Se enviará hacia el servidor web con dirección IP 167.172.23.160 con número de puerto 80 (HTTP) una cantidad total de 3000 peticiones con una velocidad de 150 conexiones por segundo.

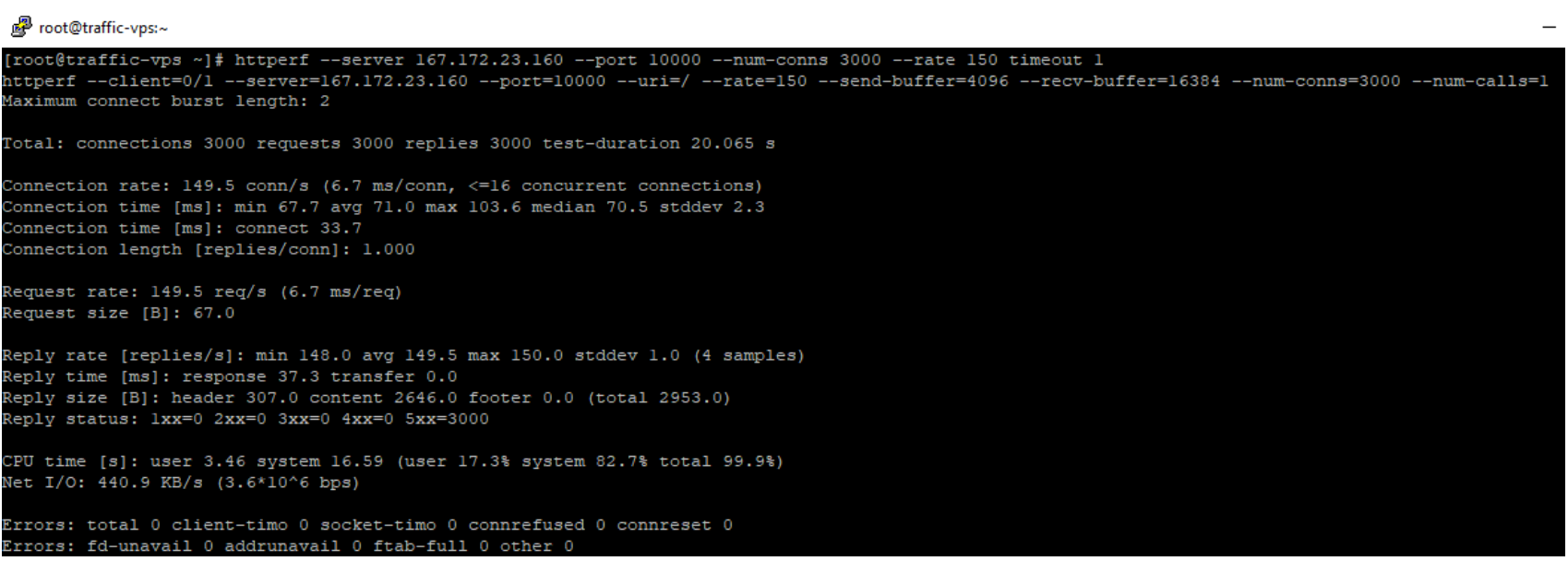

Figura 67. Resultados obtenidos en servidor simulador de conexiones hacia la aplicación Web

Elaboración propia

En la figura 67, podemos observar todos los resultados obtenidos en la prueba realizada. A continuación, se explicarán los resultados de los puntos más importantes que hemos obtenido.

Total: connections 3000 requests 3000 replies 3000 test-duration $20.065 \mathrm{~s}$

Muestra que se iniciaron 3000 conexiones, se realizaron 3000 solicitudes y se recibieron 3000 respuestas. 
También muestra que la duración total de la prueba fue de 20.065 segundos, lo que significa que la tasa de solicitud promedio fue casi exactamente 150 solicitudes por segundo.

\section{Connection rate: $149.5 \mathrm{conn} / \mathrm{s}(6.7 \mathrm{~ms} / \mathrm{conn},<=16$ concurrent connections)}

Muestra que las nuevas conexiones se iniciaron a una velocidad de 150 conexiones por segundo. Esta tasa corresponde a un período de 6.7 milisegundos por conexión. Finalmente, el último número muestra que, como máximo, diez y seis conexiones estaban abiertas al servidor en un momento dado.

\section{Connection time [ms]: min 67.7 avg 71.0 max 103.6 median 70.5 stddev 2.3}

Muestra que la vida útil de la conexión mínima (min) fue de 67.7 milisegundos, la vida útil promedio (avg) fue de 71.0 milisegundos, la vida útil máxima (max.) fue de 103.6 milisegundos, la vida mediana (median) fue de 70.5 milisegundos, y que la desviación estándar de los tiempos de vida fue de 2.3 milisegundos.

\section{Reply rate [replies/s]: min 148.0 avg 149.5 max 150.0 stddev 1.0 (4 samples)}

Muestra la tasa de respuesta mínima (min), promedio (avg) y máxima (max) fue aproximadamente de 150 respuestas por segundo. Dados estos números, la desviación estándar es 1.0 milisegundos.

\section{Errors: total 0 client-timo 0 socket-timo 0 connrefused 0 connreset 0}

\section{Errors: fd-unavail 0 addrunavail 0 ftab-full 0 other 0}

Los errores totales sumaron cero debido a que todas las conexiones resultaron exitosas.

En la ejecución de la prueba, podemos observar el consumo de los recursos de hardware de los tres nodos con Docker y los resultados se muestran en las siguientes imágenes:

Manager 01 - Docker Swarm

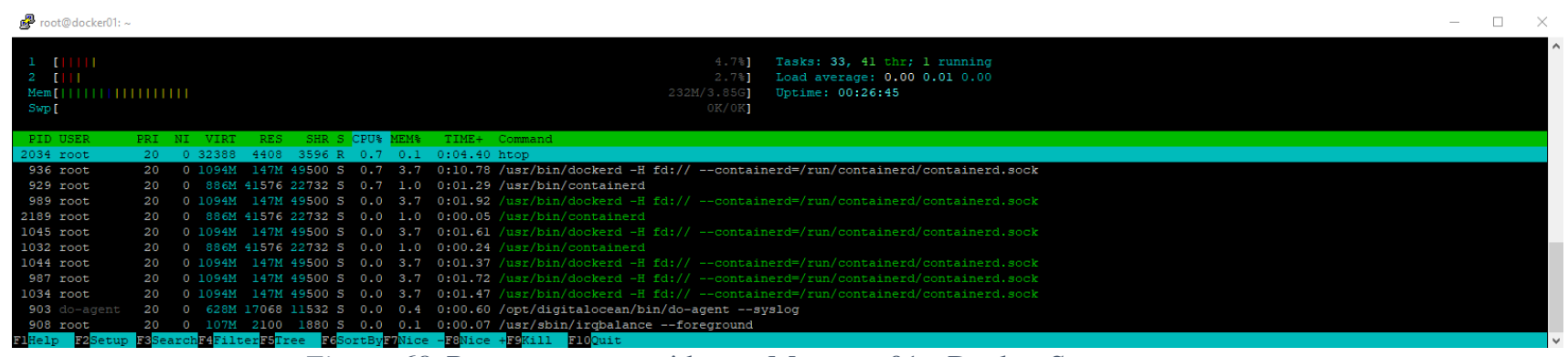

Figura 68. Recursos consumidos en Manager 01 - Docker Swarm

Elaboración propia 
Mediante la aplicación HTOP, podemos observar que los recursos de hardware del nodo Docker Swarm se mantuvo bajo debido a que únicamente está realizando el balanceo de las conexiones hacia los nodos Docker Worker. Se puede apreciar que el servicio usado es Docker. Se está usando aproximadamente $3.45 \%$ de los dos núcleos que tenemos en el procesador y $232 \mathrm{MB}$ de memoria RAM.

Worker 01 - Docker Containers (Web y MySQL)

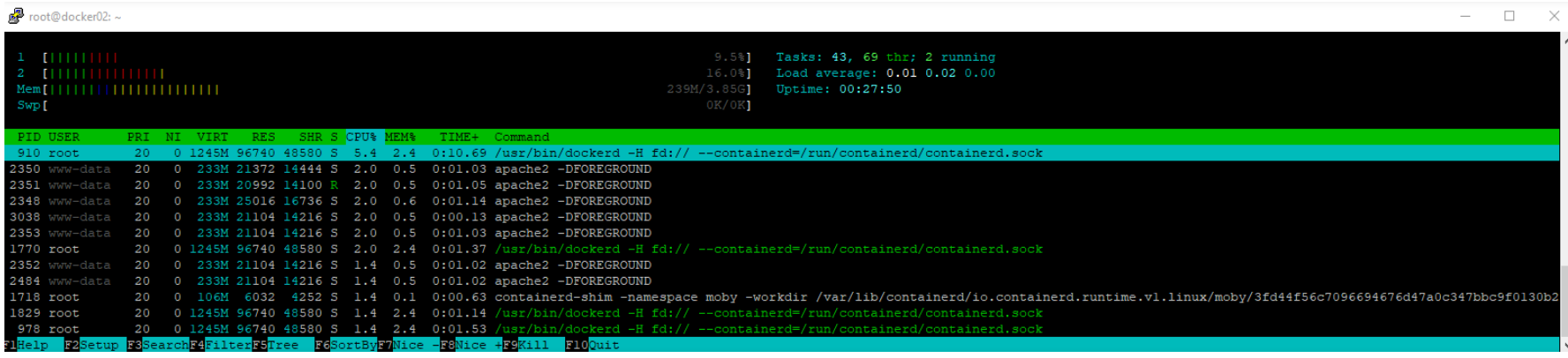

Figura 69. Recursos consumidos en Worker 01 - Docker Contenedores (Web y MySQL)

Elaboración propia

Mediante la aplicación HTOP, podemos observar que los recursos de hardware del nodo Docker Worker 01 se mantuvieron dentro de lo normal. En este servidor se están usando dos contenedores que son del servicio Web APACHE y MySQL. Se está usando aproximadamente $12.75 \%$ de los dos núcleos que tenemos en el procesador y $239 \mathrm{MB}$ de memoria RAM

Worker 02 - Docker Containers (Web APACHE y MySQL)

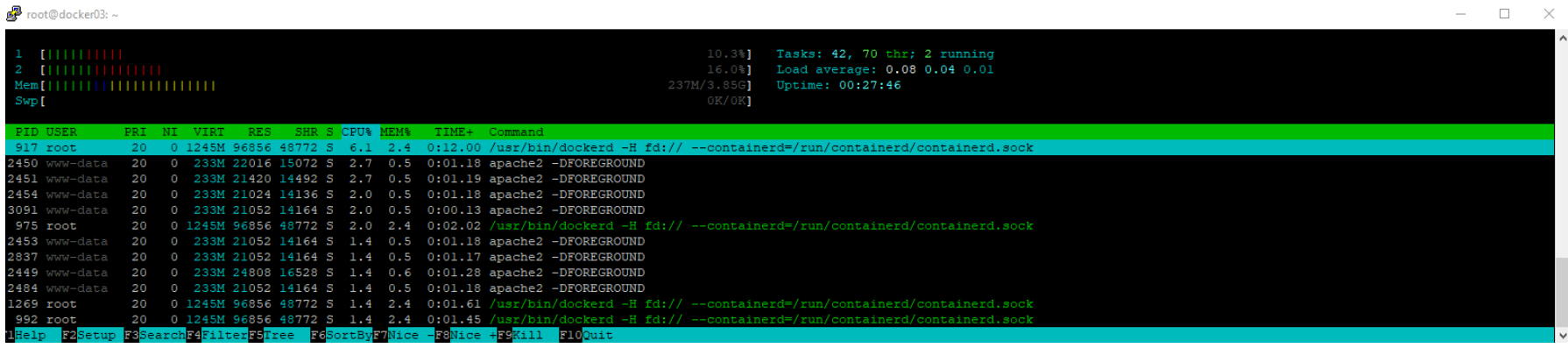

Figura 70. Recursos consumidos en Worker 02 - Docker Contenedores (Web y MySQL)

Elaboración propia 
Mediante la aplicación HTOP, podemos observar que los recursos de hardware del nodo Docker Worker 02 se mantuvieron dentro de lo normal. En este servidor, se están usando dos contenedores que son del servicio Web APACHE y MySQL. Se está usando aproximadamente $13.15 \%$ de los dos núcleos que tenemos en el procesador y $237 \mathrm{MB}$ de memoria RAM.

En los tres nodos, se observó que el consumo de hardware estaba dentro de lo normal y se llegaron a establecer todas las conexiones.

\subsubsection{Prueba 02}

Envío de un total de 3000 de conexiones con una velocidad de 250 conexiones por segundo.

Desde el servidor Simulador de Conexiones Web se ejecutará el siguiente comando: httperf --server 167.172.23.160 --port 10000 --num-conns 30000 --rate 250 timeout 1

Se enviará hacia el servidor web con dirección IP 167.172.23.160 con número de puerto 80 (HTTP) una cantidad total de 3000 peticiones con una velocidad de 250 conexiones por segundo.

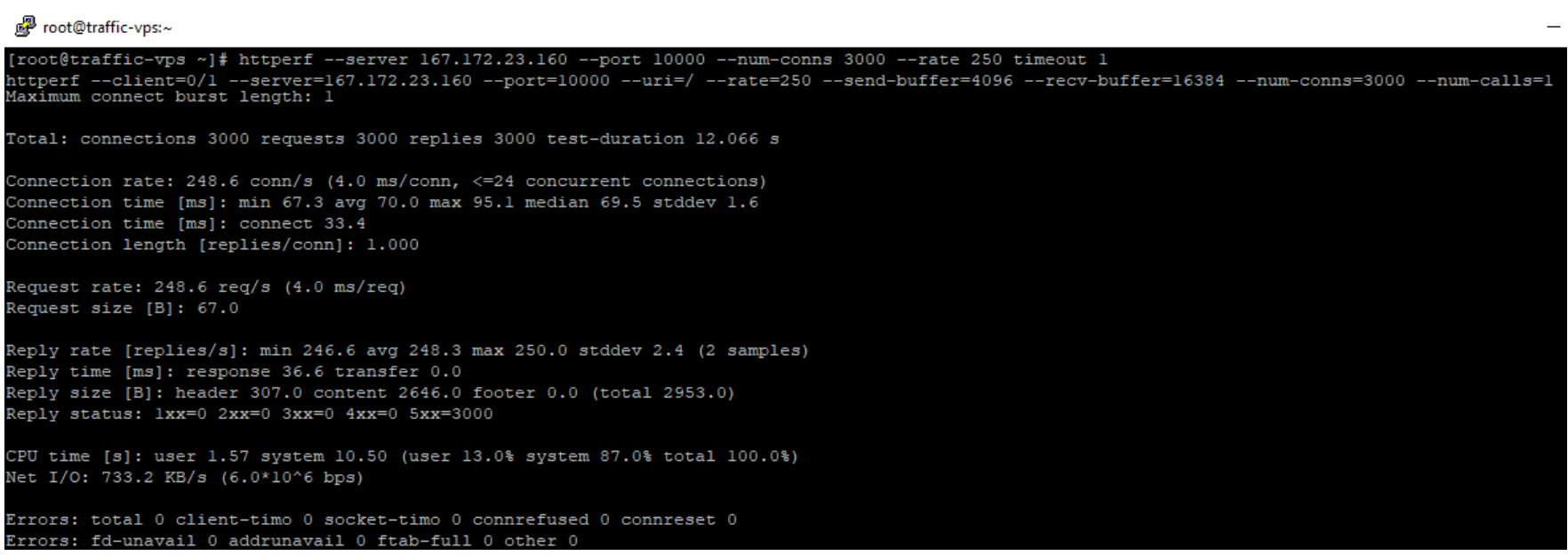

Figura 71. Resultados obtenidos en servidor Simulador de Conexiones hacia la aplicación Web 
En la figura 71, podemos observar todos los resultados obtenidos en la prueba realizada. A continuación, se explicarán los resultados de los puntos más importantes que hemos obtenido.

En el resumen, tomando los parámetros más importantes, podemos observar lo siguiente:

Total: connections 3000 requests 3000 replies 3000 test-duration $12.066 \mathrm{~s}$

Muestra que se iniciaron 3000 conexiones, se realizaron 3000 solicitudes y se recibieron 3000 respuestas.

También muestra que la duración total de la prueba fue de 12.066 segundos, lo que significa que la tasa de solicitud promedio fue casi exactamente 250 solicitudes por segundo.

\section{Connection rate: 248.6 conn/s $(4.0 \mathrm{~ms} / \mathrm{conn},<=24$ concurrent connections)}

Muestra que las nuevas conexiones se iniciaron a una velocidad de 249 conexiones por segundo. Esta tasa corresponde a un período de 4.0 milisegundos por conexión. Finalmente, el último número muestra que, como máximo, veinte cuatro conexiones estaban abiertas al servidor en un momento dado.

Connection time [ms]: min 67.3 avg 70.0 max 95.1 median 69.5 stddev 1.6

Muestra que la vida útil de la conexión mínima (min.) fue de 67.3 milisegundos, la vida útil promedio (avg) fue de 70.5 milisegundos, la vida útil máxima (max.) fue de 95.1 milisegundos, la vida mediana (median) fue de 69.5 milisegundos, y que la desviación estándar de los tiempos de vida fue de 1.6 milisegundos.

\section{Reply rate [replies/s]: min 246.6 avg 248.3 max 250.0 stddev 2.4 (2 samples)}

Muestra la tasa de respuesta mínima (min), promedio (avg) y máxima (max.) fue aproximadamente de 250 respuestas por segundo. Dados estos números, la desviación estándar es 2.4 milisegundos.

\section{Errors: total 0 client-timo 0 socket-timo 0 connrefused 0 connreset 0}

\section{Errors: fd-unavail 0 addrunavail 0 ftab-full 0 other 0}

Los errores totales sumaron cero debido a que todas las conexiones resultaron exitosas.

En la ejecución de la prueba, podemos observar el consumo de los recursos de hardware y los resultados de los tres nodos con Docker, los cuales se muestran en las siguientes imágenes: 
Manager 01 - Docker Swarm

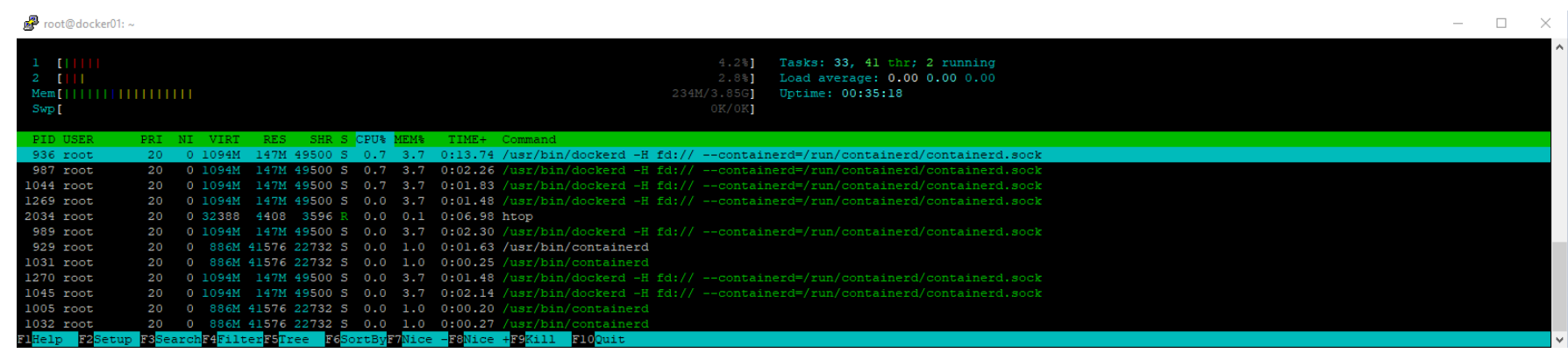

Figura 72. Recursos consumidos en Manager 01 - Docker Swarm

Elaboración propia

Mediante la aplicación HTOP, podemos observar que los recursos de hardware del nodo Docker Swarm se mantuvieron bajos debido a que únicamente está realizando el balanceo de las conexiones hacia los nodos Docker Worker. Se puede apreciar que el servicio usado es Docker. Se está usando aproximadamente $3.5 \%$ de los dos núcleos que tenemos en el procesador y 234MB de memoria RAM.

Worker 01 - Docker Containers (Web y MySQL)

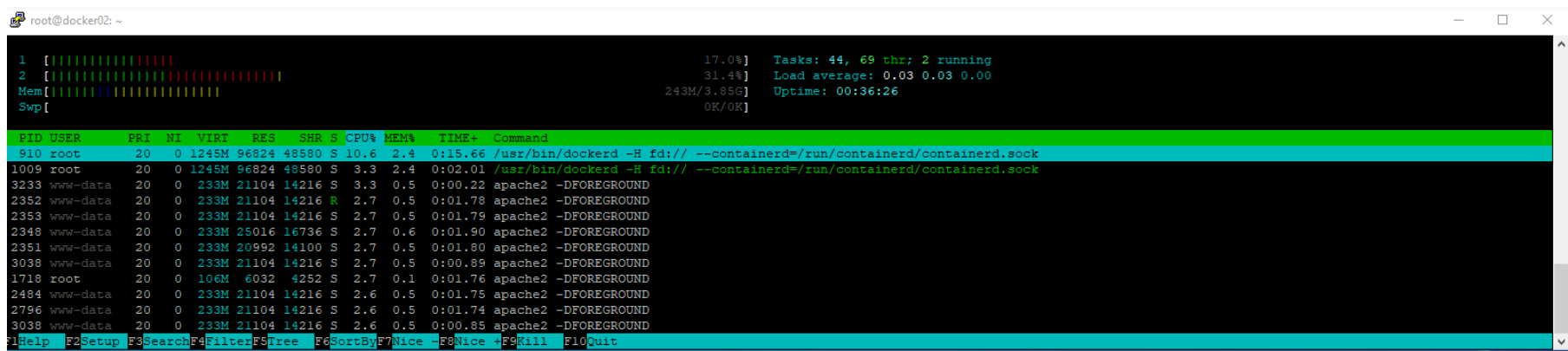

Figura 73. Recursos consumidos en Worker 01 - Docker Contenedores (Web y MySQL)

Elaboración propia

Mediante la aplicación HTOP, podemos observar que los recursos de hardware del nodo Docker Worker 01 se mantuvieron dentro de lo normal. En este nodo, se están usando dos contenedores que son del servicio Web APACHE y MySQL. Se está usando aproximadamente $24.2 \%$ de los dos núcleos que tenemos en el procesador y $243 \mathrm{MB}$ de memoria RAM. 
Worker 01 - Docker Containers (Web y MySQ)

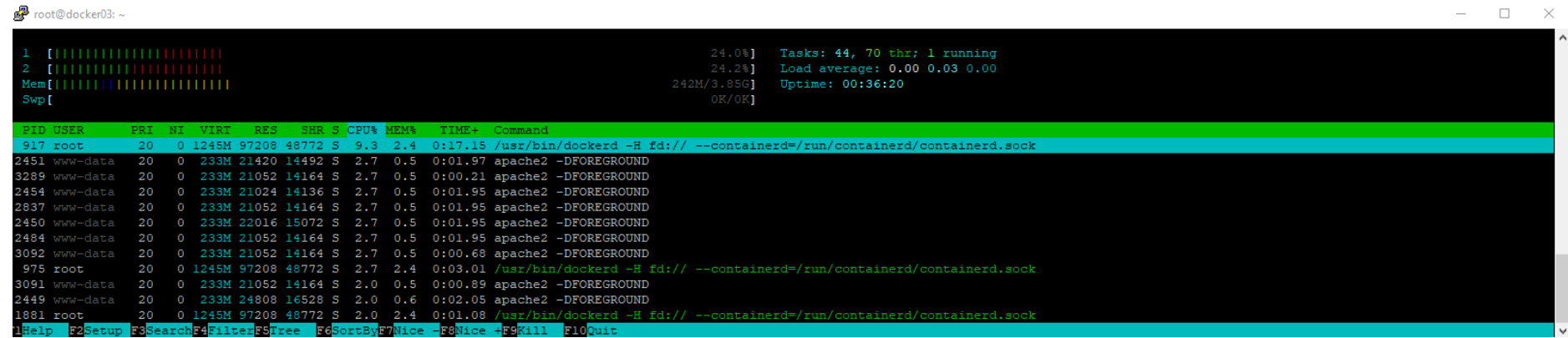

Figura 74. Recursos consumidos en Worker 02 - Docker Contenedores (Web y MySQL)

Elaboración propia

Mediante la aplicación HTOP, podemos observar que los recursos de hardware del nodo Docker Worker 02 se mantuvieron dentro de lo normal. En este nodo, se están usando dos contenedores que son del servicio Web y MySQL. Se está usando aproximadamente $24.1 \%$ de los dos núcleos que tenemos en el procesador y 242MB de memoria RAM.

En los tres nodos, se observó que el consumo de hardware estaba dentro de lo normal y se llegaron a establecer todas las conexiones.

\subsubsection{Prueba 03}

Envío de un total de 3000 de conexiones con una velocidad de 350 conexiones por segundo.

Desde el servidor Simulador de Conexiones Web se ejecutará el siguiente comando:

httperf --server 167.172.23.160 --port 10000 --num-conns 30000 --rate 350 timeout 1

Se enviará hacia el servidor web con dirección IP 167.172.23.160 con número de puerto 80 (HTTP) una cantidad total de 3000 peticiones con una velocidad de 350 conexiones por segundo. 


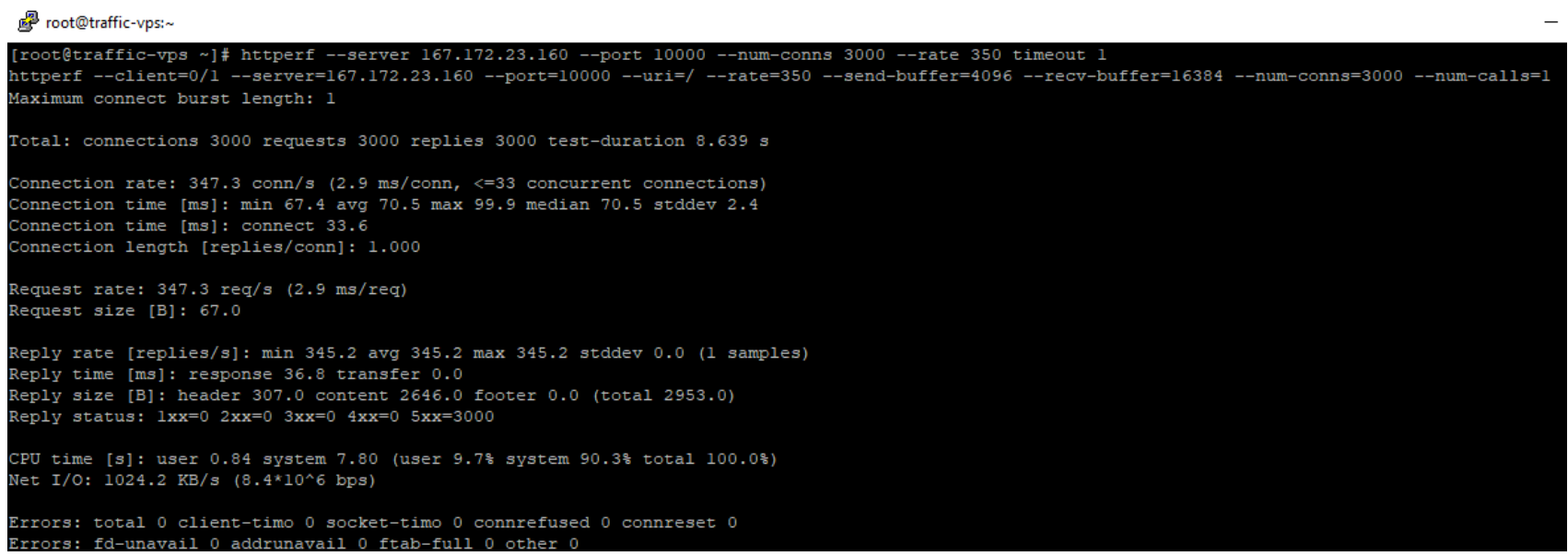

Figura 75. Resultados obtenidos en servidor Simulador de Conexiones hacia la aplicación Web Elaboración propia

En la figura 75, podemos observar todos los resultados obtenidos en la prueba realizada. A continuación, se explicarán los resultados de los puntos más importantes que hemos obtenido.

\section{Total: connections 3000 requests 3000 replies 3000 test-duration $8.639 \mathrm{~s}$}

Muestra que se iniciaron 3000 conexiones, se realizaron 3000 solicitudes y se recibieron 3000 respuestas.

También muestra que la duración total de la prueba fue de 8.639 segundos, lo que significa que la tasa de solicitud promedio fue casi exactamente 347 solicitudes por segundo.

\section{Connection rate: $347.3 \mathrm{conn} / \mathrm{s}(\mathbf{2 . 9} \mathrm{ms} / \mathrm{conn},<=33$ concurrent connections)}

Muestra que las nuevas conexiones se iniciaron a una velocidad de 347 conexiones por segundo. Esta tasa corresponde a un período de 2.9 milisegundos por conexión. Finalmente, el último número muestra que, como máximo, treinta y tres conexiones estaban abiertas al servidor en un momento dado.

Connection time [ms]: min 67.4 avg 70.5 max 99.9 median 70.5 stddev 2.4

Muestra que la vida útil de la conexión mínima (min.) fue de 67.4 milisegundos, la vida útil promedio (avg) fue de 70.5 milisegundos, la vida útil máxima (max.) fue de 99.9 milisegundos, la vida mediana (median) fue de 70.5 milisegundos, y que la desviación estándar de los tiempos de vida fue de 2.4 milisegundos.

Reply rate [replies/s]: min 345.2 avg 345.2 max 345.2 stddev 0.0 (1 samples) 
Muestra la tasa de respuesta mínima (min), promedio (avg) y máxima (max.) fue aproximadamente de 345 respuestas por segundo. Dados estos números, la desviación estándar es 0.0 milisegundos.

\section{Errors: total 0 client-timo 0 socket-timo 0 connrefused 0 connreset 0}

\section{Errors: fd-unavail 0 addrunavail 0 ftab-full 0 other 0}

Los errores totales sumaron cero debido a que todas las conexiones resultaron exitosas.

En la ejecución de la prueba, podemos observar el consumo de los recursos de hardware y los resultados de los tres servidores con Docker, los cuales se muestran en las siguientes imágenes:

Manager 01 - Docker Swarm

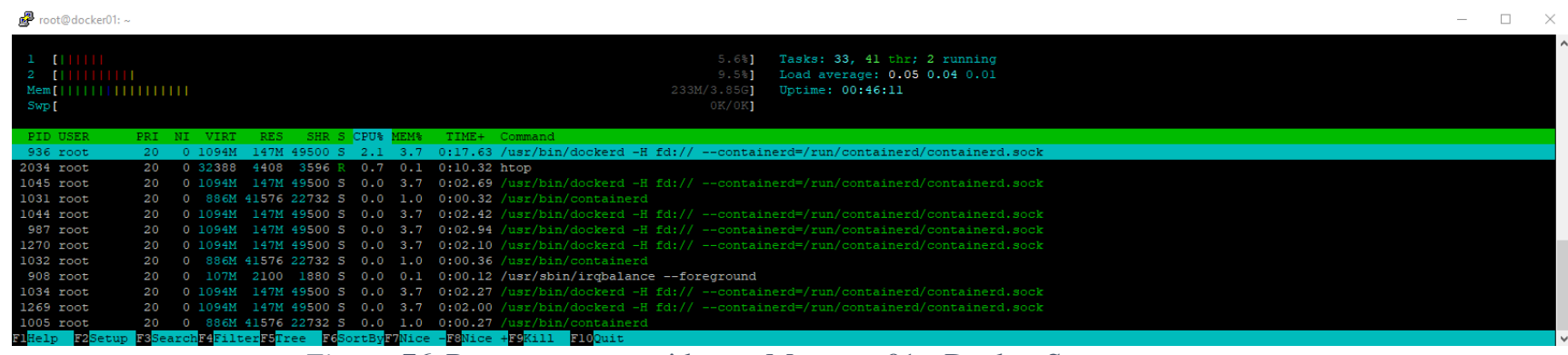

Figura 76. Recursos consumidos en Manager 01 - Docker Swarm

Elaboración propia

Mediante la aplicación HTOP, podemos observar que los recursos de hardware del nodo Docker Swarm se mantuvieron bajos debido a que únicamente está realizando el balanceo de las conexiones hacia los nodos Docker Worker. Se puede apreciar que el servicio usado es Docker. Se está usando aproximadamente $7.55 \%$ de los dos núcleos que tenemos en el procesador y $233 \mathrm{MB}$ de memoria RAM.

Worker 01 - Docker Containers (Web y MySQL) 


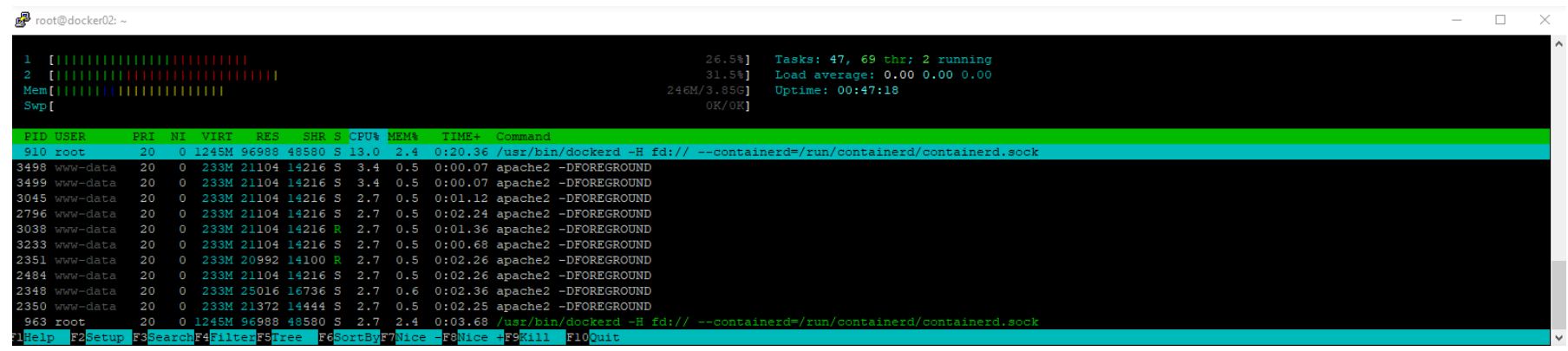

Figura 77. Recursos consumidos en Worker 01 - Docker Contenedores (Web y MySQL)

Elaboración propia

Mediante la aplicación HTOP, podemos observar que los recursos de hardware del nodo Docker Worker 01 se mantuvieron dentro de lo normal. En este nodo, se están usando dos contenedores que son del servicio Web y MySQL. Se está usando aproximadamente el 29 $\%$ de los dos núcleos que tenemos en el procesador y 246MB de memoria RAM.

Worker 02 - Docker Containers (Web y MySQL)

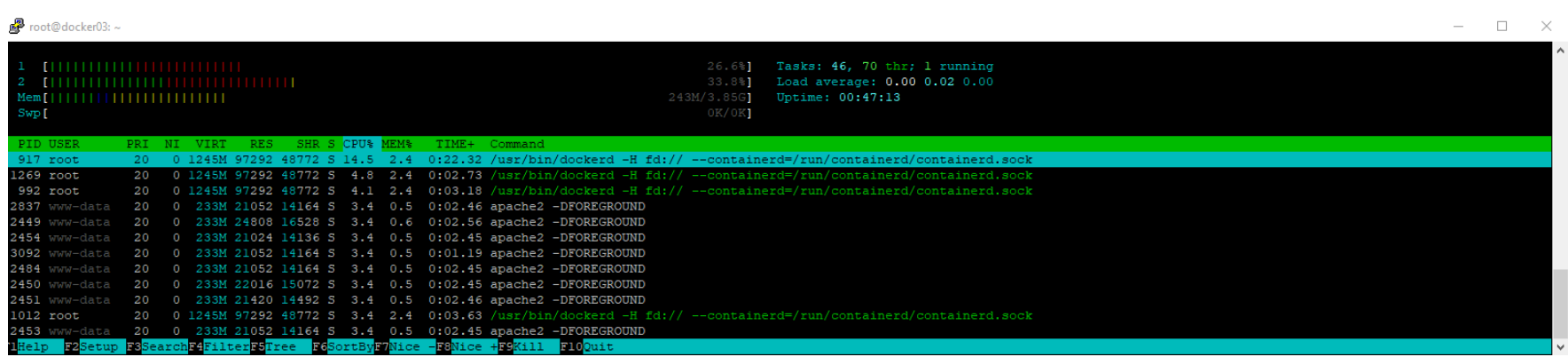

Figura 78. Recursos consumidos en Worker 02 - Docker Contenedores (Web y MySQL)

Elaboración propia

Mediante la aplicación HTOP, podemos observar que los recursos de hardware del nodo Docker Worker 02 se mantuvieron dentro de lo normal. En este nodo, se están usando dos contenedores que son del servicio Web y MySQL. Se está usando aproximadamente 30.2 $\%$ de los dos núcleos que tenemos en el procesador y 243MB de memoria RAM.

En los tres nodos, se observó que el consumo de hardware estaba dentro de lo normal y se llegaron a establecer todas las conexiones. 


\subsubsection{Prueba 04}

Envío de un total de 3 mil de conexiones con una velocidad de 400 conexiones por segundo.

Desde el servidor Simulador de Conexiones Web se ejecutará el siguiente comando: httperf --server 167.172.23.160 --port 10000 --num-conns 30000 --rate 400 timeout 1

Se enviará hacia el servidor web con dirección IP 167.172.23.160 con numero de puerto 80 (HTTP) una cantidad total de 3000 peticiones con una velocidad de 400 conexiones por segundo.

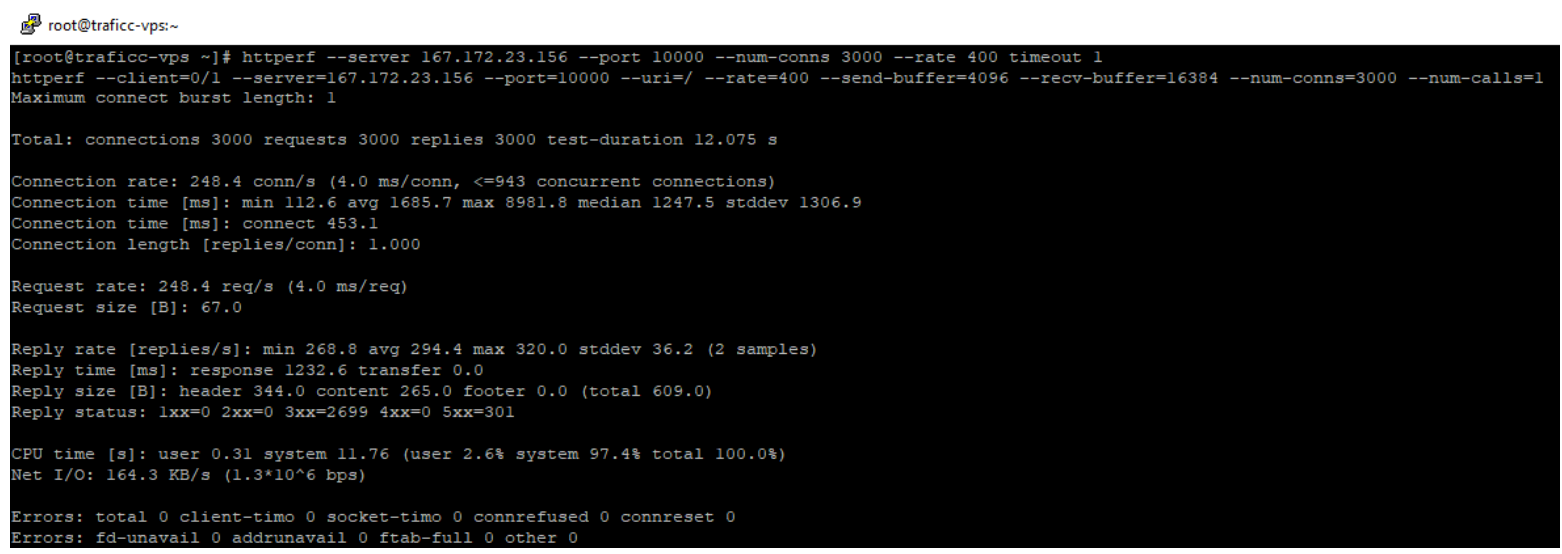

Figura 79. Resultados obtenidos en servidor simulador de conexiones hacia la aplicación Web

Elaboración propia

En la figura 79, podemos observar todos los resultados obtenidos en la prueba realizada. A continuación, se explicarán los resultados de los puntos más importantes que hemos obtenido.

Total: connections 3000 requests 3000 replies 3000 test-duration $12.075 \mathrm{~s}$

Muestra que se iniciaron 3000 conexiones, se realizaron 3000 solicitudes y se recibieron 3000 respuestas.

También muestra que la duración total de la prueba fue de 12.075 segundos, lo que significa que la tasa de solicitud promedio fue casi exactamente 248 solicitudes por segundo.

Connection rate: $248.4 \mathrm{conn} / \mathrm{s}$ ( $4.0 \mathrm{~ms} / \mathrm{conn},<=943$ concurrent connections) 
Muestra que las nuevas conexiones se iniciaron a una velocidad de 248 conexiones por segundo. Esta tasa corresponde a un período de 4.0 milisegundos por conexión. Finalmente, el último número muestra que, como máximo, novecientos cuarenta y tres conexiones estaban abiertas al servidor en un momento dado.

Connection time [ms]: min 112.6 avg 1685.7 max 8981.8 median 1247.5 stddev 1306.9

Muestra que la vida útil de la conexión mínima (min.) fue de 112.6 milisegundos, la vida útil promedio (avg) fue de 1685.7 milisegundos, la vida útil máxima (max.) fue de 8981.8 milisegundos, la vida mediana (median) fue de 1247.5 milisegundos, y que la desviación estándar de los tiempos de vida fue de 1306.9 milisegundos.

\section{Reply rate [replies/s]: min 268.8 avg 294.4 max 320.0 stddev 36.2 (2 samples)}

Muestra la tasa de respuesta mínima (min), promedio (avg) y máxima (max) fue aproximadamente de 320 respuestas por segundo. Dados estos números, la desviación estándar es 36.2 milisegundos.

\section{Errors: total 0 client-timo 0 socket-timo 0 connrefused 0 connreset 0 Errors: fd-unavail 0 addrunavail 0 ftab-full 0 other 0}

Los errores totales sumaron cero debido a que todas las conexiones resultaron exitosas.

En la ejecución de la prueba, podemos observar el consumo de los recursos de hardware y los resultados de los tres nodos con Docker los cuales se muestran en las siguientes imágenes:

Manager 01 - DockerSwarm

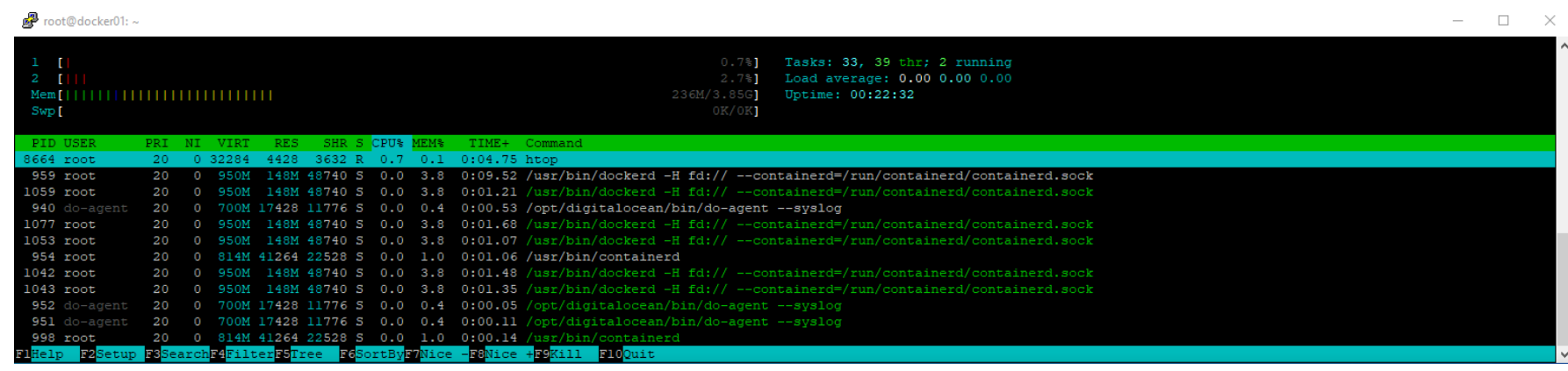

Figura 80. Recursos consumidos en Manager 01 - Docker Swarm

Elaboración propia 
Mediante la aplicación HTOP, podemos observar que los recursos de hardware del nodo Docker Swarm se mantuvo bajo debido a que únicamente está realizando el balanceo de las conexiones hacia los nodos Docker Worker. Se puede apreciar que el servicio usado es Docker. Se está usando aproximadamente $1.7 \%$ de los dos núcleos que tenemos en el procesador y $236 \mathrm{MB}$ de memoria RAM.

\section{Worker 01 - Docker Containers (Web y MySQL)}

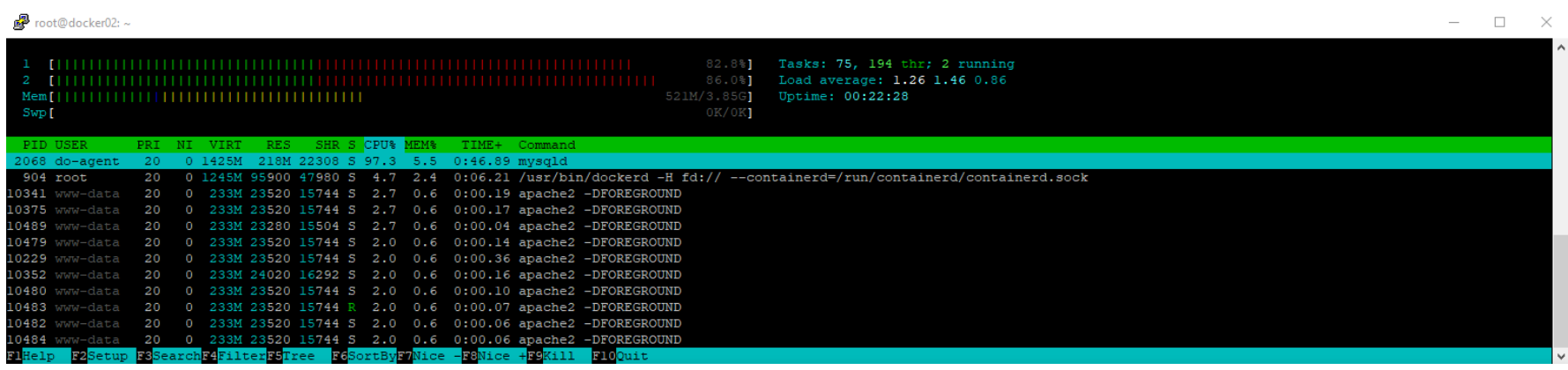

Figura 81. Recursos consumidos en Worker 01 - Docker Contenedores (Web y MySQL)

Elaboración propia

Mediante la aplicación HTOP, podemos observar que los recursos de hardware del nodo Docker Worker 01 se elevaron debido a una mayor cantidad de conexiones por segundo. En este nodo, se están usando dos contenedores que son del servicio Web y MySQL. Se está usando aproximadamente $84.4 \%$ de los dos núcleos que tenemos en el procesador y $521 \mathrm{MB}$ de memoria RAM.

Worker 02 - Docker Containers (Web y MySQL)

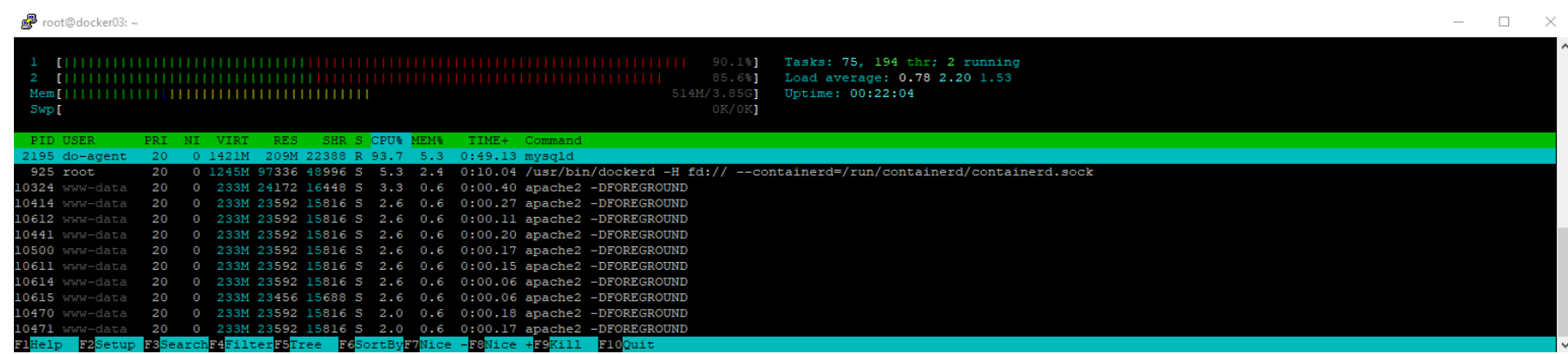

Figura 82. Recursos consumidos en Worker 02 - Docker Contenedores (Web y MySQL)

Elaboración propia 
Mediante la aplicación HTOP, podemos observar que los recursos de hardware del nodo Docker Worker 02 se elevaron debido a una mayor cantidad de conexiones por segundo. En este nodo, se están usando dos contenedores que son del servicio Web y MySQL. Se está usando aproximadamente $87.85 \%$ de los dos núcleos que tenemos en el procesador y 514MB de memoria RAM.

Se pudo observar que el consumo de hardware del Docker Manager se mantuvo dentro de lo normal mientras que los Docker Worker se elevó un poco más. En esta prueba, se llegó a establecer todas las conexiones, pero con un mayor tiempo de respuesta en comparación a las pruebas 1,2 y 3 .

\subsubsection{Prueba 05}

Envío de un total de 3000 de conexiones con una velocidad de 450 conexiones por segundo.

Desde el servidor Simulador de Conexiones Web se ejecutará el siguiente comando: httperf --server 167.172.23.160 --port 10000 --num-conns 30000 --rate 450 timeout 1

Se enviará hacia el servidor web con dirección IP 167.172.23.160 con número de puerto 80 (HTTP) una cantidad total de 3000 peticiones con una velocidad de 450 conexiones por segundo. 


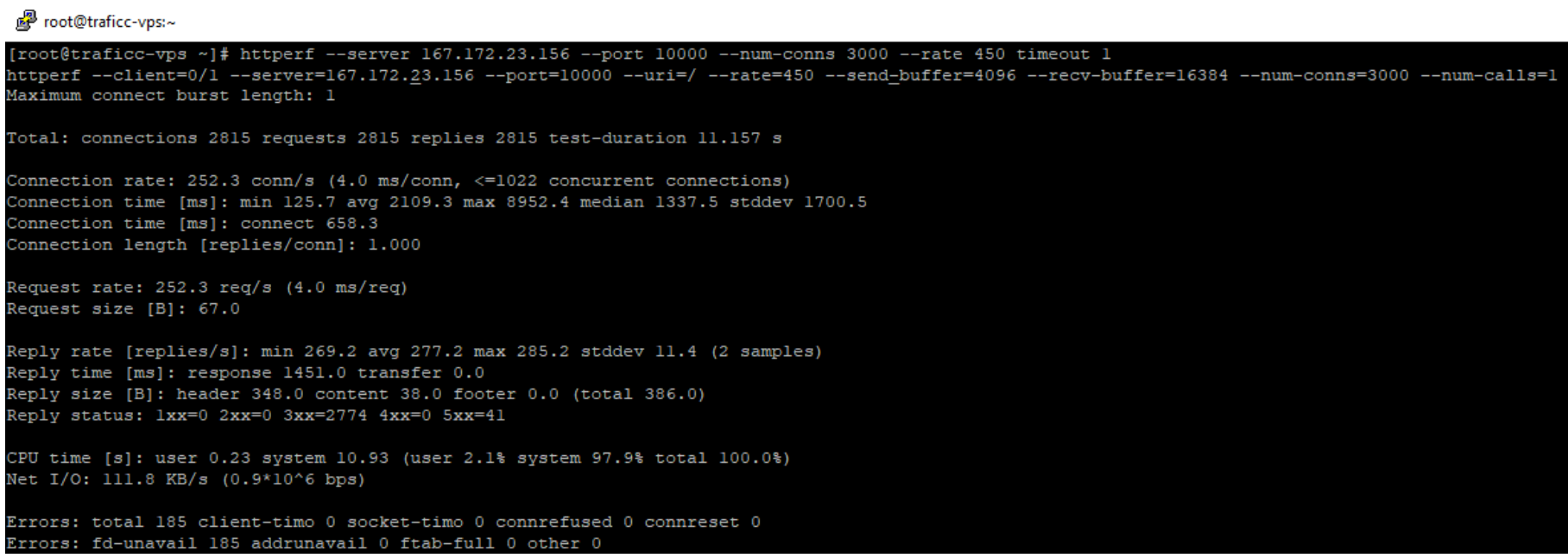

Figura 83. Resultados obtenidos en servidor simulador de conexiones hacia la aplicación Web

Elaboración propia

En la figura 83, podemos observar todos los resultados obtenidos en la prueba realizada. A continuación, se explicarán los resultados de los puntos más importantes que hemos obtenido:

Total: connections 2815 requests 2815 replies 2815 test-duration 11.157 s

Muestra que se iniciaron 2815 conexiones, se realizaron 2815 solicitudes y se recibieron 2815 respuestas de las 3000 que fueron enviadas.

También muestra que la duración total de la prueba fue de 11.157 segundos, lo que significa que la tasa de solicitud promedio fue casi exactamente 252 solicitudes por segundo.

Connection rate: $252.3 \mathrm{conn} / \mathrm{s}(4.0 \mathrm{~ms} / \mathrm{conn},<=1022$ concurrent connections)

Muestra que las nuevas conexiones se iniciaron a una velocidad de 252 conexiones por segundo. Esta tasa corresponde a un período de 4.0 milisegundos por conexión. Finalmente, el último número muestra que, como máximo, mil veintidós conexiones estaban abiertas al servidor en un momento dado.

Connection time [ms]: min 125.7 avg 2109.3 max 8952.4 median 1337.5 stddev 1700.5

Muestra que la vida útil de la conexión mínima (min.) fue de 125.7 milisegundos, la vida útil promedio (avg) fue de 2109.3 milisegundos, la vida útil máxima (max.) 
fue de 8952.4 milisegundos, la vida mediana (median) fue de 1337.5 milisegundos, y que la desviación estándar de los tiempos de vida fue de 1700.5 milisegundos.

\section{Reply rate [replies/s]: $\min 269.2$ avg 277.2 max 285.2 stddev 11.4 (2 samples)}

Muestra la tasa de respuesta mínima (min.), promedio (avg) y máxima (max.) fue aproximadamente de 285 respuestas por segundo. Dados estos números, la desviación estándar es 11.4 milisegundos.

\section{Errors: total 185 client-timo 0 socket-timo 0 connrefused 0 connreset 6751 Errors: fd-unavail 185 addrunavail 0 ftab-full 0 other 0}

La suma total de los errores fue de 185 conexiones. El error presentado se da en el fd-unavail el cual indica que el número de veces que el cliente web httperf se quedó sin respuesta debido a que sus recursos de hardware se encuentran sobrecargados.

En la ejecución de la prueba, podemos observar el consumo de los recursos de hardware y los resultados de los tres servidores con Docker, los cuales se muestran en las siguientes imágenes:

Manager 01 - Docker Swarm

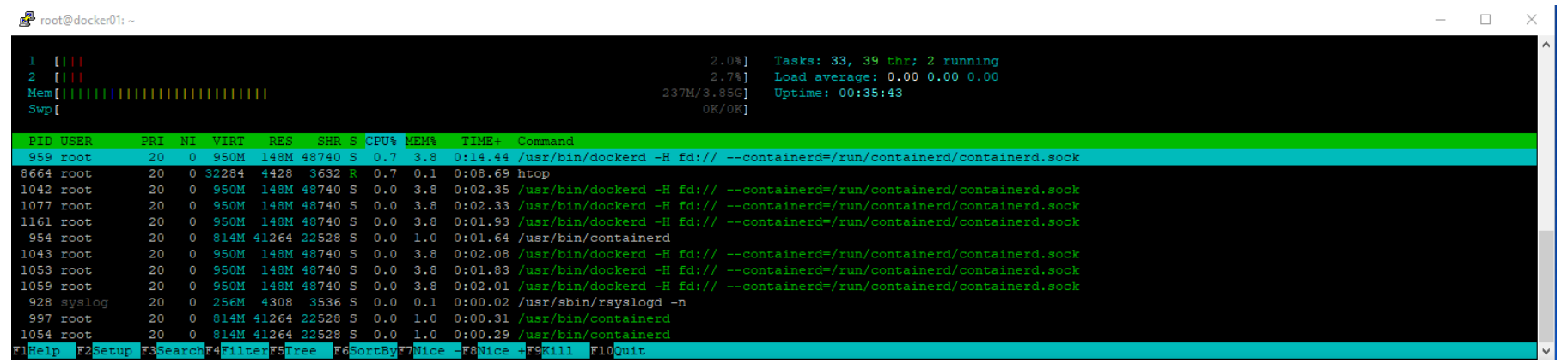

Figura 84. Recursos consumidos en Manager 01 - Docker Swarm

Elaboración propia

Mediante la aplicación HTOP, podemos observar que los recursos de hardware del nodo Docker Swarm se mantuvo bajo debido a que únicamente está realizando el balanceo de las conexiones hacia los nodos Docker Worker. Se puede apreciar que el servicio usado es Docker. Se está usando aproximadamente $2.35 \%$ de los dos núcleos que tenemos en el procesador y $237 \mathrm{MB}$ de memoria RAM. 
Worker 01 - Docker Containers (Web y MySQL)

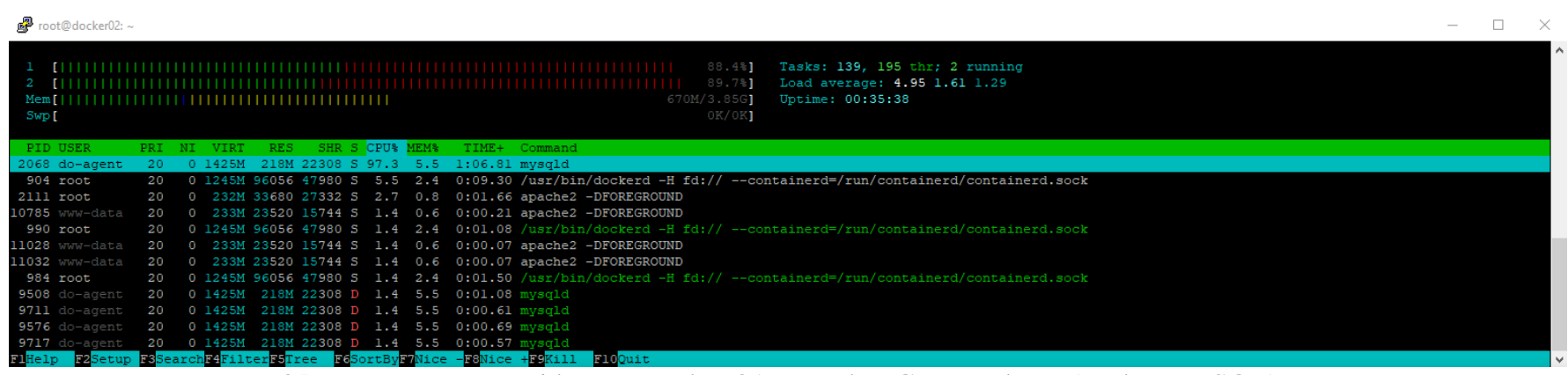

Figura 85. Recursos consumidos en Worker 01 - Docker Contenedores (Web y MySQL)

Elaboración propia

Mediante la aplicación HTOP, podemos observar que los recursos de hardware del nodo Docker Worker 01 se elevó debido a una mayor cantidad de conexiones por segundo. En este nodo, se están usando dos contenedores que son del servicio Web y MySQL. Se está usando aproximadamente $89.05 \%$ de los dos núcleos que tenemos en el procesador y 670MB de memoria RAM.

Worker 02 - Docker Containers (Web y MySQL)

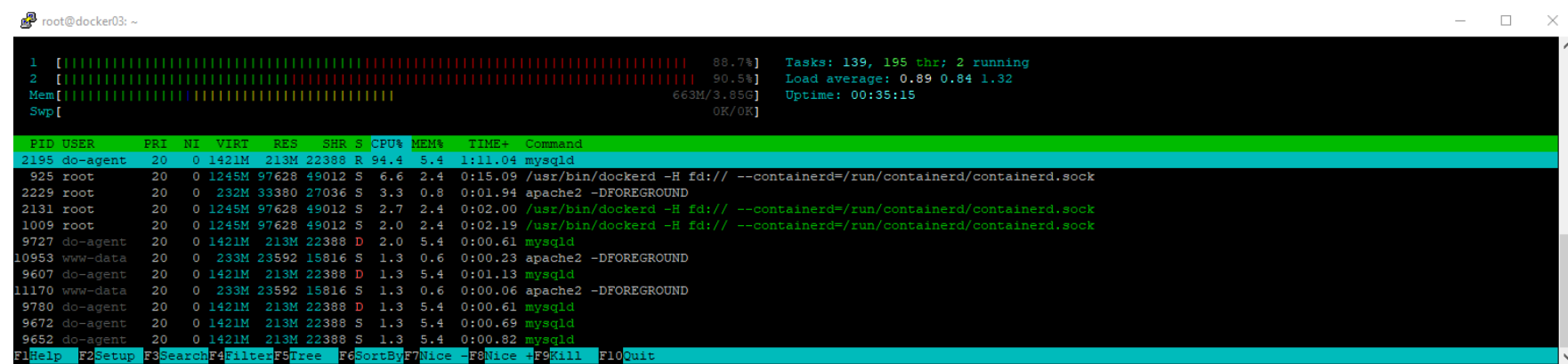

Figura 86. Recursos consumidos en Worker 02 - Docker Contenedores (Web y MySQL)

Elaboración propia

Mediante la aplicación HTOP, podemos observar que los recursos de hardware del nodo Docker Worker 02 se elevaron debido a una mayor cantidad de conexiones por segundo.

En este nodo, se están usando dos contenedores que son del servicio Web y MySQL. Se está usando aproximadamente $89.6 \%$ de los dos núcleos que tenemos en el procesador y 663MB de memoria RAM. 
Se pudo observar que el consumo de hardware del Docker Manager se mantuvo dentro de lo normal mientras que los Docker Worker se elevaron un poco más. En esta prueba, no se llegaron a establecer todas las conexiones debido a la sobrecarga de los nodos.

En las cinco pruebas realizadas. hemos obtenido diferentes resultados los cuales se muestran en la siguiente tabla y gráfica:

Tabla 17.

Resumen de los resultados de las pruebas de conexión

\begin{tabular}{|l|r|r|r|r|r|r|r|r|}
\hline $\begin{array}{c}\text { Número de } \\
\text { Prueba }\end{array}$ & $\begin{array}{c}\text { Conexiones } \\
\text { Enviadas }\end{array}$ & $\begin{array}{c}\text { Conexiones } \\
\text { Respondidas }\end{array}$ & $\begin{array}{c}\text { Conexiones No } \\
\text { Respondidas }\end{array}$ & $\begin{array}{c}\text { Tiempo de } \\
\text { respuesta de } \\
\text { la prueba }\end{array}$ & $\begin{array}{c}\text { Conexiones } \\
\text { por segundo } \\
\text { Enviadas }\end{array}$ & $\begin{array}{c}\text { Conexiones } \\
\text { por segundo } \\
\text { Respondidas }\end{array}$ & $\begin{array}{c}\text { Tiempo de } \\
\text { respuesta } \\
\text { de la Web }\end{array}$ & $\begin{array}{c}\text { Máximo de } \\
\text { respuestas } \\
\text { recibidas }\end{array}$ \\
\hline Primera & 3000 & 3000 & 0 & 20 & 150 & 150 & 0.1036 & 150 \\
\hline Segunda & 3000 & 3000 & 0 & 12 & 250 & 248 & 0.0951 & 250 \\
\hline Tercera & 3000 & 3000 & 0 & 9 & 350 & 347 & 0.0999 & 345 \\
\hline Cuarta & 3000 & 3000 & 0 & 12 & 400 & 248 & 8.9818 & 320 \\
\hline Quinta & 3000 & 2815 & 185 & 11 & 450 & 252 & 8.9524 & 285 \\
\hline
\end{tabular}

Elaboración propia

Para tener un mejor panorama de los resultados, estaremos mostrando las gráficas de las conexiones que se enviaron en total y también la cantidad de conexiones, por segundo, en cada una de ellas se estará mostrando el tiempo que se tomó en la ejecución. 


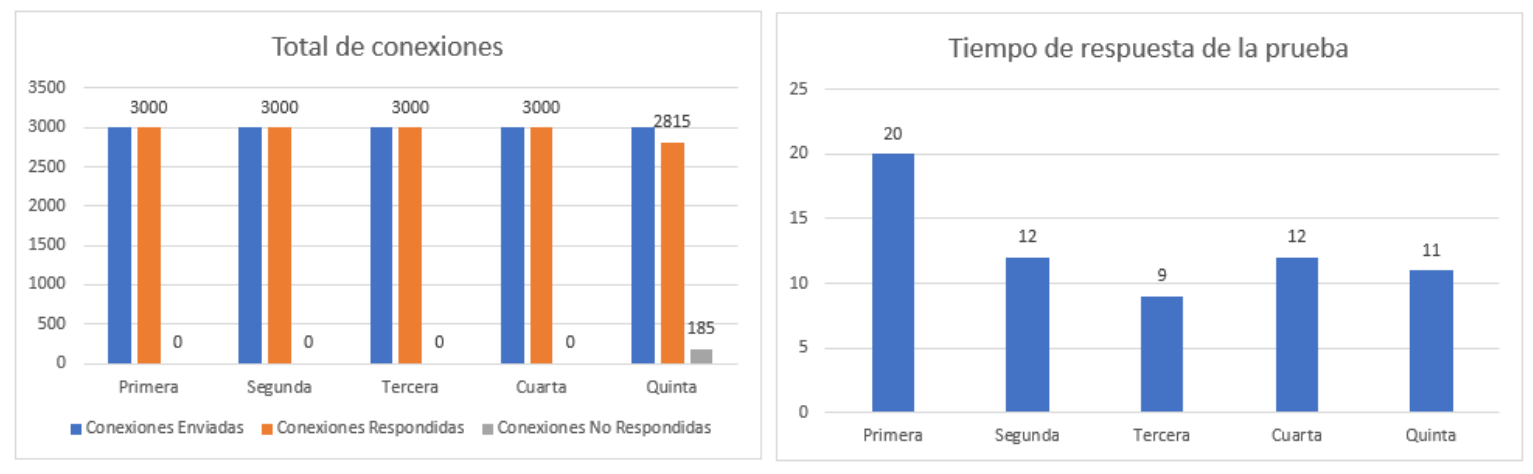

Figura 87. Conexiones enviadas y tiempo de respuesta de las pruebas

Elaboración propia

En la figura 87, podemos observar lo siguiente:

- En la primera prueba, se enviaron 3 mil conexiones, respondieron todas y el tiempo de ejecución fue de 20 segundos. Todas las conexiones se llegaron a realizar.

- En la segunda prueba, se enviaron 3 mil conexiones, respondieron todas y el tiempo de ejecución fue de 12 segundos. Todas las conexiones se llegaron a realizar.

- En la tercera prueba, se enviaron 3 mil conexiones, respondieron todas y el tiempo de ejecución fue de nueve segundos. Todas las conexiones se llegaron a realizar.

- En la cuarta prueba, se enviaron 3 mil conexiones, respondieron todas y el tiempo de ejecución fue de 12 segundos. Todas las conexiones se llegaron a realizar.

- En la quinta prueba, se enviaron 3 mil conexiones, respondieron solamente 2815 y el tiempo de ejecución fue de 11 segundos. Se llegaron a perder 185 conexiones debido a la saturación de los equipos.

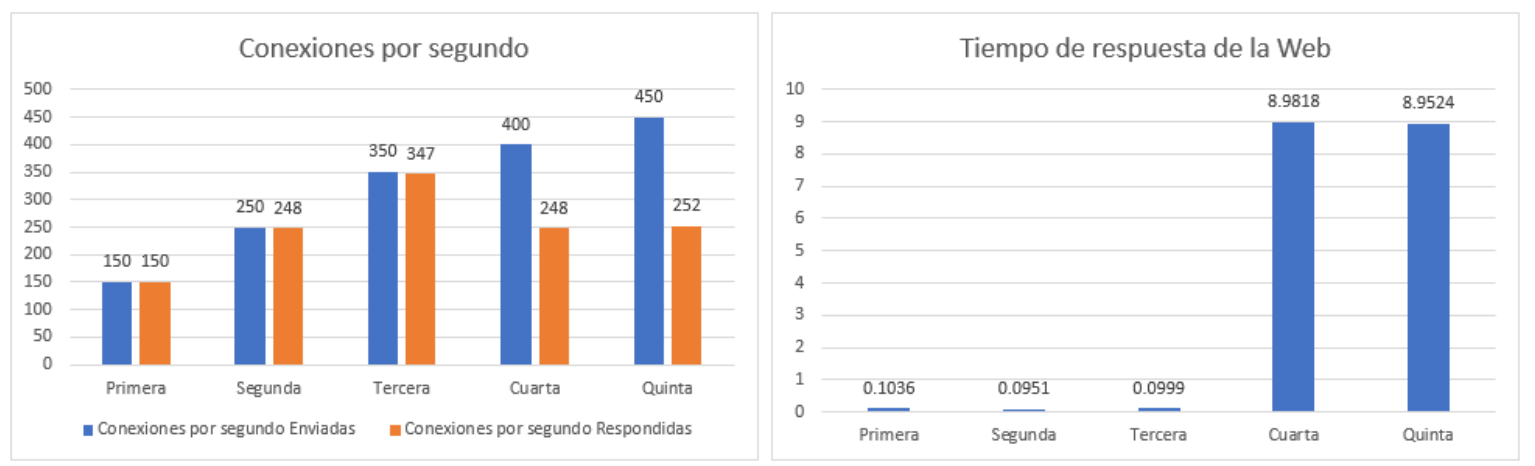

Figura 88. Conexiones por segundo y tiempo de respuesta de la Web

Elaboración propia 
En la figura 88, podemos observar lo siguiente:

- En la primera prueba, se enviaron 150 conexiones por segundo, respondieron $150 \mathrm{y}$ el tiempo de respuesta de la Web fue de 0.10 segundos.

- En la segunda prueba, se enviaron 250 conexiones por segundo, respondieron 248 y el tiempo de respuesta de la Web fue de 0.09 segundos.

- En la tercera prueba, se enviaron 350 conexiones por segundo, respondieron 347 y el tiempo de respuesta de la Web fue de 0.99 segundos.

- En la cuarta prueba, se enviaron 400 conexiones por segundo, respondieron 248 y el tiempo de respuesta de la Web fue de 8.98 segundos.

- En la tercera prueba, se enviaron 450 conexiones por segundo, respondieron 252 y el tiempo de respuesta de la Web fue de 8.95 segundos.

En resumen, podemos determinar lo siguiente:

- En las cinco pruebas ejecutadas desde el servidor Simulador de Conexiones hacia el servidor Docker Manager, se pudo observar que si llegaron a ejecutar.

- Se observó que, en la primera, segunda y tercera prueba, los recursos de hardware se elevaron, pero no llegaron a consumir su totalidad.

- En la primera, segunda y tercera prueba, se llegaron a ejecutar todas las conexiones sin ningún error.

- Se observó que, en la cuarta y quinta prueba los recursos de hardware se elevaron, pero no llegaron a consumir su totalidad.

- En la cuarta prueba, se llegaron a ejecutar todas las conexiones sin ningún error.

- En la quinta prueba, no se llegaron a ejecutar todas las conexiones.

- En la cuarta y quinta prueba, los tiempos de respuesta de la Web en fueron entre 8 y 9 segundos.

\subsection{Costos de la implementación}

Para las pruebas realizadas en el Diseño de la Solución que será la Arquitectura Basada en Contenedores Docker, las características de hardware para los tres nodos son las siguientes:

- Procesador Intel Xeon CPU E5-2697A v4 2.60GHz (2 core) 
- Memoria RAM: 4GB DDR3

- Disco Duro: 25GB SSD

El costo de este nodo es de $\$ 40$ dólares mensuales.

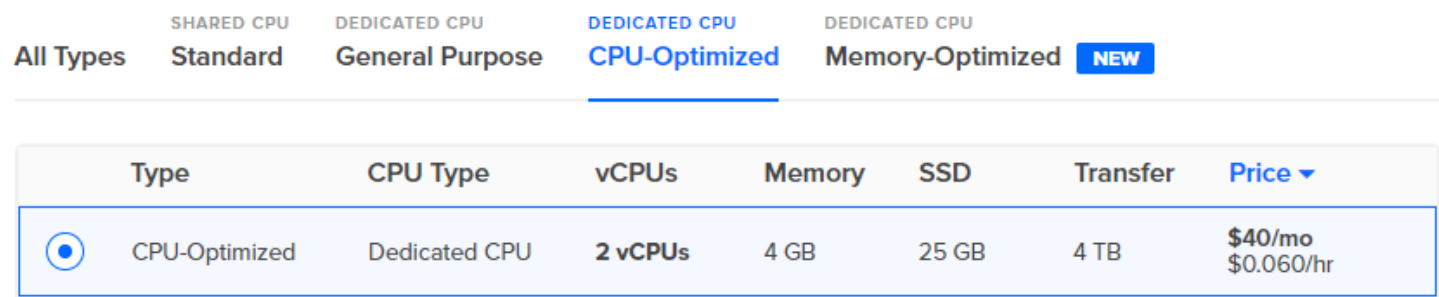

Figura 89. Costo mensual por del nodo

Adaptado de https://cloud.digitalocean.com/

En la figura 89, que fue obtenida desde el proveedor DigitalOcean, podemos ver el costo que tendrá cada uno de nuestros nodos que estamos utilizando para la Arquitectura Basada en Contenedores Docker.

El costo mensual por los tres equipos que usaremos para esta arquitectura se muestra en la siguiente tabla:

Tabla 18.

Costo mensual de la Arquitectura Basada en Contenedores Docker

\begin{tabular}{|l|l|c|}
\hline Nodos & Descripción & Costo en dólares \\
\hline Docker Maganer & Docker Swarm & $\$ 40.00$ \\
\hline Worker 01 & Docker Contenedores (Web y MySQL) & $\$ 40.00$ \\
\hline Worker 02 & Docker Contenedores (Web y MySQL) & $\$ 40.00$ \\
\hline Costo Total: & $\$ 120.00$ \\
\hline
\end{tabular}

Elaboración propia 
En la tabla 18, podemos observar el costo para Arquitectura Basada en Contenedores Docker, realizando el Escalamiento Horizontal, el cual tendrá el costo de \$120 dólares mensuales.

\subsection{Tiempo de escalabilidad de la arquitectura}

En esta arquitectura en la que se ha realizado un escalamiento horizontal desde un solo nodo hasta tres nodos, el tiempo que se ha tomado para todo está implementación a continuación:

Tabla 19.

Tiempo total para el escalamiento horizontal en la Arquitectura Basada en Contenedores Docker

\begin{tabular}{|l|c|c|c|}
\hline \multicolumn{1}{|c|}{ Proceso realizado } & \multicolumn{2}{c|}{ Tiempo en minutos en cada Nodo } \\
\cline { 2 - 4 } & Manager 01 & Worker 01 & Worker 02 \\
\hline Seleccionar el servidor con sistema operativo Linux Ubuntu 18.04 & 5 & 5 & 5 \\
\hline Actualización y configuración de seguridad en el sistema operativo & 15 & 15 & 15 \\
\hline Instalación y configuración Docker Swarm & 10 & 0 & 0 \\
\hline Instalación y configuración Docker Worker 01 (Apache y MySQL) & 0 & 10 & 0 \\
\hline Instalación y configuración Docker Worker 02 (Apache y MySQL) & 0 & 0 & 10 \\
\hline Pruebas de acceso & 5 & 5 & 5 \\
\hline Tiempo total por servidor & 35 & 35 & 35 \\
\hline Tiempo total: $\mathbf{1 0 5}$ minutos & & & \multicolumn{2}{|c}{} \\
\hline
\end{tabular}

Elaboración propia

En la tabla 19, podemos ver que para cada nodo se ha tomado un tiempo de 35 minutos en instalación, configuración y pruebas de acceso. El tiempo total que se ha tomado para esta implementación realizando el escalamiento horizontal fue de 105 minutos que equivalen una hora con cuarenta y cinco minutos (1.45 horas). 


\section{RESULTADOS Y VALIDACIONES}

A continuación, se procede con la medición de los indicadores vinculados con los objetivos específicos presentados en el capítulo 1, con el fin de evaluar el rendimiento de la nueva arquitectura propuesta. Cada uno de los indicadores, nos ayudará a verificar el rendimiento que se tendrá en las aplicaciones Web, señalar también que tipo de escenario puede mejorarse con la finalidad de tener un funcionamiento adecuado. Así mismo, se presentan los indicadores que ayudarán a evaluar el cumplimiento de los objetivos del presente documento.

Tabla 20.

Lista de indicadores y métricas

\begin{tabular}{|c|c|c|c|}
\hline & OBJETIVO ESPECÍIFICO & INDICADOR DE LOGRO & MÉTRICA \\
\hline OE1: & $\begin{array}{l}\text { Determinar el número de conexiones } \\
\text { Web por segundo que soporta las } \\
\text { arquitecturas tradicionales contra la } \\
\text { arquitectura basada en contenedores. }\end{array}$ & $\begin{array}{l}\text { Cuadros comparativos } y \\
\text { graficas en Excel de los } \\
\text { resultados obtenidos de las } \\
\text { pruebas de rendimiento. }\end{array}$ & $\begin{array}{l}\text { Número de } \\
\text { Cantidad de } \\
\text { conexiones. }\end{array}$ \\
\hline OE2: & $\begin{array}{l}\text { Comparar los costos de las arquitecturas } \\
\text { tradicionales contra la arquitectura } \\
\text { basada en Contenedores. }\end{array}$ & $\begin{array}{l}\text { Cuadros comparativos de } \\
\text { costos mediante OPEX. }\end{array}$ & Costos \\
\hline OE3: & $\begin{array}{l}\text { Calcular el tiempo de la Escalabilidad } \\
\text { de las arquitecturas tradicionales contra } \\
\text { la arquitectura basada en Contenedores. }\end{array}$ & $\begin{array}{l}\text { Cuadros comparativos que } \\
\text { muestre el tiempo que toma la } \\
\text { Escalabilidad. }\end{array}$ & Tiempo \\
\hline
\end{tabular}

Elaboración propia

5.1 Pruebas y resultados del indicador 1: Cuadros comparativos y graficas en Excel de los resultados obtenidos de las pruebas de rendimiento.

Este indicador nos permite evaluar la cantidad de conexiones web por segundo que pueden soportar las arquitecturas tradicionales contra la arquitectura de contenedores. Los valores que se han obtenido fueron los resultados que se mostraron en el capítulo 3 y capítulo 4 . 
- Objetivo: Determinar el número de conexiones Web por segundo que soporta las arquitecturas tradicionales contra la arquitectura basada en Contenedores

\section{Arquitectura tradicional}

Los resultados que se van a mostrar son los que fueron obtenidos en el capítulo 3 en el punto 3.3 Arquitectura Tradicional con Escalamiento Vertical.

\section{Tabla 21.}

Conexiones web por segundo

\begin{tabular}{|l|r|r|r|}
\hline $\begin{array}{c}\text { Número de } \\
\text { Prueba }\end{array}$ & $\begin{array}{c}\text { Conexiones por } \\
\text { segundo } \\
\text { Enviadas }\end{array}$ & $\begin{array}{c}\text { Conexiones por } \\
\text { segundo } \\
\text { Respondidas }\end{array}$ & $\begin{array}{c}\text { Tiempo de } \\
\text { respuesta de } \\
\text { la Web }\end{array}$ \\
\hline Primera & 170 & 169 & 0.41 \\
\hline Segunda & 300 & 235 & 9.41 \\
\hline Tercera & 320 & 237 & 9.71 \\
\hline
\end{tabular}

Elaboración propia

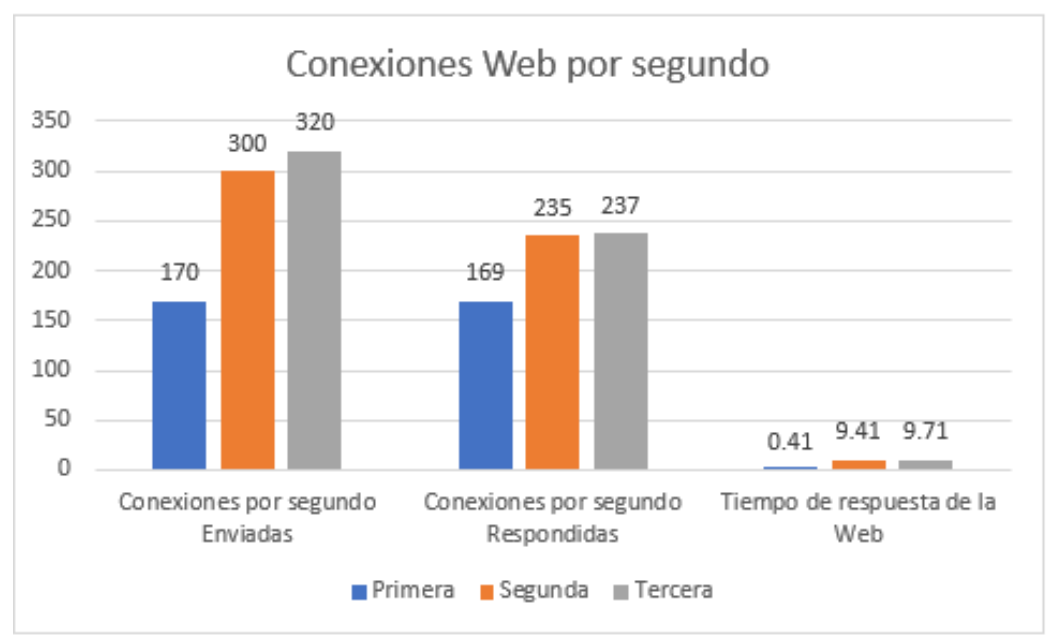

Figura 90. Conexiones Web por segundo

Elaboración propia

Esta arquitectura contó con siete servidores, la cantidad máxima de conexiones por segundo que se pudo enviar fue de 320 y respondieron a una velocidad de 237 conexiones por segundo. El tiempo de respuesta para el acceso de la Web que se obtuvo fue de 9.71 segundos. 
Arquitectura Basada en Contenedores Docker

Los resultados que se van a mostrar son los que fueron obtenidos en el capítulo 4.

Tabla 22.

Conexiones web por segundo

\begin{tabular}{|l|r|r|r|}
\hline $\begin{array}{c}\text { Número de } \\
\text { Prueba }\end{array}$ & $\begin{array}{c}\text { Conexiones } \\
\text { por segundo } \\
\text { Enviadas }\end{array}$ & $\begin{array}{c}\text { Conexiones } \\
\text { por segundo } \\
\text { Respondidas }\end{array}$ & $\begin{array}{c}\text { Tiempo de } \\
\text { respuesta } \\
\text { de la Web }\end{array}$ \\
\hline Primera & 150 & 150 & 0.1036 \\
\hline Segunda & 250 & 248 & 0.0951 \\
\hline Tercera & 350 & 347 & 0.0999 \\
\hline Cuarta & 400 & 248 & 8.9818 \\
\hline Quinta & 450 & 252 & 8.9524 \\
\hline
\end{tabular}

Elaboración propia

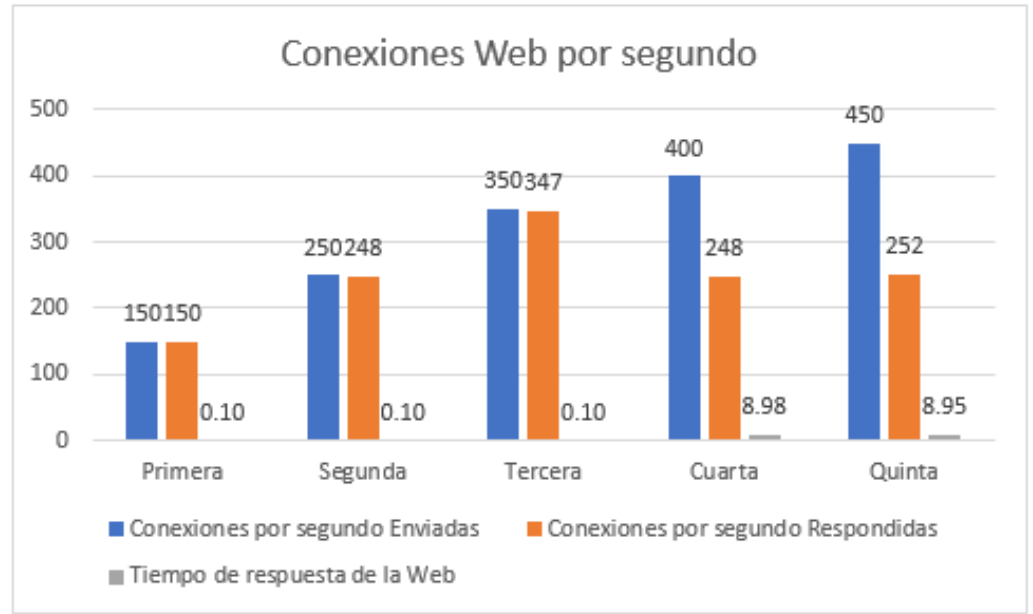

Figura 91. Conexiones web por segundo

Elaboración propia

Esta arquitectura contó con tres nodos, la cantidad máxima de conexiones por segundo que se pudo enviar fue de 450 y respondieron a una velocidad de 252 conexiones por segundo. El tiempo de respuesta para el acceso de la Web que se obtuvo fue de 8.95 segundos.

Tomando las tres primeras pruebas de ambas Arquitecturas podemos ver lo siguiente: 


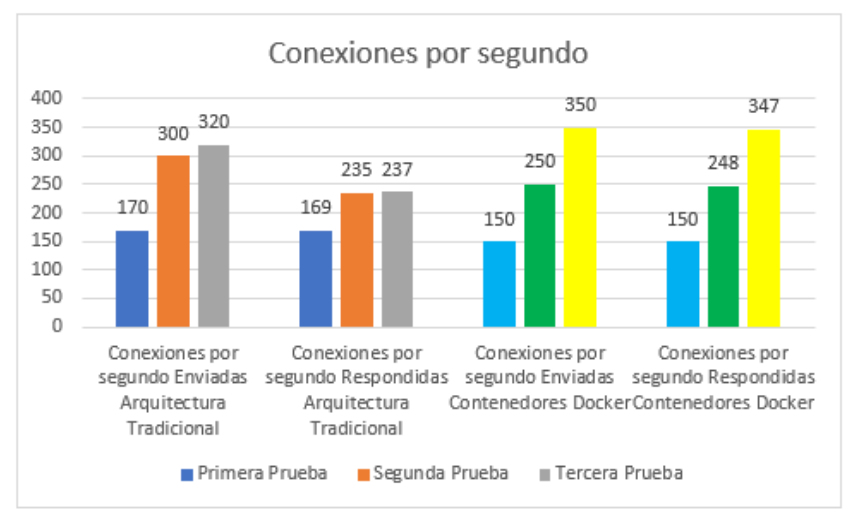

Figura 92. Conexiones Web por segundo en ambas Arquitecturas

Elaboración propia

En la figura 92, podemos observar:

- En la tercera prueba en la Arquitectura Tradicional, utilizando siete servidores se llegó a enviar 320 conexiones por segundo pero la respuesta obtenida en esta arquitectura fue de 237 conexiones por segundo.

- En la Arquitectura Basada en Contenedores Docker que utilizó tres nodos se llegó a enviar 350 conexiones por segundo pero la respuesta obtenida en esta arquitectura fue de 347 conexiones por segundo.

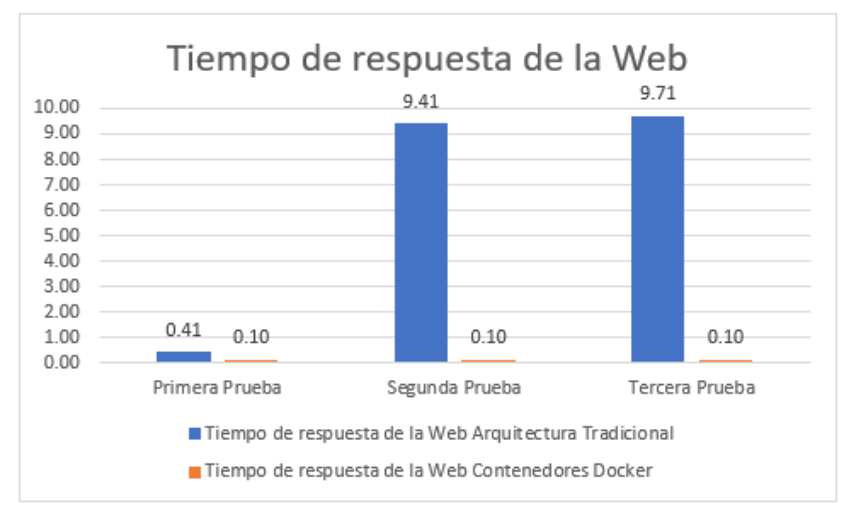

Figura 93. Tiempo de respuesta de la Web en ambas Arquitecturas

Elaboración propia

En la figura 93, podemos observar:

- En la tercera prueba, en la Arquitectura Tradicional, utilizando siete servidores el tiempo de respuesta de la Web fue de 9.71 segundos. 
- En la tercera prueba, en la Arquitectura Basada en Contenedores Docker que utilizó tres servidores el tiempo de respuesta de la Web fue de 0.10 segundos.

5.2 Pruebas y resultados del Indicador 2: Cuadros comparativos de costos mediante OPEX.

Este indicador nos permite evaluar los costos que se tendrán en el desarrollo de las arquitecturas tradicionales contra la arquitectura de contenedores. Los valores que se han obtenido fueron los resultados que se mostraron en el capítulo 3 y capítulo 4 .

- Objetivo: Comparar los costos de las arquitecturas tradicionales contra la arquitectura basada en contenedores.

Arquitectura tradicional

Los resultados que se van a mostrar son los que fueron obtenidos en el capítulo 3, en el punto 3.2 Arquitectura Tradicional con Escalamiento Horizontal.

Tabla 23.

Costo de los servidores para la arquitectura tradicional

\begin{tabular}{|l|c|}
\hline Descripción de servidores & Costo en dólares \\
\hline Balanceador Web & $\$ 40.00$ \\
\hline Web 01 & $\$ 40.00$ \\
\hline Web 02 & $\$ 40.00$ \\
\hline NFS & $\$ 40.00$ \\
\hline Balanceador BD & $\$ 40.00$ \\
\hline MySQL 01 & $\$ 40.00$ \\
\hline MySQL 02 & $\$ 40.00$ \\
\hline Costo Total: & $\$ 280.00$ \\
\hline
\end{tabular}

Elaboración propia

En la tabla 23, se observa el costo de los siete servidores que se usaron para esta arquitectura. El costo mensual que se obtuvo para la arquitectura tradicional fue de \$280 dólares. 
Arquitectura basada en contenedores Docker

Los resultados que se van a mostrar son los que fueron obtenidos en el capítulo 4, en el punto 4.2 Costos de la implementación para la arquitectura con contenedores Docker con escalamiento horizontal.

Tabla 24.

Costo de los nodos para la Arquitectura Basada en Contenedores Docker

\begin{tabular}{|l|c|}
\hline Descripción de nodos & Costo en dólares \\
\hline Docker Swarm & $\$ 40.00$ \\
\hline Docker Contenedores (Web y MySQL) & $\$ 40.00$ \\
\hline Docker Contenedores (Web y MySQL) & $\$ 40.00$ \\
\hline Costo Total: & $\$ 120.00$ \\
\hline
\end{tabular}

Elaboración propia

En la tabla 24, se observa el costo de los tres nodos que se usaron para esta arquitectura. El costo mensual que se obtuvo para la Arquitectura Basada en Contenedores Docker fue de \$120 dólares.

Proyectando el gasto durante un año, el costo que se generaría se muestra en la siguiente tabla:

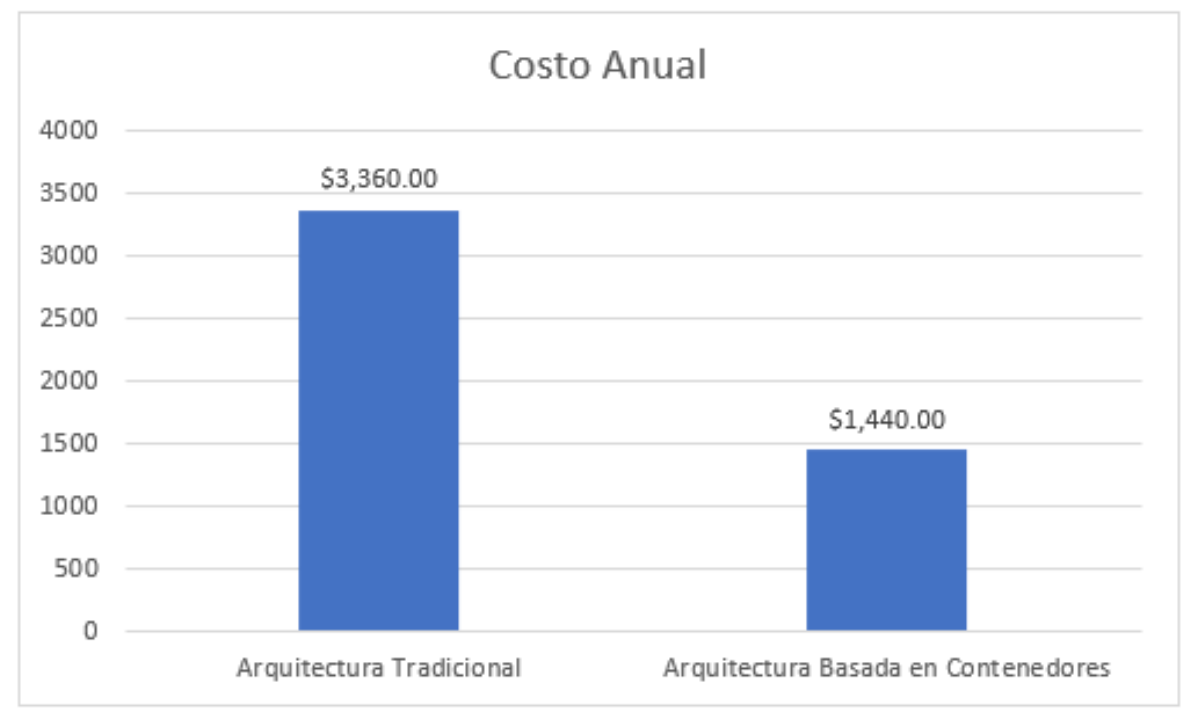

Figura 94. Costo anual Arquitectura Tradicional y Basada en Contenedores

Elaboración propia 
En la figura 94, podemos observar que el costo anual para la Arquitectura Tradicional fue de \$3,360 dólares y para la Arquitectura Basada en Contenedores fue de \$1,440 dólares.

La diferencia del costo de inversión anual entre ambas arquitecturas fue de \$1,920 dólares que al tipo de cambio a moneda nacional es S/ 6,420 soles, siendo este el monto de ahorro al utilizar una Arquitectura Basada en Contenedores.

5.3 Pruebas y resultados del Indicador 3: Cuadros comparativos que muestre el tiempo que toma la escalabilidad.

Este indicador nos permite evaluar el tiempo que se tomará para realizar el escalamiento en las arquitecturas tradicionales contra la arquitectura de contenedores. Los valores que se han obtenido fueron los resultados que se mostraron en el capítulo 3 y capítulo 4 .

- Objetivo: Calcular el tiempo de la escalabilidad de las arquitecturas tradicionales contra la arquitectura basada en contenedores.

\section{Arquitectura tradicional}

Los resultados que se van a mostrar son los que fueron obtenidos en el capítulo 3, en el punto 3.2 Arquitectura Tradicional con Escalamiento Horizontal.

Tabla 25.

Tiempo obtenido para el escalamiento horizontal en la arquitectura tradicional

\begin{tabular}{|c|c|c|c|c|c|c|c|}
\hline \multirow[b]{2}{*}{ Proceso realizado } & \multicolumn{7}{|c|}{ Tiempo en minutos en cada Servidor } \\
\hline & $\begin{array}{c}\text { Servidor } \\
01\end{array}$ & \begin{tabular}{|c} 
Servidor \\
02
\end{tabular} & \begin{tabular}{|c|} 
Servidor \\
03
\end{tabular} & $\begin{array}{c}\text { Servidor } \\
04\end{array}$ & \begin{tabular}{|c|} 
Servidor \\
05
\end{tabular} & \begin{tabular}{|c|} 
Servidor \\
06
\end{tabular} & $\begin{array}{c}\text { Servidor } \\
07\end{array}$ \\
\hline Seleccionar el servidor con sistema operativo Linux Ubuntu 18.04 & 5 & 5 & 5 & 5 & 5 & 5 & 5 \\
\hline Actualización y configuración de seguridad en el sistema operativo & 15 & 15 & 15 & 15 & 15 & 15 & 15 \\
\hline Instalación y configuración Balanceador Web HAProxy & 10 & 0 & 0 & 0 & 0 & 0 & 0 \\
\hline Instalación y configuración de servicios Web (Apache) & 0 & 10 & 10 & 0 & 0 & 0 & 0 \\
\hline Instalación y configuración de servicio NFS & 0 & 0 & 0 & 10 & 0 & 0 & 0 \\
\hline Instalación y configuración Balanceador Base Datos & 0 & 0 & 0 & 0 & 10 & 0 & 0 \\
\hline Instalación y configuración de servicios de Base de Datos (MySQL) & 0 & 0 & 0 & 0 & 0 & 10 & 10 \\
\hline Pruebas de acceso & 5 & 5 & 5 & 5 & 5 & 5 & 5 \\
\hline Tiempo total por servidor & 35 & 35 & 35 & 35 & 35 & 35 & 35 \\
\hline
\end{tabular}

Elaboración propia 
En la tabla 25, se puede observar que, para cada servidor, se ha tomado un tiempo de 35 minutos en instalación, configuración y pruebas de acceso. El tiempo total que se ha tomado para esta implementación realizando el escalamiento horizontal fue de 245 minutos que equivalen a cuatro horas con cinco minutos (4.05 horas).

Arquitectura Basada en Contenedores Docker

Los resultados que se van a mostrar son los que fueron obtenidos en el capítulo 4, en el punto 4.3 Tiempo de escalabilidad de la arquitectura con contenedores Docker con escalamiento horizontal.

Tabla 26.

Tiempo obtenido para el escalamiento horizontal en la arquitectura basada en contenedores

\begin{tabular}{|l|c|c|c|}
\hline \multirow{2}{*}{ Proceso realizado } & \multicolumn{2}{c|}{ Tiempo en minutos en cada Nodo } \\
\cline { 2 - 4 } & Manager 01 & Worker 01 & Worker 02 \\
\hline Seleccionar el servidor con sistema operativo Linux Ubuntu 18.04 & 5 & 5 & 5 \\
\hline Actualización y configuración de seguridad en el sistema operativo & 15 & 15 & 15 \\
\hline Instalación y configuración Docker Swarm & 10 & 0 & 0 \\
\hline Instalación y configuración Docker Worker 01 (Apache y MySQL) & 0 & 10 & 0 \\
\hline Instalación y configuración Docker Worker 02 (Apache y MySQL) & 0 & 0 & 10 \\
\hline Pruebas de acceso & 5 & 5 & 5 \\
\hline Tiempo total por servidor & 35 & 35 & 35 \\
\hline Tiempo total: 105 minutos & & & \\
\hline
\end{tabular}

Elaboración propia

En la tabla 26, se puede observar que, para cada nodo, se ha tomado un tiempo de 35 minutos para realizar el escalamiento horizontal. El tiempo total que se ha tomado para realizar este escalamiento en los tres nodos fue de 105 minutos que equivalen a una hora con cuarenta y cinco minutos (1.45 horas). 


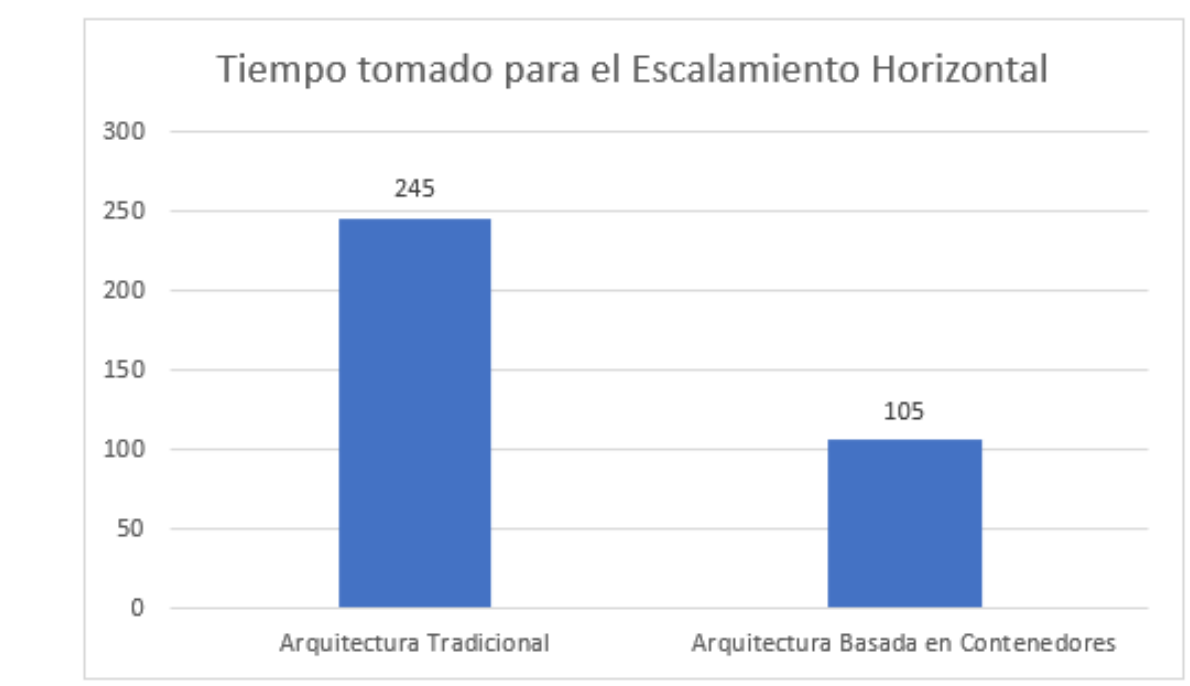

Figura 95. Escalamiento horizontal en arquitectura tradicional y basada en Contenedores

Elaboración propia

En la figura 95, podemos observar que el tiempo que se tomó para el Escalamiento horizontal en la arquitectura tradicional fue de 245 minutos que equivalen a 4.05 horas, mientras que en la Arquitectura Basada en Contenedores fue de 105 minutos que equivale a 1.45 minutos.

La diferencia del tiempo de implementación entra ambas arquitecturas fue 140 minutos que equivale a 2.20 horas, siendo este el tiempo que se puede disminuir al utilizar una Arquitectura Basada en Contenedores. 


\section{CONCLUSIONES}

- En la arquitectura basada en contenedores Docker, se puede mejorar drásticamente la cantidad de conexiones atendidas por segundo y el tiempo de respuesta en una aplicación web; 347 conexiones por segundo frente a 237 de la arquitectura tradicional y 0.10 segundos de tiempo de respuesta frente a 9.71 segundos en la arquitectura tradicional.

- Utilizando la Arquitectura Basada en Contenedores Docker se ha podido ahorrar un monto de \$1,920 dólares americanos que, al tipo de cambio a moneda nacional es S/.6,420 soles, durante el periodo de un año, en el presupuesto de implementación.

- El tiempo que tomó realizar el escalamiento horizontal se redujo en 2.20 horas con la arquitectura basada en contenedores.

- El uso de plataformas de virtualización basadas en contenedores como Docker ahorran recursos de hardware, mediante la instalación de un sistema operativo anfitrión en el servidor principal haciendo que los contenedores solo utilicen los recursos necesarios de cada servicio.

- Muchas empresas están invirtiendo en esta tecnología, ya que, al trabajar con contenedores basados en Docker, se cuenta con las herramientas idóneas y la documentación suficiente (ebooks, foros, noticias, etc.) para la implementación y desarrollo de esta tecnología. 


\section{RECOMENDACIONES}

- Para toda startup que inicia operaciones, es recomendable que utilicen los recursos que brinda la nube debido a la flexibilidad, la escalabilidad, el mínimo capital inicial que ofrecen los diversos proveedores.

- Los servidores de recursos de hardware compartidos no son los adecuados para el funcionamiento de una aplicación web, debido a que en un determinado momento todos estos recursos estarán siendo utilizados por los clientes que se comparte el recurso.

- Para un buen funcionamiento de la aplicación web, se recomienda que los servidores para utilizar sean de recursos de hardware dedicados.

- Para las Arquitecturas de Microservicios, se recomienda utilizar la tecnología de Docker debido a que se cuenta con las herramientas idóneas y la documentación suficiente (ebooks, foros, noticias, etc.) para la implementación y desarrollo de esta tecnología.

- La solución de contenedores basada en Docker puede ser desplegado sobre Sistemas Operativos Linux (Centos, Ubuntu, OpenSuse), Microsoft y MAC, sin embargo, es recomendable realizar el despliegue sobre Ubuntu, debido a que se cuenta con la mayor cantidad de información en cuanto a documentación de la tecnología y soporte existente para esta distribución.

- A nivel de servidores se recomienda que el Kernel del sistema operativo se encuentre actualizado. La razón principal es proporcionar soluciones a las fallas de seguridad que se hayan descubierto, además de la revisión de la estabilidad de los errores y, finalmente, proporcionar soporte de hardware actualizado. Antes de realizar este proceso, se debe verificar que no afecta de los servicios que se tiene en producción. 


\section{SIGLARIO}

TI. Tecnología de la Información.

TIC. Tecnología de la Información y la Comunicación.

UX - User eXperiencie. Experiencia de usuario.

PaaS - Platform as a Service. Plataforma como servicio.

IaaS - Infrastructure as a service. Infraestructura como servicio.

IOT - Internet Of Things. Internet de las cosas.

BSD - Berkeley Software Distribution. Sistema operativo derivado de Unix.

API - Application Programming Interface. Interfaz de programación de aplicaciones.

ZFS - Zettabyte File System. Sistema de Archivos de Oracle.

LXC - Linux Containers. Linux Contenedores.

LXD - Linux Containers Hypervisor. Linux Contenedores Hipervisor.

GNU - GNU's Not Unix. GNU no es Unix.

GLP - General Public License. Licencia Pública General.

NAS - Network Attached Storage. Almacenamiento conectado en red

SAN - Storage Area Network. Red de área de almacenamiento

NFS - Network File System. Sistema de archivos de red.

HTTP - Hypertext Transfer Protocol. Protocolo de transferencia de hipertexto.

TCP - Transmission Control Protocol. Protocolo de control de transmisión.

TLS - Transport Layer Security. Seguridad de la capa de transporte.

LTS - Long Term Support. Soporte a largo plazo. 


\section{BIBLIOGRAFÍA}

AWS. ¿Qué es un contenedor?[online]. Disponible en: https://aws.amazon.com/es/containers/]

BLANCARTE, O. (2017) Escalabilidad horizontal y vertical. Blog [online]. Disponible en: https://www.oscarblancarteblog.com/2017/03/07/escalabilidad-horizontal-y-vertical/

CAÑETE, I. (25 abril 2018). ¿Qué es una Startup? BBVA Artículo [Online]. Disponible en: https://www.bbva.com/es/que-es-una-startup/

COREOS.COM (2019) Overview. [online]. Disponible en: https://coreos.com/rkt/

DE LA TORRE, C., WAGNER, B. y ROUSOS, M. (2019). NET Micro services: Architecture for Containerized .NET Applications. NET and Visual Studio product teams. Disponible en https://aka.ms/microservicesebook

DOKER.COM (2019) ¿Qué es un contenedor? [Online]. Disponible en: https://www.docker.com/resources/what-container

DORANTES, R. (22 de agosto 2018) ¿Qué es una Startup? Revista Entrepreneur [Online]. Disponible en : https://www.entrepreneur.com/article/304376

FERNANDEZ, H., co-fundador de Economía TIC. Una visión diferente sobre escalabilidad y modelos de negocio. [online]. Disponible en: https://economiatic.com/concepto-escalabilidad/

G2 CONSULTORES. ¿Cuánto dinero realmente necesitas para iniciar una startup? Revista Entrepreneur. [online]. Disponible en: https://www.entrepreneur.com/article/302535

HAPROXY.ORG (2019). Description. [online]. Disponible en: http://www.haproxy.org/ 
IT TRENDS. (2019) El mercado de orquestación de contenedores crecerá hasta 2026. ITTRENDS [online]. Disponible en: https://www.ittrends.es/software-y-apps/2019/12/elmercado-de-orquestacion-de-contenedores-crecera-hasta-2026

LINUXCONTAIBERS.ORG (2019) Introduction to LXC. [online]. Disponible en: https://linuxcontainers.org/lxc/introduction/

MOSBERGER, D. y JIN, T. HTTPERF (1998). A Tool for Measuring Web Server Performance. Hewlett-Packard Company. SIGMETRICS (Measurement and Modeling of Computer Systems)

MOUAT, A. (2015) Using Docker:Developing and Deploying software with containers. Primera Edición. O’ Reilly

OPEN CONTAINER INITIATIVE (2019) About. [online]. Disponible en: https://www.opencontainers.org/about

OSNAT, R. (2020), A Brief History of Containers: From the 1970s Till Now, Aqua Security Blog, [Online], consultado: 20/01/2020. Disponible en: https://blog.aquasec.com/a-brief-history-of-containers-from-1970s-chroot-to-docker-2016

PAHL, C. (2015). Containerization and the PaaS cloud. Cloud Computing, IEEE, 2(3), 24-31. doi:10.1109/MCC.2015.51

PETHURU RAJ, JEEVA S. CHELLADHURAI, VINOD SINGH. (2015). Learning Docker: Optimize the power of Docker to run your applicationsquickly and easily. Packt Publishing

QI ZHANG, LING LIU, CALTON PU, QIWEI DOU, LIREN WU, AND WEI ZHOU (2018) A Comparative Study of Containers and Virtual Machines in Big Data Environment. IEEE International Conference On Cloud Computing 
RED HAT. CONTENEDORES: ¿Qué es un contenedor de Linux? [online]. Disponible en: https://www.redhat.com/es/topics/containers/whats-a-linux-container

SALAMERO, J.; CARTER, E. y KNOXANDERSON (2018) Running Containers in Production. Especial Edition. John Wiley y Sons

TURNBULL, J. (2016) The Docker Book: CONTAINERIZATION IS THE NEW VIRTUALIZATION. [OnLine]. Disponible en: https://dockerbook.com/

VASE, T. (2015) ADVANTAGES OF DOCKER. Tesis de bachillerato. UNIVERSIDAD DE JYVÄSKYLÄ. Departamento de Informática. Finlandia

XAVIER, M., DE OLIVEIRA, I., ROSSI, F., DOS PASSOS, R., MATTEUSSI, K. y DE ROSE, C. (2015). A performance isolation analysis of disk-intensive workloads on container-based clouds. Parallel, Distributed and Network-Based Processing (PDP), 2015 23rd Euromicro International Conference On, 253-260. doi:10.1109/PDP.2015.67 